\title{
A TECHNIQUE TO ASSESS THE CHARACTERISTICS OF BOTTOM AND SUBBOTTOM MARINE SEDIMENTS
}

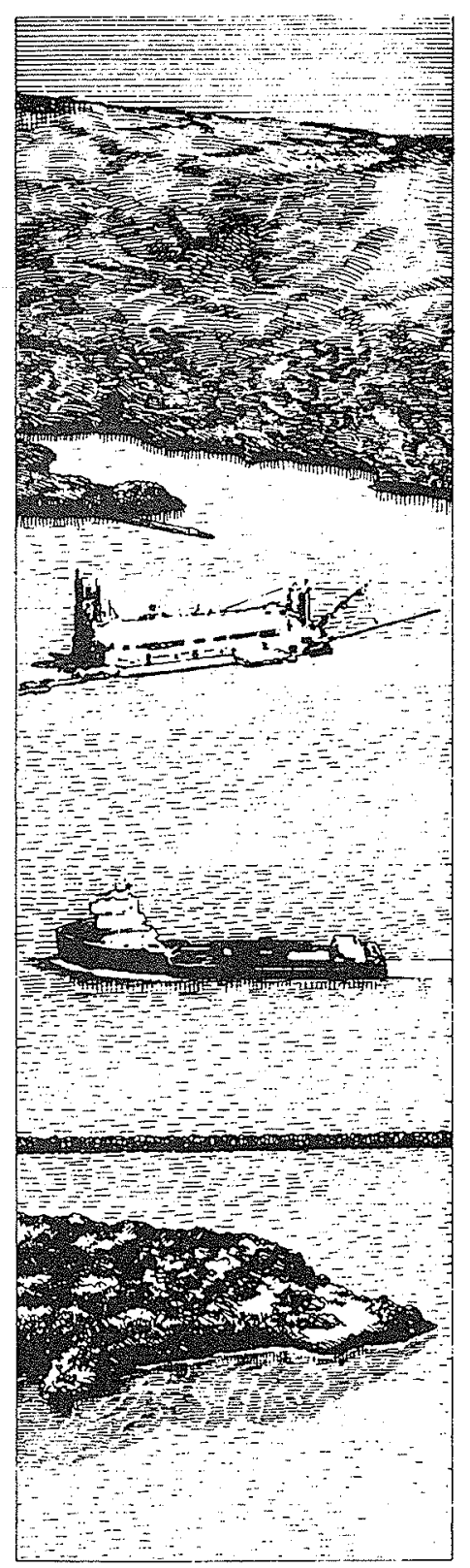

by

Richard G. McGee, Robert F. Ballard, Jr.

DEPARTMENT OF THE ARMY

Waterways Experiment Station, Corps of Engineers

3909 Halls Ferry Road, Vicksburg, Mississippi 39180-6199

and

David D. Caulfield

Caulfield Engineering Group

RRI

15051 Hayton Road

Oyama, BC Canada VOH IWO

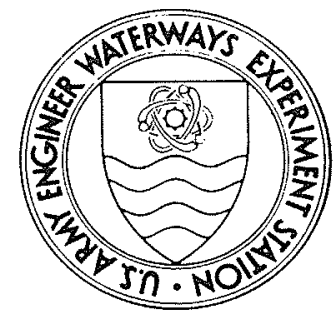

March 1995

Final Report

Approved For Public Release; Distribution Is Unlimited

Prepared for DEPARTMENT OF THE ARMY

U.S. Army Corps of Engineers

Washington, DC 20314-1000

Under Work Unit 32470 
The Dredging Research Program (DRP) is a seven-year program of the US Army Corps of Engineers. DRP research is managed in these five technical areas:

Area 1 - Analysis of Dredged Material Placed in Open Waters

Area 2 - Material Properties Related to Navigation and Dredging

Area 3 - Dredge Plant Equipment and Systems Processes

Area 4 - Vessel Positioning, Survey Controls, and Dredge Monitoring Systems

Area 5 - Management of Dredging Projects

The contents of this report are not to be used for advertising, publication, or promotional purposes. Citation of trade names does not constitute an official endorsement or approval of the use of such commercial products. 

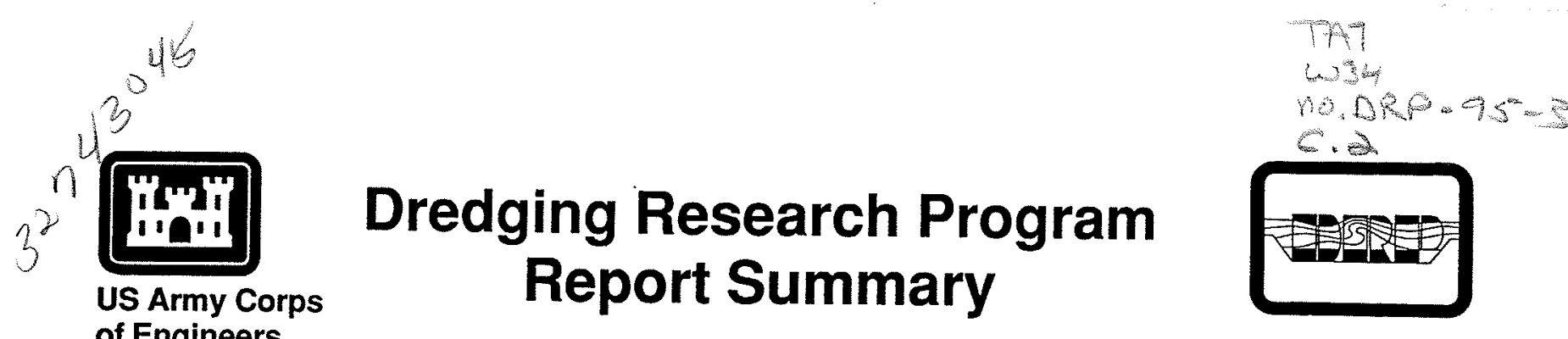

Waterways Experiment

Station

\section{A Technique to Assess the Characteristics of Bottom and Subbottom Marine Sediments (TR DRP-95-3)}

ISSUE: The accurate characterization of bottom and subbottom sediments is critical in all aspects of dredging operations from planning to actual removal and disposal of the sediment. A need existed to develop a rapid geophysical technique for determination of the physical properties of materials scheduled for dredging.

RESEARCH: A decision was made that acoustic principles might be the best to use in developing a reliable technique to determine the dredgeability of sediment. The work had two objectives:

- Develop an electronic package to send and analyze acoustic signals to provide geophysical information from the acoustic reflectivity strength of the signals.

- Survey existing geophysical equipment and develop a rapid technique and appropriate instrumentation to determine the physical properties of bottom and subbottom materials.

The effort was accomplished in three separate but consecutive phases:

I. A field demonstration of an acoustic profiler's ability to measure and relate acoustic reflectivity to density.
II. Continued field testing at a second site.

III. Incorporation of results of reimbursable field tests and continued development of acoustic impedance (AI) approach.

SUMMARY: The study resulted in an optimum AI system. The report includes discussions of equipment and technical development of the AI concept; details of survey planning; and data processing, interpretation, and presentation. Since several AI surveys were conducted as reimbursable projects during the course of the research study, selected sites were included in the report to illustrate the AI concept, its application, and ground-truth comparisons.

AVAILABILITY OF REPORT: The report is available on Interlibrary Loan Service from the U.S. Army Engineer Waterways Experiment Station (WES) Library, telephone (601) 6342355. National Technical Information Service (NTIS) report numbers may also be requested from the WES librarians.

To purchase a copy, call NTIS at (703) 487 4650.

About the Authors: Mr. Riehard G. McGee is a Civil Enginer in the Hydraulics Laboratory (WES) and Mr. Robert F. Ballard, Jt. is a Geophysicist in the Geotechnical Laboratory (WES). Mr. Ballard is also Principal Investigator. Mr. David D. Caulfield is an engineering consultant. Caulfield Engineering Group. Messrs. McGee and Ballard are points of contact. For further infornation about the DRP, contact Mr. E. Clark McNair, Jr., Manager, Dredging Research Program at (601) 634-2070. 


\section{A Technique to Assess the Characteristics of Bottom and Subbottom Marine Sediments}

by Richard G. McGee, Robert F. Ballard, Jr.

U.S. Army Corps of Engineers

Waterways Experiment Station

3909 Halls Ferry Road

Vicksburg, MS 39180-6199

David D. Caulfield

Caulfield Engineering Group

RRI

15051 Hayton Road

Oyama, BC Canada VOH IWO

Final Report

Approved for public release; distribution is unlimited

Prepared for U.S. Army Corps of Engineers

Washington, DC 20314-1000

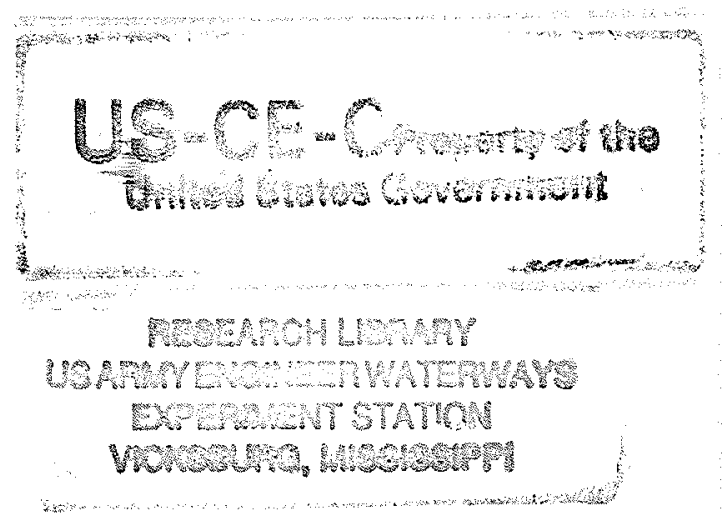

Under Work Unit 32470 


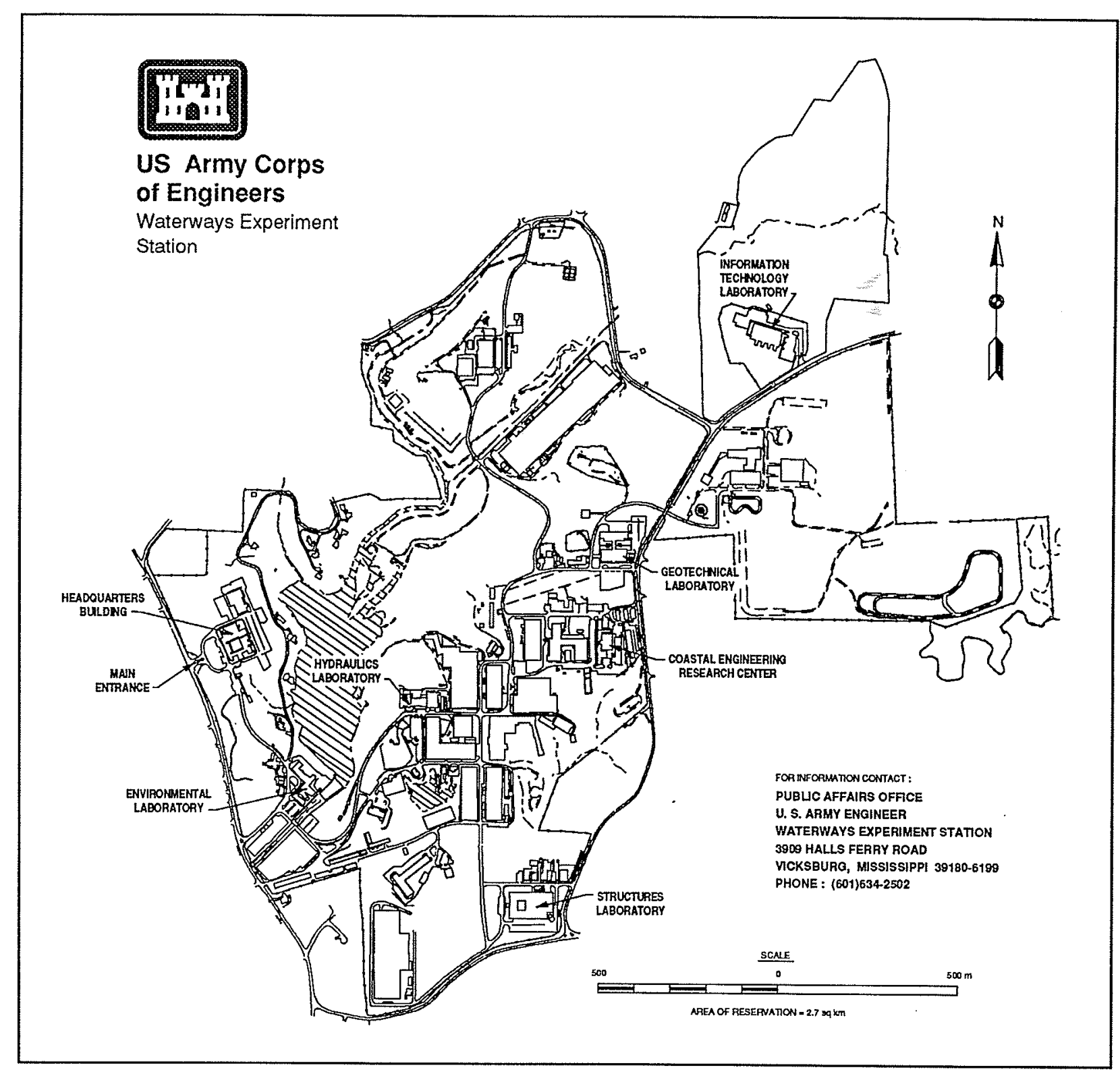

\section{Waterways Experiment Station Cataloging-in-Publication Data}

McGee, Richard G.

A technique to assess the characteristics of bottom and subbottom marine sediments / by Richard G. McGee, Robert F. Ballard, Jr., David D. Caulfield ; prepared for U.S. Army Corps of Engineers.

174 p. : ill. ; $28 \mathrm{~cm}$. - (Technical report ; DRP-95-3)

Includes bibliographic references.

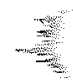

1. Marine sediments - Acoustic properties. 2. Acoustic impedance.

3. Dredging. I. Ballard, Robert F. II. Caulfield, David D. III. United States. Army. Corps of Engineers. IV. U.S. Army Engineer Waterways Experiment Station. V. Dredging Research Program. VI. Title. VII. Series: Technical report (U.S. Army Engineer Waterways Experiment Station) ; DRP-95-3.

TA7 W34 no.DRP-95-3 


\section{Contents}

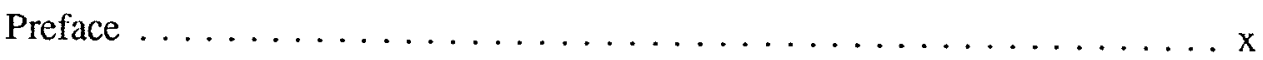

Summary $\ldots \ldots \ldots \ldots \ldots \ldots \ldots \ldots \ldots \ldots \ldots \ldots \ldots \ldots$ xii

Primary Products $\ldots \ldots \ldots \ldots \ldots \ldots \ldots \ldots \ldots \ldots \ldots \ldots \ldots \ldots$

Support Products $\ldots \ldots \ldots \ldots \ldots \ldots \ldots \ldots \ldots \ldots \ldots$ xiii

Areas of Potential Cost Savings $\ldots \ldots \ldots \ldots \ldots \ldots \ldots \ldots$ xiii

Spinoffs and Future Prospects $\ldots \ldots \ldots \ldots \ldots \ldots \ldots$ xiv

Conversion Factors $\ldots \ldots \ldots \ldots \ldots \ldots \ldots \ldots \ldots \ldots \ldots \ldots$

1 -Introduction $\ldots \ldots \ldots \ldots \ldots \ldots \ldots \ldots \ldots \ldots \ldots \ldots \ldots \ldots$

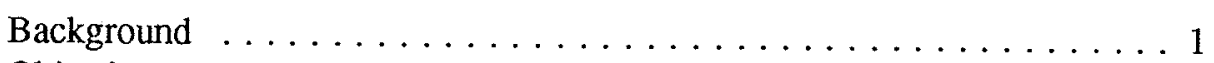

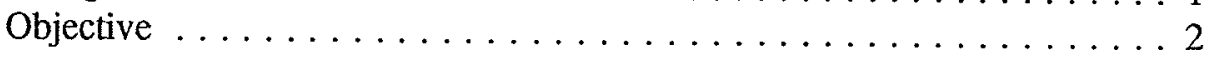

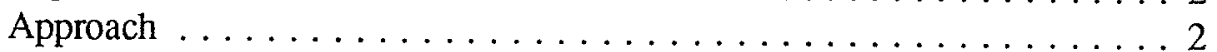

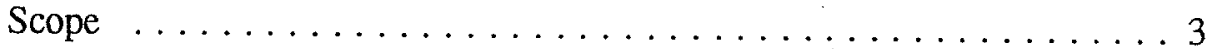

2 -Technical Development $\ldots \ldots \ldots \ldots \ldots \ldots \ldots \ldots \ldots \ldots \ldots$

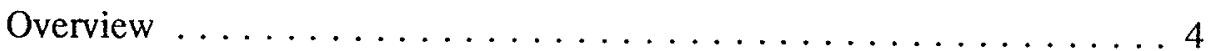

Acoustic Impedance Concept $\ldots \ldots \ldots \ldots \ldots \ldots \ldots \ldots$

Principles of Acoustic Reflection $\ldots \ldots \ldots \ldots \ldots \ldots \ldots \ldots \ldots$

Relationship of Acoustic Impedance to Geotechnical Properties . . . . . 12

Engineering Approach . . . . . . . . . . . . . . . . 13

Layer Identification Methods $\ldots \ldots \ldots \ldots \ldots \ldots \ldots$

3-Survey Planning . . . . . . . . . . . . . . . 60

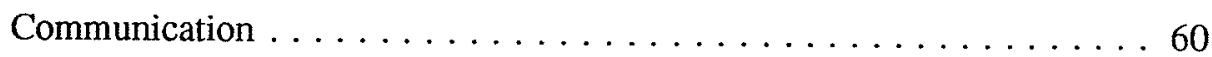

Surveying and Reporting $\ldots \ldots \ldots \ldots \ldots \ldots \ldots \ldots \ldots \ldots \ldots$

4 Case Studies $\ldots \ldots \ldots \ldots \ldots \ldots \ldots \ldots \ldots \ldots \ldots \ldots \ldots \ldots \ldots$

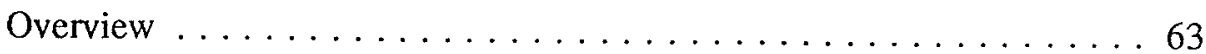

Gulfport and Mobile Ship Channels . . . . . . . . . . . . 64

Galveston Ship Channel . . . . . . . . . . . . . . . 66

Boston Harbor . . . . . . . . . . . . . . . . . 67

Delaware Atlantic Coast . . . . . . . . . . . . . . . . 68

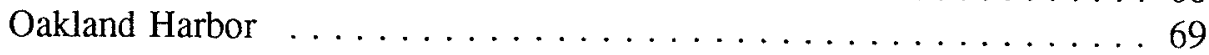

Statistical Assessment $\ldots \ldots \ldots \ldots \ldots \ldots \ldots \ldots \ldots \ldots$ 
5 -Boundary Conditions and Limitations $\ldots \ldots \ldots \ldots \ldots$

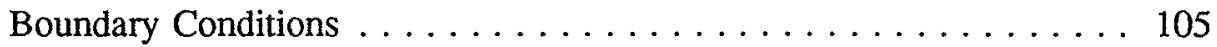

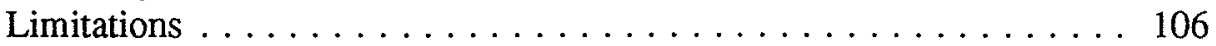

6 -Conclusions and Recommendations $\ldots \ldots \ldots \ldots \ldots$

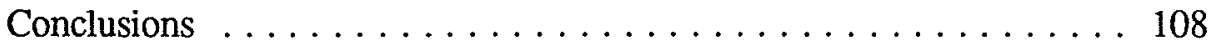

Recommendations . . . . . . . . . . . . . . . . . . . . 109

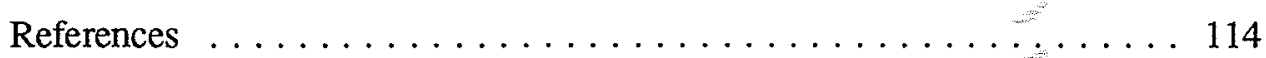

Appendix A: Equipment $\ldots \ldots \ldots \ldots \ldots \ldots \ldots \ldots \ldots \ldots \ldots$

Appendix B: Survey Planning $\ldots \ldots \ldots \ldots \ldots \ldots \ldots \ldots \ldots \ldots$

Appendix C: Epilogue $\ldots \ldots \ldots \ldots \ldots \ldots \ldots \ldots \ldots \ldots \ldots \ldots$

\section{List of Figures}

Figure 1. Typical project flowchart . . . . . . . . . . . . . 24

Figure 2. Acoustic impedance processing flowchart $\ldots \ldots \ldots 25$

Figure 3. Simulated reflection energy envelopes showing influence of material type on signal amplitude $\ldots \ldots \ldots \ldots \ldots \ldots$

Figure 4. Waves generated at an interface by an incident P-wave (after Officer (1958)) . . . . . . . . . . . . . . . . . 26

Figure 5. Multilayer reflectivity model after Robinson and Treital (1980) . . . . . . . . . . . . . . . . . . . . . 27

Figure 6. Scatter diagram for ray paths at a layer interface $\ldots \ldots \ldots 27$

Figure 7. Attenuation as a function of frequency (Hamilton 1972a) . . . 28

Figure 8. Attenuation versus porosity and mean grain size (Hamilton 1972a) . . . . . . . . . . . . . . . . . . . . . 29

Figure 9. Impedance versus density (continental terrace, shelf, and slope) (Hamilton and Bachman 1982) . . . . . . . . . 30

Figure 10. Delaware coast model: impedance versus density; impedance versus mean grain size $\ldots \ldots \ldots \ldots \ldots \ldots \ldots$

Figure 11. Density versus mean grain size $\ldots \ldots \ldots \ldots 2$

Figure 12. Elements in the calibration system for sonar equations $\ldots \ldots 32$

Figure 13. Amplifier gain calibration curve ............. 33

Figure 14. Typical transducer specification data . . . . . . . . . . . 34

Figure 15. Delaware coast survey geometry and computation of directivity index $(D I)$ versus water depth and transducer separation . . . 35

Figure 16. Typical $3.5-\mathrm{kHz}$ calibration data . . . . . . . . . . 36 
Figure 17. Example source level $(S L)$ and bottom loss $(B L)$ calibration . . 37

Figure 18. Receiving array sensitivity calibration configuration . . . . 38

Figure 19. Example receiving array sensitivity calibration . . . . . . 39

Figure 20. Typical surface sediment characterization $\ldots \ldots \ldots \ldots$

Figure 21. Determination of $B L$ from multiple reflections . . . . . 41

Figure 22. Typical AC50 output: amplitude plot . . . . . . . . 42

Figure 23. Typical AC50 output: impedance plot ...........43

Figure 24. Typical AC50 output: density plot with table . . . . . . . 44

Figure 25. Typical AC50 output: altemating impedance and raw data plot ..................... 45

Figure 26. Typical spectral output (DSA 10): pinger (3.5-kHz) reflection data $\ldots \ldots \ldots \ldots \ldots \ldots \ldots \ldots \ldots \ldots \ldots \ldots \ldots \ldots$

Figure 27. Typical spectral output (DSA 10): boomer reflection data . . . 47

Figure 28. Typical spectral output (DSA 10): chirped source wavelet data . . . . . . . . . . . . . . 48

Figure 29. Correlation analysis: pinger $(3.5 \mathrm{kHz})$ with noise . . . . . . 49

Figure 30 . Correlation analysis: boomer with noise $\ldots \ldots \ldots \ldots$

Figure 31 . Correlation analysis: chirped signal with noise $\ldots \ldots \ldots 51$

Figure 32. Correlation output: raw data versus correlated (boomer) . . . . 52

Figure 33. Example geologic models: (a) sand over soft mud over hard clay (b) sand over hard clay $\ldots \ldots \ldots \ldots \ldots \ldots \ldots \ldots$

Figure 34. Synthetic seismograms: sand/soft mud/hard clay . . . . . . . 54

Figure 35. Synthetic seismograms: sand/hard clay . . . . . . . 55

Figure 36. Synthetic seismogram matched filter correlation - boomer

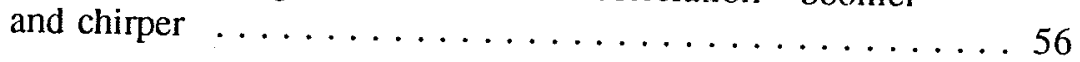

Figure 37. Synthetic seismogram spiking deconvolution $\ldots \ldots \ldots \ldots 7$

Figure 38. Forward model comparison with actual data $\ldots \ldots \ldots \ldots 8$

Figure 39. Example of spectral attenuation: sand/clay/sand . . . . . . . 59

Figure 40. Amplitude color plot, $20-$ and $45-\mathrm{kHz}$ survey profiles . . . . . 71

Figure 41. Acoustic impedance density prediction versus nuclear

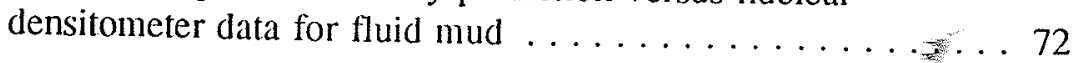

Figure 42. Hamilton's impedance function (modified by Caulfield (1992 $2 \mathrm{a}$ ) with Gulfport and Mobile data superimposed . . . . . . 73

Figure 43. Acoustic predictions versus core data - Mobile . . . . . . 74

Figure 44. Acoustic predictions versus core data - Gulfport . . . . . . 75 
Figure 45. Density cross sections in Gulfport Ship Channel . . . . . . 80

Figure 46. 3-D view of a section of Gulfport Ship Channel $\ldots \ldots \ldots 81$

Figure 47. Volumetric calculations for sand in a section of Gulf Ship Channel ................... 81

Figure 48. Pinger (3.5 kHz) amplitude cross section, Galveston

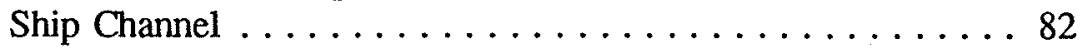

Figure 49. Bottom surface calibration at WES Core CERC-4, Anchorage

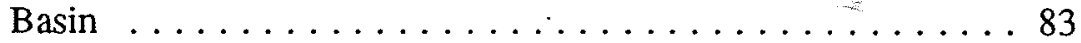

Figure 50. Bottom surface calibration at WES Core CERC-8, Inner Bar Channel . . . . . . . . . . . . . . . . . 84

Figure 51. Subbottom sediment calibration at Cores CERC-3 and 3ST-87,

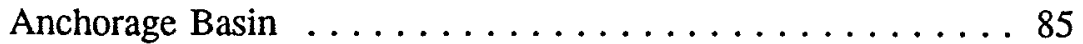

Figure 52. Check calibration at Core CERC-9, Inner Bar Channel . . . . 86

Figure 53. Check calibration Core CERC-5, Anchorage Basin . . . . . . . 87

Figure 54. 3-D perspective view of Inner Bar and Anchorage Basin, Galveston Harbor. Axes are displayed in northing and easting coordinates . . . . . . . . . . 88

Figure 55. 2-D slice from selected portion of 3-D density display $\ldots \ldots 88$

Figure 56. 2-D profile showing area of interest within depth and

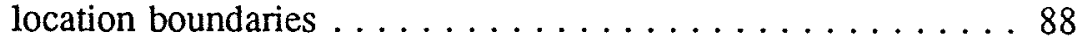

Figure 57. 2-D profile model showing only material $>1.7 \mathrm{~g} / \mathrm{cm}^{3}$ density within area of interest $\ldots \ldots \ldots \ldots \ldots$

Figure 58. Typical calibration comparison display of acoustic data versus laboratory density and lithographics (Boston Harbor) . . . . 89

Figure 59. Geoacoustic calibration data versus laboratory results (Delaware Coast) . . . . . . . . . . . . . . . . . . . . . 90

Figure 60. 2-D profile of sediment material (Delaware coast) $\ldots \ldots \ldots 95$

Figure 61. Oakland Harbor geoacoustic calibration (CORE CH-3) . . . . 97

Figure 62. Oakland Harbor geoacoustic calibration (CORE IC-18) . . . . 98

Figure 63. Oakland Harbor geoacoustic calibration (CORE 00-CH-1) . . 99

Figure 64. Oakland Harbor geoacoustic calibration (CORE 00-W-2) . . 100

Figure 65. Typical sediment profile from Oakland Harbor . . . . . . . 101

Figure 66. 3D visualization of a portion of Oakland Harbor . . . 103

Figure 67. Statistical analysis of measured density versus acoustically derived density . . . . . . . . . . . . . . . . . 104

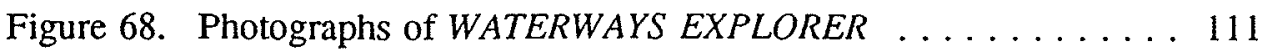

Figure A1. Block diagram of WES integrated geophysical system . . . . A4 
Figure A2. Over-the-side deployment of pinger transducers $\ldots \ldots \ldots \ldots$ A5

Figure A3. Coherent noise due to coupling of transmitter and receiver . . A6

Figure A4. Improvement in signal-to-noise due to separated configuration $\ldots \ldots \ldots \ldots \ldots \ldots \ldots \ldots \ldots \ldots \ldots \ldots \ldots \ldots \ldots$

Figure A5. Typical boomer system in tow $\ldots \ldots \ldots \ldots \ldots \ldots$ A8

Figure A6. Typical pinger data record $\ldots \ldots \ldots \ldots \ldots \ldots$ A9

Figure A7. Typical boomer data record . . . . . . . . . . A10

Figure A8. Typical bubble pulse data record $\ldots \ldots \ldots \ldots \ldots$ A 11

Figure B1. Boston Harbor, MA, Navigation Improvement Project information sheet $\ldots \ldots \ldots \ldots \ldots \ldots \ldots \ldots \ldots \ldots \ldots$

Figure B2. WES Memorandum for Record $\ldots \ldots \ldots \ldots \ldots \ldots$ B8

Figure B3. Final proposal submitted to NED ............ B13 


\section{Preface}

The work described herein was authorized by Headquarters, U.S. Army Corps of Engineers (HQUSACE) and performed under Work Unit 32470 (Rapid Measurements of Properties of Consolidated Sediments) of the Dredging Research Program (DRP), Technical Area 2, Material Properties Related to Navigation and Dredging. Technical Area 2 Manager was Dr. Don C. Banks. Messrs. Robert H. Campbell and Barry W. Holliday were DRP Chief and TA 2 Technical Monitors from HQUSACE, respectively. Mr. E. Clark McNair, Jr., Coastal Engineering Research Center (CERC), was DRP Program Manager, and Dr. Lyndell Z. Hales, CERC, was Assistant Program Manager. Mr. Robert F. Ballard Jr., Geophysicist, and Mr. Thomas S. Harmon, Equipment Specialist, Earthquake Engineering and Geosciences Division, Geotechnical Laboratory (GL), were Co-Principal Investigators for Work Unit 32470.

This study was jointly performed over the period October 1988 through August 1994 by Messrs. Robert F. Ballard, Jr., Thomas S. Hammon (GL), and Mr. Richard G. McGee, Hydraulics Laboratory (HL). Initial work on this project was performed by Mr. Dale Hart (HL) prior to his retirement in June 1989. At that time responsibility for the project was transferred from HL to GL. Work continued with a cooperative effort between personnel of the Geotechnical and Hydraulics Laboratories and the Instrumentation Services Division. The final report was written jointly by Messrs. Richard McGee, Robert Ballard, and David Caulfield. Mr. McGee was under the administrative supervision of Dr. Bobby J. Brown, Chief, Hydraulic Analysis Branch, HL, and Mr. Frank A. Herrmann, Jr., Director, HL. Mr. Ballard was under the administrative supervision of Dr. Arley G. Franklin, Chief, Earthquake Engineering and Geosciences Division, GL, and Dr. W. F. Marcuson, III, Director, GL. Mr. Caulfield, a primary contractor, was President of Caulfield Engineering Group, Oyama, British Columbia, Canada.

It must be noted that any degree of success achieved in this project can largely be attributed to the talents of those individuals working with the authors in this interlaboratory team effort: Tom Harmon, Keith Sjostrom, Rodney Leist, and Tina Grau (GL) and Darla McVann, Janie Vaughn, and Brian Williams (HL), U.S. Anny Engineer Waterways Experiment Station (WES). Bob Meader, U.S. Army Engineer Division, New England, contributed materials used in Appendix A. 
During publication of this report, Dr. Robert W. Whalin was Director of WES. COL Bruce K. Howard, EN, was Commander.

The contents of this report are not to be used for advertising, publication. or promotional purposes. Citation of trade names does not constitute an official endorsement or approval of the use of such commercial products. 


\section{Summary}

This report presents the theoretical concept, assembly, and field testing of a waterbome seismic acoustic impedance technique which has been developed to characterize bottom and subbottom sediments as they relate to removal by dredging. This method, developed under the Dredging Research Program (DRP), provides estimates of in situ density and soil type in a rapid, costeffective manner using digital acoustic subbottom profiling methodology. In situ densities obtained by the acoustic impedance technique to date, when compared to those obtained by conventional means at several different sites under a wide variety of marine conditions, have statistically been within \pm 10 percent. However, only marine sediments considered to be fully saturated, inorganic, and uncontaminated have been investigated and "ground truthed." After comparisons with ground truth information and laboratory testing, a critical analysis of the acoustic impedance technique reveals it to be a valid and useful approach to bottom and subbottom material and density prediction. While some development is still needed to fully establish advantages and limitations, its potential usefulness warrants technology transfer now, provided proper cautions are observed. This supposition is corroborated by the fact that numerous reimbursable surveys have been successfully conducted while products were still in the development stage. Each site surveyed provided valuable input to the research and development evolutionary processes and enabled researchers to fine-tune procedures while still providing a useful and timely service to sponsoring Districts and Divisions.

The following benefits have been derived as a result of this work:

\section{Primary Products}

a. A rapid geophysical technique using acoustics to characterize bottom/subbottom conditions.

$b$. A computer visualization process for displaying subbottom density and material type predictions and volumetric calculations in three dimensions. 
c. Specifications and assembly of waterborne integrated geophysical system (assembly and components funded by sources other than DRP).

\section{Support Products}

a. Sediment density estimates.

b. Material type predictions.

c. Subbottom stratigraphic information for project planning and design.

d. Project monitoring.

e. Volume estimates of sediment.

f. Contractual evidence.

g. Geologic database for long-term planning.

\section{Areas of Potential Cost Savings}

(The following are based upon DRP benefits analysis (Griffis 1994).)

a. Direct savings:

(1) Continuous coverage of bottom and subbottom conditions.

(2) Optimum boring placement and elimination of those unnecessary.

(3) Accurate assessment of material type, density, and volume.

b. Environmental enhancements:

(1) Presence of cultural resources.

(2) Long-term monitoring of disposal berms.

c. Mission enhancements:

(1) Location of under-channel utilities.

(2) Determination of fluid mud zone thickness. 
d. Cost avoidances:

(1) Contractor claims on volumes of material and surprises associated with material changes.

(2) Elimination of needless borings.

(3) Change of channel routing to avoid undesirable conditions.

\section{Spinoffs and Future Prospects}

(The following are authors' opinions based upon observations made at some 15 sites surveyed and communication with product users.)

a. Spinoffs:

(1) Incorporation of airborne/waterborne Navy EM for reconnaissance determinations of sediments and topographic/bathymetric surveying (large area site characterization).

(2) Determination of navigable depth (fluid mud assessment).

(3) Assessment of integrity of disposal berms.

b. Future prospects:

(1) Location of contaminated materials.

(2) Location of marine sand deposits.

(3) Location of dredging hazards and utility crossings.

(4) Bottom/subbottom conditions in lakes and reservoirs.

(5) Description of geologic formations. 


\section{Conversion Factors, Non-SI to SI Units of Measurement}

Non-SI units of measurement used in this report can be converted to SI units as follows:

\begin{tabular}{|l|c|l|}
\hline Multiply & By & To Obtain \\
\hline \hline cubic yards & 0.7645549 & cubic meters \\
\hline degrees (angle) & 0.01745329 & radians \\
\hline feet & 0.3048 & meters \\
\hline inches & 0.0254 & meters \\
\hline miles (U.S. statue) & $1,609.347$ & meters \\
\hline tons (force) & $8,896.444$ & newtons \\
\hline yards & 0.9144 & meters \\
\hline
\end{tabular}




\section{Introduction}

\section{Background}

During fiscal year 1988 the U.S. Army Corps of Engineers (USACE) began a research and development program of major proportions to address problems and needs arising in the performance of its dredging mission. This effort, called the Dredging Research Program (DRP), is a major thrust toward developing improved technologies that can reduce the costs of dredging operations. The program concentrates on problem areas related to the physical aspects of dredging or dredging projects.

The USACE Directorate of Civil Works is involved in virtually every navigation dredging operation performed in the United States. The Corps dredging mission entails maintenance and improvement of 25,000 miles ${ }^{1}$ of commercially navigable channels serving 400 ports, including 130 of the nation's 150 largest cities. Connecting waterways to the nation's ports and harbors handle about 2 billion tons of commerce each year as waterborne transport continues to be the most cost- and energy-efficient means of shipping bulk cargos. Additionally, the waterways network constitutes an infrastructure component essential to the nation's defense capabilities.

The Corps of Engineers dredges an average of 250 to 300 million cu yd of sedimentary material at a current expenditure level of about $\$ 400$ million per year in order to maintain and operate the nation's existing navigation system. Dredging is the single most costly item in the Corps' Civil Works Operations/ Maintenance budget.

The Corps has been actively involved in dredging for over 160 years. Originally, the Corps maintained a large fleet of its own dredges, but in recent years the bulk of field operations have shifted from the government fleet to the private sector. In order to fulfill its mission within budget and time constraints, the Corps will be continually challenged to meet dredging needs in an efficient, cost-effective manner. To meet these needs, it was recognized that a research and development program would be needed to identify areas with

1 A table of factors for converting non-SI units of measurement to Sl unit is presented on page $\mathrm{xv}$. 
high potential for large paybacks through the investment of Corps research dollars. Eventually, a direction was established using informational input from those involved in Corps dredging operations which led to the identification of five specific problem areas. Accomplishments reported herein fall within the purview of Problem Area 2, Material Properties Related to Navigation and Dredging. The specific objectives of Problem Area 2 are: (1) development of instrumentation and operating procedures for rapid surveys of fluid mud properties, (2) definition of navigable depth in fine-grained sediment, (3) development of instrumentation for analyzing properties of consolidated sediments, and (4) establishment of dredging-related soil and rock descriptors. Work Unit 32470, Rapid Measurements of Properties of Consolidated Sediments, was undertaken to meet objective (3) cited above. To date, accomplishments show outstanding promise, and continued future development will enable Corps personnel to more accurately assess the characteristics of bottom and subbottom sediments as they relate to removal by dredging.

\section{Objective}

The objective of DRP Work Unit 32470 was to develop a rapid geophysical technique and identify/recommend the appropriate instrumentation necessary for determination of the physical properties of bottom and subbottom materials scheduled for dredge removal.

\section{Approach}

In the early stages of the DRP, Work Unit 32470 was conceived to combat a problem identified as the Corps' need to categorize and quantify the dredgeability of bottom sediment in a rapid, widely accepted manner. At that time it was decided that acoustic principles might best be used to fulfill the solution. Descriptive subbottom information would be valuable in dredging applications and in preparing government estimates for dredging contracts, selecting the most efficient and productive dredge, and selecting appropriate disposal sites. The full objective was to develop an electronic package to send and analyze acoustic signals to provide geophysical information such as density, shear strength, and grain size from the acoustic reflectivity strength of the signals. Secondly, the program incorporated a survey of existing geophysical equipment and development of a rapid geophysical technique and the appropriate instrumentation to determine the physical properties of bottom and subbottom materials for dredge removal purposes.

The effort was divided into three separate but consecutive phases. Phase I consisted of a field demonstration of an acoustic subbottom profiler's ability to measure and relate acoustic reflectivity of bottom sediments to density of the material. Phase II was structured to involve a continuation of field tests at a second well-documented site while industry-wide searches were conducted to determine those properties of sediments which were descriptive of the relative 
ease of removal by dredging. Phase III was originally to consist of an evaluation of other seismic methods, while configuring an optimum waterborne system for a variety of USACE applications. However, since a high degree of success was achieved during Phase II and at several follow-on test sites where surveys were performed on a reimbursable basis, it was decided to incorporate representative data and limit further evaluations to various types of seismic sources while concentrating on full development of the Acoustic Impedance (AI) approach. Further, through other sources, funds were secured to purchase a vessel and a full complement of geophysical equipment. In the life of this program, the optimum AI system was bom and rapid progress made in survey performances and continued technological improvements in data processing and displays. That system is now available for use in a wide range of problem applications, whether civil or military.

\section{Scope}

This report contains discussions on equipment, technical development of the acoustic impedance concept, data processing and interpretation, data presentation (visualization), survey planning, limitations, and recommendations. Since numerous AI surveys have been successfully conducted, selected sites will be . used to illustrate the AI concept, its applications, and ground truth comparisons. This report is not intended to serve as a user's guide or as an Engineer Manual. Procedures developed and reported herein require hands-on training of specialized personnel skilled in the application of geophysical methods, data processing, and interpretation. 


\section{Technical Development}

\section{Overview}

The Al method was developed to rapidly and accurately assess engineering properties of shallow marine sediments, providing virtually continuous coverage for delineation of both horizontal and vertical extents of those sediments as they relate to dredging. Another goal was to provide this "hardware/software package" on an affordable, standardized computer platform, consequently making the technology accessible to a wide variety of users. Finally and most importantly, development of "black boxes" was avoided. As with many geophysical techniques, there exists a variety of situations or environments whose response characteristics to a particular external event, such as seismic excitation, are neither theoretically nor empirically uniquely defined. Without proper physical verification, or ground truthing, significant errors in interpretation are possible. In other words, the state-of-the-art has not advanced to the point where any one device or system is capable of accurately assessing all feasible situations because certain combinations of physical factors can cause nearly identical seismic signatures.

The AI method incorporates specially designed software packages, hardware configurations, and standardized field data collection methods into a structured geoacoustic modeling program. A geoacoustic model as defined by Hamilton (1980) is "a model of the real seafloor with emphasis on measured, extrapolated, and predicted values of those properties important in underwater acoustics and those aspects of geophysics involving sound transmission." Hamilton further shows that a geoacoustic model should include the following information for each sediment layer:

a. Sediment information (cores).

b. Thickness of layers.

c. Properties of overlying water mass.

d. Locations, thickness, and properties of reflectors within the sediment body at various frequencies. 
e. Properties of rock layers.

f. Details of the bottom topography.

It is this concept of geoacoustic modeling that was used to direct the development of the AI method, specifically targeting the needs of the DRP. For example, any particular application of the AI method is basically divided into four phases:

a. Data collection.

b. Data processing.

c. Direct sampling.

d. Geoacoustic modeling.

Figure 1 is a typical project flowchart from a comprehensive AI study conducted off the coast of Delaware for the Philadelphia district. Discussion of the AI method will begin with a presentation of technical issues regarding the capability of performing quantitative analysis on acoustic reflection data for the purpose of characterizing engineering properties of marine sediments. The remaining discussion will follow according to the above phases. Specific theories, hardware, software, or procedures will be discussed in detail under the appropriate topic.

\section{Acoustic Impedance Concept}

The AI method is an extension of techniques developed by Caulfield and Yim (1983) and Caulfield, Caulfield, and Yim (1985). It must be emphasized that the model is an empirical technique which compensates for absorption in each layer as a function of the center frequency of a band-limited seismic trace, corrects for spherical spreading, and utilizes classical multilayer reflective mathematics to compute reflection coefficients at sediment horizons. Reflection coefficients are converted to impedances and classified according to established relationships between acoustic impedance and geotechnical properties of marine sediments, thereby classifying the lithostratigraphy. Figure 2 illustrates the general processing steps required by the method in practice. Figure 3 shows a hypothetical echo sounding or seismic pulse impinging on the bottom and subbottom. The pulse has a finite time width $(\Delta t)$ and will have different return amplitudes based on the acoustic impedance $(Z)$ and the absorption $(\alpha)$ of each layer.

\section{Reference units and the decibel scale}

Since nearly all computations and results are given in decibels (abbreviated as $d b$ ), a brief explanation of the system is provided. The unit of intensity in 
underwater sound for purposes of this report is the intensity of a plane wave having an $\mathrm{rms}$ pressure equal to 1 dyne per square centimeter (dyne $/ \mathrm{cm}^{2}$ ). This differs from the new American National Standard ${ }^{1}$ of 1 micropascal $\left(1 \mu \mathrm{Pa}=10^{-5}\right.$ dyne $\left./ \mathrm{cm}^{2}\right)$. The dyne $/ \mathrm{cm}^{2}$ standard is used herein to correlate with the work of previous researchers.

Historically, decibel units have been used for reckoning acoustic quantities due to their convenience in dealing with large changes in variables, thereby simplifying the computational process. The decibel is a logarithmic expression of the ratio of two amounts of power, specifically

$$
n=10 \log _{10}\left(P / P_{0}\right)
$$

where

$$
\begin{aligned}
& P=\text { amount of power being considered } \\
& P_{o}=\text { reference power }
\end{aligned}
$$

This equation is used whenever a unit of power or total energy is being considered, such as the source level of an acoustic device which is normally expressed in kilowatts, or when evaluating the total energy of a wavelet in the frequency domain. In the case of acoustic sound pressures, the decibel value is expressed as

$$
n=20 \log _{10}\left(p / p_{o}\right)
$$

where

$$
\begin{aligned}
& p=\text { given pressure level }(\mathrm{db}) \\
& p_{o}=\text { reference pressure }(\mathrm{db})
\end{aligned}
$$

It should be emphasized that the decibel is a comparison of intensities rather than a direct comparison of acoustic pressures. The statement " $20 \mathrm{db}$ referenced to one dyne $/ \mathrm{cm}^{2}$ " actually means " $20 \mathrm{db}$ relative to the intensity of a plane wave of pressure equal to one dyne/ $\mathrm{cm}^{2}$." Nearly all computations involved in the AI method are accomplished using the decibel scale.

1 Preferred Reference Quantities for Acoustical Levels, ANSI S1.8-1969 (R1974), American National Standards Institute, New York. 


\section{Principles of Acoustic Reflection}

The principles governing acoustic reflection are well-known, are presented in many texts, and will not be repeated here. The reader is referred to the work of Officer (1958) for an excellent discussion of the theories of sound transmission. Because AI is a quantitative approach, a discussion concerning the basic theory utilized in remotely determining the acoustic impedance of a sediment layer using sound is appropriate.

Consider wave propagation across a boundary. If a seismic wave propagating through a medium arrives at the boundary of another medium, part of the energy of the wave will be reflected, part transmitted, and a portion absorbed within the upper medium. Starting from Snell's Law governing refraction and applying the appropriate boundary conditions of continuity of normal and tangential stresses, it is possible to represent the relationship between the incident, reflected, and transmitted waves in terms of their velocities and angle of propagation relative to the normal. This relationship is shown by Figure 4 and was first demonstrated by Zoeppritz in 1919. According to Snell's Law, for the case of normal-incidence compressional (P-wave) propagation across the boundary of a horizontally oriented system, the Zoeppritz equation for the amplitude coefficients of the incident $\left(A_{i}\right)$, reflected $\left(A_{c}\right)$, and transmitted $\left(A_{t}\right)$ waves becomes, by continuity of displacement, simply

$$
A_{i}=A_{c}+A_{t}
$$

and for continuity of stress becomes

$$
A_{i}-A_{c}=\frac{E_{2} / v_{2}}{E_{1} / v_{1}} A_{t}
$$

where $E_{1}$ and $E_{2}$ are the elastic moduli of medium 1 and 2, respectively, and $v_{1}$ and $v_{2}$ are the velocities in each. For a perfectly elastic medium $E=\rho v^{2}$, where $\rho$ is the mass density and $v$ the elastic P-wave velocity, the quantity $\rho v$ is called the acoustic impedance $Z$ of the medium and thus represents the influence of the medium's characteristics on reflected and transmitted waves. Solving the equations of stress and displacement continuity for $A_{c}$ and $A_{t}$ in terms of $A_{i}$ gives

$$
A_{c}=\frac{Z_{1}-Z_{2}}{Z_{1}+Z_{2}} A_{i}=R A_{i}
$$


and

$$
A_{t}=\frac{2 Z_{1}}{Z_{1}+Z_{2}} A_{i}=T A_{i}
$$

The coefficients $R$ and $T$ are called the reflection and transmission coefficients, respectively, and represent the actual percentage of the wave's reflected and transmitted energy. In terms of the reflection coefficient, the Zoeppritz equations can be written as

$$
Z_{2}=Z_{1} \frac{(1+R)}{(1-R)}
$$

providing a straightforward method for determining acoustic impedance. By knowing the first $Z$ and the succeeding $R s$, all the acoustic impedances can then be calculated. In this case the first layer is always seawater, which has a known typical impedance value of $1,55010^{2} \mathrm{~g} / \mathrm{cm}^{2} \mathrm{~s}$. By calculating the remaining $R \mathrm{~s}$, the problem is solved. However, as will be shown, this solution is not as simple as it seems.

\section{Classical multilayer reflectivity}

The previous discussion presents the mechanics of seismic wave propagation across a single boundary between two media without accounting for absorption effects. What follows is the case of a multilayered system consisting of more than two layers. This is not presented as a derivation of the mathematics involved; rather, it is provided to familiarize the reader with potential complexities to be faced in any attempt to develop a system capable of evaluating multilayered systems. Excellent detailed presentations of the mathematics of propagation in layered systems are found in the work of Officer (1958), Robinson and Treitel (1980), and T. M. McGee (1991).

Discussion will be restricted to compressional (P-wave) propagation along the vertical axis in a horizontally layered system. For convenience, however, the diagrams are drawn with time along the horizontal axis so that the rays appear to be angled through the layers. For this discussion, the layers are assumed to be equal travel-time thicknesses. Figure 5, adapted from Robinson and Treitel (1980), shows the ray paths of the multilayered reflectivity model, which should not be confused with the commonly seen angled ray-path plots in multilayered systems with increasing velocities.

The multilayered system presents us with a number of new variables not evident in the simple case of wave propagation across a single boundary. The effects of upward-traveling waves and absorption must be considered. The relationship between wave coefficients is defined in terms of the reflection and transmission coefficients. Figure 6 presents a closeup look at the interface 
between layers $k$ and $k+1$ at time $i$. The symbols $u$ and $d$ represent upwardand downward-traveling waves, respectively, and the prime symbol signifies the wave is at the bottom of the layer. Therefore, the coefficient $u_{k^{\prime}}(i)$ is the upward-traveling wave in the bottom of layer $k$, comprising the part due to the reflection of $d^{\prime} k^{(i)}$ and the part due to the transmission of $u_{k+1}^{\prime}(i)$ as follows:

$$
u_{k}^{\prime}(i)=R d_{k}^{\prime}(i)+T^{\prime} u_{k+1}(i)
$$

Likewise, the coefficient $d_{k+1}(i)$ is given as

$$
d_{k+1}(i)=T d^{\prime}{ }_{k}(i)+R^{\prime} u_{k+1}(i)
$$

These equations can be further manipulated to yield the following two simultaneous equations describing the situation at the interface at time $i$ :

$$
T d^{\prime} k(i)=d_{k+1}(i)+R u_{k+1}(i)
$$

and

$$
T u_{k}^{\prime}(i)=R d_{k+1}(i)+u_{k+1}(i)
$$

Solution of the simultaneous equations can then be accomplished using $z$-transform theory giving the expression for the absorption-free case of propagation across interface $i$ in the matrix form

$$
\left[\begin{array}{c}
U^{\prime}{ }_{k}(z) \\
D^{\prime}{ }_{k}(z)
\end{array}\right]=\frac{1}{T_{k}}\left(\begin{array}{cc}
1 & R_{k} \\
R_{k} & 1
\end{array}\right)\left[\begin{array}{l}
U_{k+1}(z) \\
D_{k+1}(z)
\end{array}\right]
$$

The situation becomes further complicated when the effects of absorption are introduced. Absorption is a frequency-dependent attenuation of the amplitude of a waveform as it propagates through a given sediment layer. In order to accurately determine the reflection coefficient- and thus impedance- at a given interface, the energy loss resulting from absorption must be accounted for. This effect can be modeled in the above approach by applying the appropriate absorption operator. A proposed solution is presented by T. M. McGee (1991) and will not be repeated here. Specifics of the AI method, offering a practical approach to the problem, will be presented in detail later in this chapter. 


\section{Absorption and other losses}

One of the primary energy losses encountered during acoustic wave propagation through differing media is that due to absorption. Acoustic reflections are generated from impedance mismatches within the sediment body. The amount of retumed energy depends on the length of the sound path and the attenuation of sound along the path. Attenuation along the sound path results from a number of mechanisms as described by Hamilton (1980) and Sheriff (1975), some of which include:

a. Spherical spreading or transmission loss. This loss, as described by Urick (1983), is a geometrical effect representing the regular weakening of a sound signal as it spreads outward from the source. As will be shown later, spreading loss varies with range according to the logarithm of the range.

b. Transmission through reflectors. These losses include multiple reflections, reflection and refraction, and conversion of compressional to shear waves.

c. Reflector roughness and curvature. These are the focusing and defocusing effects of concave and convex reflectors.

d. Scattering due to inhomogeneities within the sediment body.

$e$. Intrinsic absorption. This loss involves a process of conversion of acoustic energy into heat and thereby represents a true loss of acoustic energy to the medium in which propagation is taking place (see Equation 14).

A discussion concerning the assessment of absorption will be addressed later in the sections "Absorption Calibration" and "Spectrum Analysis." The total of all losses is called the effective attenuation, and because of the randomness of items $c$ and $d$ above (and many other possible factors not mentioned), it is nearly impossible to completely account for in the real world of acoustic profiling. However, the major sources of attenuation (i.e., spreading, reflection, and absorption) have been researched extensively, providing reasonable approximations of the actual losses occurring. For the case of absorption in marine sediments, there has been considerable debate conceming the most appropriate attenuation model. Stoll (1974) following Biot (1956a and 1956b) favors a theoretical model where at low frequencies (generally less than $10 \mathrm{kHz}$ ) absorption has an $f^{2}$ dependence and at the higher frequencies an $f^{1 / 2}$ dependence. Hamilton (1972a and 1972b) and others (refer to Hamilton papers), on the other hand, present convincing experimental evidence as to absorption's relationship to the first power of frequency. Hamilton (1972a) presents the following important observations:

a. Absorption is dependent on the first power of frequency. 
$b$. Velocity dispersion is insignificant when compared to $a$.

c. Intergrain friction appears to be, by far, the dominant cause of waveenergy dampening in marine sediments.

Specifically, absorption varies as a function of frequency according to the empirical equation

$$
\alpha=k f^{n}
$$

where

$$
\begin{aligned}
& \alpha=\text { absorption, } d b / m \\
& f=\text { frequency, } \mathrm{kHz} \\
& k=\text { attenuation coefficient, } d b / m / k H z \\
& n=\text { exponent of frequency }
\end{aligned}
$$

The constant $n$ has been experimentally determined to be essentially unity for the frequencies of interest (Figure 7) leaving $k$ in Equation 13 as the only variable. This constant varies with sediment type and is related to porosity and mean grain size as shown in Figure 8. Because of the extensive experimental data utilized, Hamilton's linear relationship was chosen as the model for the AI method. A modification of this model as described by Caulfield and Yim (1983) and Caulfield, Caulfield, and Yim (1985) is utilized in the AI method to estimate the engineering properties of marine sediments. A reasonable measure of absorption, in keeping with Equation 13, is provided assuming an exponential correction as a function of frequency by

$$
\alpha=10 \log _{10} e^{\frac{\rho(2 \pi f)}{k c} \times X}
$$

where

$$
\begin{aligned}
& \rho=\text { density of layer, } \mathrm{gm} / \mathrm{cc} \\
& c=\text { sound velocity of layer } \\
& k=\text { attenuation coefficient (similar to Hamilton's) } \\
& X=\text { precision absorption correction factor }
\end{aligned}
$$

The coefficient $k$ is either experimentally derived or estimated from Hamilton's regression equation (refer to Figure 8). A correction factor $X$ is included to compensate for localized variations in the absorption properties of sediments 
in a given geologic setting. This value normally remains unity, is applied in a linear manner, and is only altered when detailed core data are available. The value of $X$ is increased or decreased so that the acoustically derived impedance estimates match the laboratory measured core properties. It is important to note that research regarding the acoustic absorption in marine sediments has been widely studied. A compilation of the various absorption theories and models is provided by Hampton (1974). The model utilized in the AI method is by no means totally perfect in terms of applicability to all possible marine environments. Rather, it is designed to provide a reasonable estimate towards the prediction of actual sediment properties and, upon critical examination of actual in situ conditions, to be refined to precisely model a particular sediment environment.

\section{Relationship of Acoustic Impedance to Geotechnical Properties}

Because acoustic impedance basically represents the influence of a medium's characteristics on reflected and transmitted waves, many geotechnical properties such as porosity, density, mean grain size, bulk modulus, etc., exhibit excellent correlation with impedance. During the last two decades, the ability to predict geotechnical properties from normal reflectivity through impedance calculations has become very much established. However, seismic signatures, and therefore acoustic impedances, are not considered unique. Several combinations of geologic conditions could conceivably yield similar signal characteristics. Therefore, a critical stage in the process is development of geoacoustic relationships which are used to model a specific geologic environment. General relationships for acoustic impedance versus density are given by Hamilton and Bachman (1982) in Figure 9 and for soil type by Caulfield and Yim (1983) in Table 1. These relationships (or estimates) are based on worldwide averages of impedance versus sediment properties from primarily deep ocean environments and do not necessarily constitute the precise characterization of all geologic situations.

The AI method utilizes a regional calibration approach. For a particular study area (for example, Panama City Harbor or Delaware Bay), computed acoustic impedance values are related directly to the soil parameters measured from at least ten cores representative of the area. A recently completed study in the predominantly sand environment off the coast of Delaware by McGee (in publication) presents an excellent example of the regional approach to geoacoustic modeling. Figure 10 presents the relationship between computed impedance and the soil properties of density and mean grain size for the Delaware Coast project. It is important to note that for the Delaware model, the predictions are only applicable for the sediment ranges presented. Figure 11 shows an example of density versus mean grain size derived from laboratory measurements of core samples collected by the U.S. Army Engineer Waterways Experiment Station (WES) from Panama City Harbor and Gulfport Ship 


\begin{tabular}{|l|l|}
\hline \multicolumn{2}{|l|}{$\begin{array}{l}\text { Table } 1 \\
\text { Soil Classification versus Acoustic Impedance }\end{array}$} \\
\hline \hline Description & $\begin{array}{l}\text { Acoustic Impedance } \\
\frac{\mathbf{x} \mathbf{0}^{2} \mathrm{~g}}{\mathrm{~cm}^{2} \mathbf{s}}\end{array}$ \\
\hline \hline Water & $1450-1550$ \\
\hline Silty Clay & $2016-2460$ \\
\hline Clayey Silt & $2460-2864$ \\
\hline Silty Sand & $2864-3052$ \\
\hline Very Fine Sand & $3052-3219$ \\
\hline Fine Sand & $3219-3281$ \\
\hline Medium Sand & $3281-3492$ \\
\hline Coarse Sand & $3492-3647$ \\
\hline Gravelly Sand & $3647-3880$ \\
\hline Sandy Gravel & $3880-3927$ \\
\hline
\end{tabular}

Channel. Core samples from Savannah Ship Channel were obtained from the South Atlantic Division Laboratory.

These examples by no means constitute the entire library of impedance versus soil properties accumulated during development of the AI method. As a matter of fact, geoacoustic relationships are under continual refinement as new surveys are performed in geologically different areas. Geoacoustic data have been collected in over 17 areas to date. These include work performed in Pacific coast harbors, the Gulf of Mexico, Atlantic coastal harbors, and some inner rivers and reservoirs. More specifics on these areas, including a complete listing, will be presented in Chapter 4, "Case Studies." Research utilizing this extensive database is ongoing at WES in the development of comprehensive geoacoustic relationships of sediments representative to the riverine, harbor, and near-coastal environments typical of Corps projects. A statistical analysis of acoustic data collected from several of the above sites is presented at the conclusion of Chapter 4, "Case Studies."

\section{Engineering Approach}

Utilizing proper calibration procedures with data of high signal-to-noise ratio, seismic reflection data can be processed to accurately estimate the density and soil type of bottom and subbottom sediments. Site-specific calibrations are performed on every job by correlating acoustic impedance calculated from seismic reflection data at a core location with in situ information (density, mean grain size, etc.) at that location. Experience to date has shown that calibrations made at a few locations within a geologic region produces the 
shallow seismic parameters necessary to adequately calibrate and describe the entire region as presented in R. G. McGee (1991); Ballard and McGee (1991); Ballard, McGee, and Harmon (1991); Ballard, McGee, and Whalin (1992); Ballard et al. (1992); Ballard et al. (1993); Sjostrom, Ballard, and McGee (1991, 1992); Sjostrom, McGee, and Ballard (1992).

\section{Source calibration model and reflection coefficient}

Sonar equations. The geoacoustic parameter calibration procedure begins by determining the total acoustic energy incident at the bottom surface. This basically involves determining the precise reflection coefficient for the first reflector (bottom surface) and its associated acoustic bottom loss for a given sediment. Since the sound velocity of water and its density can be readily measured, the absolute impedance of water can be calculated. Knowledge of the reflection coefficient for the water bottom interface, which is completely independent of frequency, allows direct computation of the absolute impedance of the first layer of the bottom. The total energy produced by the source, or source wavelet, must be known absolutely. This is accomplished through use of a calibration hydrophone allowing determination of source level $(S L)$ and transmission losses associated with underwater acoustic wave propagation through the sonar equations. The sonar equations, discussed thoroughly by Urick (1983), describe quantitative effects on sonar equipment created by many phenomena peculiar to underwater sound production. These equations are both design and prediction tools for underwater sound applications and relate effects of the medium, target, and equipment. The general sonar equation is given as follows:

$$
S_{R}=S L-N_{w}-N_{h y d}+N_{A}+D I+B L
$$

where

$$
\begin{aligned}
S_{R}= & \text { bottom reflection energy at receiver, } \mathrm{db} \\
S L= & \text { total energy of source, } \mathrm{db} \\
N_{w}= & 20 \times \log _{10} \text { (range, meters), db (transmission loss due to spherical } \\
& \text { spreading along the path of propagation) } \\
N_{h y d}= & \text { receiver sensitivity, } \mathrm{db} \\
N_{A}= & \text { amplifier gain, } \mathrm{db} \\
D I= & \text { directivity index of receiving array, db (function of transducer beam } \\
& \text { pattem) } \\
B L= & \text { bottom loss, } \mathrm{db}=20 \log _{10}(R)
\end{aligned}
$$




$$
R=\text { reflection coefficient }
$$

The following sections of this report will discuss the many variations and utility of the sonar equation in performing precise field calibrations of equipment and surface reflections. Figure 12 is a detailed depiction of the physical elements in a normal calibration and bottom reflection sonar equation solution case. The $N_{A}$ value includes all preamplifiers and amplifiers and is obtained from the electrical calibration of the receiving equipment. Figure 13 shows a typical amplifier gain calibration curve necessary for determination of absolute energy. The calibration hydrophone sensitivity $\left(N_{h y d c}\right)$ is available from manufacturers of the hydrophone and should be traced to the ANSI Standard. The receiving array sensitivity $\left(N_{h y d r}\right)$ may also be available from the manufacturer or can be easily calibrated in the field using the calibration hydrophone and an alternate form of the sonar equation. This procedure will be discussed in detail later in this report.

A suite of signal analysis programs has been developed by WES in the course of this study specifically to perform all aspects of seismic calibrations. Additionally, these programs are used to evaluate all parameters of the sonar equations and to analyze measured acoustic signals representative of bottom conditions.

Directivity index. The directivity index $(D I)$ is a function of the beam pattern of the transducer array and is an indication of the amount of the total signal the hydrophone is permitted by its sensitivity pattern as shown in Figure 14. The higher the $D l$, the more discriminating the hydrophone is against signals arriving from directions other than along the desired acoustic axis. Figure 14 presents the directional pattern of the MASSA Model TR-75A transducer, typical of transducers utilized in the "pinger" class of profiling systems. Because WES typically offsets its receivers horizontally from the transmitter, as explained in Appendix A, the $D I$ becomes a significant parameter due to reflection angles along the path of propagation. Figure 15 presents (a) equipment geometry for the Delaware coast survey and its effect on directivity, and (b) the $D I$ correction versus water depth for application in the sonar equation.

Source level (SL) calibration. The first step in the calibration process is to determine the absolute source level. Some sonars have this data available from the manufacturers. Unfortunately, many seismic systems do not have this information readily available, and even if they did, field operating conditions vary to such an extent that the published levels are not sufficient for precise reflection computations.

The direct wave calibration of the sonar source level is accomplished by writing the sonar equation for the measurement of the direct wave via calibration hydrophone as follows:

$$
S_{D}=S L-N_{w d i r}-N_{h y d c}+N_{A}
$$


where

$S_{D} \quad=$ direct wave signal level, $\mathrm{db}$

$N_{w d i r}=$ transmission loss between source and cal phone, $\mathrm{db}$

All the terms in Equation 16, except $S L$, are either absolutely known or directly measured. Therefore, solving for $S L$, the absolute source level for any particular seismic system can be determined.

The calibration hydrophone is introduced into the sound field along the acoustic axis of the source. The hydrophone must be no closer than about $5 \mathrm{~m}$ to the source to avoid near-field wave form problems. Normally calibration data are taken at various depths to vary the transmission loss and to confirm that the hydrophone is very near the acoustic axis. The calibration signal should obey the inverse square law; i.e., $20 \log _{10}\left(e_{1}-e_{2}\right)=20 \log _{10}\left(r_{2}-r_{1}\right)$ where $e_{1}$ is the voltage generated by the hydrophone at range $r_{1}$ and $e_{2}$ is the voltage generated by the hydrophone at range $r_{2}$.

Figure 16 presents a typical seismic system calibration data plot recorded during a recent field exercise. This single data record contains all the field data required to completely calibrate all aspects of equipment operations and provides calibration data for the surface sediment impedance. The source level calibration is performed utilizing the data between file number 0002 and 0004 where variations in amplifier gain and hydrophone range are occurring. An example calculation is provided in Figure 17 on data collected in Delaware Bay just off Cape May Inlet, NJ. The figure presents results spatially averaged over 40 consecutive soundings with the table showing the statistical variations typical of acoustic profiling. The statistical properties of the $S L$ (source level) and $B L$ (bottom loss) are given in decibels for the subfile pc110012 as well as for the sequence of files between subfiles 0012 and 0015 .

Receiving hydrophone sensitivity calibration. As with the source level, the array sensitivity of receiving hydrophones $\left(N_{h y d c}\right)$ must be absolutely known. Field calibration is performed by comparing the signal levels of the receiving array with the calibration hydrophone over the same bottom condition. The calibration hydrophone is located in the immediate vicinity of the receiving array at the same depth elevation as presented in Figure 18. The sonar equation is designed to solve for $N_{h y d r}$ as follows:

$$
N_{h y d r}=N_{h y d c}+S_{R r}-S_{R c}-N_{A r}+N_{A c}
$$

where $S_{R r}, N_{A r}$ and $S_{R c}, N_{A c}$ are the received signals and amplifier gains for the receiving array and calibration hydrophone, respectively. Figure 19 is an example calculation from the same calibration trial discussed for $S L$ determination. 
Determination of bottom loss and surface reflection coefficient. Once all equipment parameters are known, the transmission loss defined, and all deployment parameters (such as $D I$ ) assessed, the bottom surface characteristics can be evaluated through the sonar equation by rearranging Equation 15 to solve for $B L$ as follows:

$$
B L=S_{R}+N_{h y d}-S L+N_{w}-N_{A}-D I
$$

Since ail terms on the right side of the equation are now known, $B L$, and therefore the surface reflection coefficient $\left(B L=20 \log _{10} R\right)$ and acoustic impedance (Equation 7), can be readily determined as shown in Figure 17. If the desired result is an assessment of the bottom surface characteristics, the acoustic solution is complete. All that remains is the correlation of the acoustic parameters with physical sediment properties through geoacoustic relationships (Table 1, Figures 9 and 10). Figure 20 shows a typical surface sediment characterization in terms of mean grain size and density.

Another straightforward method for determining the acoustic bottom loss is the utilization of multiple reflections when present. The difference in energy between the bottom echo wavelet and the multiple wavelet over the same bottom is simply the sum of transmission loss and bottom loss. Figure 21 presents this relationship in terms of the sonar equation with an example calculation. It is important to note that this method is only good when high-quality multiple data are available. This is a function of the frequency of the sound source and the relative competence of bottom materials. Also, survey conditions, such as a high sea state, or equipment deployment can affect the quality of multiple data.

As stated earlier, with the first $Z$ and the succeeding $R$ s known, all the acoustic impedances can be calculated. All that remains is to apply the appropriate absorption model to the acoustic data.

\section{Subbottom reflection coefficients (absorption calibration)}

An overview of the model utilized as an initial estimate of the absorption characteristics of marine sediments has been provided by Equations 13 and 14 . Caulfield and Yim (1983) describe this in some detail. There are a number of theories on the absorptive properties of different marine sediments, any of which might be better suited to a specific site than the Caulfield model. Therefore, the procedure allows the use of different absorption algorithms, basically through modification of the velocity versus density relationships utilized in the AC50 program (Caulfield 1992a). However, this shoutfonly be done when corroborating core data are available to verify the model prediction.

The software procedure was developed (Caulfield 1992a) to provide both "precision" analysis of unique seismic traces and "production-type" processing of continuous seismic profile lines. The AC50 program, developed through 
this work unit, is described in detail in the above reference and basically follows the methodology described. Once $S L$ calibrations and initial $B L$ characteristics are determined, providing initial calibration coefficients, the AC50 program utilizes the classical multilayer reflectivity algorithm with appropriate absorption operator to determine reflection coefficients and associated acoustic impedances for each succeeding reflection horizon.

Specifically, each data trace is converted to an energy matrix yielding energy versus travel time. Since the program now is designed to handle only the band-limited center frequency case, this energy matrix consists of only one vector of energy values $E\left(\omega_{m}, d t_{n}\right)$ where $\omega_{m}$ is the center frequency and $d t_{n}$ is the data window subsection. Each matrix element is then corrected for absorption. An initial assumption is made concerning the average density and sediment velocity based on the duration of the bottom signal. A long-duration signal usually implies high clay content, a short signal a predominance of sand. Energy matrix elements corrected for absorption are in the form

$$
E_{a b s}\left(\omega_{m}, d t_{n}\right)=E \cdot e^{\frac{\rho \omega_{m}}{k c} x_{n}}
$$

where the exponent is the same as in Equation 13. Now that the initial absorption correction has been applied for the frequency utilized, the total energy per layer can be calculated as

$$
E_{t}\left(d t_{n}\right)=\sum_{m=1}^{M} E_{c o r r}\left(\omega_{m}, d t_{n}\right)
$$

where

$$
\begin{aligned}
E_{t} & =\text { total energy per layer } \\
m & =\text { sample number } \\
M \quad & =\text { total number of samples } \\
E_{c o r r} & =E_{a b s}+\text { spherical spreading correction }
\end{aligned}
$$

The reflection coefficient of the $n^{\text {th }}$ layer is the ratio of the energy from that layer divided by the total energy incident on the bottom minus the energy reflected from the previous layers. After the reflection coefficients have been computed, the sediment impedance for any layer may be calculated by Equation 7.

If core data are available, this process is repeated, changing the absorption correction factor until the layer estimates match those of the core data. Sediment characterization is then accomplished using the appropriate geoacoustic 
model and should apply for the site under investigation. Examples of outputs generated during this process are given in Figures 22-25. A detailed study of each parameter in the process, including sensitivity analysis of each of the variables, is provided by Caulfield (1990). Ground truth examples are provided in Chapter 4, "Case Studies."

\section{Spectrum analysis}

Knowledge of the spectral content of acoustic signals (frequency and total energy) is vital to the accurate application of the process. Frequency content of a seismic trace is highly useful because the frequency content governs both temporal and spatial resolution. The spectral response of any portion of the data also indicates the absorptive nature of overlying sediments, since different sediments have characteristic absorptive tendencies. Also, as stated in previous sections, not all of the energy loss exhibited in the data is due to absorption. The energy loss beneath a hard layer, for instance, is due both to classical absorption and to the fact that a large percentage of the energy is reflected upwards. Since higher frequencies resolve thin beds better, it may be that a thin, high impedance bed will selectively reflect higher frequency seismic energy. The spectral analysis will provide insight into the absorptive properties of unique sediments by measuring the distribution of energy content across the spectrum, leading to the classification of the sediments.

Spectral analysis is also quite useful in differentiating random noise from true seismic reflections. By studying the effects of different filters and the signatures of various seismic sources, data acquisition can be optimized.

The Digital Spectral Analysis (DSA10) shallow seismic software (Caulfield 1991b) was developed to provide seismic amplitude and power spectra versus time analysis using Fourier transforms of the DFAS digital data. Figures 26 28 show typical time-frequency plots produced by the DSA 10 program for $3.5-\mathrm{kHz}$ (pinger) and boomer reflection data, and chirp source wavelet data. On the far left of the figures is the amplitude record for a single subfile of digital data, which is a collection of 40 consecutive soundings. A single amplitude trace (usually the last sounding in the subfile) is plotted with signal amplitude in volts plotted along the horizontal axis. The vertical axis for all plots is time and represents depth. The remainder of the display is the spectral analysis plot. The horizontal axis represents frequency, increasing to the right. Each colored box represents the energy at a particular frequency in time. A legend relating color to energy levels is provided on Figure 26. The darker the color, the higher the energy content of the frequency component. To the right of the spectral plot are the parameters used in the display. An ASCII-file (not shown) of all the time-frequency energy values provides detailed anatysis. This display has a dynamic range of over $60 \mathrm{db}$, and consequently the "empty" water column may have frequency values corresponding to random noise.

By comparing the energies at specific frequencies between reflection horizons and compensating for reflection, energy loss due to absorption can be 
determined. Also, by evaluating attenuation across the spectrum between horizons, layer characteristics can be estimated. The DSA10 program is an important tool required to develop and apply the appropriate absorption operators for the subbottom (absorption) calibration in the AC50 program.

\section{Layer Identification Methods}

The procedure described so far computes impedances as a function of the reflection coefficient at layer boundaries. In the purely classical model of natural marine sediments, the lithostratigraphy is usually modeled as multiple layers of increasing impedances, and for this case the model presented here works beautifully. However, as stated earlier, several combinations of geologic conditions could exhibit very similar signal characteristics, resulting in incorrect sediment characterizations based solely on acoustic impedance. Therefore, a number of different tools have been developed to assist the engineer in correctly assessing the geoacoustic model.

Correlation processing. Correlation analysis aids in determining the general statistical properties of sonar signals, allowing optimization of the detection process by improving both the signal-to-noise $(\mathrm{S} / \mathrm{N})$ and the time resolution. Also, the correlation of good $\mathrm{S} / \mathrm{N}$ broad-band data, such as "chirped" signals, provides information for determining the polarity of the reflection coefficient. The Digital Shallow Seismic Processing and Correlation System (DPC10), developed to meet these objectives, is generally discussed below and is described in detail by Caulfield (1991c).

The correlation process employed is a matched filter, equivalent to crosscorrelation of the received reflection data with the source wavelet. In other words, if two wavelets are identical, the filter output is simply the auto-correlation function of the source wavelet, and the filter is said to be "matched" to the source wavelet. The cross-correlation function of a time series $X(t)$ with the source wave form $Y(t)$ is:

$$
\varphi_{x y}(\tau)=\frac{X_{n}(t) * Y_{n}(t-\tau)}{X_{n}(t) * X_{n}(t)}
$$

where

$$
\begin{aligned}
& X_{n}(t)=\text { amplitude of the } n^{t h} \text { sample } \\
& \tau \quad=\text { lag or offset in } \Delta t \text { (normally the sampling interval) }
\end{aligned}
$$

In this version of the correlation process, the reference signal is provided as an $n$-sample length source signal wavelet, typically measured directly with the calibration hydrophone as described in the source level calibration section. This signal is then correlated against the reflection data and output is digitally 
siored in the DFAS output format. To ensure consistency and to allow AC50 processing of the correlated data, the program ensures that the energy content of the raw signal trace and the correlated signal trace are equal. The data are also normalized to maintain the relative amplitudes of the reflection signals. Figures 29-31 show the improvements in $\mathrm{S} / \mathrm{N}$ and resolution possible through correlation analysis of noisy pinger, boomer, and chirped signals. Detailed examples of the benefits of correlation processing on a wide variety of seismic data are illustrated in Caulfield's manual (1991c). Figure 32 shows the improvement in $\mathrm{S} / \mathrm{N}$ provided by correlation processing on boomer data collected during a previous survey. Since this correlation process is utilized in many of the layer identification methods described below, specific examples of the correlation applications will be presented under that topic.

Synthetic forward modeling. An important tool utilized in layer identificafion, project planning and feasibility studies, and optimization of data acquisition and analysis methodologies is the process of manufacturing synthetic seismograms through geoacoustic forward modeling. The modeling techniques developed for this method involve creating one-dimensional synthetic seismograms by simply convolving a known wave form, such as the source wavelet measured during calibration, with a reflectivity function derived from actual geologic data. The simplest and therefore most straightforward approach is the aflectivity model utilizing primary waves only, with no absorption corrections, and assuming normal incidence. For very shallow (upper $20 \mathrm{ft}$ of subbottom), relatively thin sediment units, this assumption is usually sufficient. The modeling technique described below includes correlation processing and deconolution processing and is discussed as an example calculation.

Two geologic situations very common to the near-shore environment were considered: (1) sand over soft mud over hard clay, and (2) sand over comacted clay (Figure 33). The properties of each sediment unit were modeled and are shown with each figure as computed impedances and reflection coefficients. Source wavelets for a boomer signal, a shaded 1- to 6-kHz chirp, and a $7-\mathrm{kHz}$ pinger are convolved with the reflection model to generate simulated subbottom reflection data as shown in Figures 34 and 35 . The chirp data must be correlated with the source wavelet before it provides any useful information. Whereas the seismograms provide reasonable pictures of the magnitudes of the reflections expected at each horizon, the pinger and boomer data show vertical resolutions on the order of only $1.5 \mathrm{ft}$ and in practical applications make it impossible to identify the sign $( \pm)$ of the reflector. However, the processes of correlation and deconvolution can assist in making these determinations.

The correlation technique is used to perform the matched filter process described previously and, for the boomer and chirp data, improves both the $\mathrm{S} / \mathrm{N}$ and resolution. An example of the correlated boomer signal for reflection sequences is provided in Figure 36 and shows a factor-of-3 improvement in resolution and an indication of the sign of the reflection coefficient. 
Correlation of the shaded chirp signal for the reflection sequences provides improvement in vertical resolution by more than a factor of 4 , as shown in Figure 36. Events within $0.5 \mathrm{ft}$ can be resolved. Also, some indication of reflection sign is shown.

The process of deconvolution involves generating a filter that transforms the calibrated source wavelet into a spike. Figure 37 illustrates the results of deconvolution as applied to boomer data for both reflection sequences. It can be seen that the resolution of peaks can be easily resolved to within $0.3 \mathrm{ft}$. More importantly, the sign of the reflection coefficient is readily determined, allowing for easy identification of sands over soft clays. The same spiking deconvolution can be applied to correlated chirp data for further improving resolution and sign identification.

The modeling process is also utilized to assist in the interpretation of sediment characteristics by comparing modeled results with actual subbottom data. An example of this approach is presented in Figure 38 for boomer data collected in an area where fine sediments were bounded above and below by competent sands and gravels. Actual boomer data, both raw and correlated, are compared to the synthetic seismogram generated from the reflection sequence developed from core log data obtained from the surveyed area. The data show a thin layer of high-impedance sand overlying clayey sands and silty clays overlying poorly graded gravels. Note the polarity of the reflection coefficients and how the correlated boomer trace provides some indication of the direction of impedance change. In this case, the modeling process provided further verification of the geoacoustic analysis.

Polarity of reflection coefficient. Broad-banded data having good $\mathrm{S} / \mathrm{N}$, such as chirper or even boomer data, can be analyzed using correlation processing to provide an indication of the nature of the impedance change (higher or lower) at reflection horizons. For example, a soft layer underneath a hard layer will produce a minus impedance change, or negative reflection coefficient. This negative reflection coefficient results from the phase change of the reflected signal occurring when the wave reflects off a softer layer. The match-filter correlation of the source wavelet with the reflected wave from a deeper soft layer results in a "flipped" or negative reflection signal as shown by Figure 38. This technique works only on data with good $\mathrm{S} / \mathrm{N}$ and is very difficult, if not impossible, to perform on band-limited data such as those produced by pingers. A beta version of an updated AC50 program incorporates estimation of the reflection coefficient polarity with very encouraging results. At the time of this writing, however, one must determine the sign (+ or -$)$ outside the AC50 program through either correlation processing or determination of the signal phase. Corrections are then externally applief Experience has shown that in the dynamic near-shore environment, which concerns most Corps projects, it is common for soft sediments to be overlaid by more competent materials. Therefore, it is very important that results be verified with core data and that seismic data be collected concurrently at different frequencies. Any future developments of this method should include dependable 
algorithms for automatically assessing the polarity of the reflection coefficient (see Chapter 6, "Recommendations").

Assessing attenuation across frequency band. Another approach to layer identification involves detailed spectrum analysis to detect possible frequency shifts in the reflection data at each horizon. Generally speaking, acoustic energy experiences higher attenuation in more competent materials, such as sands, than in the softer silts and clays. The rate of attenuation in a particular sediment unit is also a function of the frequency, i.e., attenuation increases with increasing frequency. The frequency spectrum from data having good $\mathrm{S} / \mathrm{N}$ should indicate less energy at the higher frequencies for subbottom reflectors below sand layers and little to no signal attenuation across the frequency spectrum for horizons below a soft sediment layer. This process has been used extensively as an aid in the identification of sediment layers. Figure 39 refers to the in situ condition of Figure 38 and shows an example of a clay pocket between sand layers. In this case, the competent surface sands reflect most of the higher frequency data. Little signal attenuation occurs at the bottom of the clay layer. The center frequency of each reflection horizon is shown "shifting" to the lower frequencies below the sand layer, and no comparable shift occurs below the clay layer.

To summarize, no one general solution accurately assesses all real-world situations. Without adequate core data, it is important when making predictions of sediment characteristics that the solution be derived from a variety of different methodologies if possible. This chapter has presented a robust suite of tools that can be successfully used to perform a given characterization study. When utilized properly with data of good $\mathrm{S} / \mathrm{N}$ and adequate ground truth information, the AI method developed here can provide reliable information regarding engineering properties of marine sediments. To illustrate this point, Chapter 4, "Case Studies," will present numerous examples of "groundtruthed" data from a variety of field situations. 


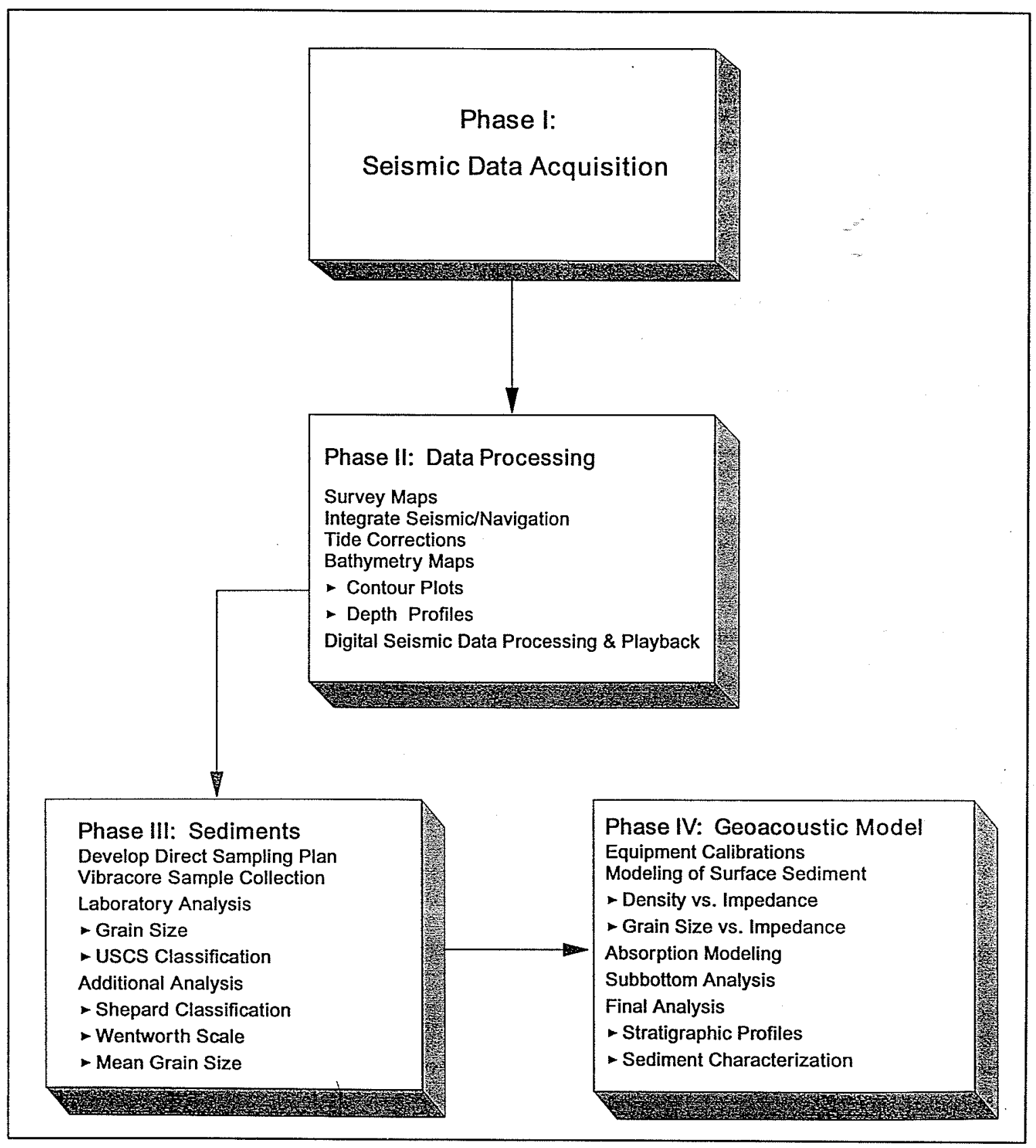

Figure 1. Typical project flowchart 


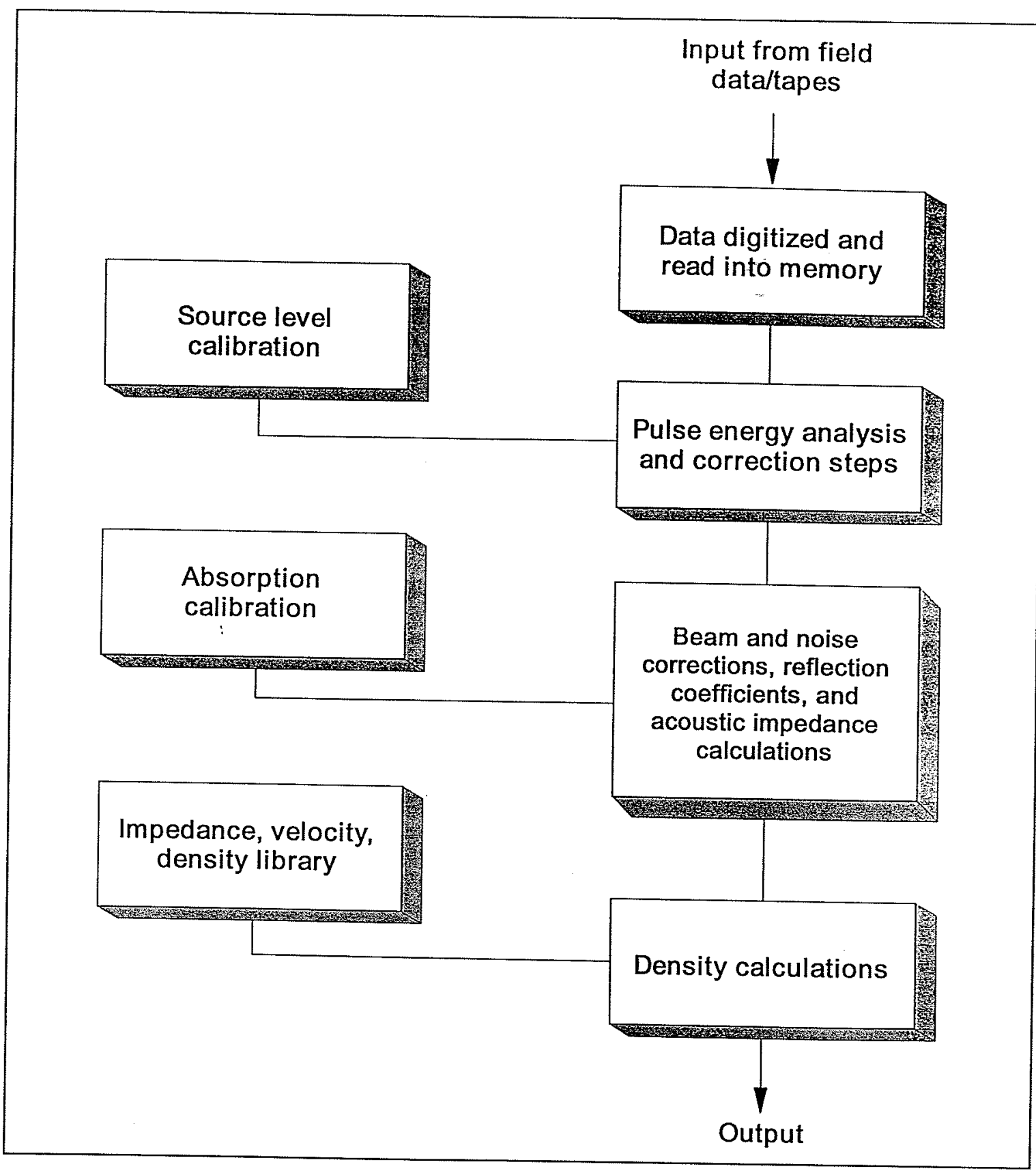

Figure 2. Acoustic impedance processing flowchart 


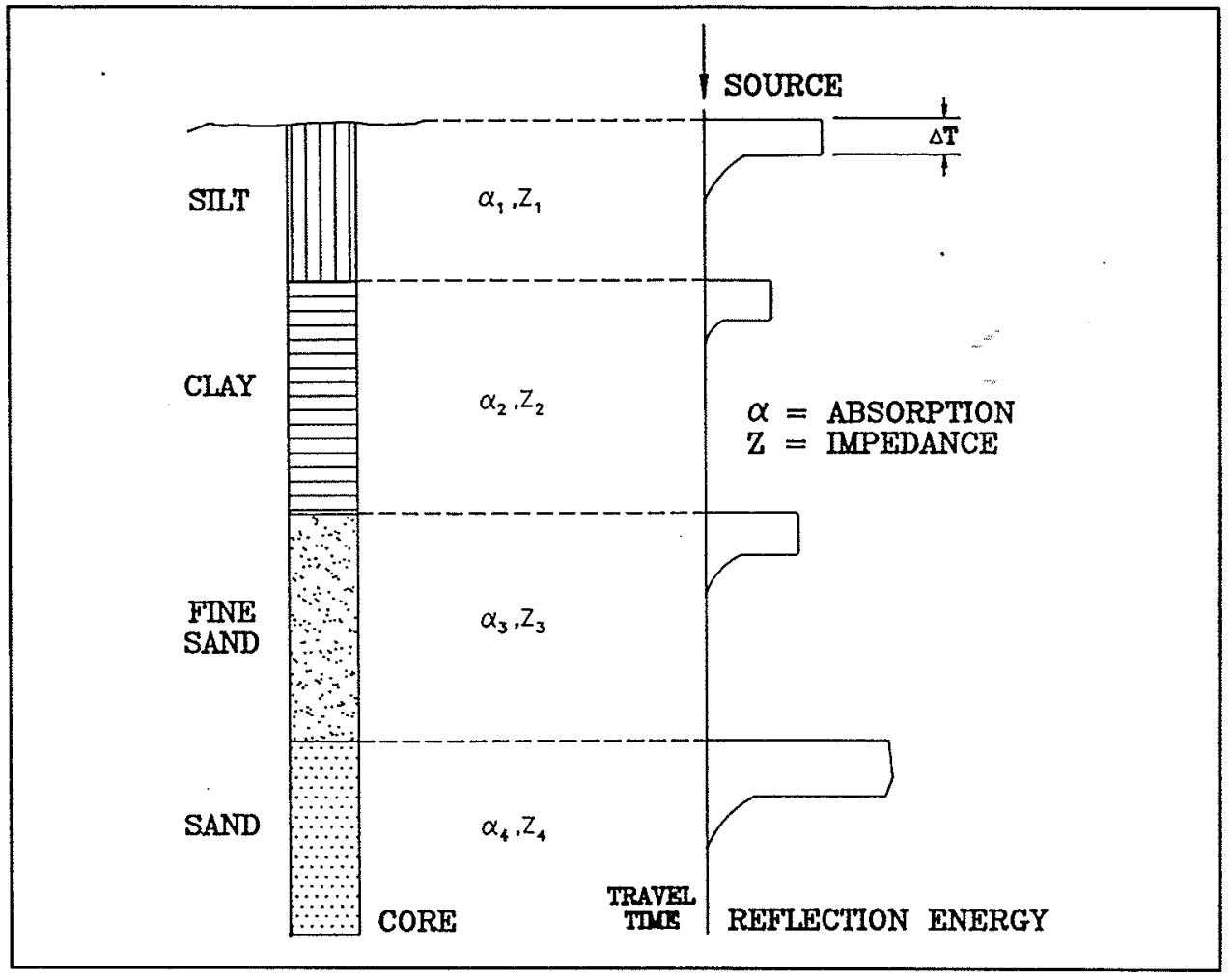

Figure 3. Simulated reflection energy envelopes showing influence of material type on signal amplitude

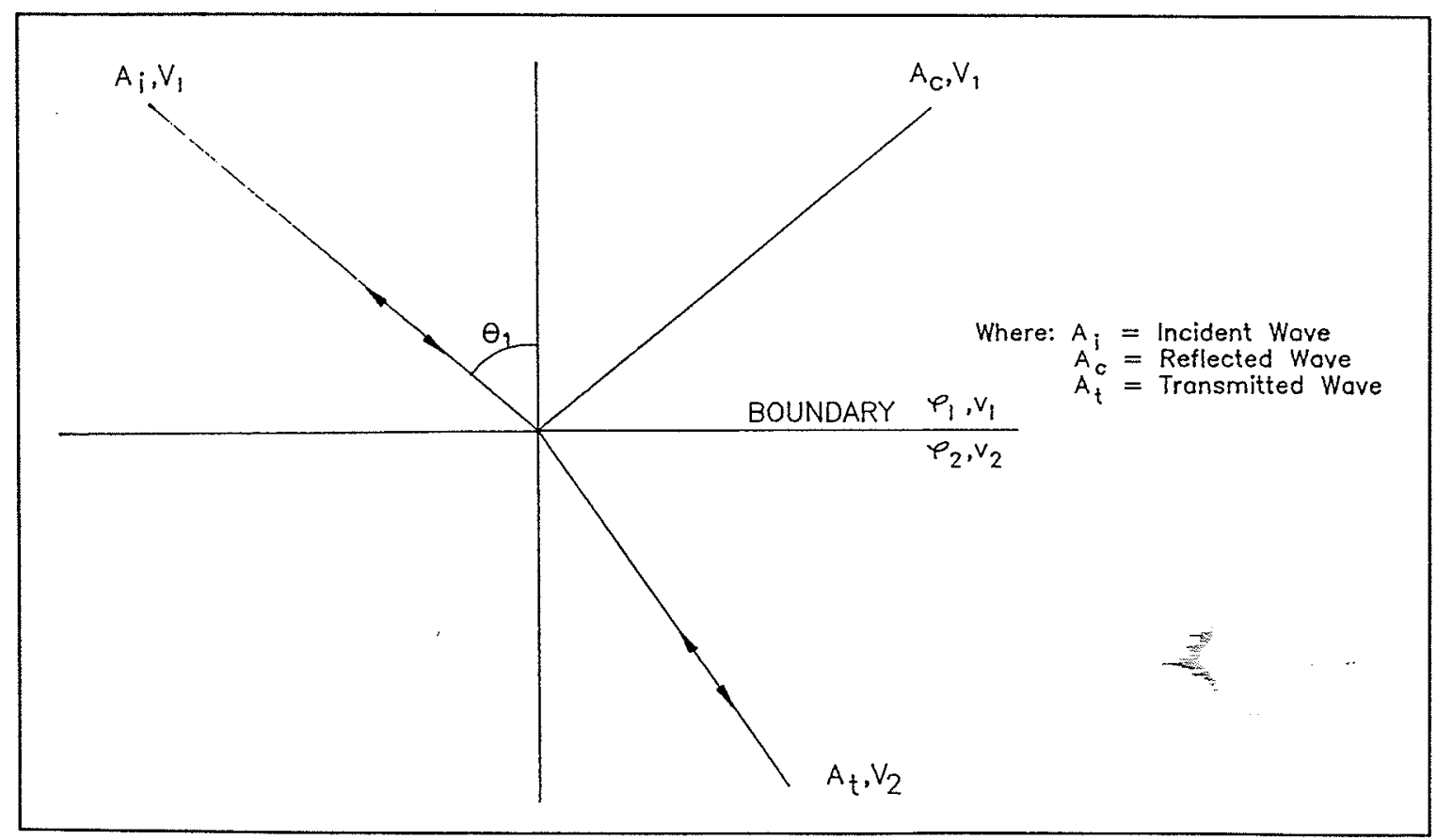

Figure 4. Waves generated at an interface by an incident P-wave (after Officer (1958)) 


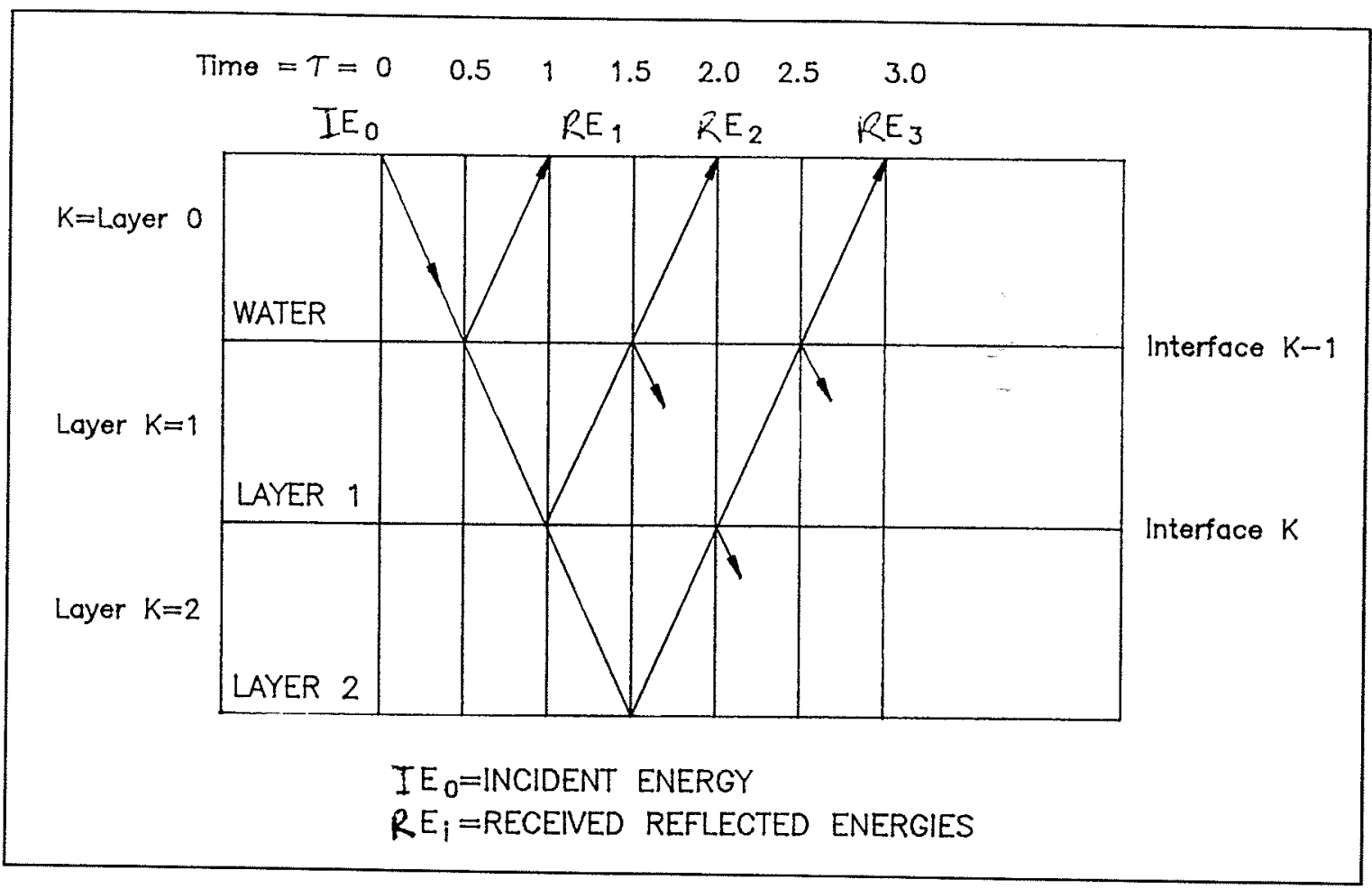

Figure 5. Multilayer reflectivity model after Robinson and Treitel (1980)

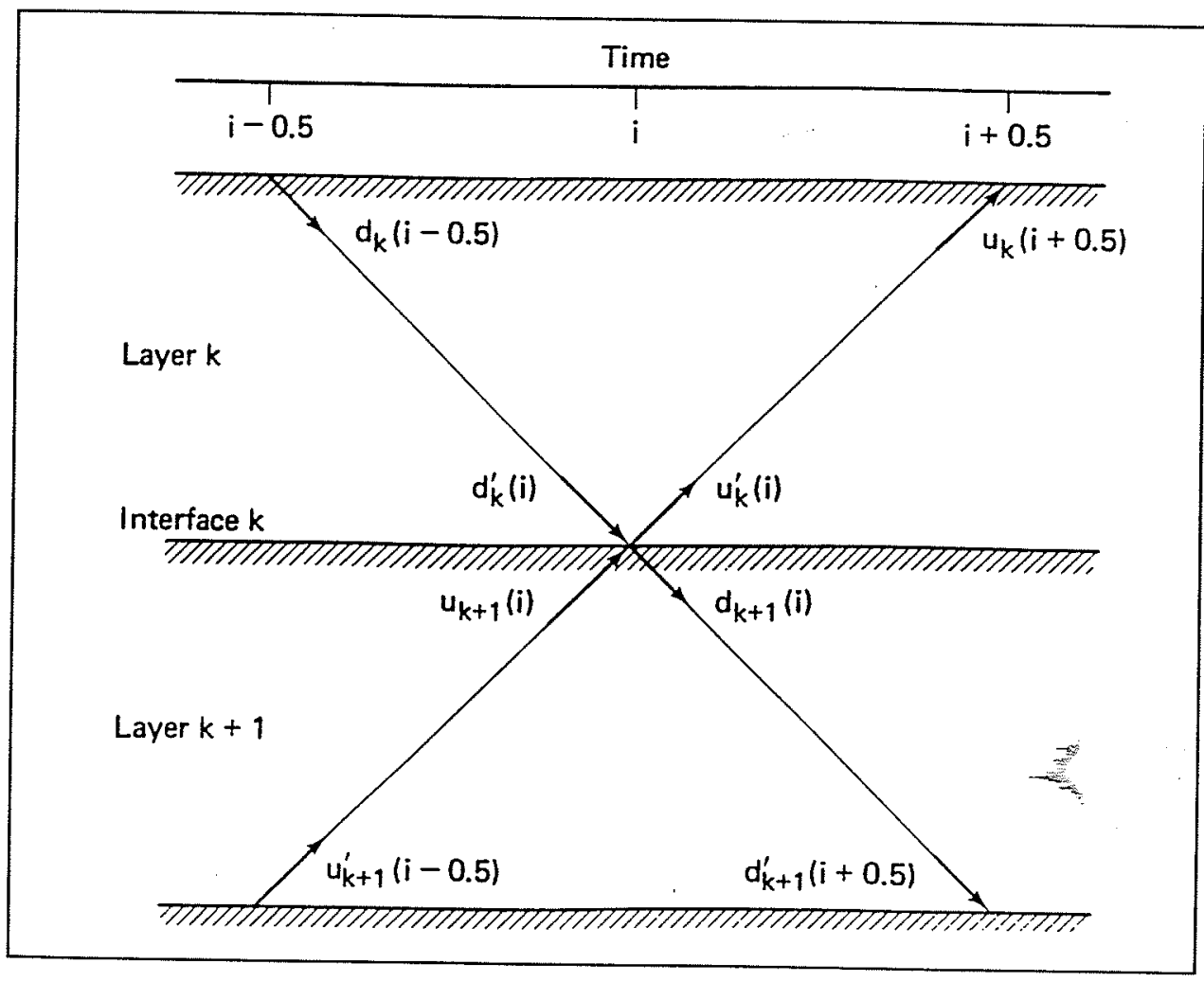

Figure 6. Scatter diagram for ray paths at a layer interface 


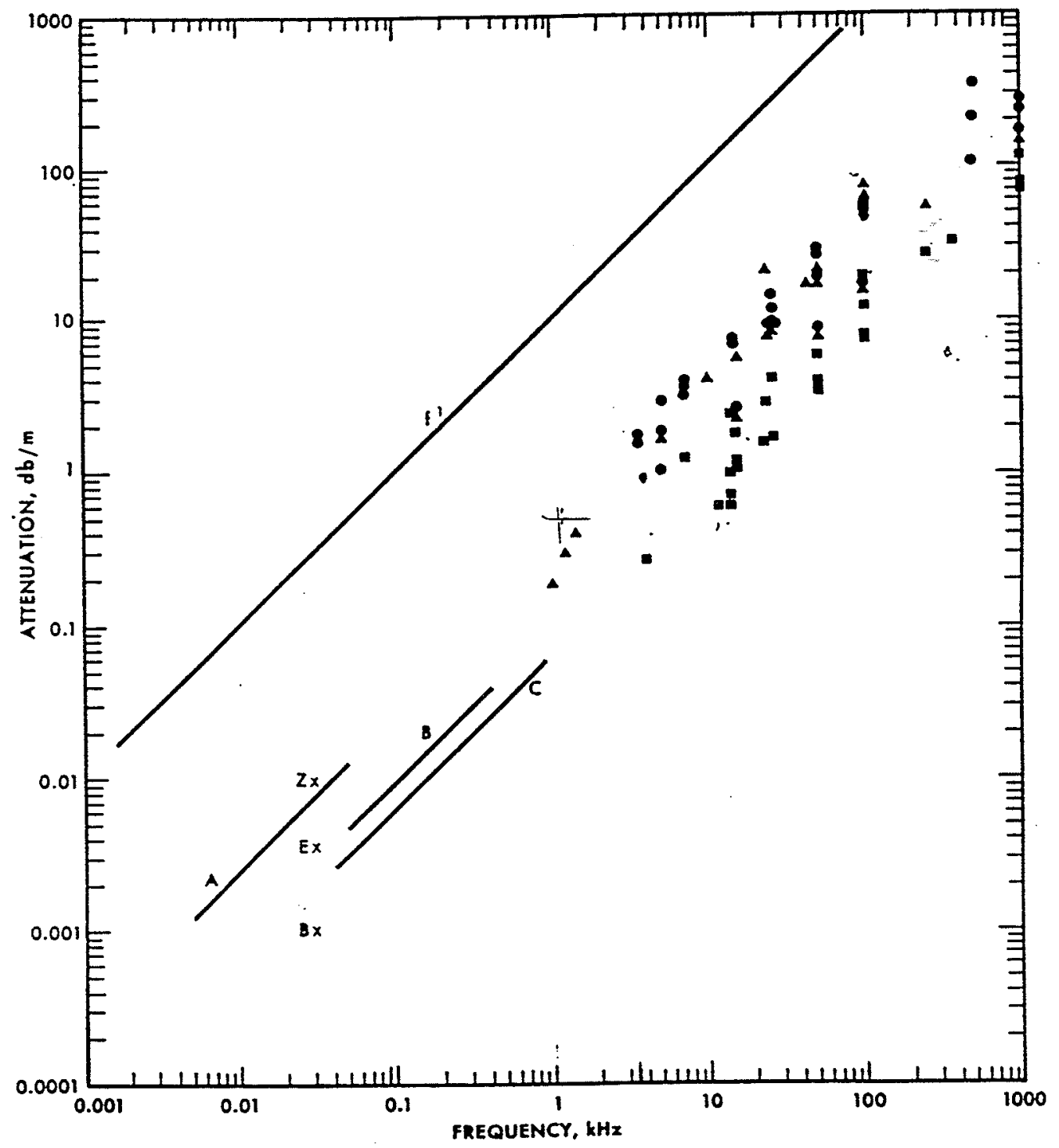

Attenustion versus frequency in natural, saturated sediments and sedimentary strata; data from Tables 1-4b. Symbols: circles-sands (all grades); squares-clayey silt, silty clay; triangles-mixed sizes (e.g., silty sand, sandy silt, sand-silt-clay); sand data at 500 and $1000 \mathrm{khz}$ from Busby and Richardson (1957). Low-frequency data: line A-Zemstov, 1969 (land, sedimentary strata); B-Tullos and Reid, 1969 (Gulf of Mexico coastal claysand); C-Bennett, 1967 (sea floor, reflection technique); Z-Zhadin (in Vasil'ev and Gurevich, 1962); E and BEpinatyeva et al, and Berzon (in Zemstov, 1969). Line labelled $f^{1}$ indicates slope of any line having a dependence of attenuation on the first power of frequency.

Figure 7. Attenuation as a function of frequency (Hamilton 1972a)

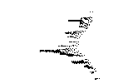




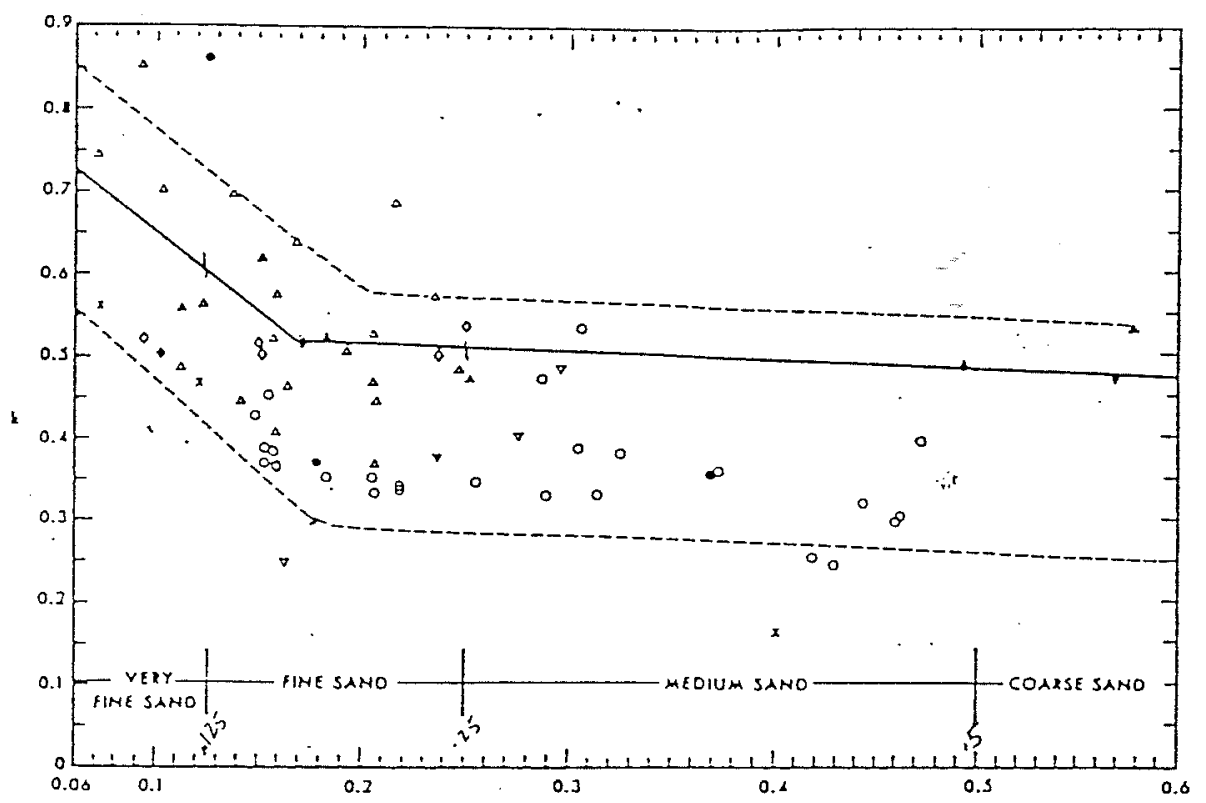

Pes grain size num versus $k$ (in $\alpha=k f^{1}$ ). Data, symbols, and remarks: same as in caption for Figure 3 . Plut of mcan grain size in $\mathrm{mm}$ enphasizes relationships in sands (see text). Regression equations for solid lines: Coarse, medium, and fine sand, in part $(0.6100 .167 \mathrm{~nm} n): k=0.537 t-0.1113(3 \%)$. Fine sand (in part), and very fine sand $(0.167$ to $0.063 \mathrm{~mm}): z=0.8439-1.9431(. \mathrm{K}$,$) .$

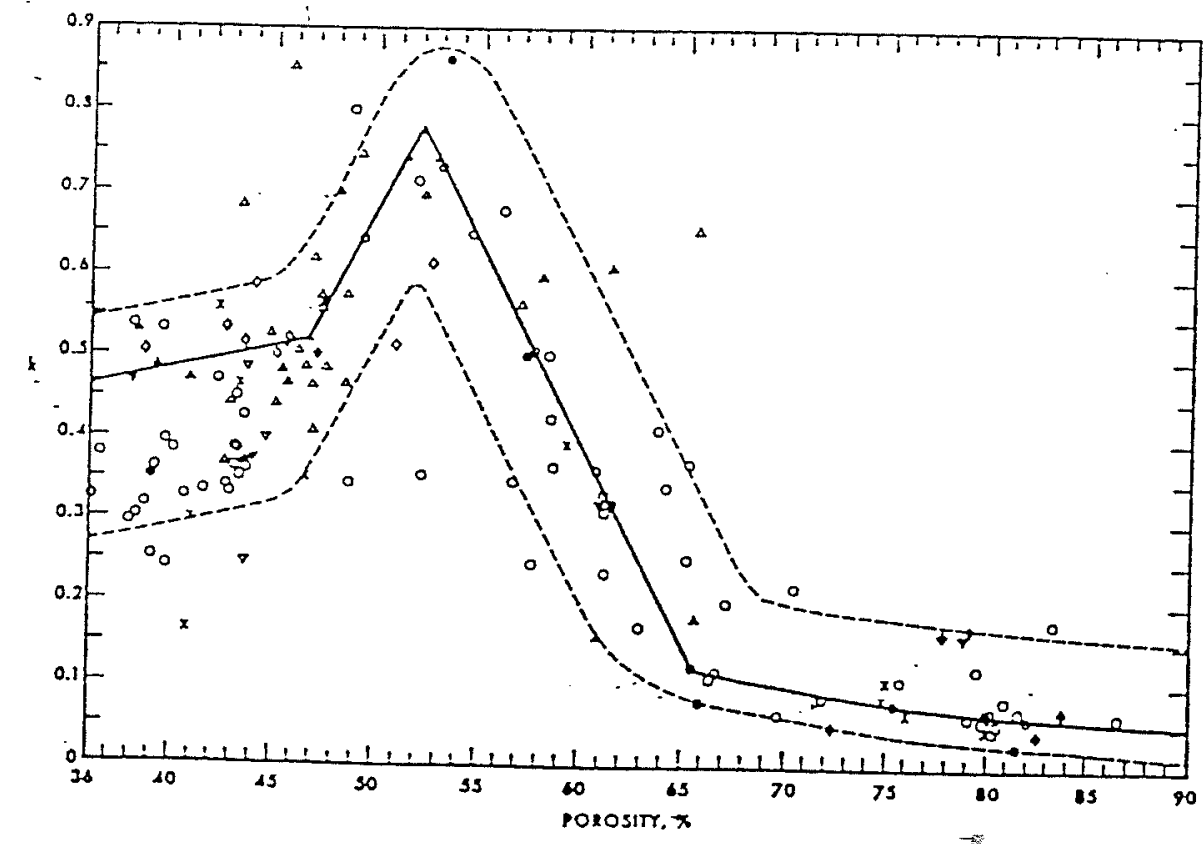

Porosity $n$, percent, versus $k$ (in $\alpha=k / 2$ ). Data, symbols, and romarks same as in caption for Figure 3 . Regression equatioss for solid line: Caarse, mediurn, and fine sand (36 to 46.7 percent): $k=0.2747+0.00527(\mathrm{n}$ ). Very äne sand and lower-porcsity mixed size (46.7 to 52 percent): $k=0.04903$ percent): $k=0.2747+0.00527$ (n). percent): $k=3.3232-0.0 .89$ ( $(n)$. Silt -lays $(65$ to 90 percent $): k=0.7602-0.01487(n)+0.000073(n)^{2}$.

Figure 8. Attenuation versus porosity and mean grain size (Hamilton 1972a) 


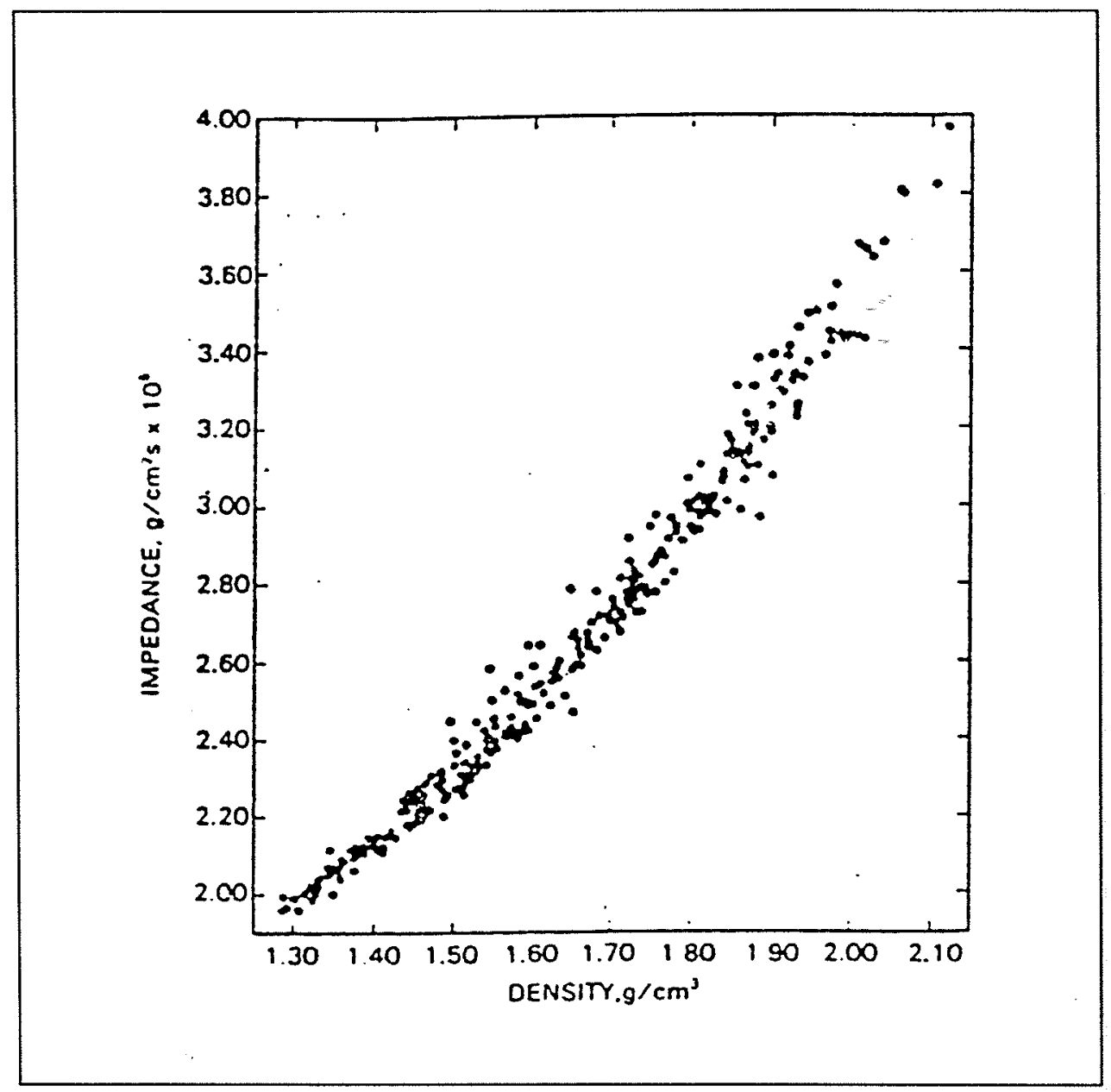

Figure 9. Impedance versus density (continental terrace, shelf, and slope) (Hamilton and Bachman 1982) 


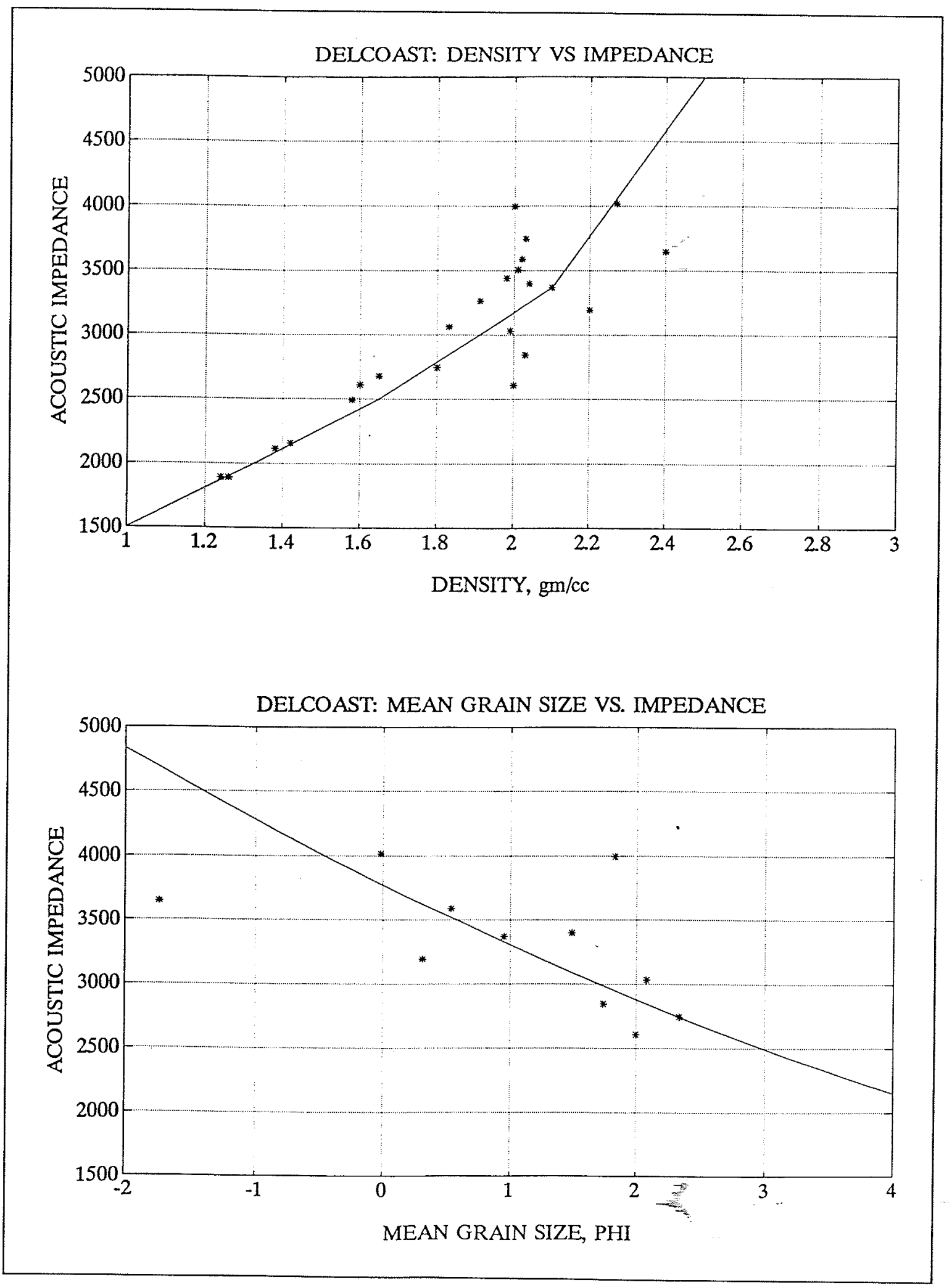

Figure 10. Delaware coast model: impedance versus density; impedance versus mean grain size 


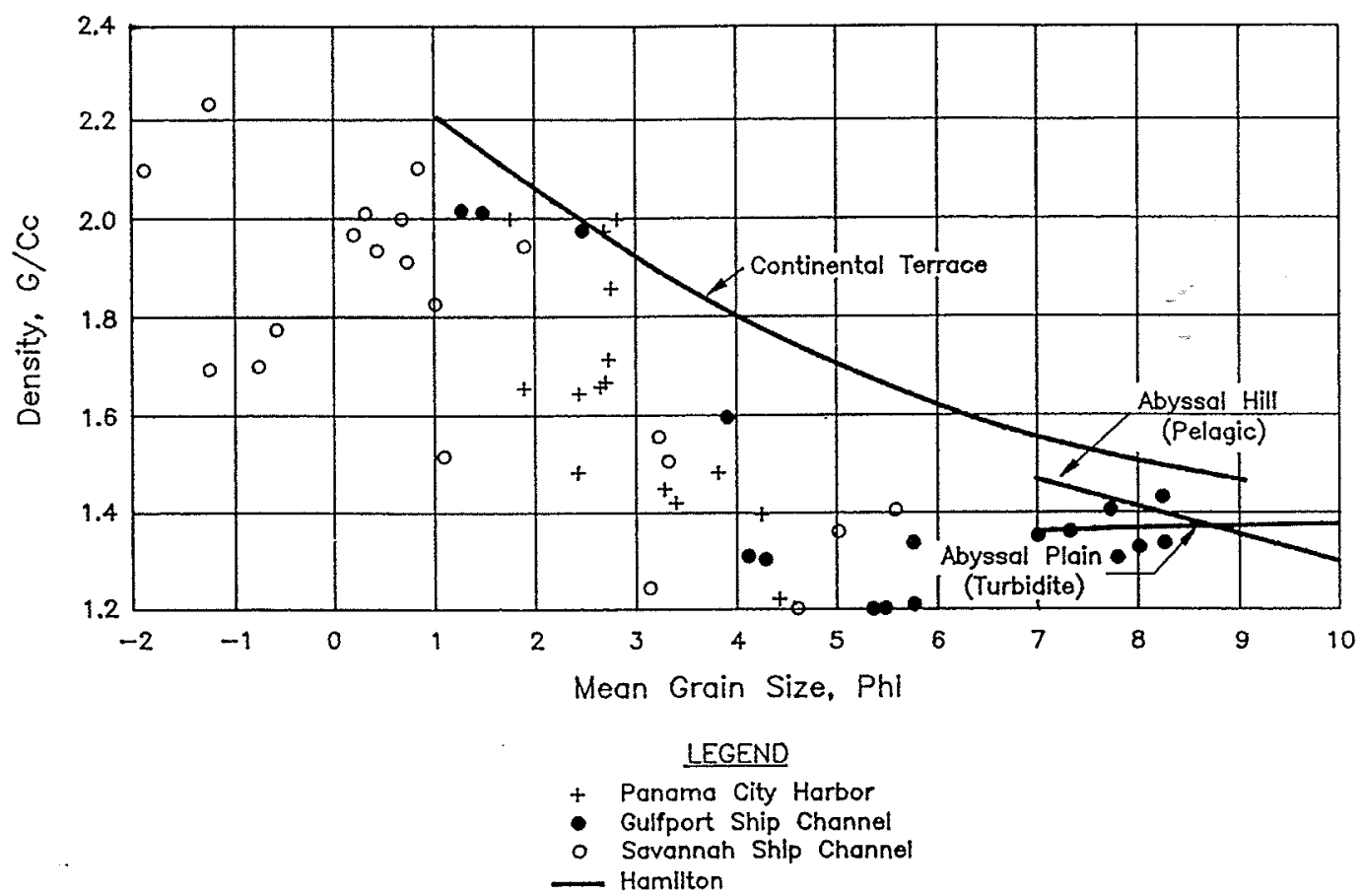

Figure 11. Density versus mean grain size

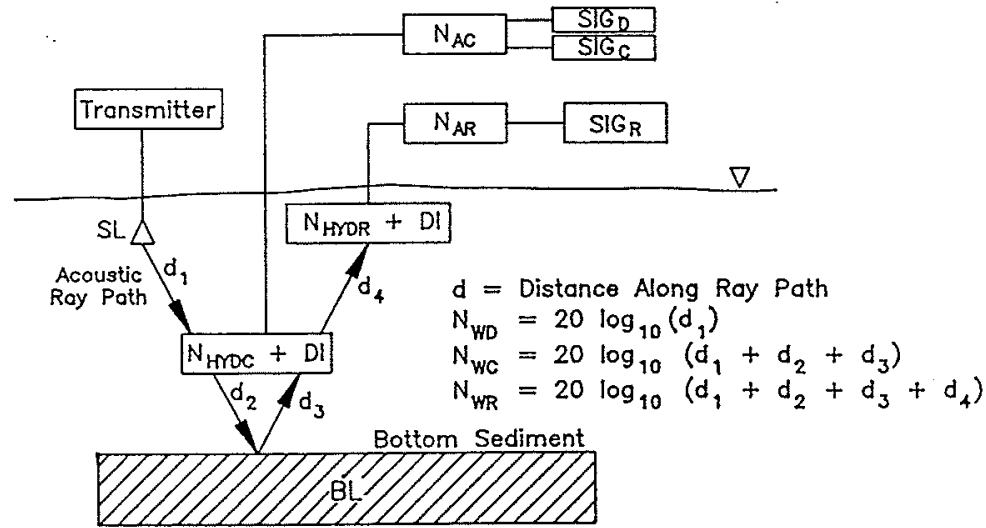

Note: Refer to Equation 15 for Definition of Terms

SONAR EQUATIONS:

$$
\begin{aligned}
& S I G_{R}=S L-N_{W R}-N_{\text {HOR }}+N_{A R}+D I+B L \\
& S I G_{C}=S L-N_{W C}-N_{\text {HOC }}+N_{A C}+D I+B L \\
& S I G_{D}=S L-N_{W D}-N_{\text {HOC }}+N_{A C}
\end{aligned}
$$

Where:

$S I G_{R}=$ Bottom Reflection Signal From Receiver Arroy.

$S I G C_{C}=$ Bottom Reflection Signal From Calibration Hydrophone

SIG ${ }_{0}=$ Direct Wave Signal From Calibration Hydrophone.

Figure 12. Elements in the calibration system for sonar equations 


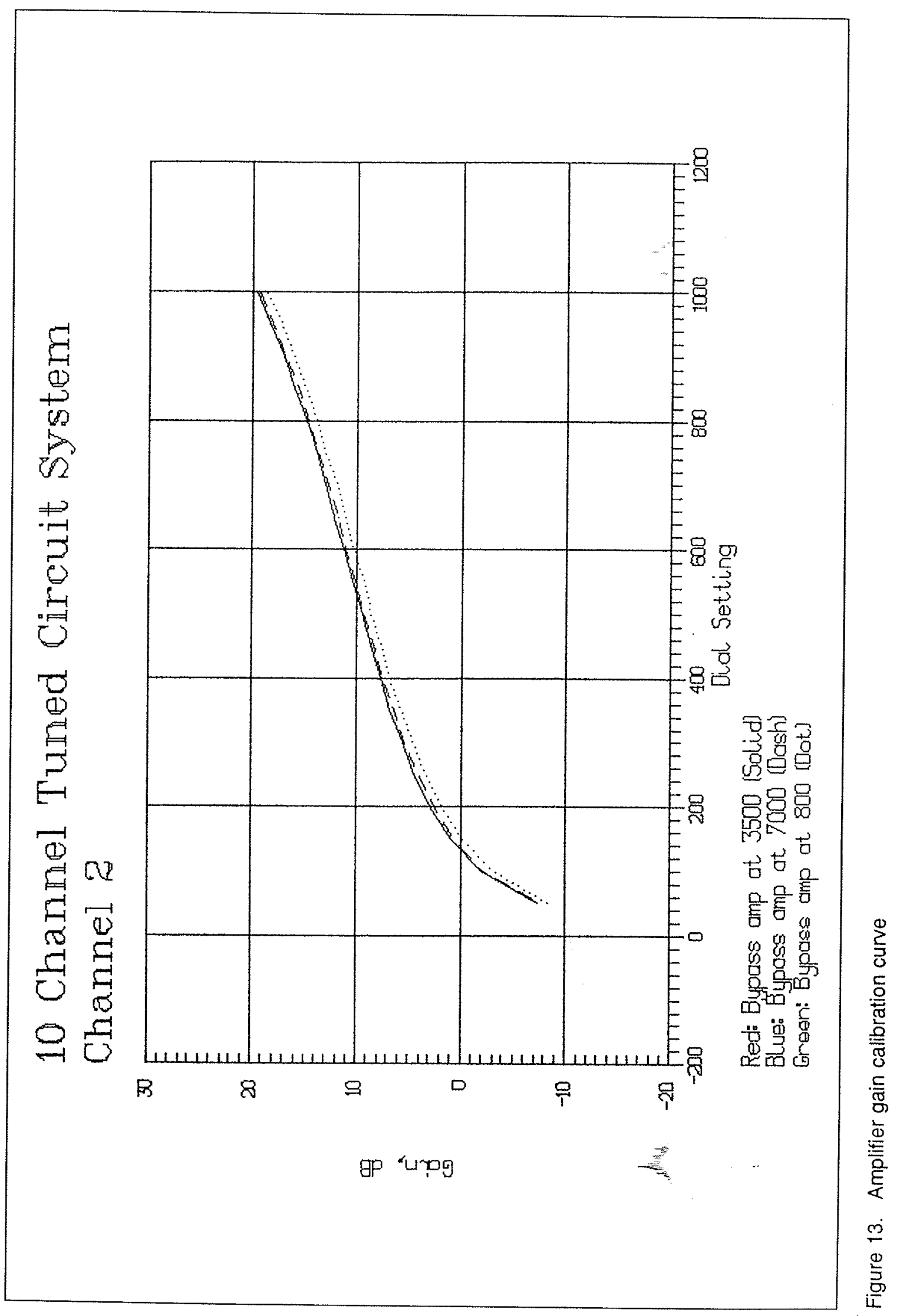



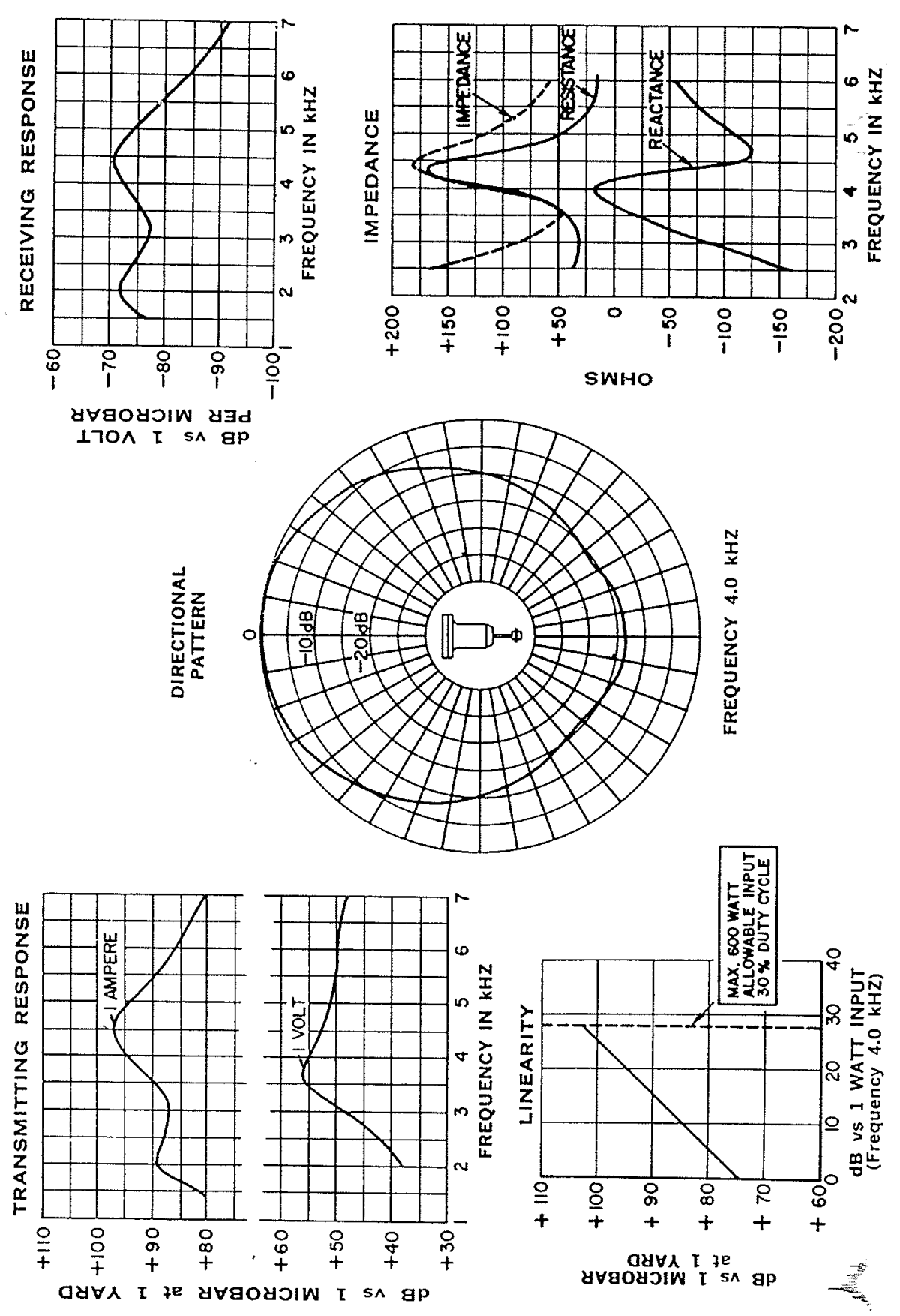

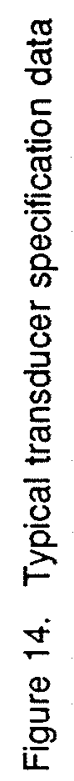




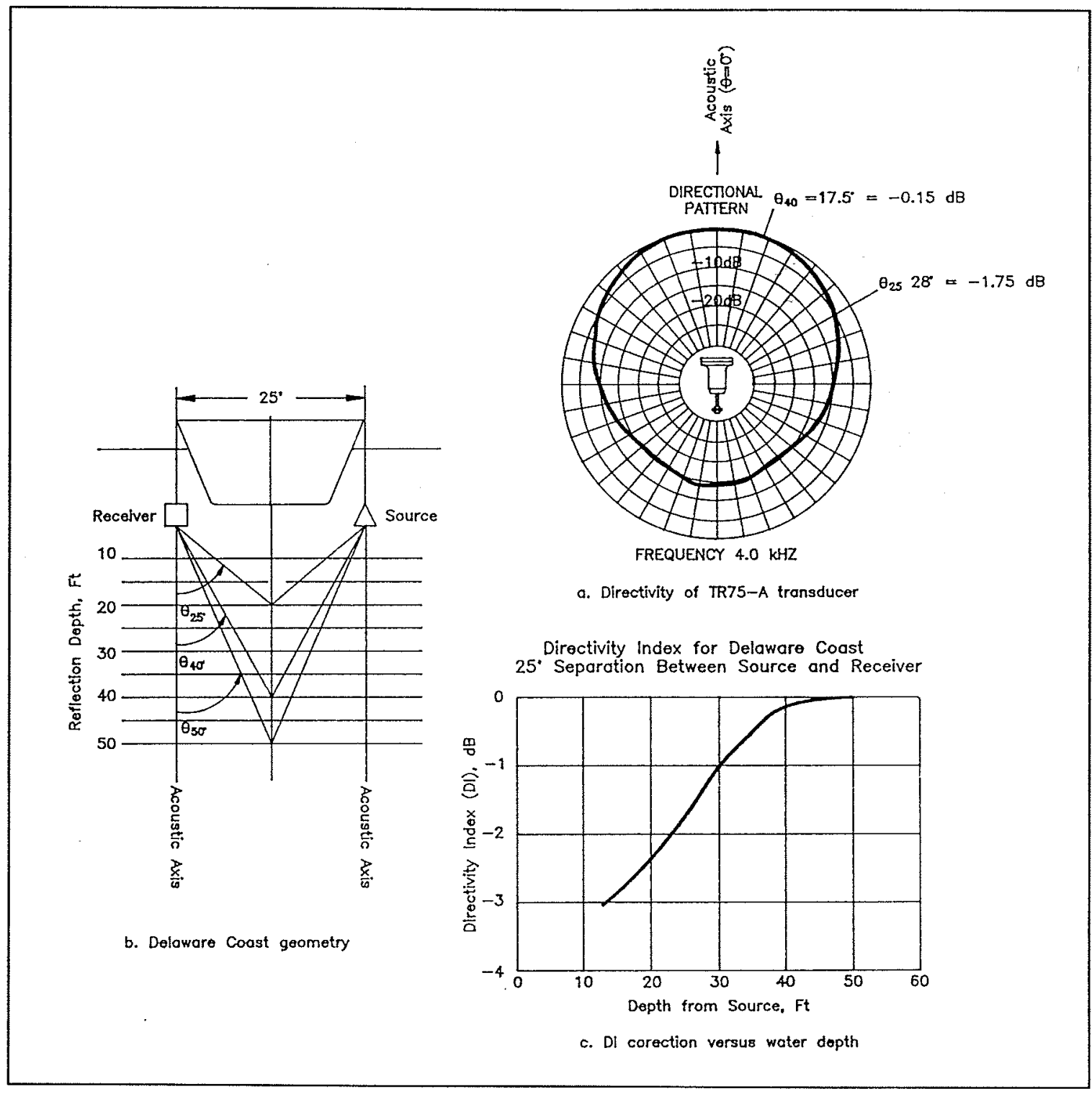

Figure 15. Delaware coast survey geometry and computation of directivity index $(D I)$ versus water depth and transducer separation 


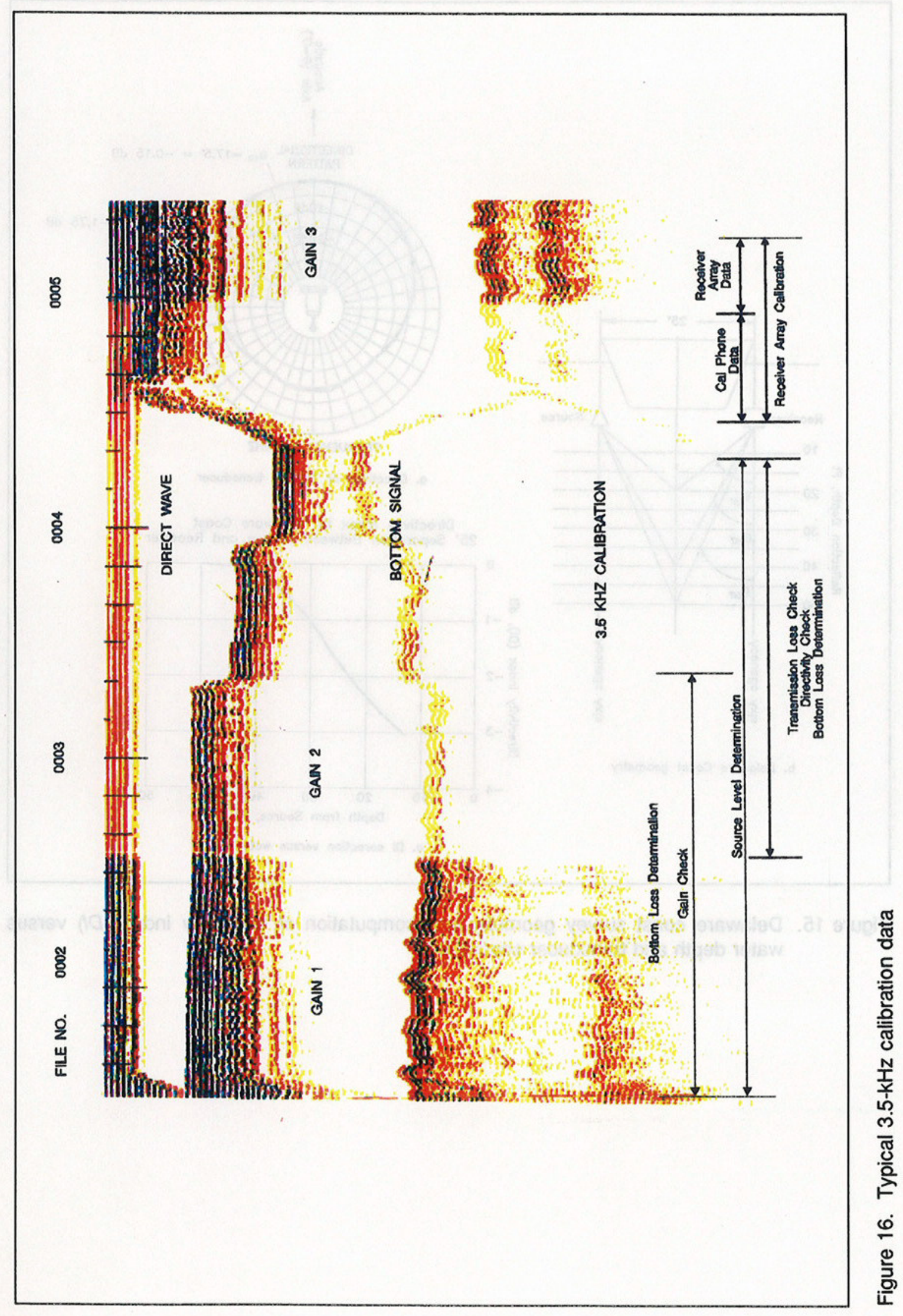




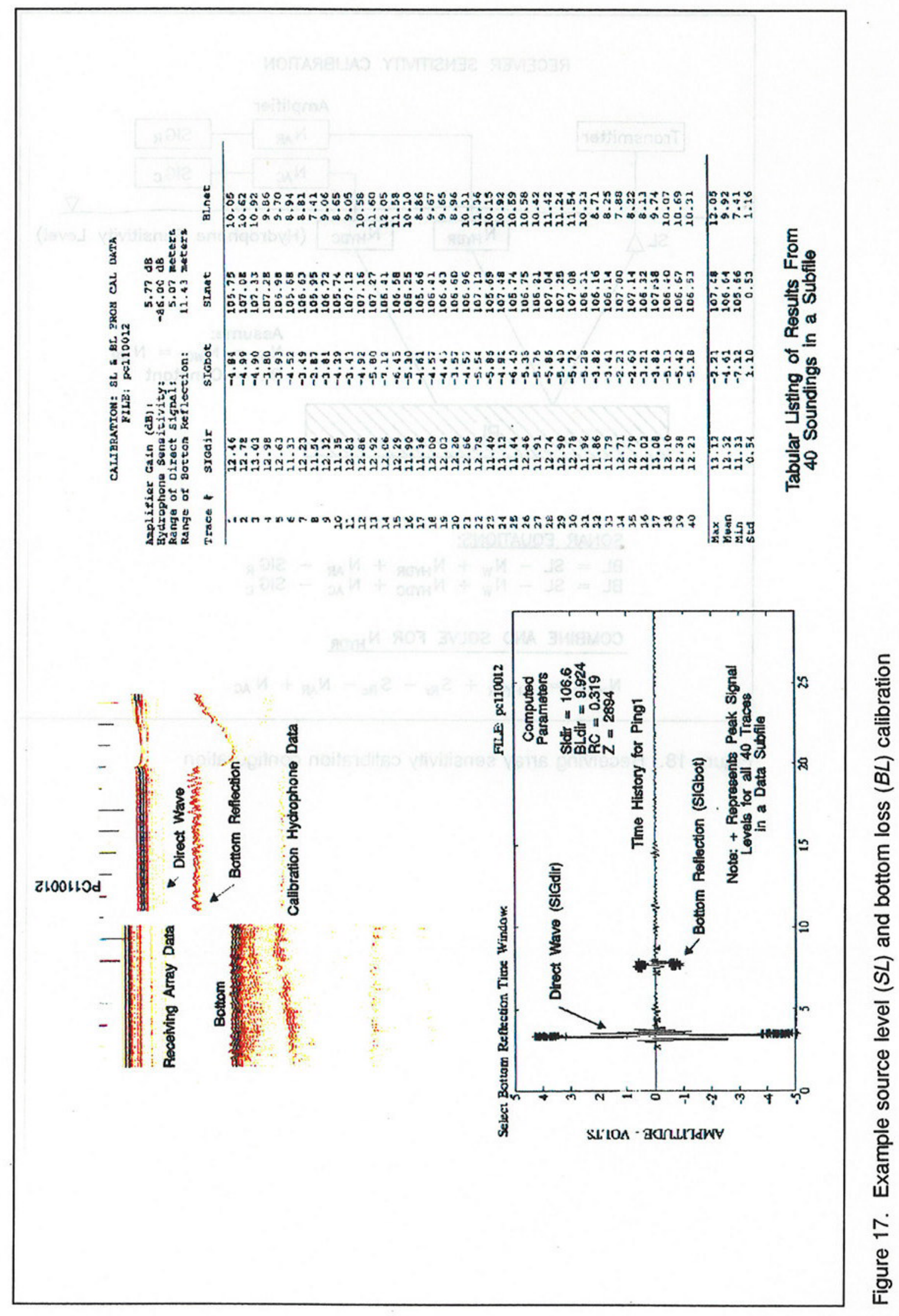


RECEIVER SENSITIVITY CALIBRATION

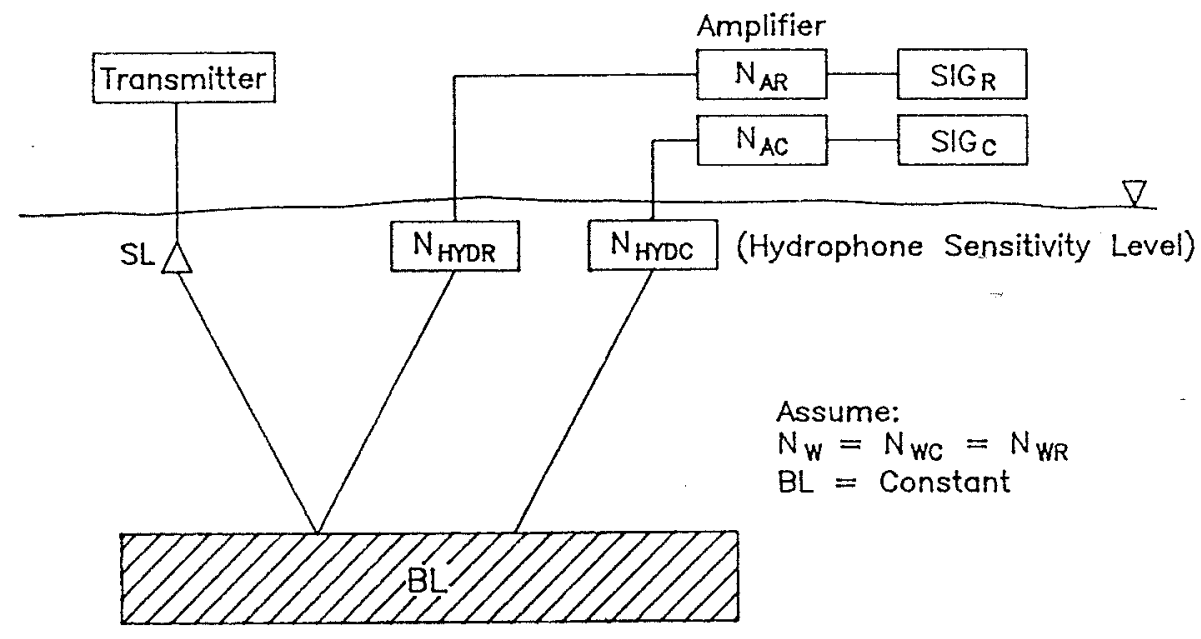

SONAR EQUATIONS:

$B L=S L-N_{W}+N_{H Y D R}+N_{A R}-S I G_{R}$

$B L=S L-N_{W}+N_{H M D C}+N_{A C}^{A R}-S I G_{C}$

COMBINE AND SOLVE FOR $N_{\text {HMR }}$

$N_{H M D R}=N_{H Y D R}+S_{R r}-S_{R c}-N_{A R}+N_{A C}$

Figure 18. Receiving array sensitivity calibration configuration 

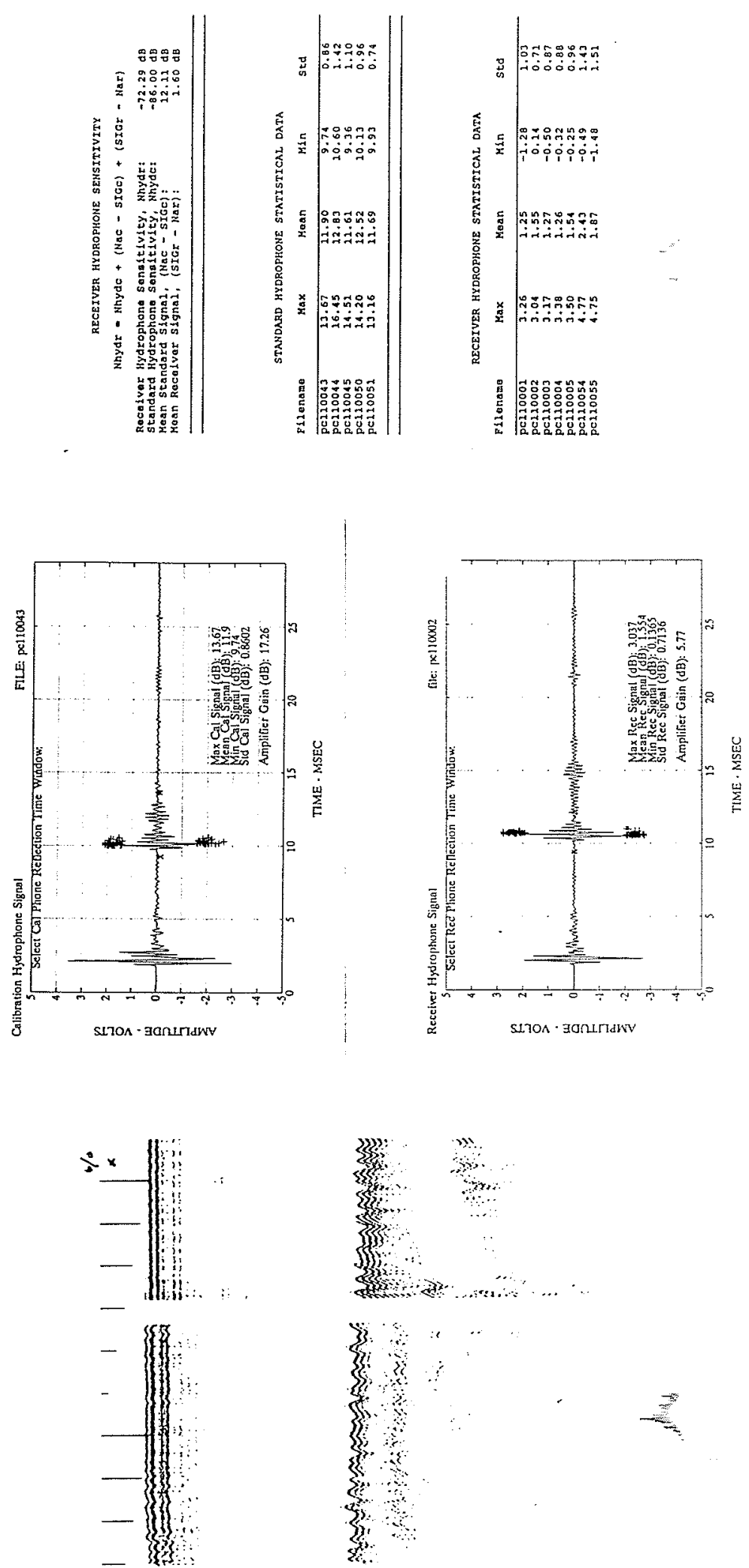

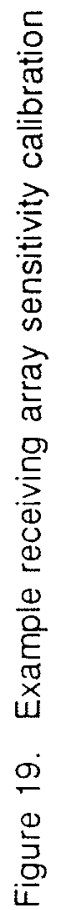




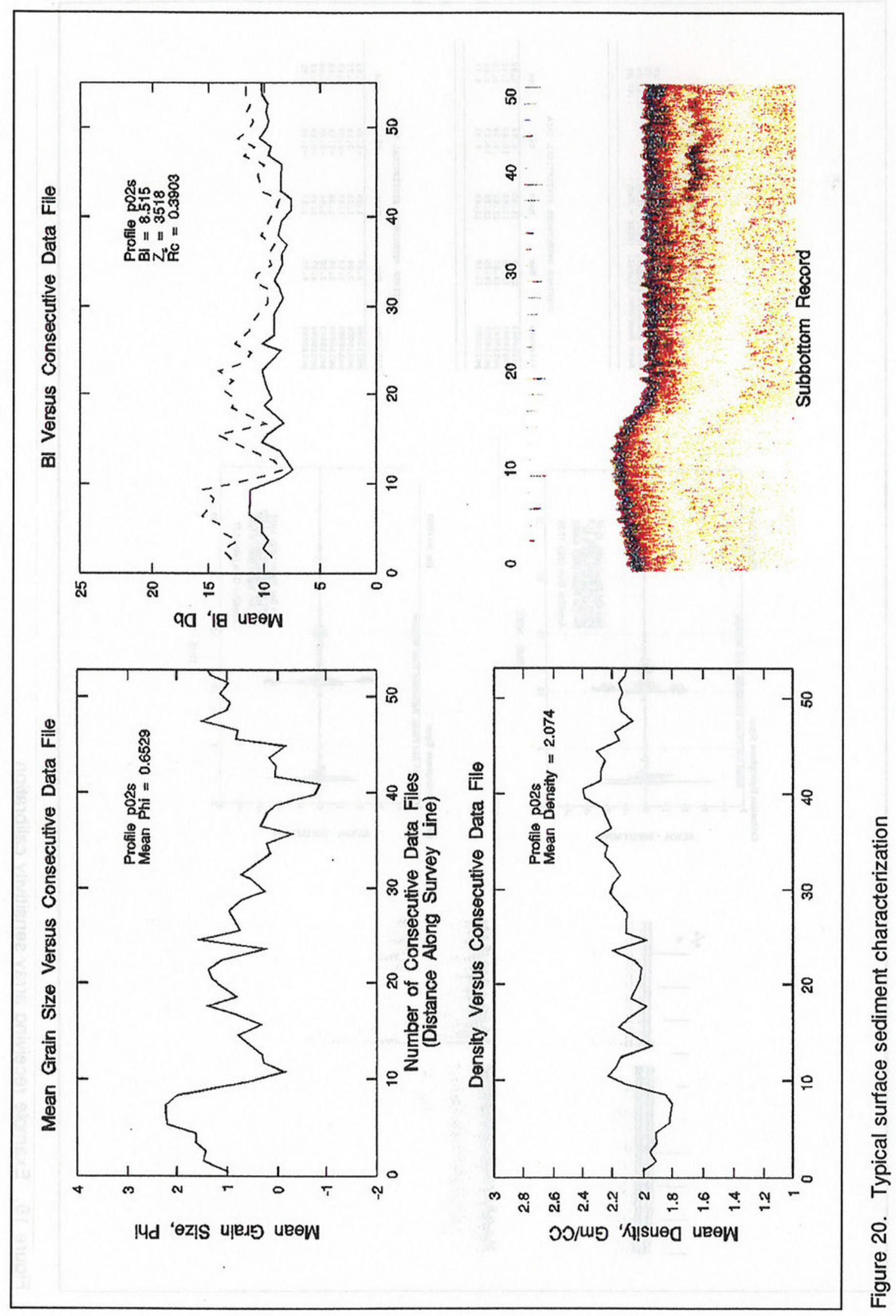



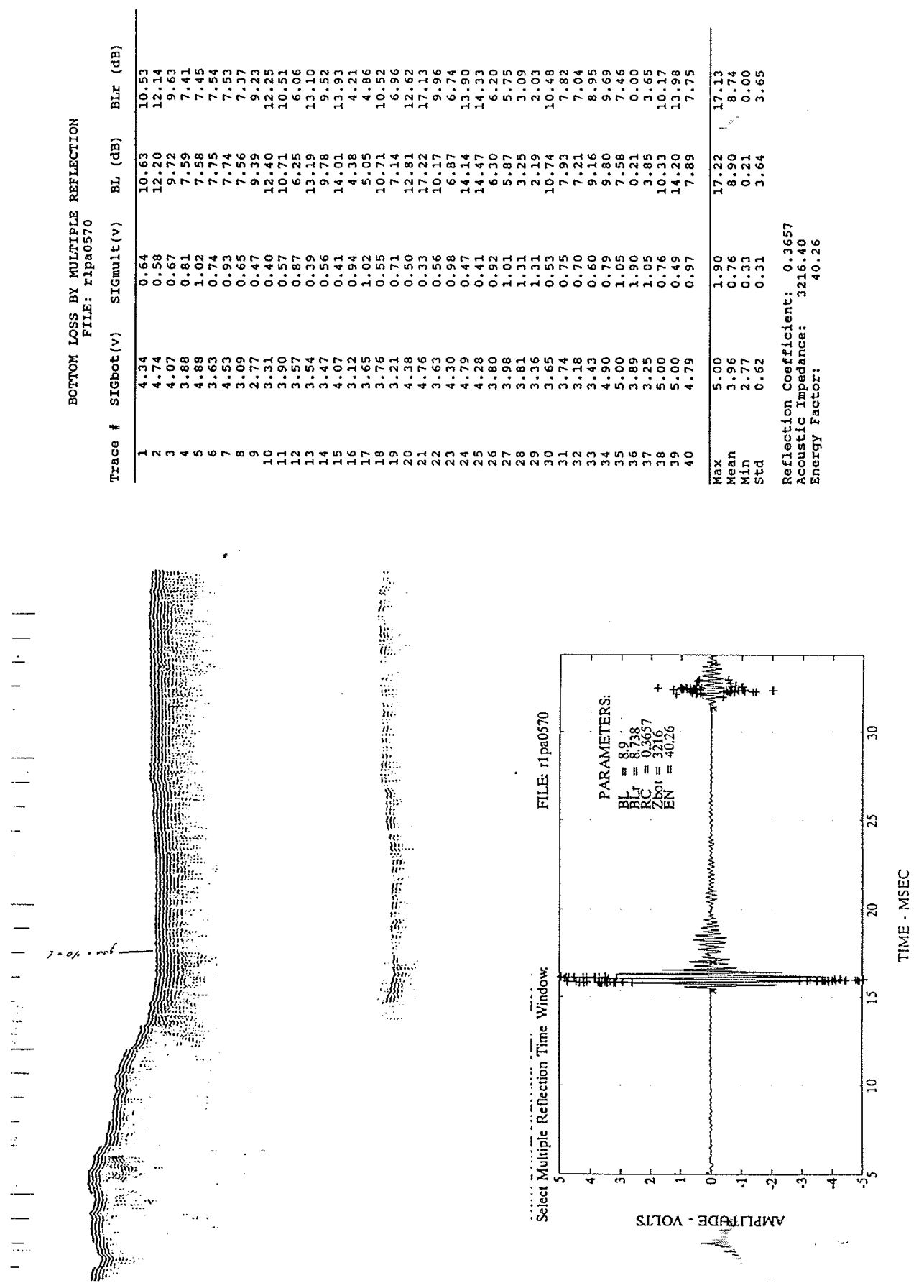

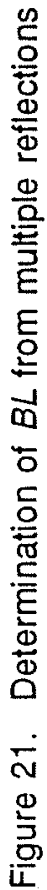




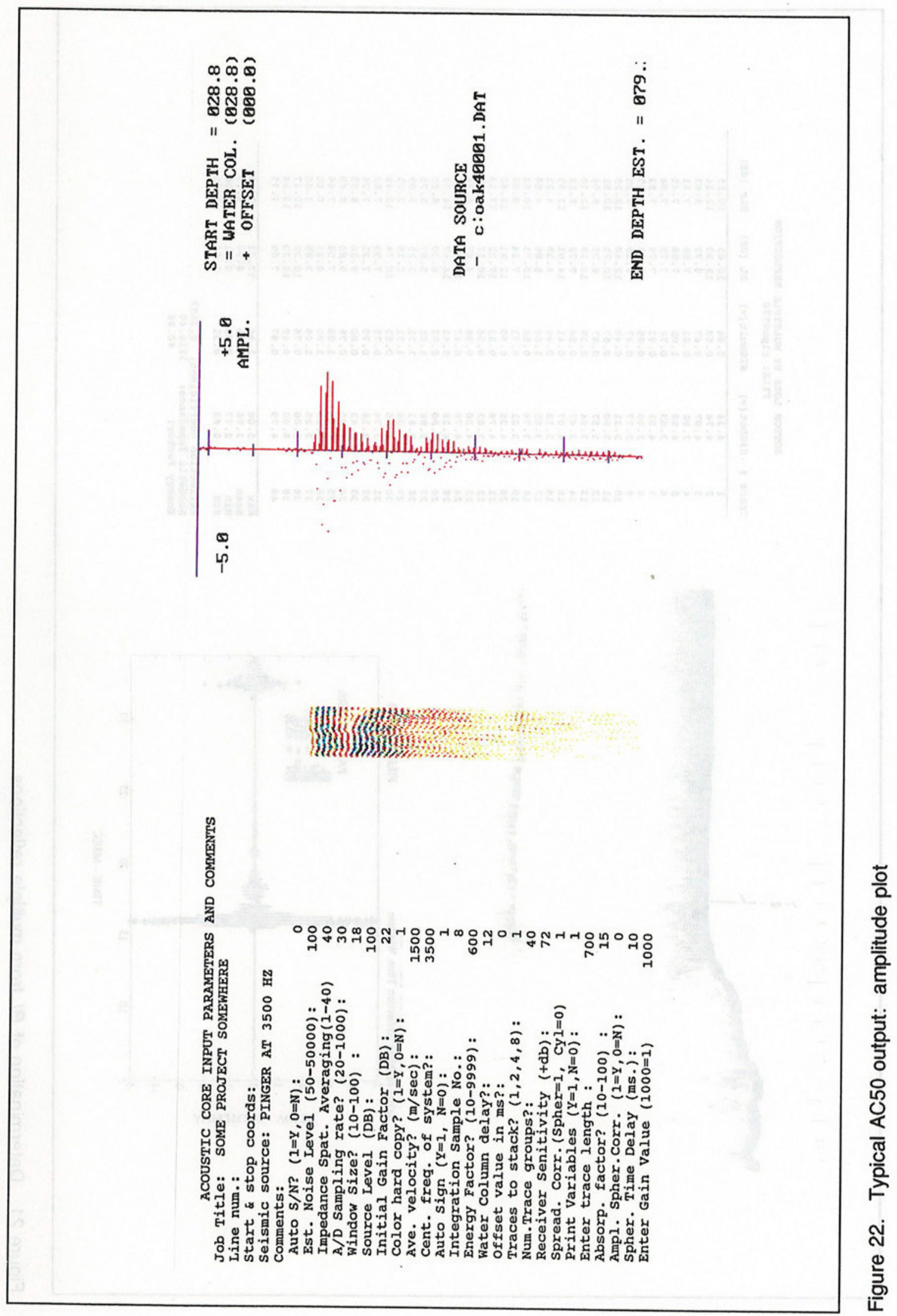


๓

跑

$\triangle \Phi$

II

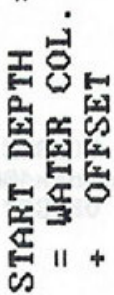

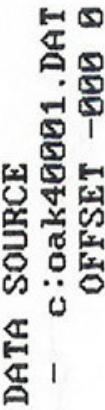

足

齿呈

흥

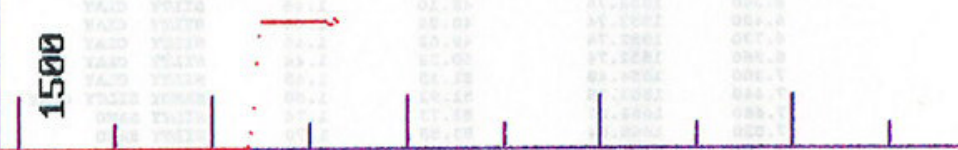

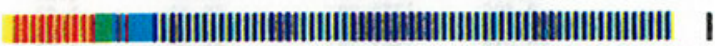
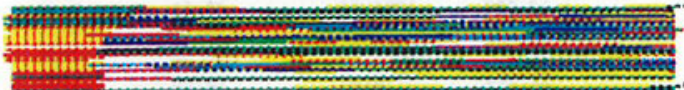

III

촘

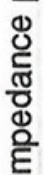

$\ddot{3}$

옹

융

\&

तु

$\stackrel{2}{2}$

लุ่

힌 


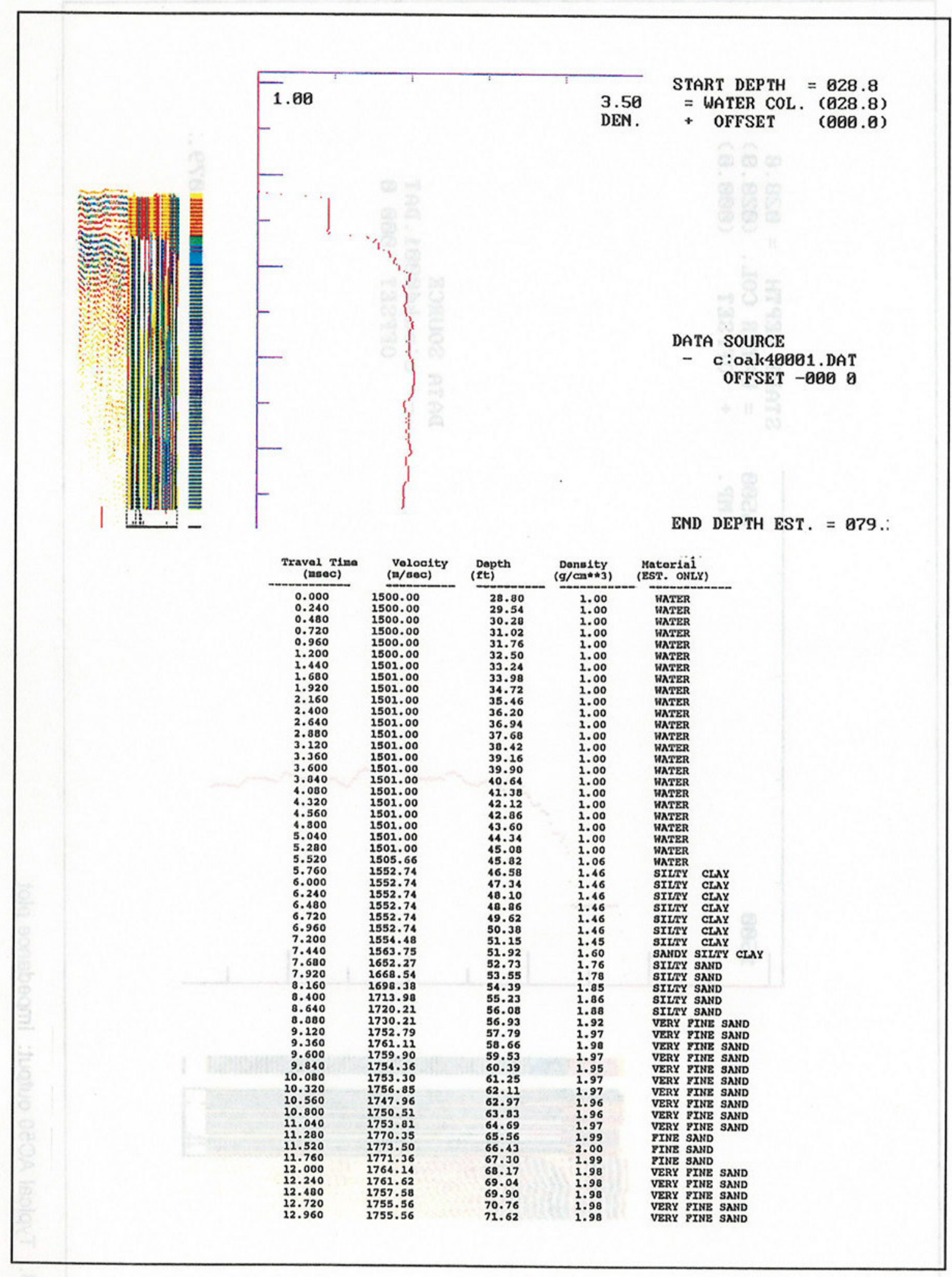

Figure 24. Typical AC50 output: density plot with table 


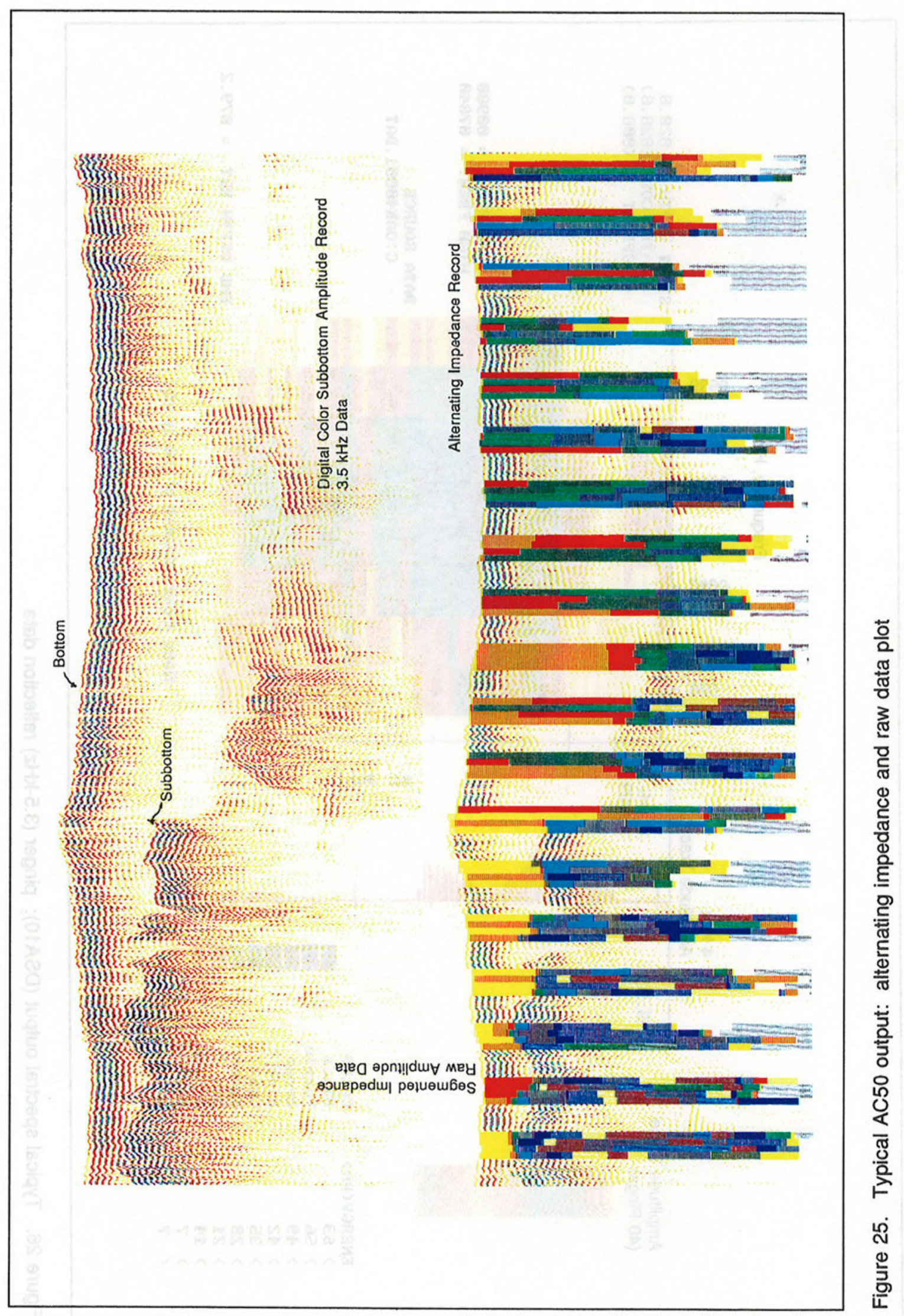




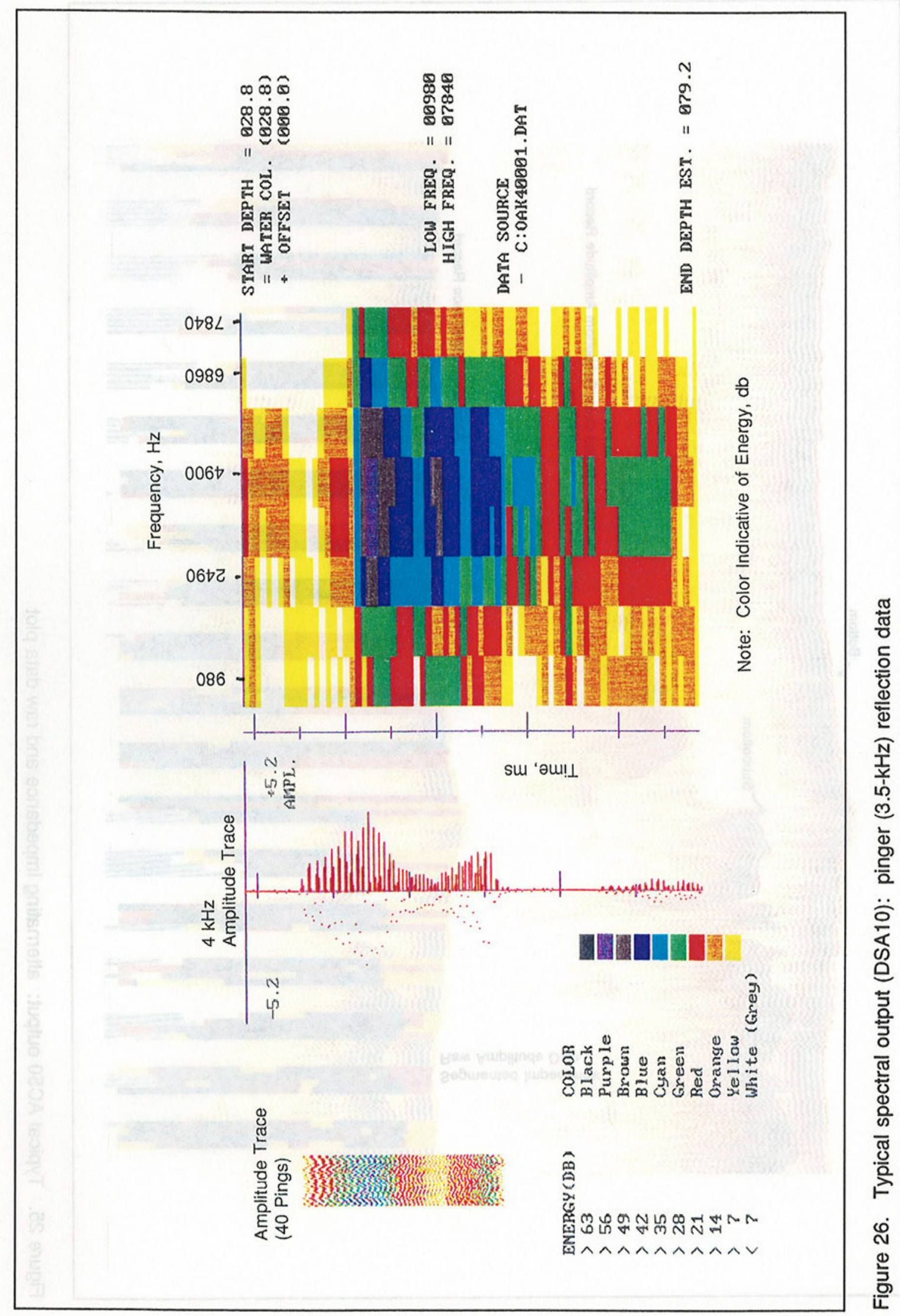




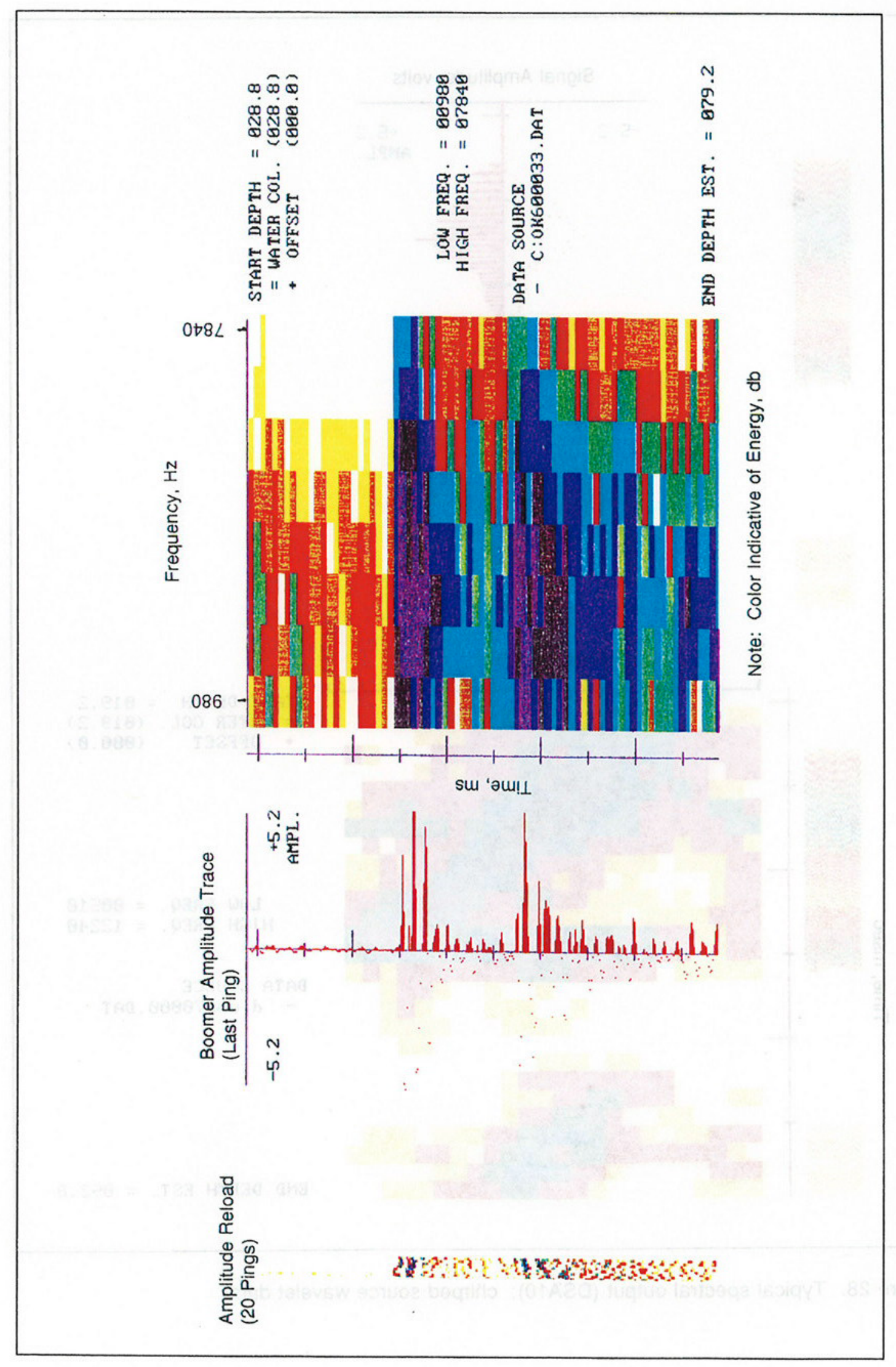

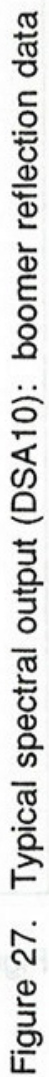




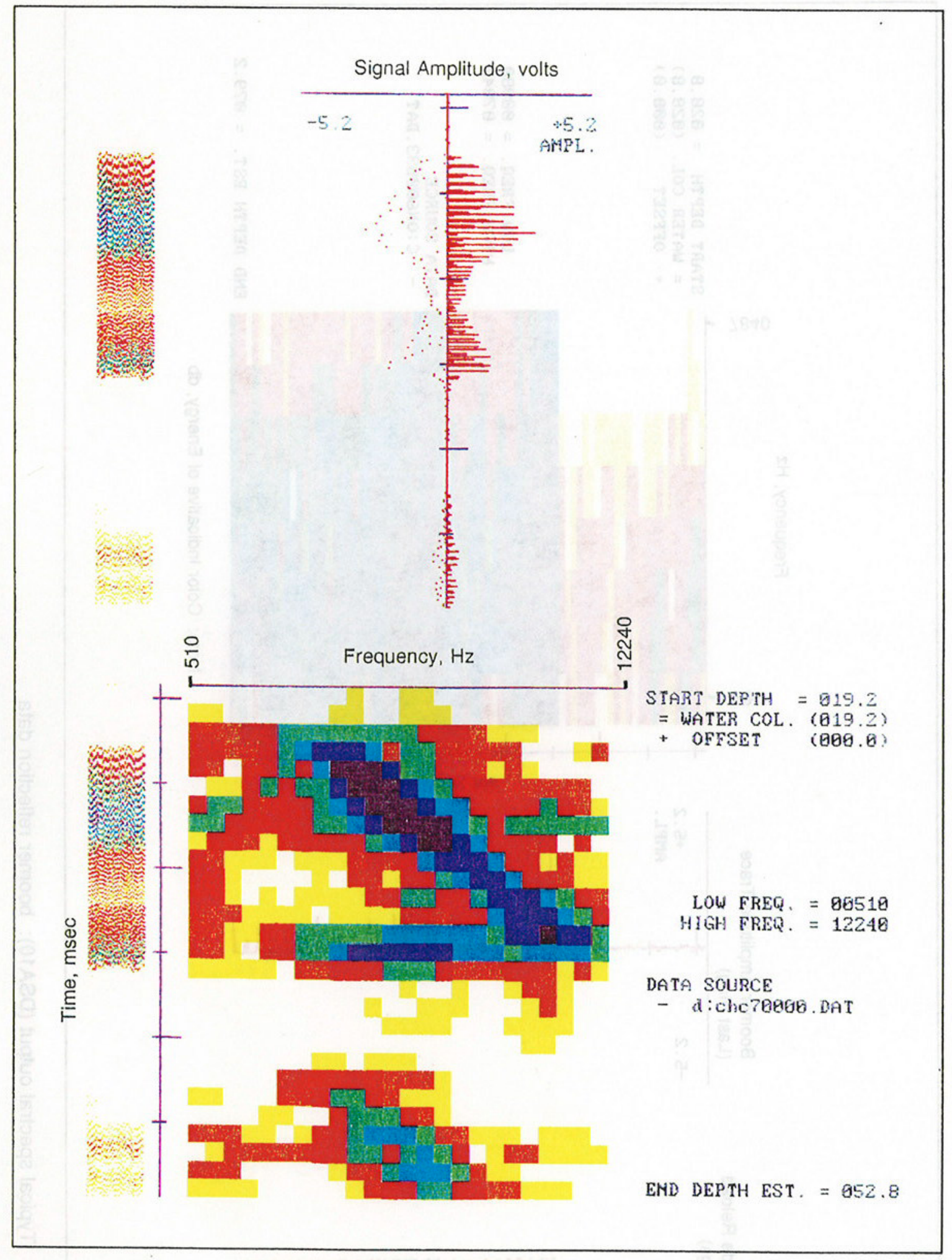

Figure 28. Typical spectral output (DSA10): chimped source wavelet data 


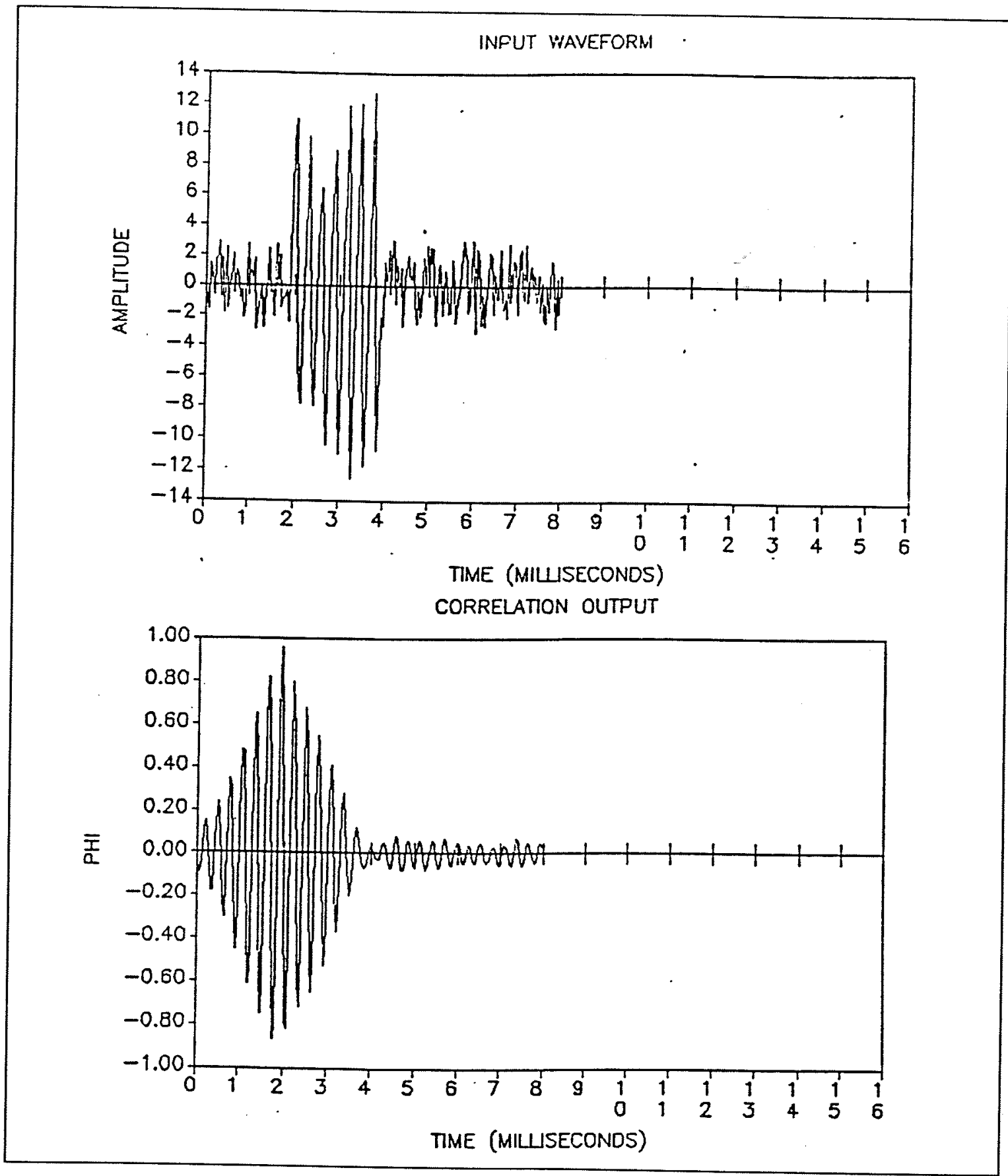

Figure 29. Correlation analysis: pinger $(3.5 \mathrm{kHZ})$ with noise

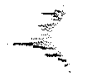




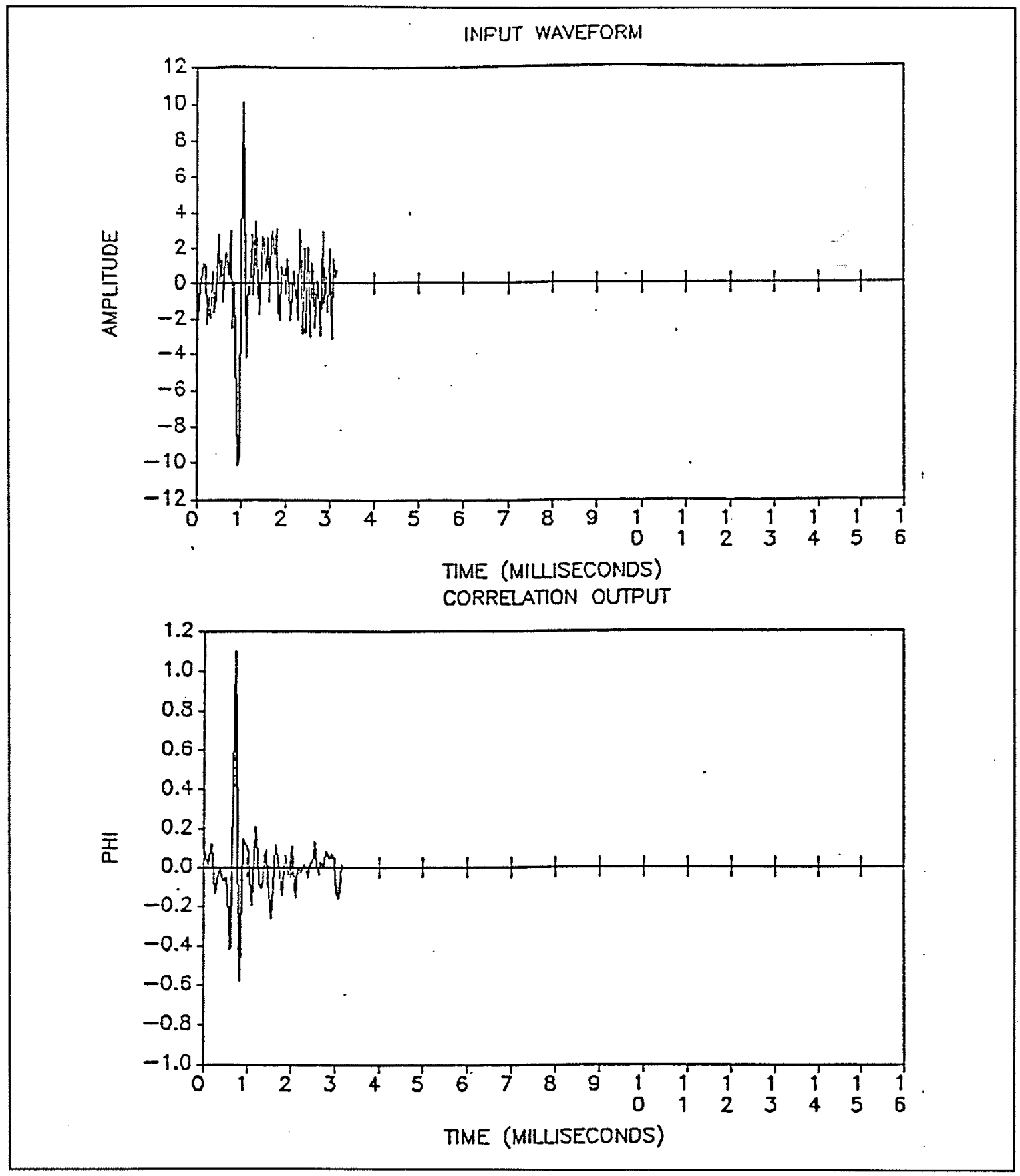

Figure 30. Correlation analysis: boomer with noise 


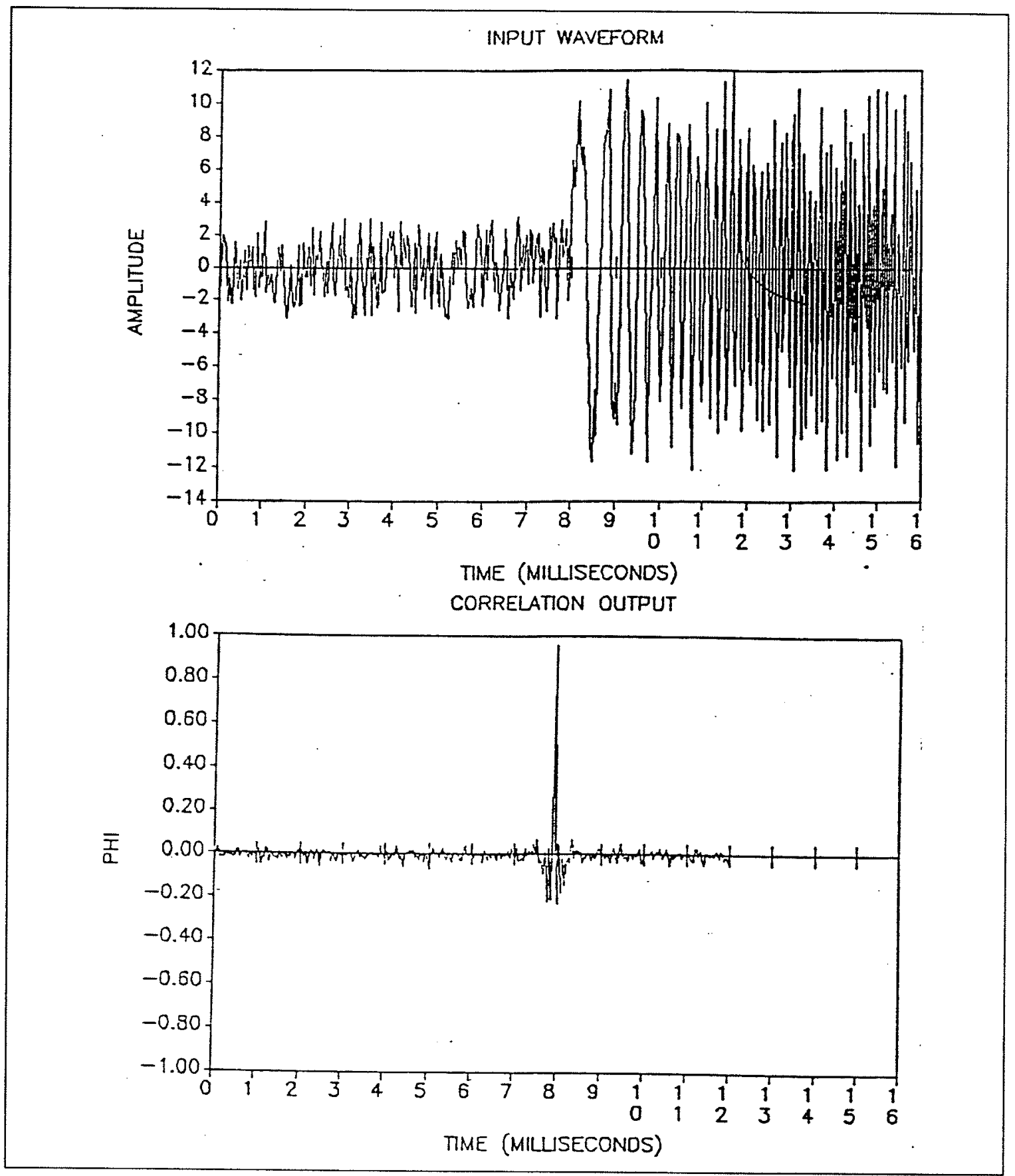

Figure 31. Correlation analysis: chirped signal with noise

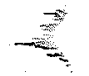




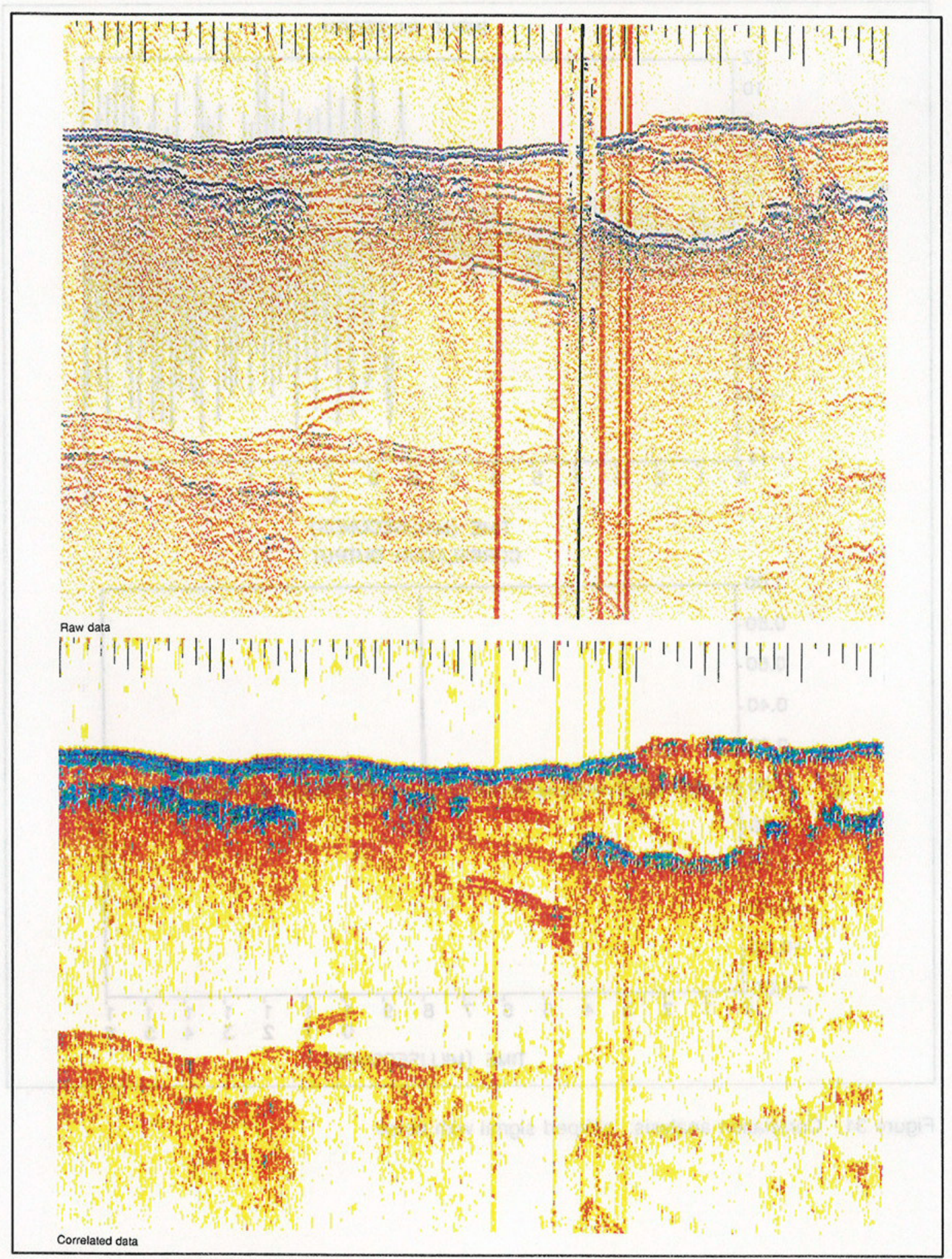

Figure 32. Correlation output: raw data versus correlated (boomer) 


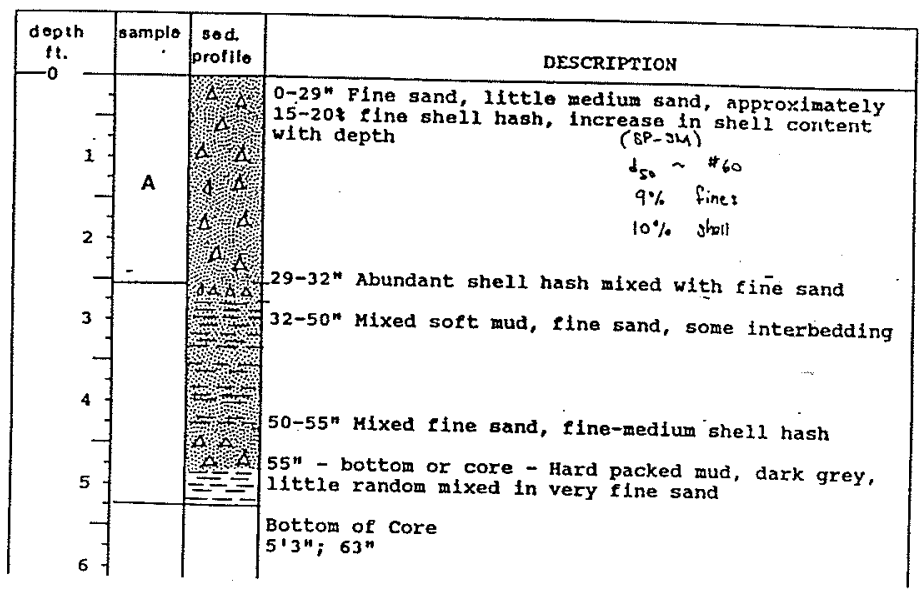

\begin{tabular}{|l|l|l|l|l|}
\hline \multicolumn{5}{|c|}{$\begin{array}{l}\text { Table } \\
\text { Simulated Site Core Data }\end{array}$} \\
\hline \multicolumn{5}{|c|}{ REFLio3 } \\
\hline Depth & Density & Velocity & Iupedance & $\begin{array}{l}\text { Reflection } \\
\text { CoeffIcIent }\end{array}$ \\
\hline 0 & 1.00 & 1500 & 1500 & $0.000-$ Hater \\
\hline 20 & 2.03 & 1836 & 3734 & $0.409-$ Sand \\
\hline 22 & 1.43 & 1535 & 2198 & -0.258 - Soft mud \\
\hline 26 & 2.20 & 2000 & 4400 & 0.337 - Hard clay \\
\hline
\end{tabular}

Sand over soft mud over hard clay

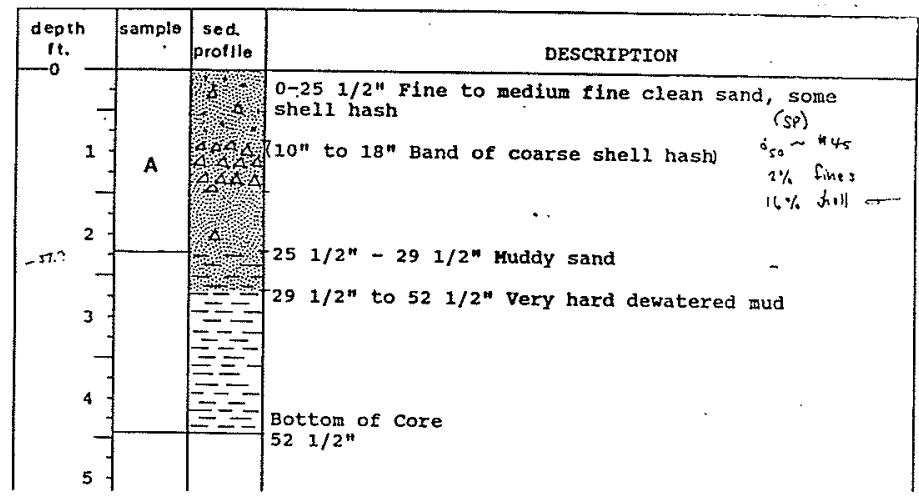

\begin{tabular}{|c|c|c|c|c|}
\hline \multicolumn{5}{|c|}{$\begin{array}{l}\text { Table } \\
\text { Simulated Site Gore Data }\end{array}$} \\
\hline Depth & Density & Velocity & Impedance & $\begin{array}{l}\text { Reflection } \\
\text { Coefficlent }\end{array}$ \\
\hline 0 & 1.00 & 1500 & 1500 & 0.000 - Nater \\
\hline 20 & 2.03 & 1836 & 3734 & $0.409-$ Sand \\
\hline 25 & 2.20 & 2000 & 4400 & 0.081 - Hard clay \\
\hline
\end{tabular}

Sand over hard clay

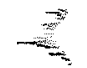

Figure 33. Example geologic models: sand over soft mud over hard clay; sand over hard clay 


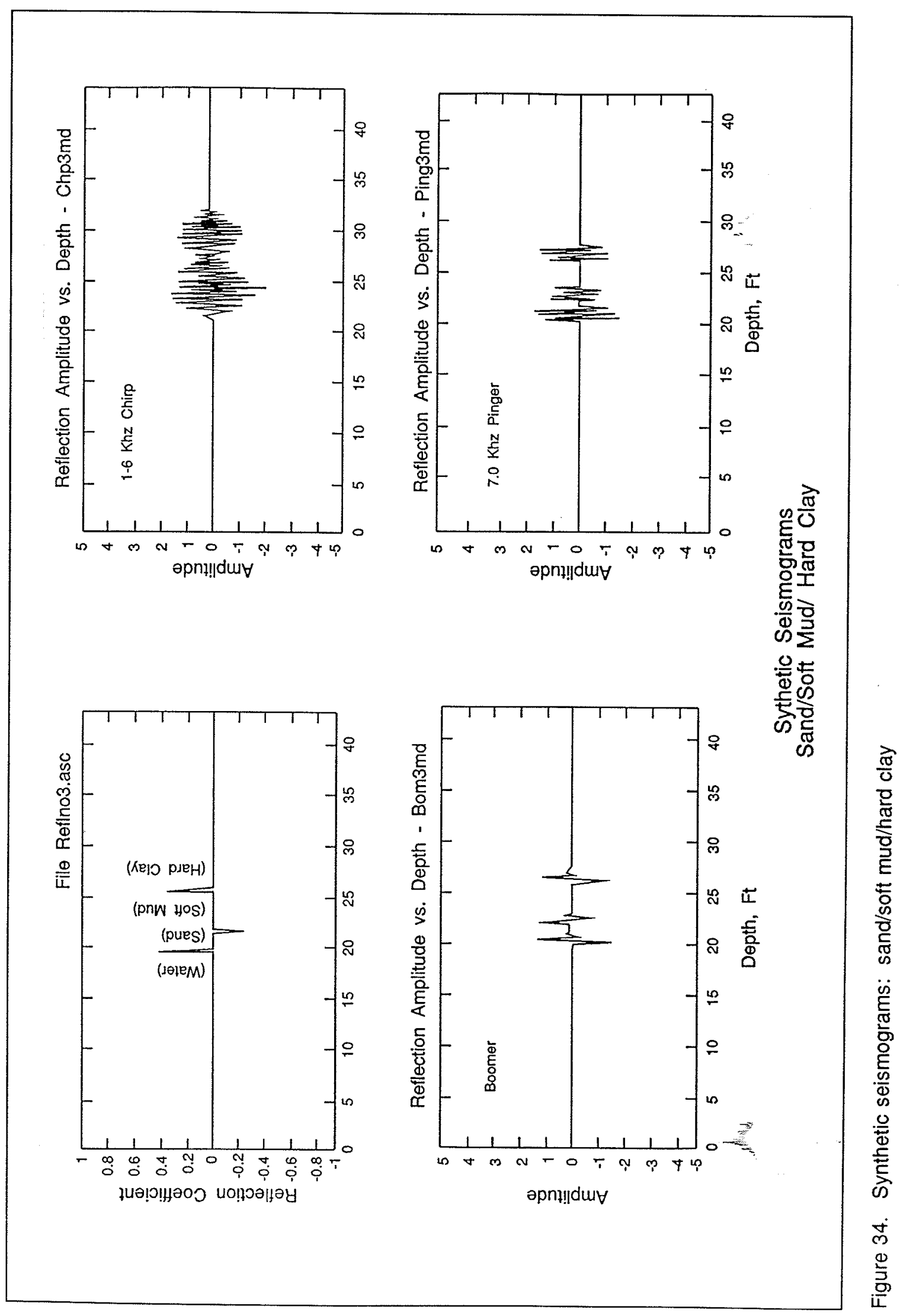



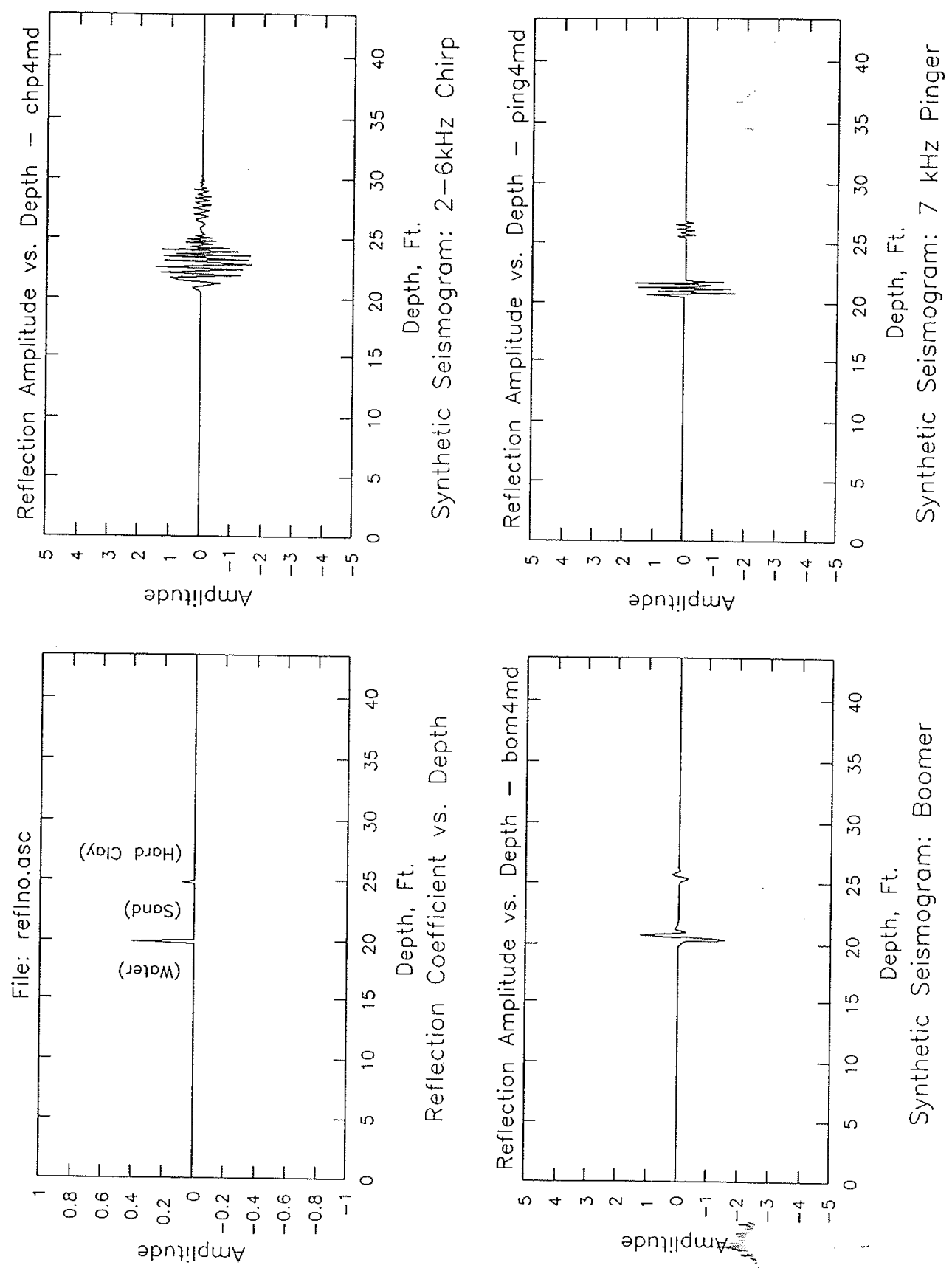

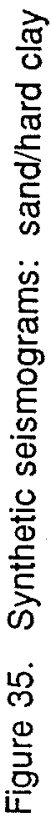




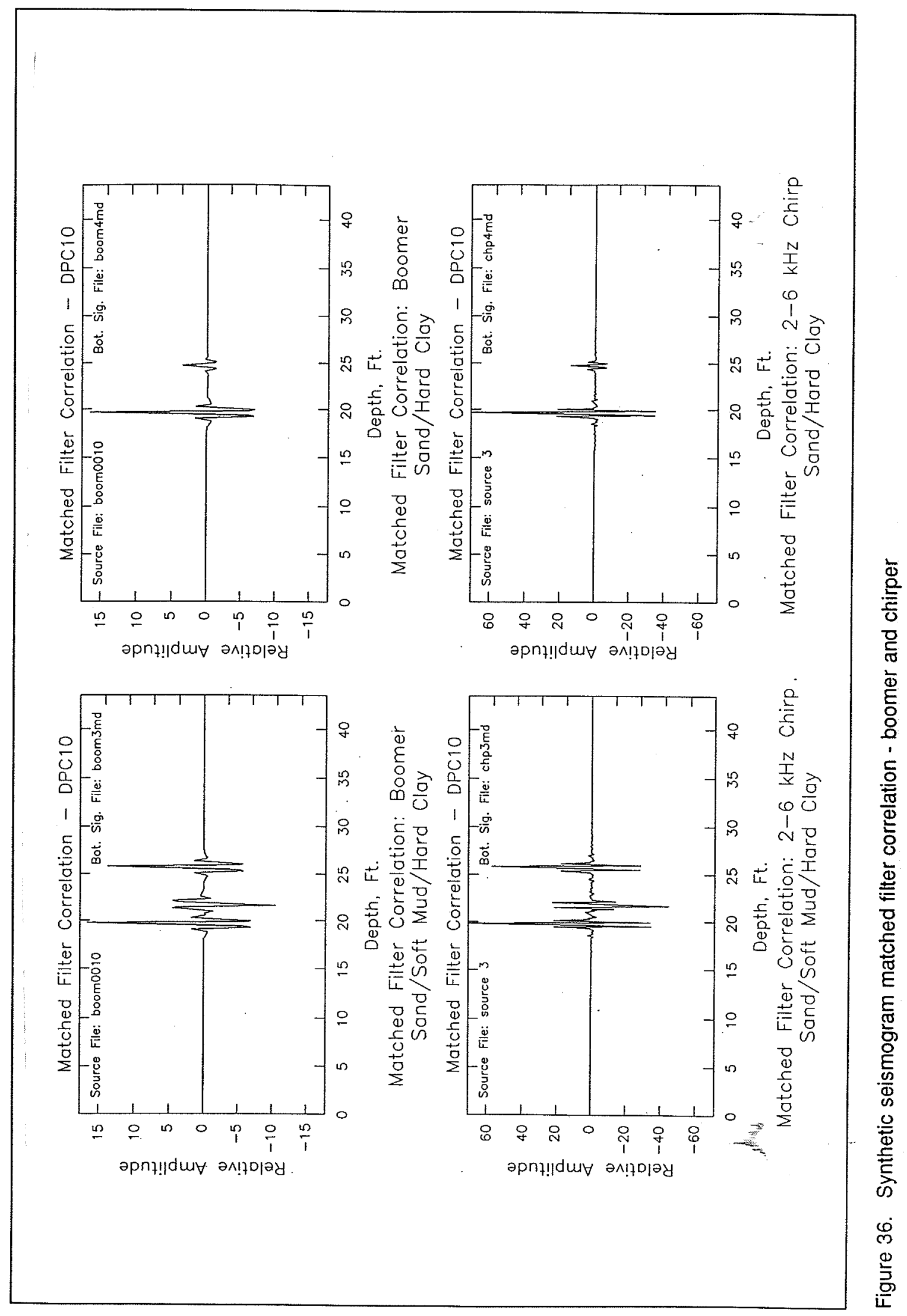




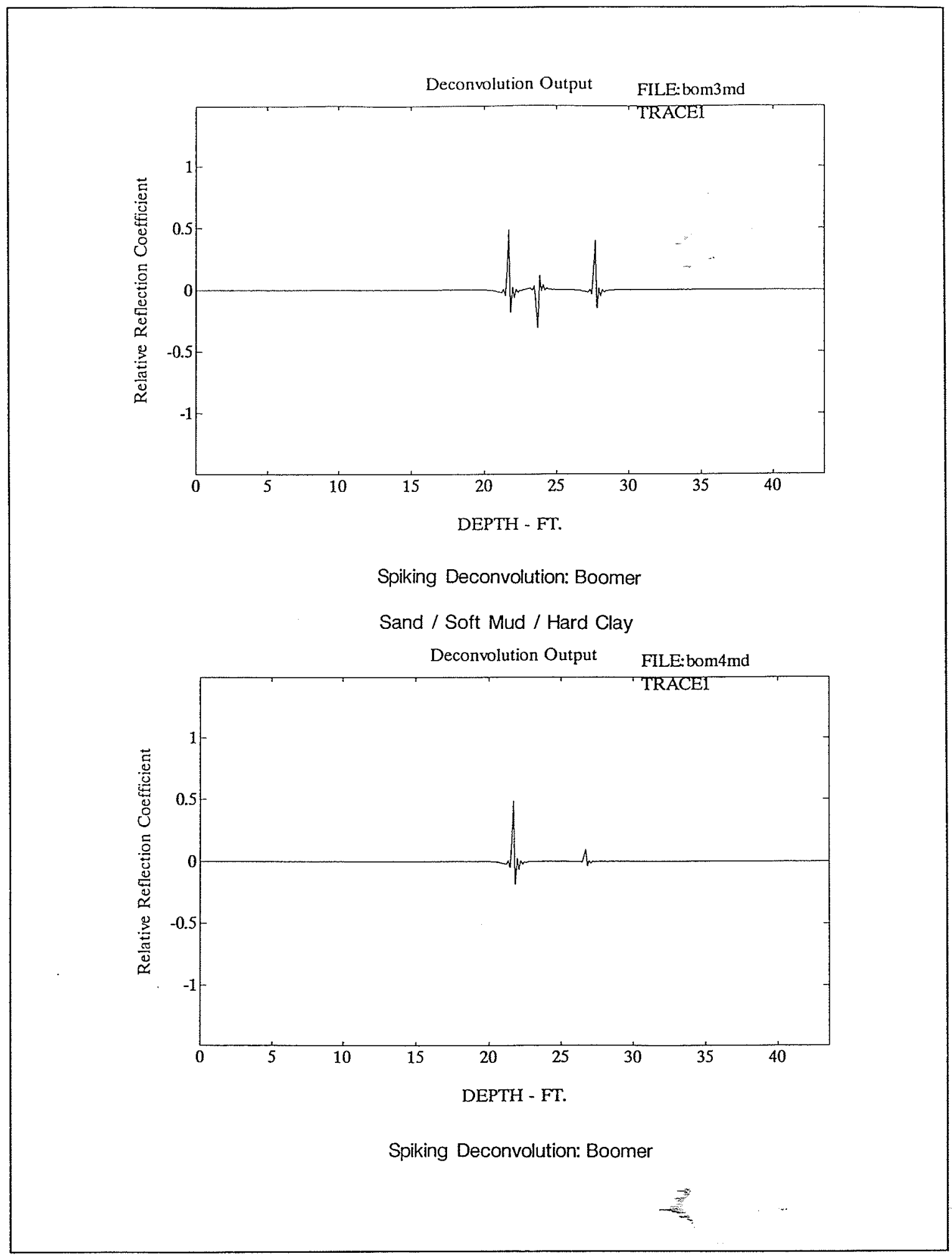

Figure 37 . Synthetic seismogram spiking deconvolution 


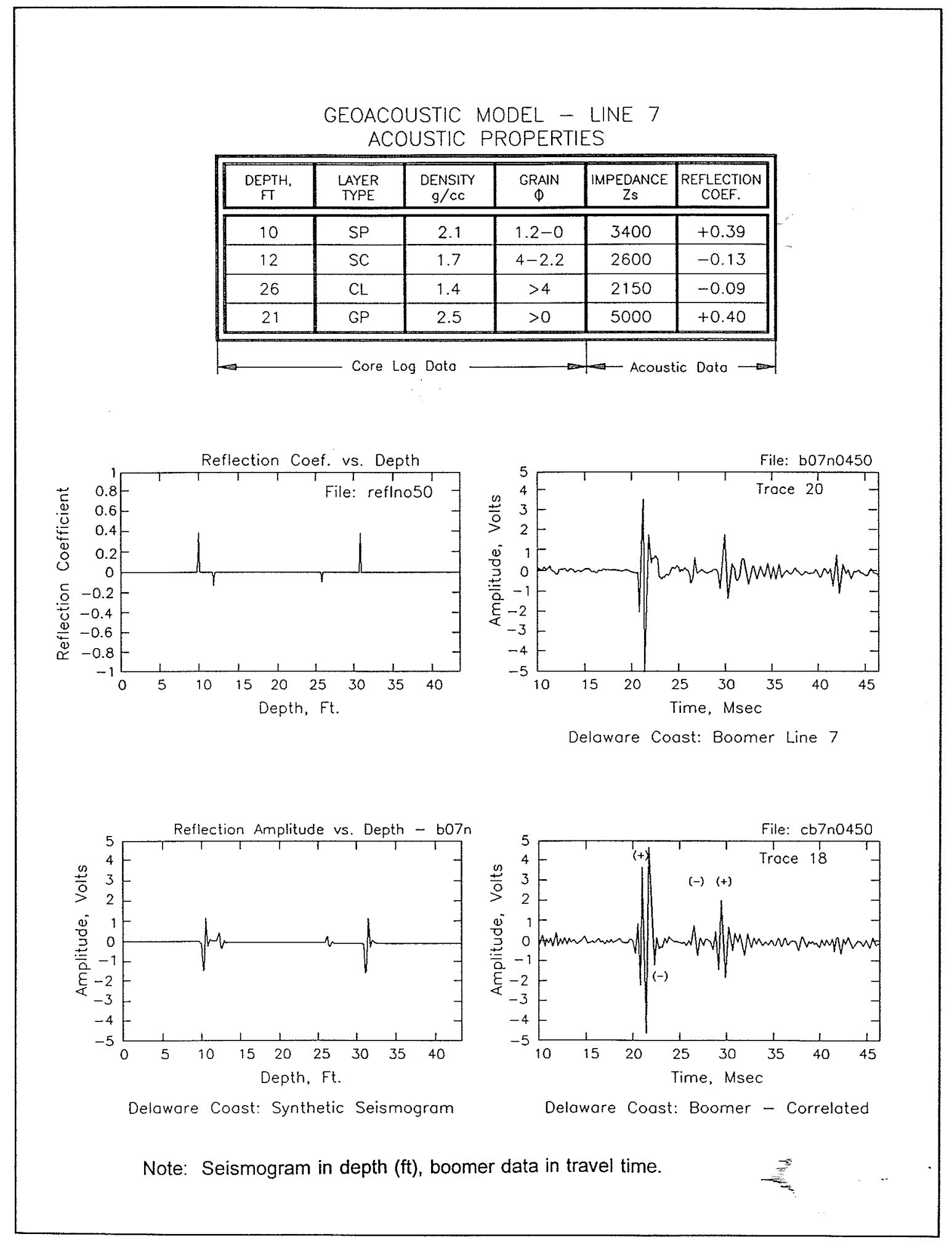

Figure 38. Forward model comparison with actual data 


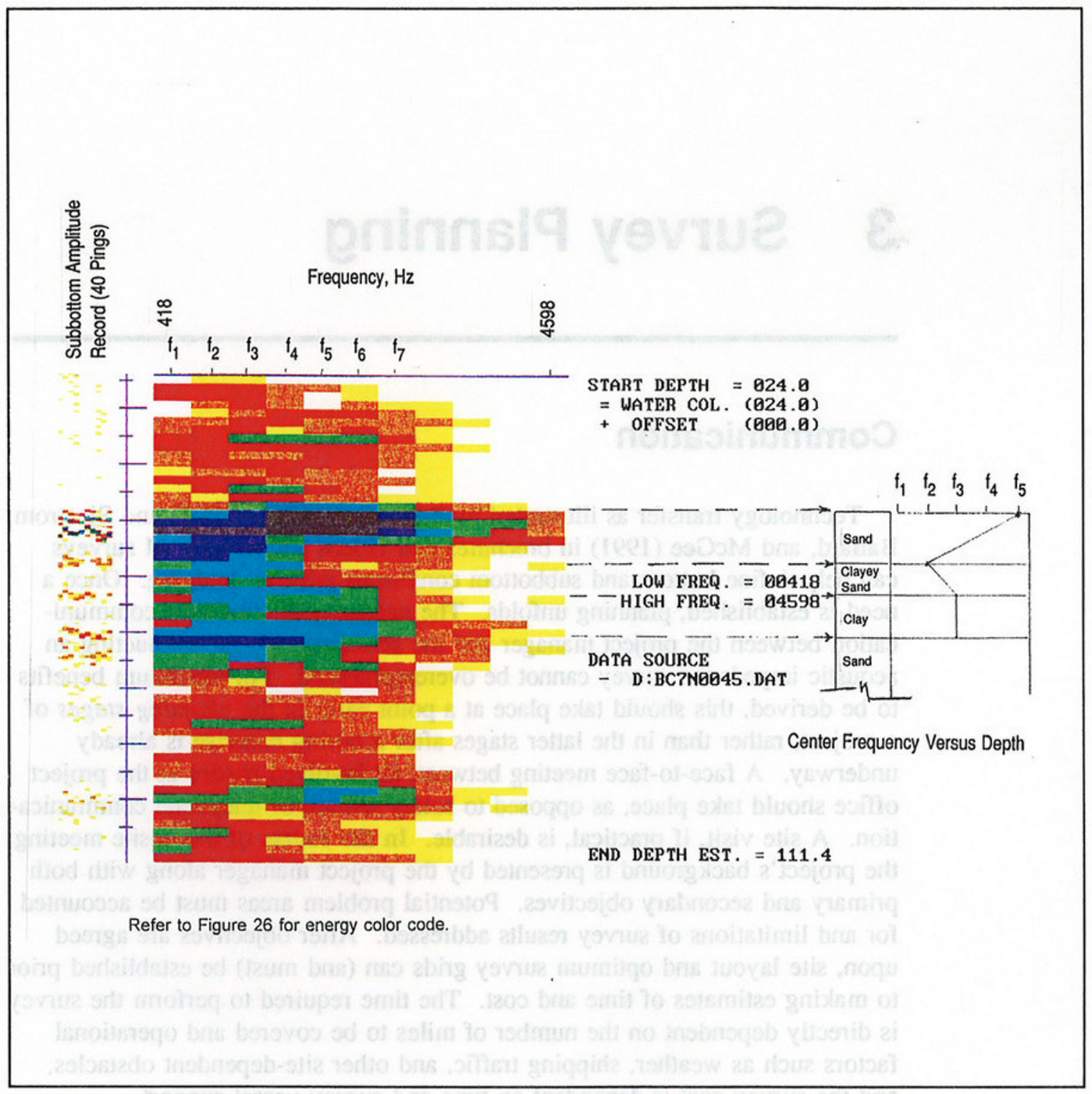

Figure 39. Example of spectral attenuation: sand/clay/sand 


\section{Survey Planning}

\section{Communication}

Technology transfer as illustrated by Ballard and Grau (1992) and Sjostrom, Ballard, and McGee (1991) in brochures and videos shows how AI surveys can help define bottom and subbottom conditions prior to dredging. Once a need is established, planning unfolds. The necessity for two-way communication between the project manager and the scientist/engineer conducting an acoustic impedance survey cannot be overemphasized. For maximum benefits to be derived, this should take place at a point early in the planning stages of a project, rather than in the latter stages after a boring exercise is already underway. A face-to-face meeting between all involved parties at the project office should take place, as opposed to solely written or telephone communication. A site visit, if practical, is desirable. In the course of the onsite meeting, the project's background is presented by the project manager along with both primary and secondary objectives. Potential problem areas must be accounted for and limitations of survey results addressed. After objectives are agreed upon, site layout and optimum survey grids can (and must) be established prior to making estimates of time and cost. The time required to perform the survey is directly dependent on the number of miles to be covered and operational factors such as weather, shipping traffic, and other site-dependent obstacles, and the survey cost is dependent on time and survey vessel support.

The single most elusive factor influencing time and cost is weather. Operating conditions must be safe and conducive to gathering high signal-to-noise ratio data. In these terms, "sea state" is governed by such factors as where operations are conducted--in open water as opposed to a sheltered harbor; in deep $(>100 \mathrm{ft})$ as opposed to shallow $(<30 \mathrm{ft})$ water. In gencral, wave height should not exceed about $3 \mathrm{ft}$ for acceptable operations because pitch and roll of the transducers and survey platform can produce unknown signal directionality. Whitecapping, which is a function of wind, water depthe and shelter conditions, also produces excessive seismic noise. For these reatsons, operational decisions must be made (from the safety standpoint) on a daily basis by the survey vessel pilot in conjunction with the data acquisition expert. Weather allowances are primarily based upon seasonal history but, in the view of both parties, should be subject to change. In the early stages of 
communication and negotiation, agreement should be reached concerning the handling of standby or "weather" days.

A comprehensive review of background materials including existing boring logs and site geology must also be performed. Support requirements of the survey team must be addressed along with the time frame for survey performance, interim and final reporting, and costs.

All of the above factors are critical to optimum job performance and benefits. To illustrate the manner in which good survey planning should occur, an actual example of dialogue exchange between the New England Division (NED) and WES is presented in Appendix B. This project, fully documented by Sjostrom and Leist (1994), was chosen not only because of its overall success, but as an example of support provided by the Dredging Operations Technical Support (DOTS) Program. Documents used for illustration include an information summary sheet (Figure B1) on the Boston Harbor, MA, Navigation Improvement Project which provided the necessary background to WES personnel for preparation of a face-to-face planning meeting and seminar held at NED. Also included is a Memorandum for Record (Figure B2) prepared by WES scientists documenting that meeting. The final proposal submitted by WES to NED is also included (Figure B3) because of its detailed treatment of such items as the following:

a. A clear statement of the objective.

b. The scope of work to be performed (including instrumentation).

c. The proposed survey grid to be used at four sites of interest.

d. Support requirements to be provided by NED.

e. Scheduling and reporting (both interim and final).

These serve to further illustrate the point that communication is critical throughout the entire planning stage.

\section{Surveying and Reporting}

During field experience with conduct of AI surveys some pitfalls became readily apparent. Foremost were navigational problems. Obviously, data are worthless if locations are not known; consequently, great care must be taken to ensure that accurate grid coordinates are firmly tied to the seismic dâta acquisition system, i.e., the systems must be able to communicate. Early pröblems arose as the result of interface compatibility between navigation equipment provided by the support element and the seismic data acquisition system. Once recognized, these problems were quickly overcome but required a thorough understanding of the system to be used--its setup time requirements (range-range land stations, manpower, etc.) and limitations (in some instances, 
data were not stored by survey instrumentation, and if problems arose, an entire seismic survey line would have to be repeated). A second pitfall was establishment of the water depth datum plane. Many Corps support elements use $200-\mathrm{kHz}$ echosounders exclusively to define "bottom." In actuality this can be the top of a fluid mud layer rather than true hard bottom as defined by the AI seismic source. A solution was reached when echo sounder data were compared to pinger data and the fluid mud thickness accounted for. In final analysis, the actual datum plane or bottom elevation is established with reference to tide gauges in accordance with local operational procedures. No longer does either of these pitfalls involving $X, Y, Z$ coordinates present a problem. The WES AI integrated data management and navigation system coordinates satellite (GPS) navigation with an Innerspace 445 echo sounder and seismic source data. All combined data are now stored on hard disk.

Visualization of critical data will be an important factor for the user, whose preferences should be made explicit as exemplified by NED. In that specific case, the grid shape would not have been conducive to three-dimensional (3-D) visualization, and users actually preferred cross-sectional representations of channel conditions.

Actual conduct of the survey must be planned well in advance so that data can be acquired in a manner consistent with the desired type of presentation. Data presentations most often consist of two-dimensional (2-D) cross sections color-coded in terms of material densities or type of material. (In earlier presentations, 2-D plots in shades of gray were the only choice.) However, the user may wish to color-code a site in three dimensions so that "pockets" of materials and volumetric calculations take on additional meaning. It should be noted that 3-D presentations are more time-consuming and consequently more costly to produce, but in the words of many users "well worth the price." Examples of various types of visualization will be discussed and illustrated in Chapter 4.

If at all possible, the project manager or the person(s) using the survey data should physically participate in the actual field exercise and data processing/ interpretation phases of the survey, thereby becoming an integral part of the "team" and developing a keen insight into the quality of data and its limitations. Further, many decisions can and should be made onboard the survey vessel as data are acquired.

Upon completion of the final report, a comprehensive discussion of findings should be presented in person by the surveyors to the project manager and other end-product users in their office. This discussion should include all aspects of the survey from planning through conduct, data processing, interpretation, computer biases, and limitations. Recommendations should be made regarding placement of verification borings and the degree to which objectives have been met. 


\section{Case Studies}

\section{Overview}

Presented in this section are site calibration and verification results (ground truthing) conducted at a number of test sites around the country. Although surveys have been conducted at some 16 sites, ground truth information is not available for all sites. In some instances, sampling is still underway. Hence, only those data obtained from projects whose objectives fully exploited the AI procedures will be presented. Only two examples, the Gulfport fluid mud study and one area of Oakland Harbor, were actually funded by DRP. Other surveys, having a variety of objectives, were performed on a fully reimbursable basis, sponsored by various Corps District and Division offices or other agencies. Geoacoustic data are presented for direct comparison to ground truth information derived from conventionally accepted Corps practices. These comparisons consist of acoustically derived sediment properties, and measured sediment properties and/or lithology. Since it was the ultimate goal of this work to produce a validated procedure sufficiently accurate for characterizing bottom and subbottom materials, a concerted effort was made to quantify the degree of accuracy. It was recognized that the procedures should provide unrestricted use by Corps personnel for planning purposes or even as evidence for use in court dredging claims. In virtually all instances, geoacoustic predictions were accurate to within \pm 10 percent while in many cases accuracy was within \pm 5 percent.

In addition to discussions on ground truth, examples of 2- and 3-D visualization and volumetric calculations are presented. These serve to provide potential users with the versatility of this technique.

Following is a complete listing of sites surveyed to date using the acoustic impedance approach: 


\begin{tabular}{|ll|}
\hline Project & Sponsor \\
\hline Oakland Harbor & San Francisco District \\
Mobile Ship Channel & Mobile District \\
Gulfport Ship Channel & Mobile District \\
Panama City Coastline & Mobile District \\
Pascagoula Ship Channel & Mobile District \\
Savannah Harbor & Savannah District \\
Galveston Ship Channel & Galveston District \\
Houston Ship Channel & Galveston District \\
Delaware River Channel & Philadelphia District \\
Delaware Bay Coastlines & Philadelphia District \\
New Jersey Shoreline & Philadelphia District \\
& \\
Delaware River Ship & Philadelphia District \\
Channel/ Harbor & \\
Boston Harbor & New England Division \\
Baltimore Harbor & Baltimore District \\
Picatinny Lake & Army Environmental Center \\
Clinch River/Poplar Creek & Department of Energy \\
Charleston Harbor/Ship Channel & Charleston District \\
& \\
\hline
\end{tabular}

For reasons previously explained, it is beyond the scope of this report to present all data; however, substantive data from a wide range of geologically different sites will be discussed and statistically reported.

\section{Gulfport and Mobile Ship Channels}

The Gulfport field exercise was conducted in the summer of 1990 as the second evaluation of the acoustic impedance method developed under DRP sponsorship. During this evaluation phase, the target application was to .. explore the effectiveness of the technique in density determinations of fluid mud. Figure 40 shows amplitude plots of $20-\mathrm{kHz}$ and $45-\mathrm{kHz}$ surveys conducted in Gulfport Ship Channel, MS. Figure 41 shows acoustic impedance density predictions versus nuclear densitometer data for fluff/fluid mud type materials in the Gulfport Ship Channel as shown in Ballard, McGee, and 
Whalin (1992). Correlation proved to be excellent, within an average percentage difference of -1.60 .

Data acquisition. Under a reimbursable agreement with Mobile District, Gulfport Ship Channel was revisited to survey the route of a proposed new channel. The primary objective of this investigation was to determine densities of subbottom materials, isolate sands, and compute an estimate of their volume. Mobile Ship Channel was investigated separate from Gulfport, but since the projects are geographically similar and were both sponsored by the Mobile District, it is fitting to describe their results collectively. However, prior to a discussion of the ground truthing of these data, a comparison with Hamilton's worldwide database will prove interesting. A plot of the impedance function versus laboratory measurements of density from core samples taken in the Mississippi Sound and Mobile Bay is presented in Figure 42. A slight modification by Caulfield (1992a) to Hamilton's data is represented by the solid line in Figure 42. It shows remarkable agreement with the data at both sites. Figure 43 shows the acoustic predictions versus core data for consolidated materials in Mobile Ship Channel. In this case, results are within 1 percent. Figure 44 shows the same data for materials in Gulfport Ship Channel. Note that this comparison format (Figure 44 ) is currently preferred by users. This figure displays a segment of the actual acoustic reflection record color-coded to represent changes in signal amplitude followed by the acoustic impedance processing of that record. Next, the computed density plotted as a function of depth is shown along with laboratory-derived densities from core samples in the same vicinity. Finally, the predicted lithology computed from acoustic data is shown adjacent to lithology obtained from core analysis. (If no core samples are available, the core section is omitted from the display.)

Visualization. Three 2-D profile views representative of a segment of the Gulfport Ship Channel are illustrated in Figure 45 with survey line 9 positioned along the center line of the proposed channel. Lines 1 and 18 are parallel to each edge of the proposed channel. This type of display delineates the extent of pertinent density zones of interest to the engineer, and the virtually continuous data coverage greatly decreases the possibility of significant material changes going undetected.

Density predictions. By incorporating the virtually continuous coverage of subbottom materials with digital terrain modeling techniques, rapid and accurate computations can be made of volume and material type to be removed by dredging. Furthermore, a detailed database has now been established for project monitoring and long-term planning. Computed sediment densities within the project area can be displayed in a color-coded, 3-D view as shown in Figure 46 if desired by the user. In this example, red, brown, and yellows shadings are indicative of less-dense material. Blues represent sands.

Volumetric calculations. At the project planner's discretion, an area of interest may be viewed from other angles or other displays created by stripping or slicing at any desired coordinate. Volume of any material to be removed can be easily calculated and displayed as shown in Figure 47. This example 
predicts the configuration of sands underlying the segment of Gulfport Ship Channel shown in Figure 46. Ground truth information concerning the Gulfport Ship Channel, as related to predictions of material type and location, could only be obtained qualitatively from the Mobile District project manager as dredging progressed. In his words, the materials and quantities predicted closely matched those dredged.

It should also be noted that, possibly for the first time in USACE history, Mobile District advertised site conditions for dredging at Gulfport Ship Channel using density predictions determined by geophysical acoustic impedance surveying in addition to information normally supplied. Information derived from continuous site characterization rather than borings alone is considered (by Mobile District personnel) to be beneficial to the potential dredging contractor and the Corps for planning purposes.

\section{Galveston Ship Channel}

During the summer of 1992, an acoustic impedance survey of Galveston Ship Channel was conducted (synopsized in Ballard et al. (1992)). Although several objectives were accomplished, the phase concerning volumetric determinations of "dirty" sands (density of $1.7-1.95 \mathrm{~g} / \mathrm{cc}$ ) underlying the proposed channel was of specific interest because of its potential use for beaches. The following discussion presents the methodology used to locate, identify, and quantify that material of interest to the U.S. Army Engineer District, Galveston.

Data acquisition. Figure 48 is a typical $3.5-\mathrm{kHz}$ pinger amplitude cross section reproduced from a color field record obtained in Galveston Ship Channel. Note that the top of the graph is not the water surface but an assigned water column delay. This offset allows full vertical expansion of the subbottom display, which in this case extends into the subbottom more than $40 \mathrm{ft}$. Changes in stratigraphy are readily apparent. Records of this type are used as quick-look guidance in boring placement.

Density predictions. Figures 49-53 display acoustic predictions versus core data for consolidated materials in Galveston Ship Channel. Analysis shows acoustically derived density values vary $\pm 0.2 \mathrm{~g} / \mathrm{cm}^{3}$ from in situ values. As previously described, computed sediment densities within the project area can be displayed in a color-coded, 3-D view (Figure 54). In this example, lighter shadings are indicative of less-dense material--the darkest analogous to densities $>1.7 \mathrm{~g} / \mathrm{cc}$.

Volumetric calculations. Using Figure 54 as an example, the volume of any material to be removed can be easily calculated. This example will predict the configuration of silty ("dirty") sands (>1.7 g/cc density; 2864-3052 $\times$ $10^{2} \mathrm{~g} / \mathrm{cm}^{2} \mathrm{sec}$ acoustic impedance) underlying a selected segment of the project study area. The volume of material present within a selected area of 
the perspective model is arrived at by calculating the volume of material present within the corresponding area of each profile line model.

In the example, the profile line model shown in Figure 55 corresponds to the section of the 3-D perspective model (see Figure 54) nearest the viewer. Note that the axis labels in Figure 54 show northing and easting coordinates, while the axis label in Figure 55 reflects relative feet from start-of-line. This conversion is necessary in order to correlate the profile line models to amplitude records which are plotted with locations relative to start-of-line. - Before volumes are calculated, the area of interest must be sliced out of the computer model and the material density range to be displayed must be selected. In this example, the volume of material present in the area between the bottom to -55.0-ft depth and between 3,000 to 7,000 ft from start-of-line, having a density of $>1.7 \mathrm{~g} / \mathrm{cc}$, will be selected. The section of the model below $-55.0 \mathrm{ft}$ is stripped away, and the sections from 0 to $3,000 \mathrm{ft}$ and 7,000 to $19,000 \mathrm{ft}$ are sliced from the display as shown in Figure 56. Finally, the density of material to be displayed is set to $>1.7 \mathrm{~g} / \mathrm{cc}$. Calculations based on these parameters are then computer-generated and displayed as shown in Figure 57, yielding an estimated volume of $167,366 \mathrm{cu}$ yd of "dirty" sand (materials $>1.7 \mathrm{~g} / \mathrm{cc}$ ) within the specified boundaries. This step is repeated for each profile line model within the area of interest, summing the estimated volumes for an overall project volume total.

\section{Boston Harbor}

At the request of NED, WES performed a reimbursable waterborne seismic reflection and side-scan sonar survey of three tributaries to Boston Harbor, Massachusetts, during November 1992 . The survey, reported in its entirety by Sjostrom and Leist (1994) and further discussed in Appendix B, included Mystic and Chelsea Rivers, Reserved Channel, and the Inner Confluence Area. The objective of the survey was to quantify, as a function of depth, bottom and subbottom sediments in terms of density and soil type to elevation $-42 \mathrm{ft}$ mean low water $(\mathrm{mlw})$ in all areas except the Chelsea River where the desired datum was $-40 \mathrm{ft}$ mlw. Information was to be used to facilitate positioning of soil borings, particularly in areas of suspected rock outcroppings. During earlier phases of maintenance dredging work, NED had obtained some boring information, but little was documented regarding laboratory density analysis. An additional six shallow penetration cores were collected following the geophysical survey to more accurately calibrate the geoacoustic model and develop the necessary acoustic parameters to derive estimates of bottom and subbottom material density. Laboratory densities were obtained from these cores. - Length of the core samples ranged from 1.6 to $2.0 \mathrm{ft}$. Consequently, direct coms parisons with acoustic data were restricted to the upper $2.0 \mathrm{ft}$. Fifteen additional cores (containing no laboratory density information) ranging between 6 and $17 \mathrm{ft}$ were completed in June 1993 and were also used for subbottom material comparison purposes. 
Laboratory-derived density values ranged from 1.38 to $1.84 \mathrm{~g} / \mathrm{cm}^{3}$. Figure 58 is a typical calibration comparison display showing both acoustic and shallow laboratory-derived density values. This figure was selected for presentation because it also contained subbottom lithographic information described in NED boring FD-93-K. Note the agreement between lithology and acoustic densities, i.e., high densities imply GPs and SPs. Acoustically derived density estimates using the determined calibration parameters showed excellent correlation with one possible exception which showed the acoustic data to be approximately 10 percent lower than the laboratory. In the other cases a match of about 5 percent was observed. It was interesting to note that, in all cases, laboratory densities in the subbottom upper $2.0 \mathrm{ft}$ were higher than those obtained acoustically in the Boston area.

\section{Delaware Atlantic Coast}

An acoustic impedance survey sponsored by the Philadelphia District was conducted along the Delaware Atlantic coast in the fall of 1992 as part of a feasibility study for shore protection solutions. This survey was selected for discussion because its objective was quite different from that of typical harbor dredging projects. The objective was to quantify, versus depth, bottom and subbottom sediments in terms of in situ density, mean grain size, and soil type to a depth of about $20 \mathrm{ft}$ below the ocean bottom, where possible, for a 3-mile-wide area between Cape Henlopen and Fenwick Island along the Delaware coast. The results were to provide initial estimates of the sediment characteristics for the purpose of defining the limits of available granular materials which could be used for a variety of purposes.

Geoacoustic calibration. The geoacoustic calibration was accomplished using sediment grain size versus acoustic impedance. Density values were computed based on empirical relationships for density and mean grain size, such as presented in Figure 11. Figure 59 presents a summary of the geoacoustic calibration of $3,500-\mathrm{Hz}$ pinger data with core information collected for the Delaware coast survey. Each figure includes a representative section of the reflection data in the vicinity of the core; plots of the acoustically derived estimates of impedance, density, and mean grain size versus depth; measured mean grain size versus depth; and the core lithology. Note that the format of these plots differs from the color versions presented previously, illustrating the fact that visual data presentation must be tailored to the needs of the user. In this case, shades of gray suffice to convey the message intended. Density predictions, based upon Hamilton's extensive database, can only be estimated to be within \pm 10 percent of in situ since no density measurements were conducted on the core samples. According to an assessment by Sjostrom and Leist (1994), had laboratory density analysis been available for calibration purposes, these results could likely have been improved to possibly 5 to 7 percent. Estimates of mean grain size, especially for the surface sediments, are within about $\pm 0.5 \phi$, based upon actual laboratory analysis. This is quite 
encouraging since acoustic response characteristics of sediments as related to mean grain size tend to exhibit more scatter in the data.

Example sediment profile. After calibration and verification, the acoustic reflection data are processed to characterize the sediment properties throughout the survey area. An example presentation of the distributions of computed sediment densities and mean grain sizes within the project area is given in Figure 60 as a 2-D profile illustrating the primary bottom and subbottom interfaces and differing zones of sediment material. The profile illustrates the depth to a particular interface in feet mean lower low water (mllw), representative sediment properties, and corresponding location along the survey line. An area of primarily granular sediments is identified near the southern end of the survey line. Two relic-incised channels filled with lagoonal muds and silts, and reworked clayey sands, are detected. The labelled black dots at the top of each profile denote the survey track line and direction. Each dot also represents the beginning of every seismic data file recorded in order to give an indication of the data coverage along each line and assist in correlating the raw data and interpreted results. The associated label represents the data file number and correlates with the data file number on the color-coded subbottom reflection records. Lines of latitude are displayed on each profile. The sediment profiles have been completely adjusted for horizontal position (effects of boat speed) and survey heading. All profiles are presented heading in a southerly direction, allowing consistency in the data interpretation. Actual boat heading is in the direction of increasing data file numbers on the profiles. Finally, all cores collected along the survey line are identified and core logs plotted directly on the profiles.

\section{Oakland Harbor}

An abbreviated AI survey of Oakland Harbor was conducted in conjunction with a conventional subbottom survey which was ongoing as a reimbursable project by WES for the San Francisco District. The objective of the survey was to differentiate "young" bay muds from more competent sand sediments for expeditious environmental testing. Circumstances related to the ongoing survey provided a "target of opportunity" to simultaneously collect data in the AI format. Limited DRP funds were allocated for this study to evaluate the AI concept in a highly complex geologic environment. Figures 61-64 show a comparison of the geoacoustic data and boring lithology. Of particular interest on most of the density plots (which continue to evolve in format according to sponsor request) is a plot labeled "sign acoustic core." These data are output from a newly developed software program designed to automatically determine the polarity of the reflection coefficient. It is included for comparison with the "standard" method of acoustic core determinations. This new method for assessing correct polarity appears to work reasonably well, but comparisons will continue to be monitored until sufficient detailed analytical verification has been accomplished. Figure 65 presents a typical sediment profile from the Oakland Harbor Inner Tangent. The sediment profile developed using the AI method displays a layered sediment environment consisting of muds, clays, and 
silts overlaying the more competent sands. Figure 66 is a color-coded (by material type) 3-D visualization of the surveyed area.

\section{Statistical Assessment}

Figure 67 shows the correlation of laboratory-measured densities from core samples with acoustically derived estimates of density at those locations. It must be emphasized that most of the samples are disturbed samples collected using vibracore methods which can result in possible errors with the laboratory measurements. Even so, the 95-percent confidence interval (i.e., 95 percent of the data fall within this boundary) is $\pm 0.19 \mathrm{~g} / \mathrm{cm}^{3}$. The standard error estimate of acoustic density predictions as compared to the "perfect agreement" is $\pm 0.10 \mathrm{~g} / \mathrm{cm}^{3}$. In other words, data verify the fact that density can be acoustically derived to within \pm 10 percent of in situ conditions. 


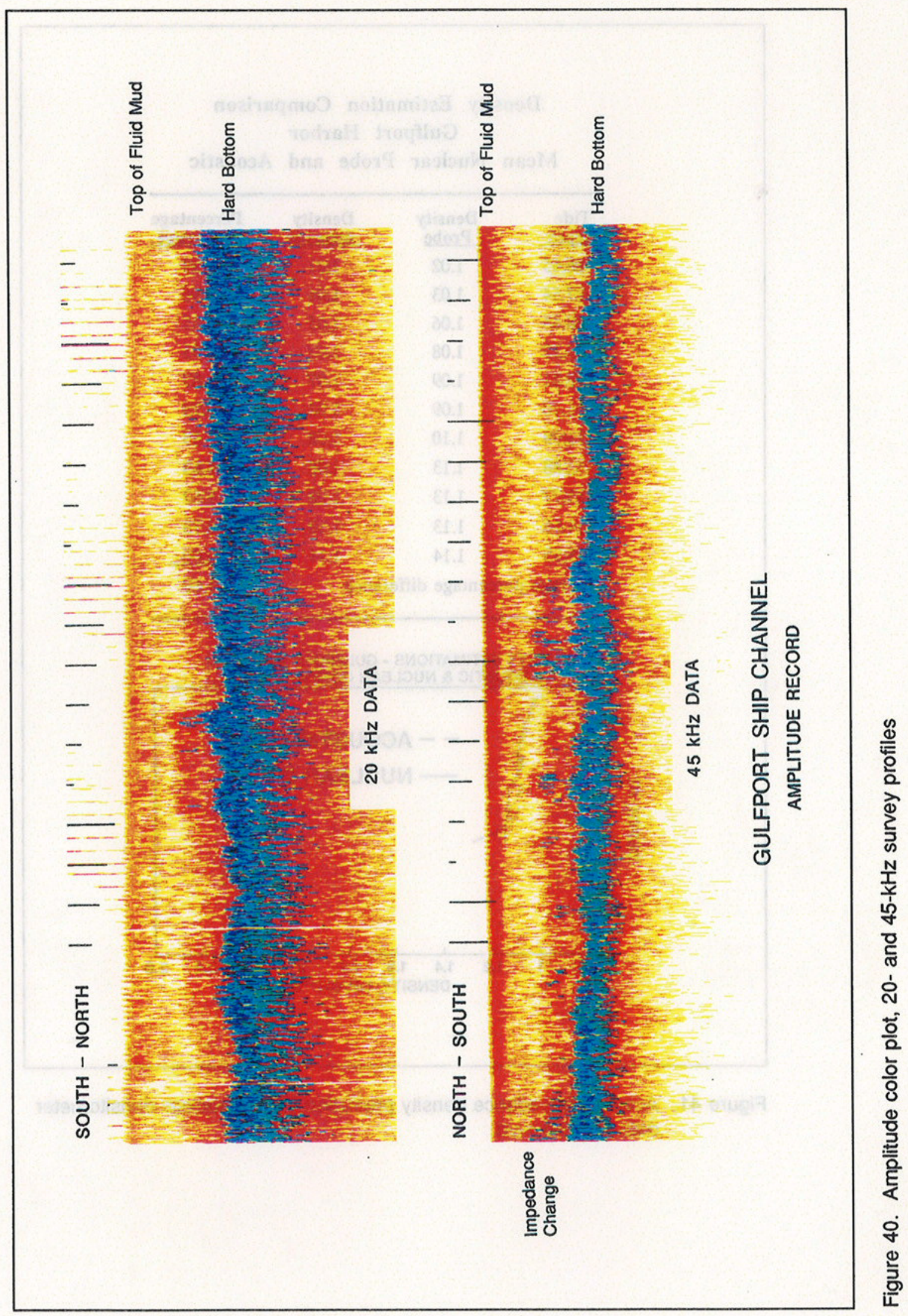




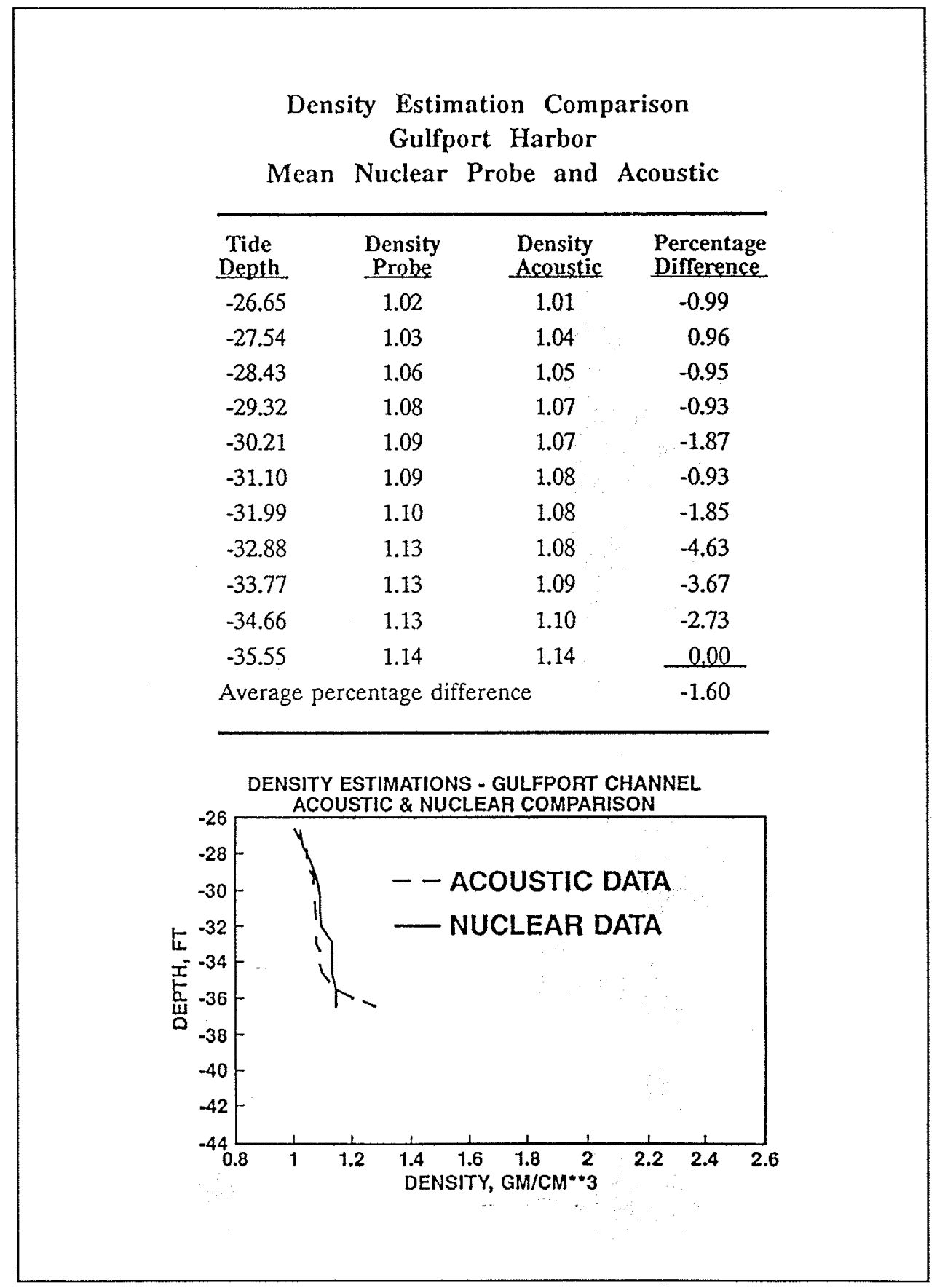

Figure 41. Acoustic impedance density prediction versus nuclear densitometer data for fluid mud 


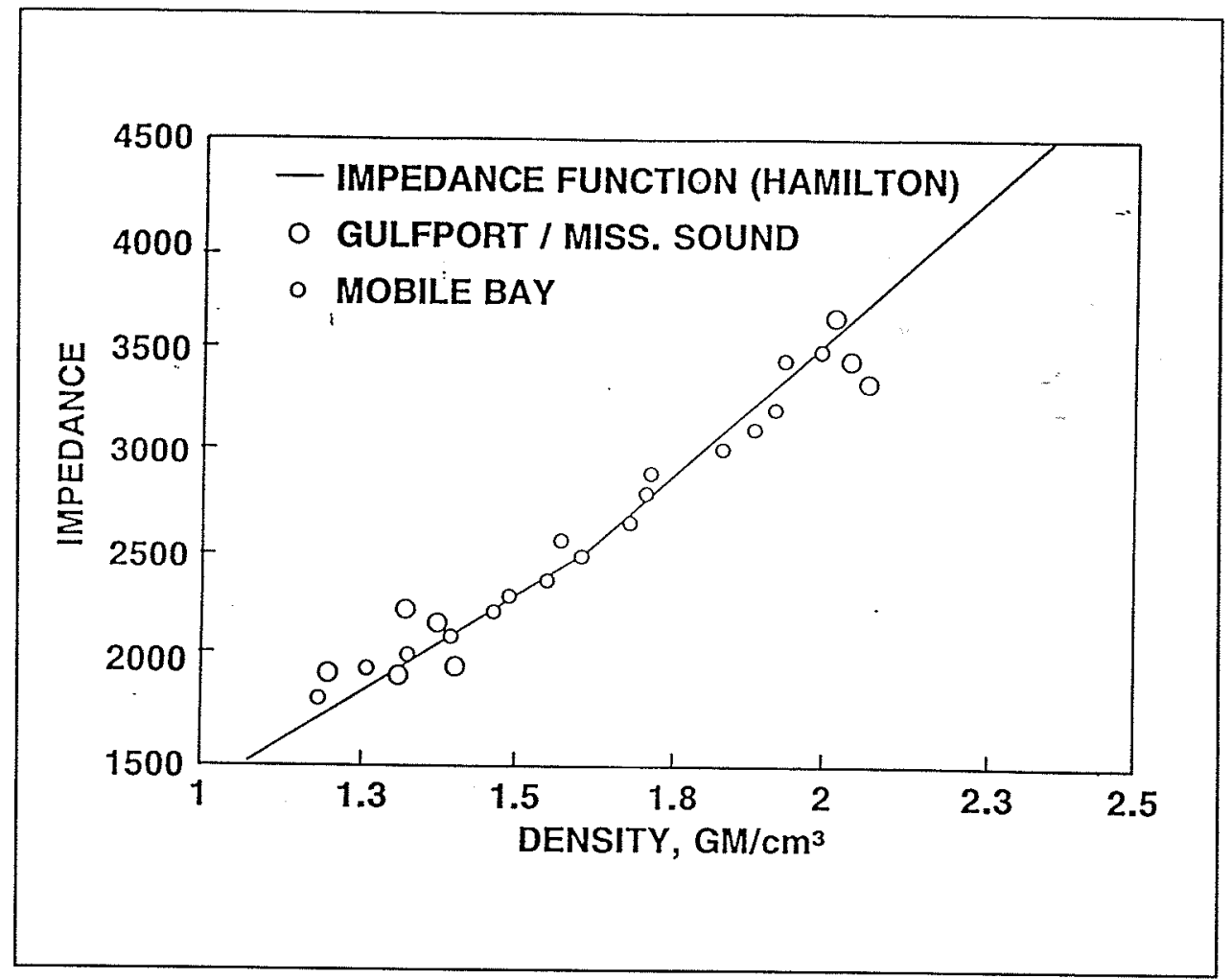

Figure 42. Hamilton's impedance function (modified by Caulfield (1992a)) with Gulfport and Mobile data superimposed 
Density Estimations - Mobile Bay

Acoustic Core Versus Core Logs

Line MOB7

\begin{tabular}{cccc}
\hline $\begin{array}{c}\text { Depth } \\
\text { Below } \\
\text { Bottom }\end{array}$ & Acoustic & Core & $\begin{array}{c}\text { Percentage } \\
\text { Difference }\end{array}$ \\
-1.83 & 1.51 & 1.51 & 0.00 \\
-3.66 & 1.51 & 1.51 & 0.00 \\
-4.60 & 1.54 & 1.51 & -1.95 \\
-7.34 & 1.54 & 1.51 & -1.95 \\
-9.18 & 1.54 & 1.56 & 1.30 \\
-11.02 & 1.54 & 1.56 & 1.30 \\
-12.86 & 1.54 & 1.56 & 1.30 \\
-14.70 & 1.52 & 1.47 & -3.29 \\
-16.54 & 1.52 & 1.47 & -3.29 \\
-18.37 & 1.48 & 1.47 & -0.68 \\
-20.20 & 1.48 & 1.49 & 0.68 \\
-22.03 & 1.48 & 1.49 & 0.68 \\
-23.87 & 1.52 & 1.49 & -1.97 \\
-25.72 & 1.60 & 1.57 & -1.88 \\
-27.59 & 1.62 & 1.57 & -3.09 \\
Average percentage difference & & -0.86 \\
& & & \\
\hline
\end{tabular}

DENSITY ESTIMATIONS - MOBILE BAY

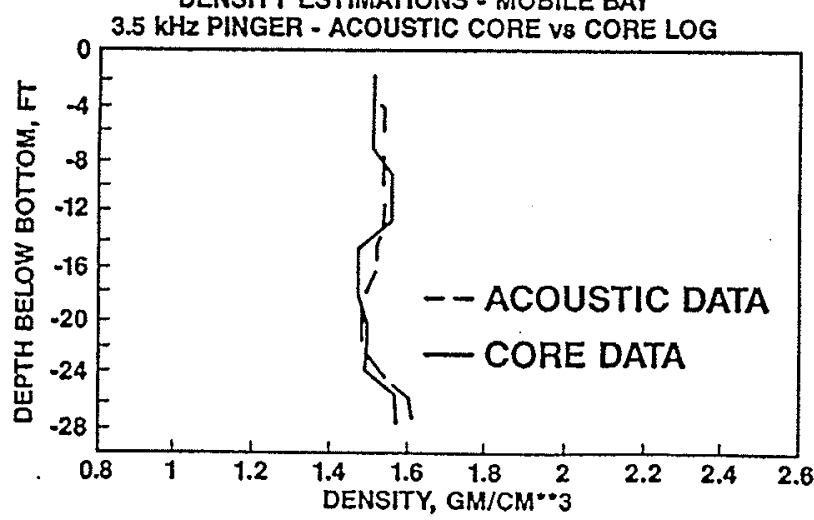

Figure 43. Acoustic predictions versus core data - Mobile 

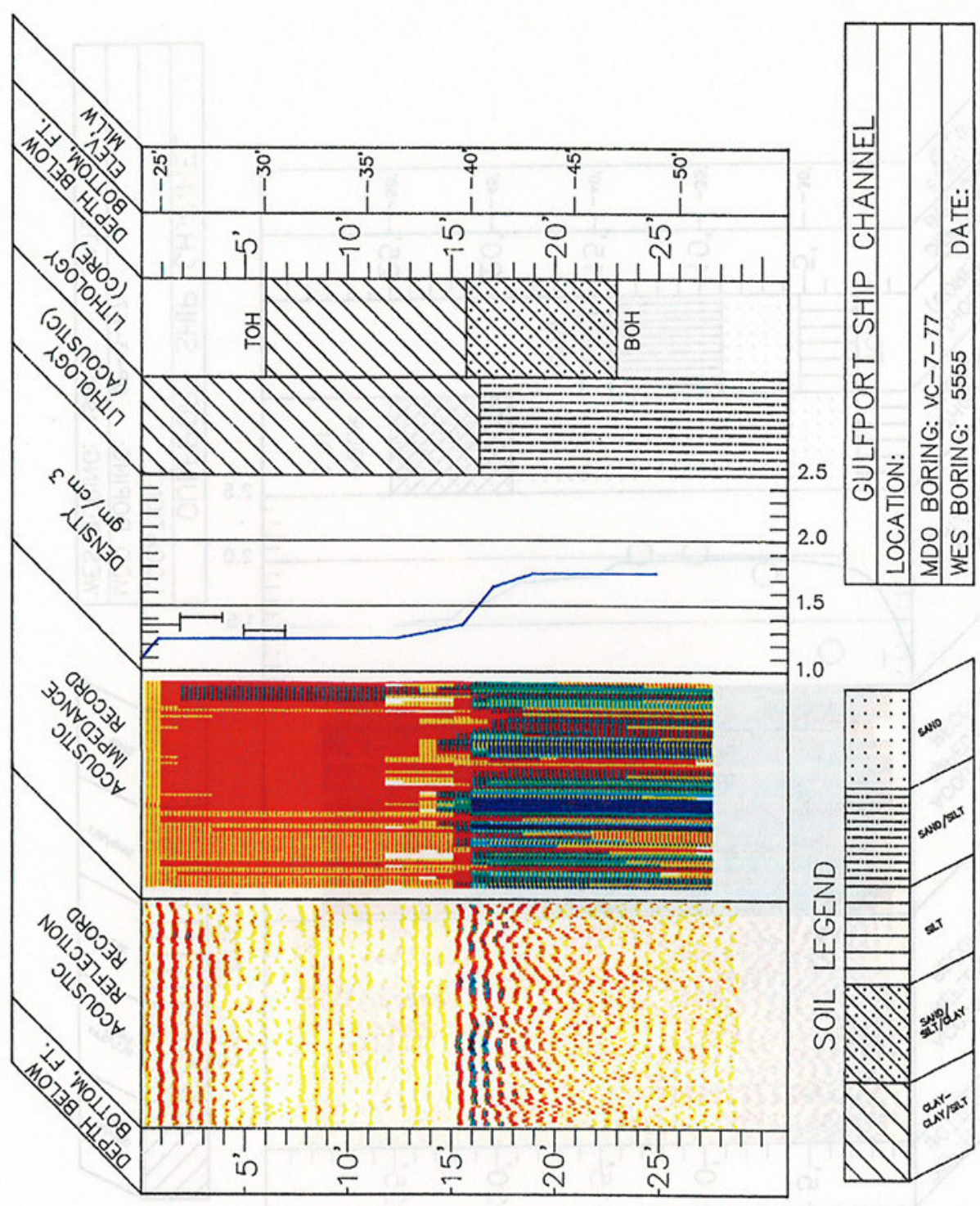

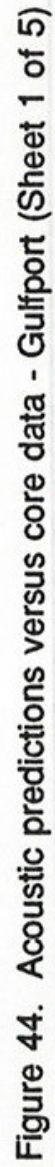




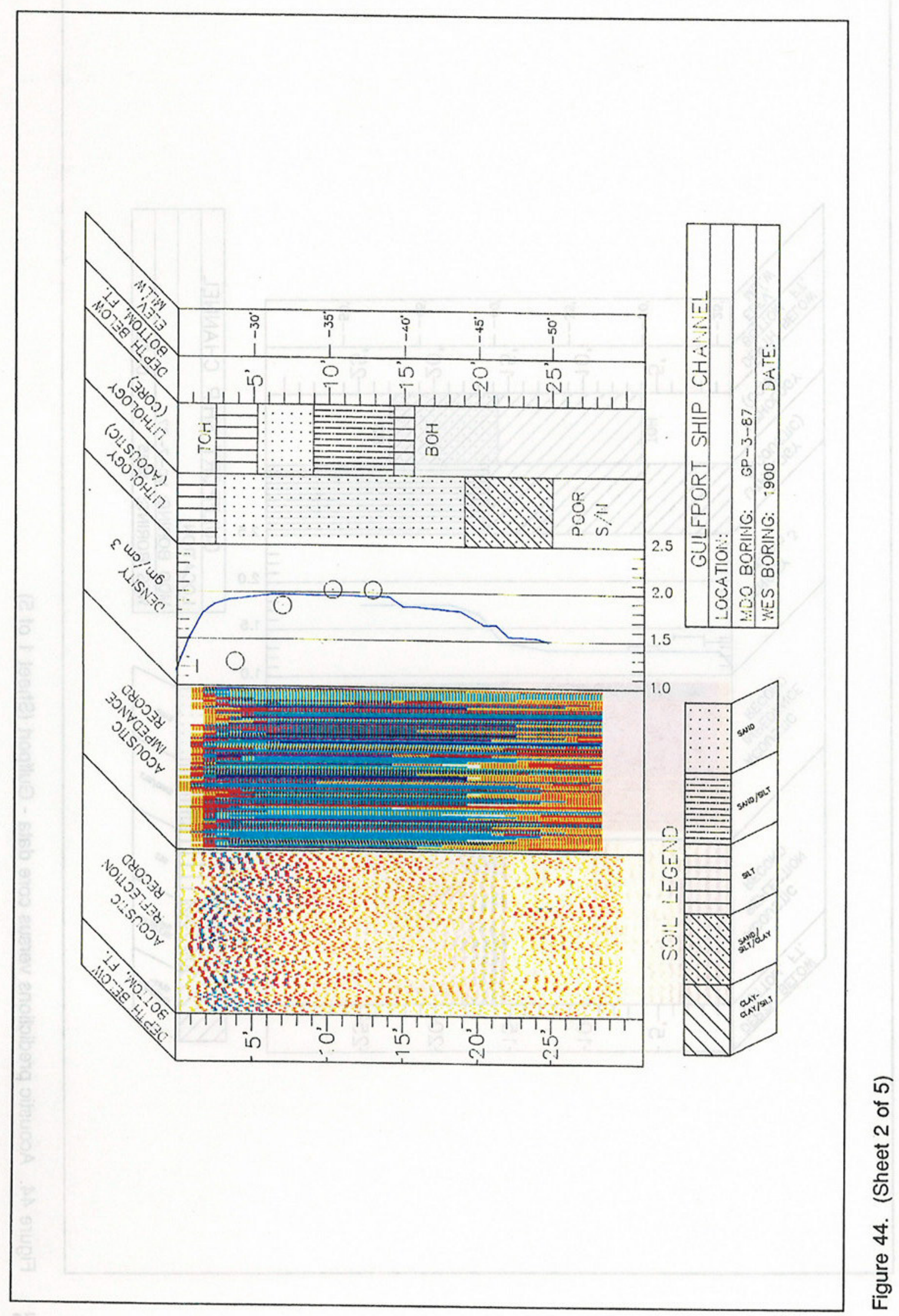




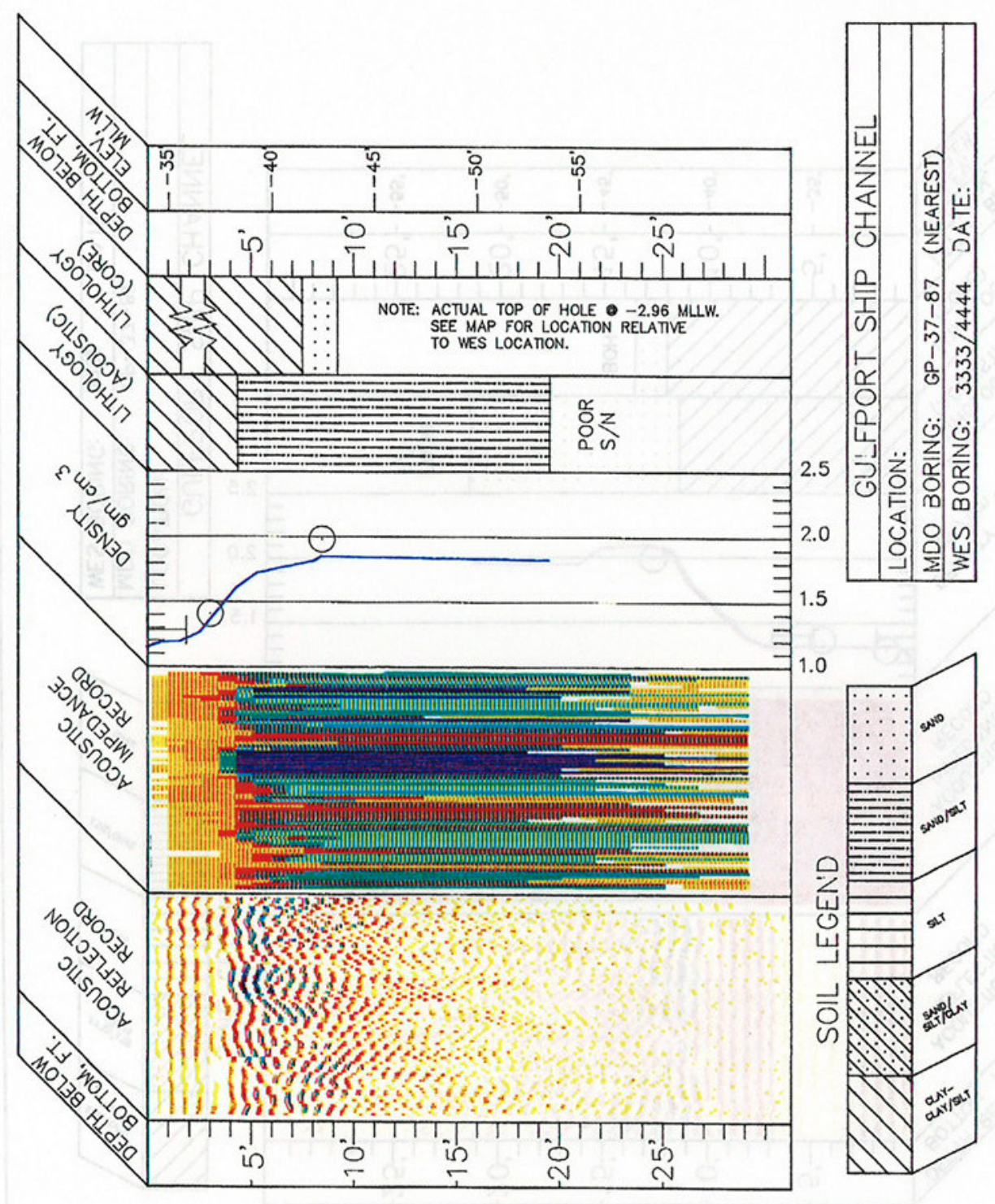




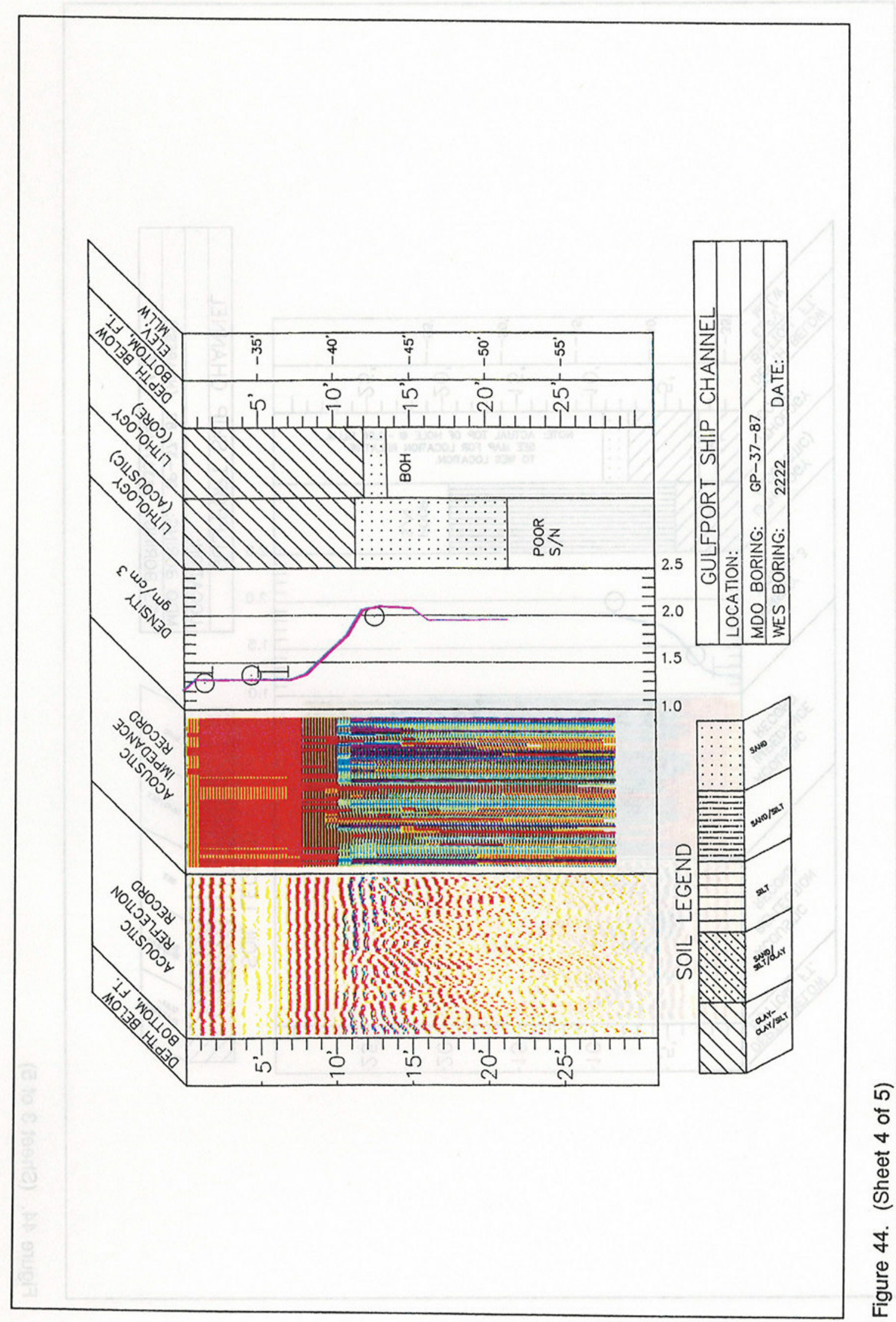




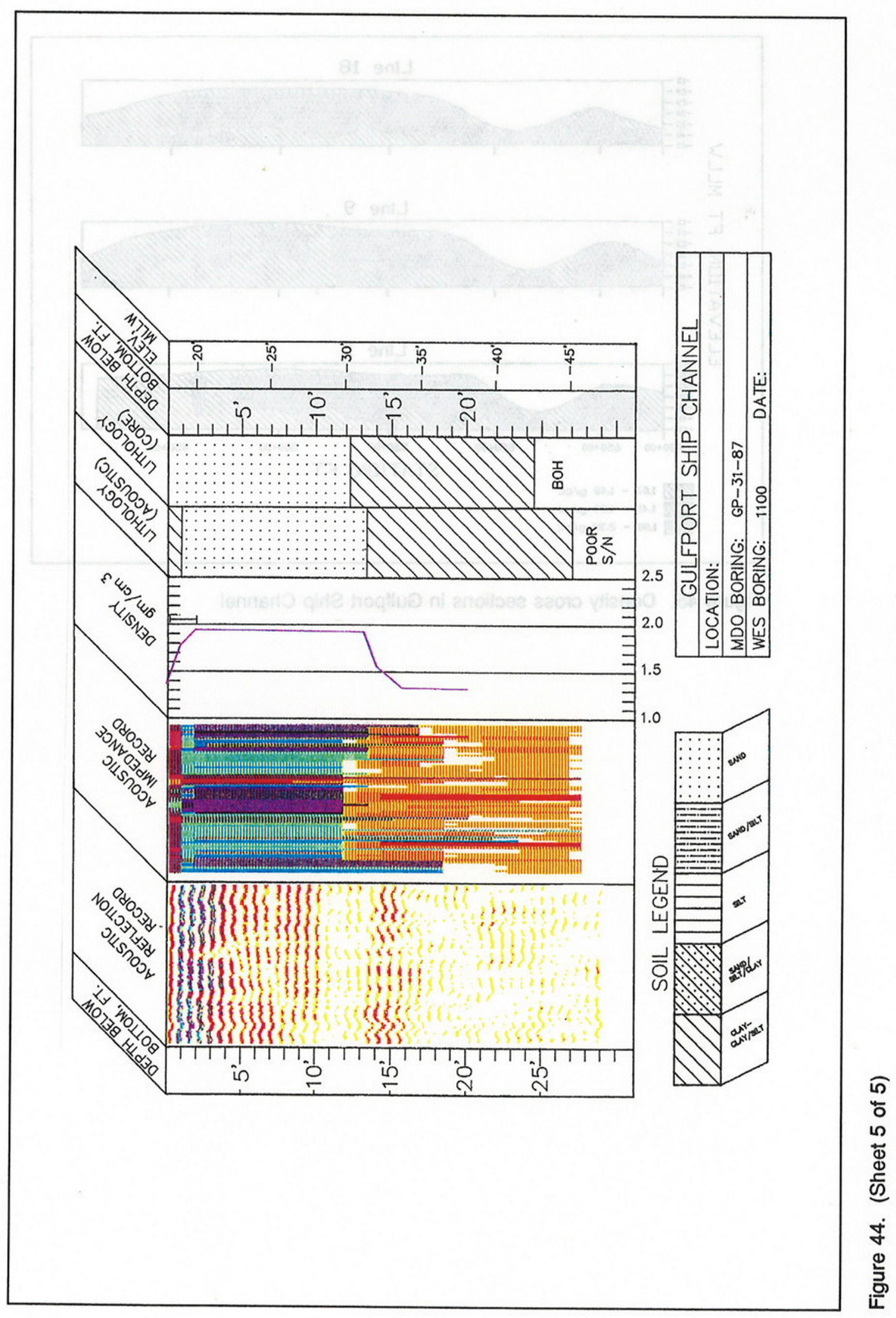




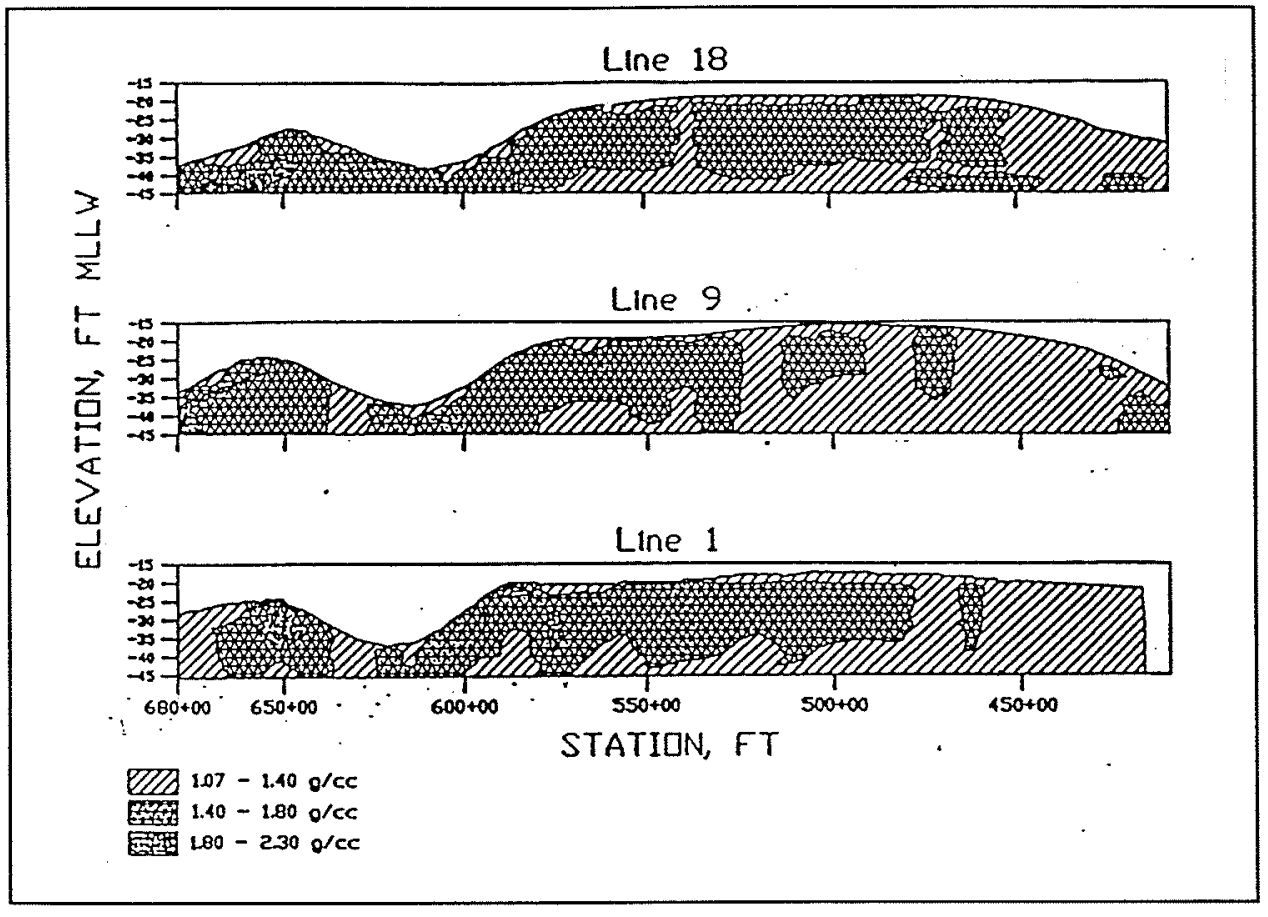

Figure 45. Density cross sections in Gulfport Ship Channel 


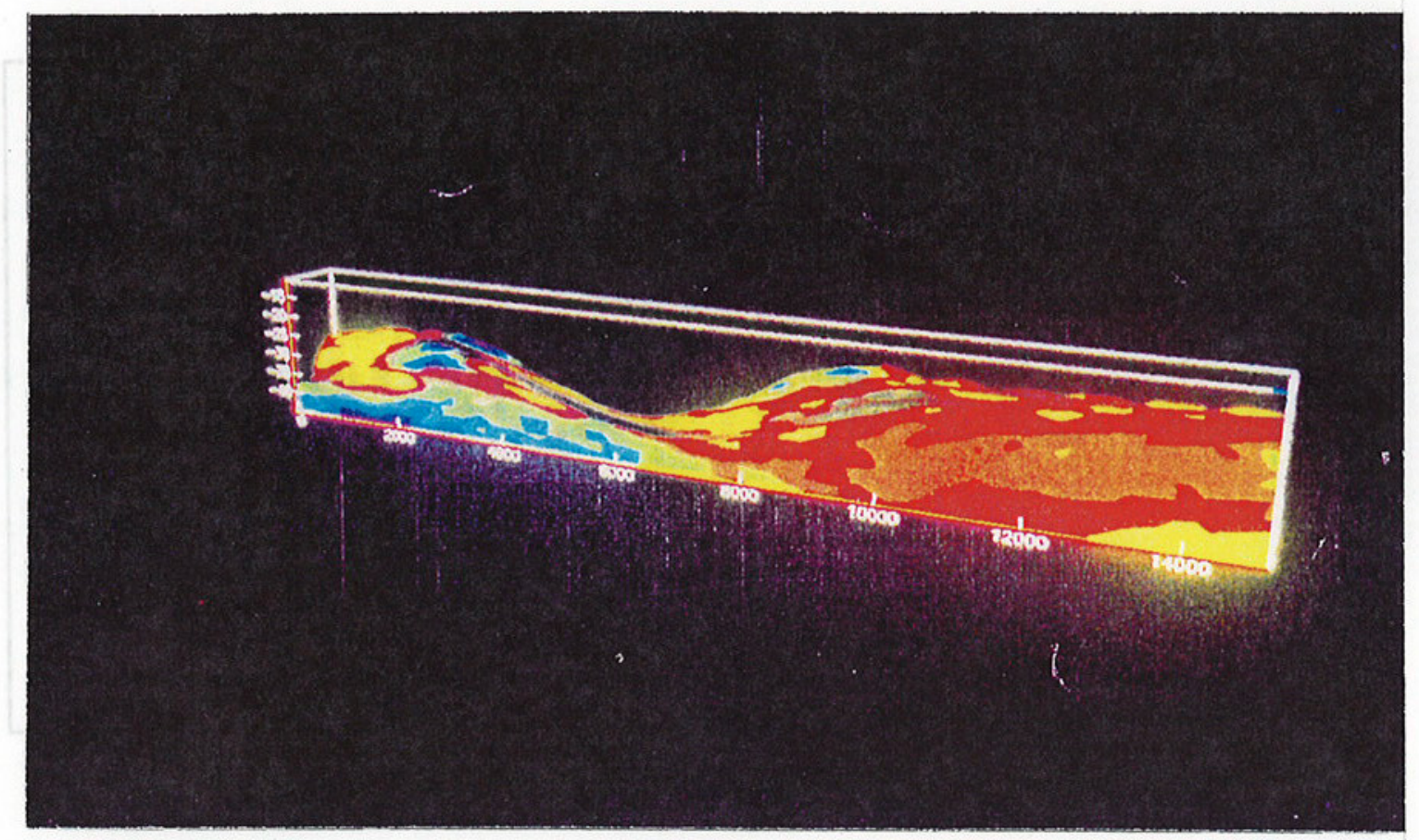

Figure 46. 3-D view of a section of Gulfport Ship Channel

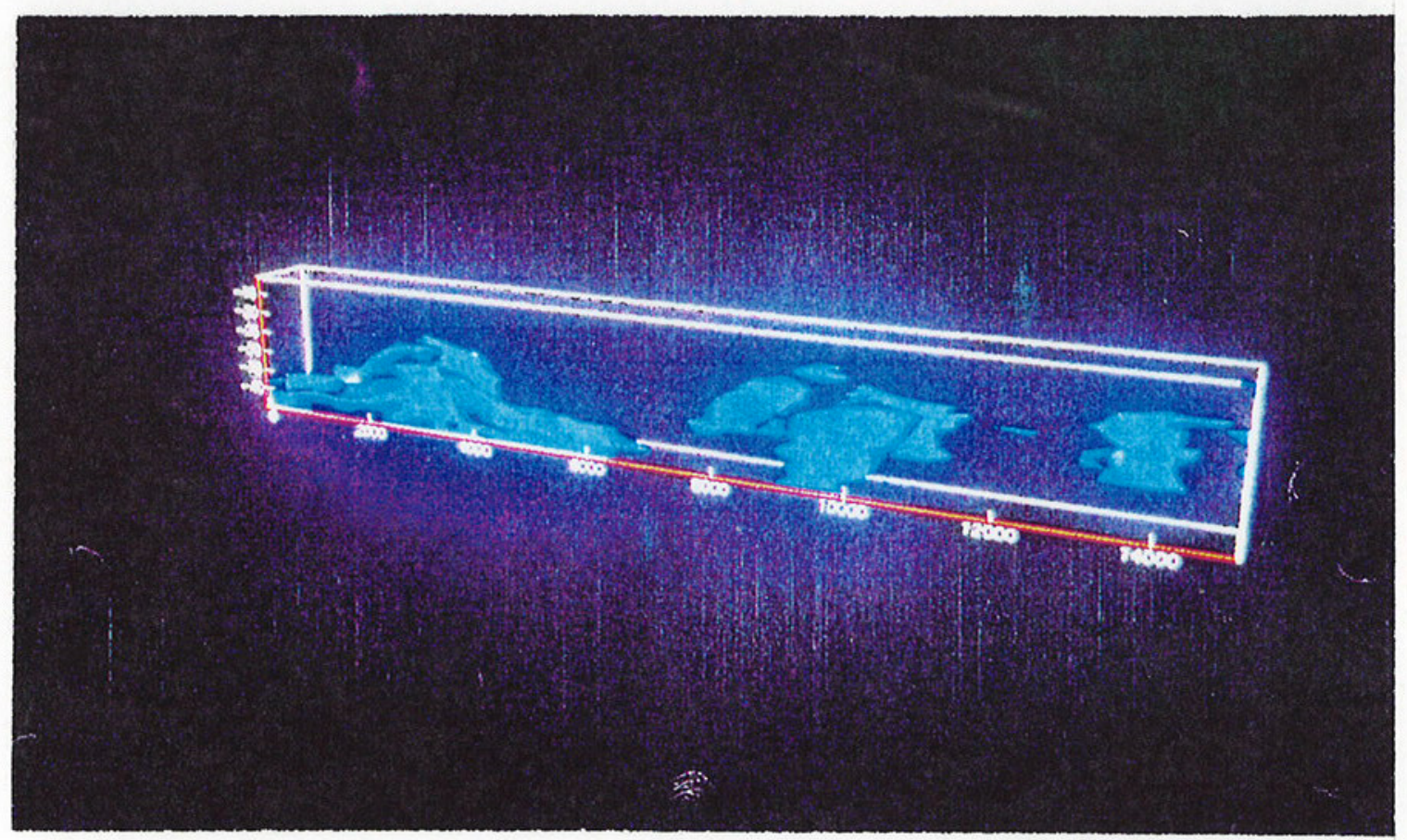

Figure 47. Volumetric calculations for sand in a section of Gulfport Ship Channel 


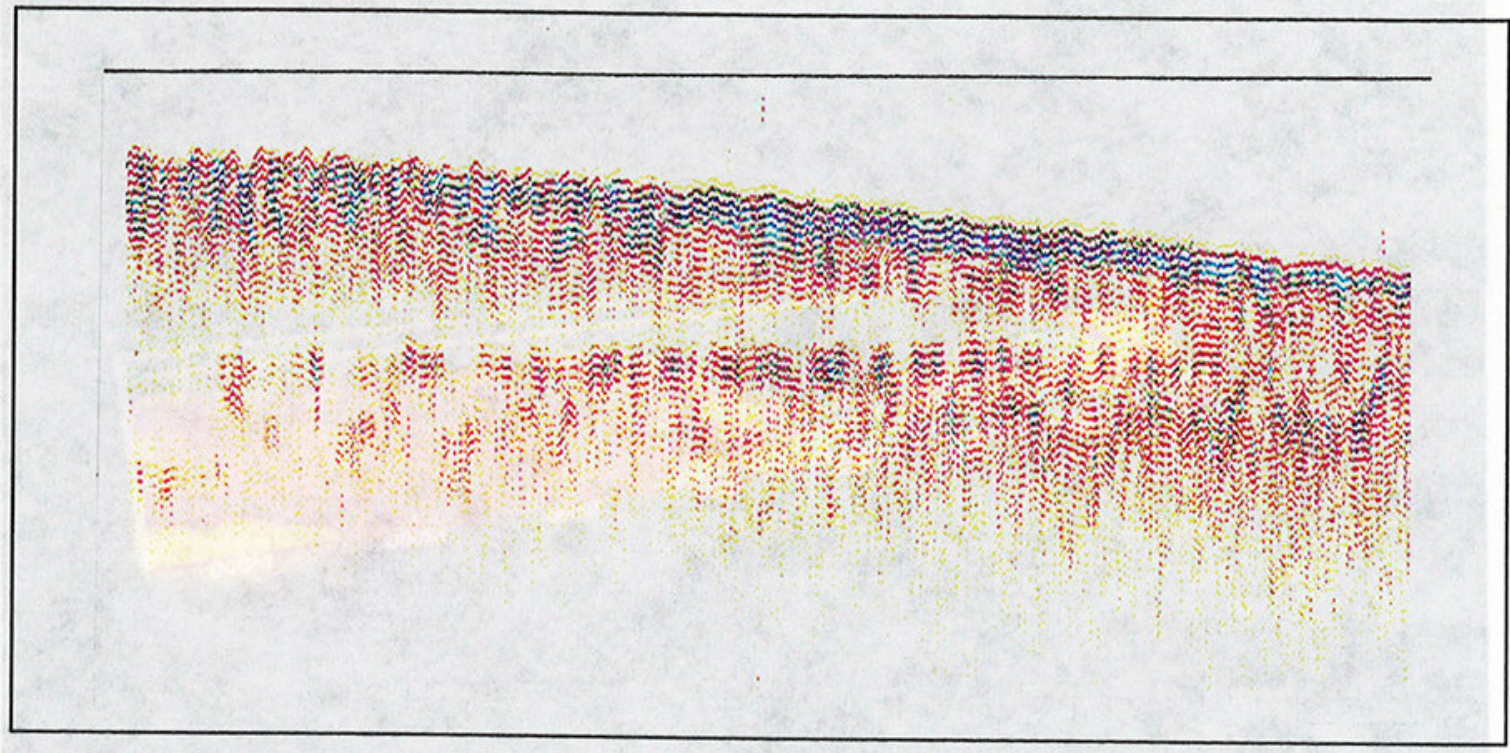

Figure 48. Pinger $(3.5 \mathrm{kHz})$ amplitude cross section, Galveston Ship Channel 


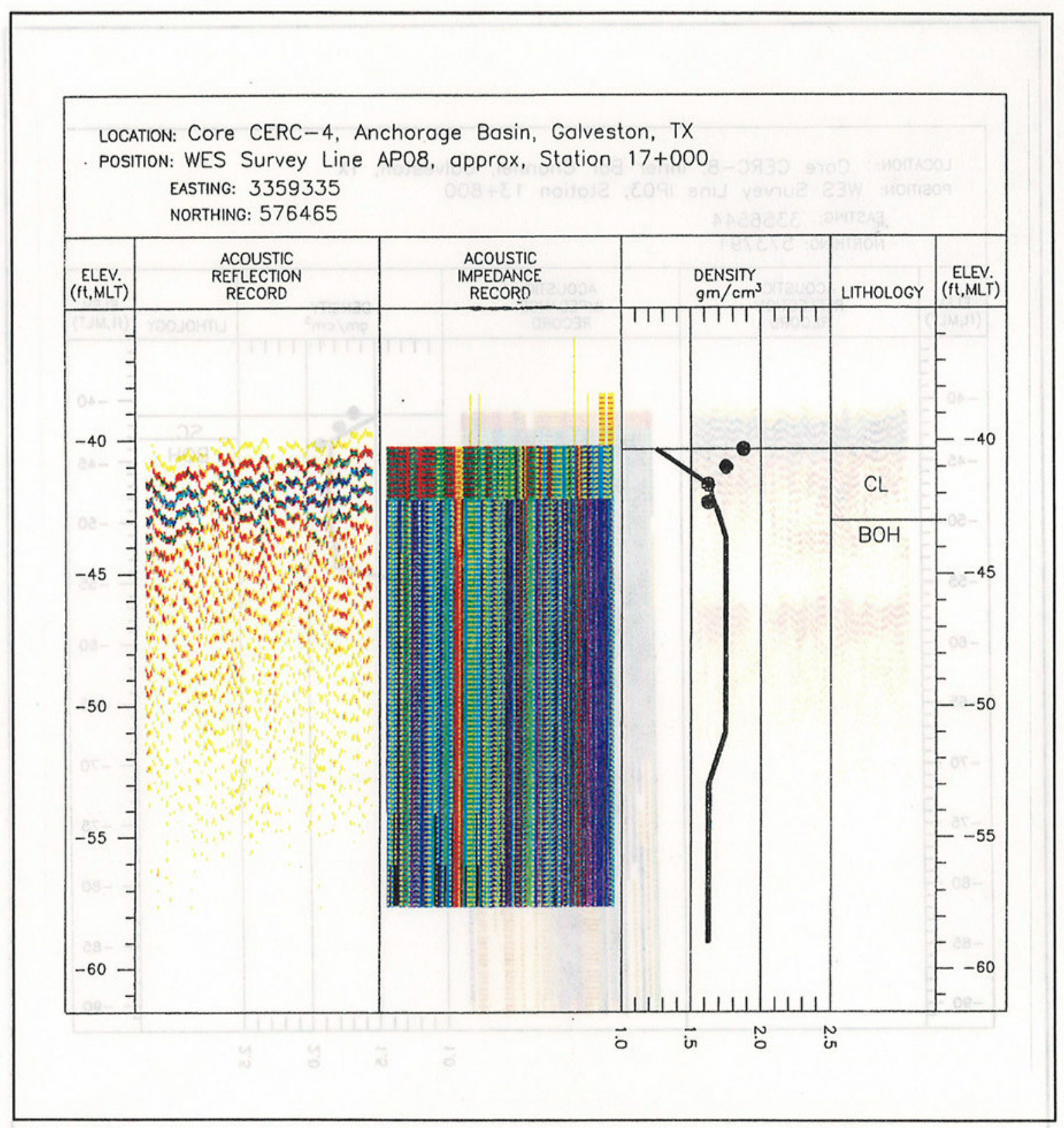

Figure 49. Bottom surface calibration at WES Core CERC-4, Anchorage Basin 


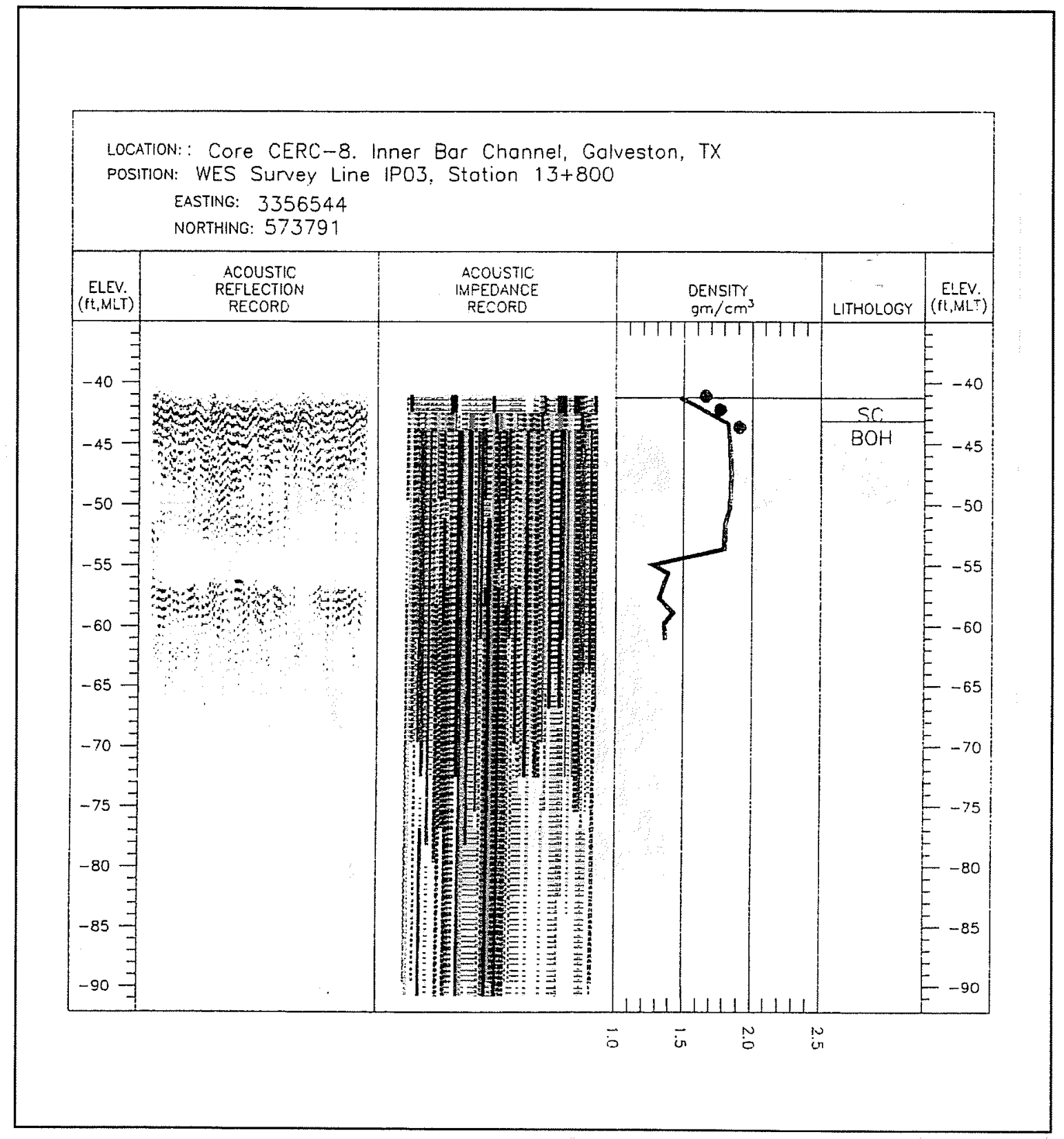

Figure 50. Bottom surface calibration at WES Core CERC-8, Inner Bar Channel 


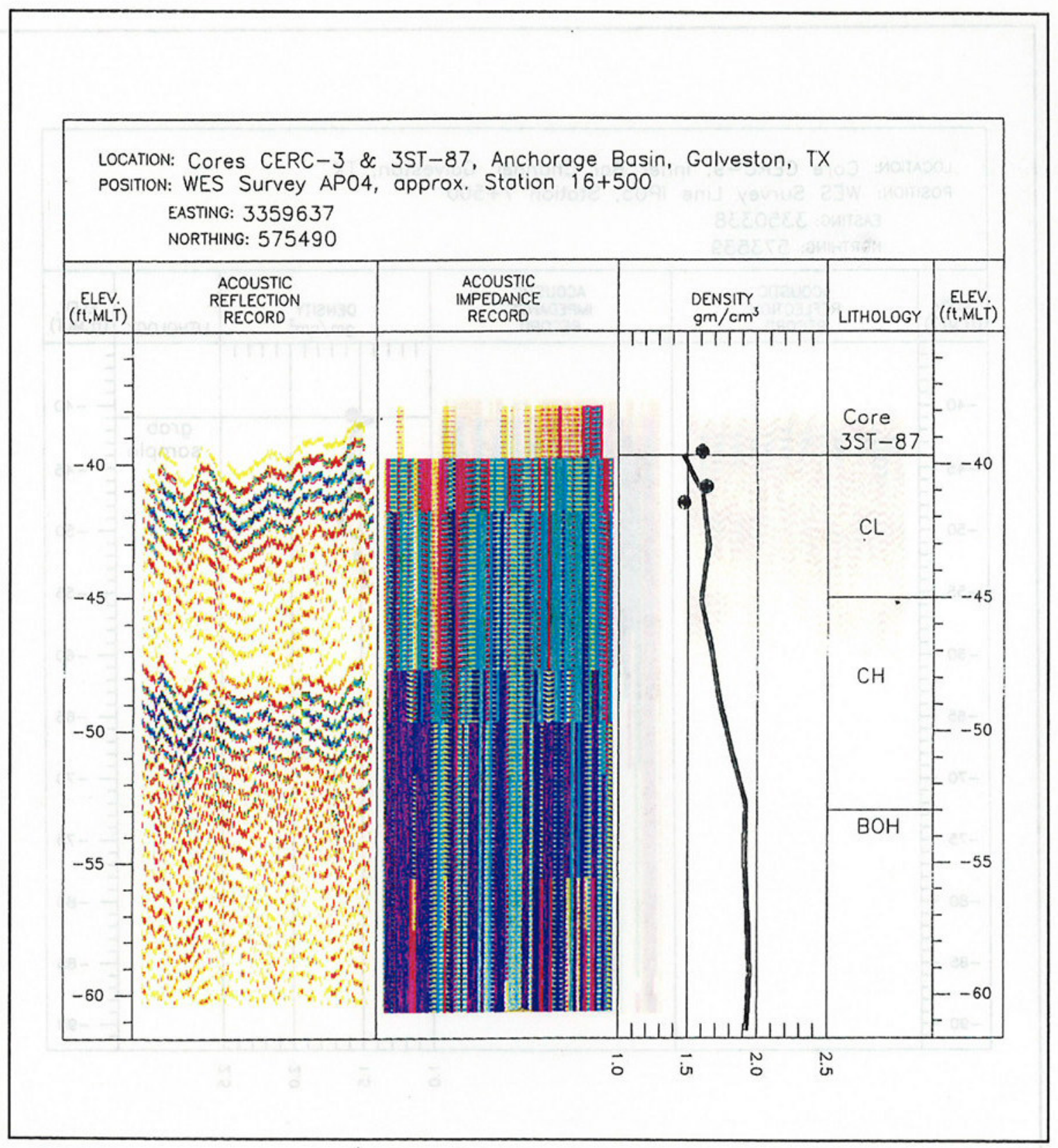

Figure 51. Subbottom sediment calibration at Cores CERC-3 and 3ST-87, Anchorage Basin 


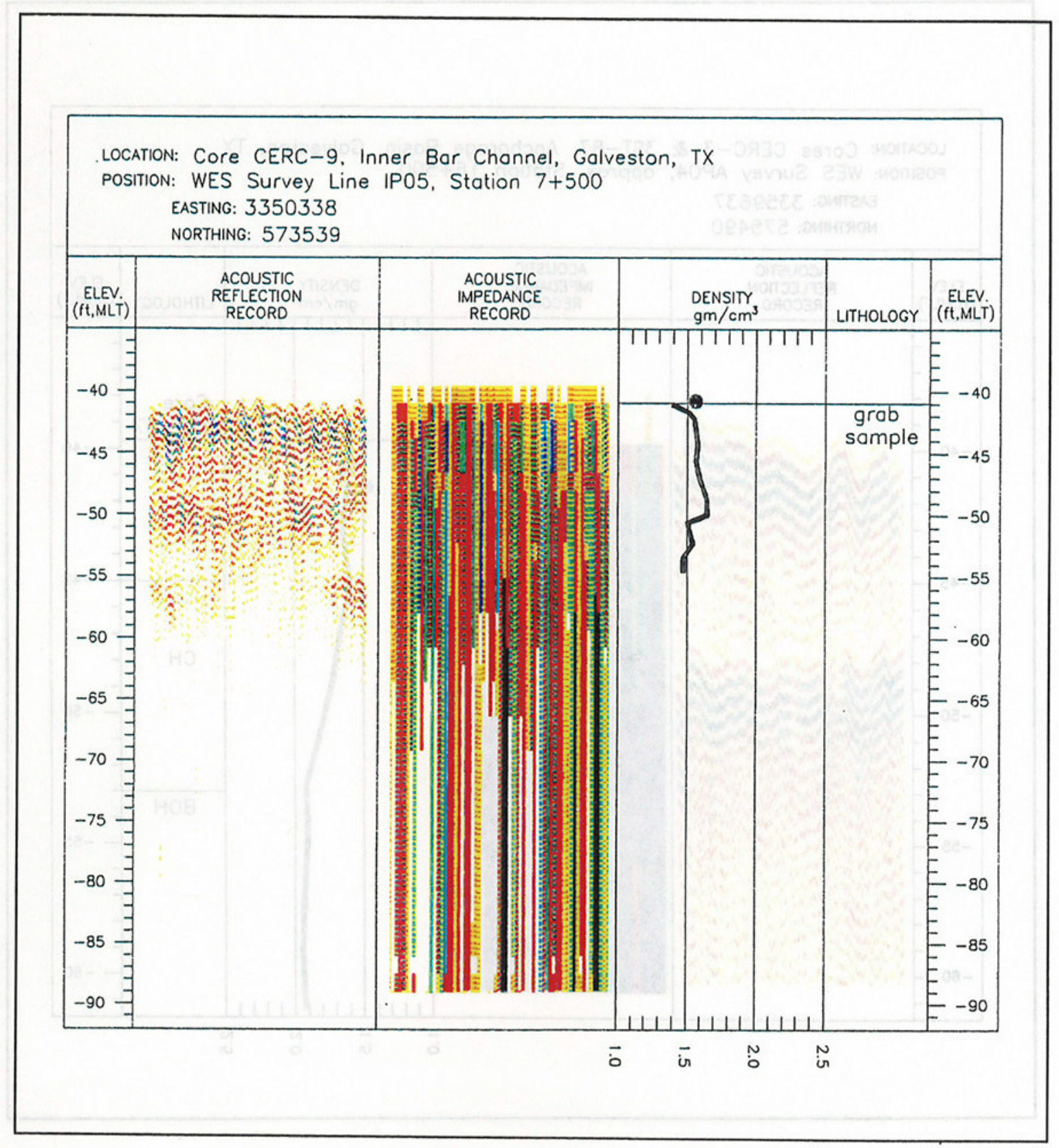

Figure 52. Check calibration at Core CERC-9, Inner Bar Channel 


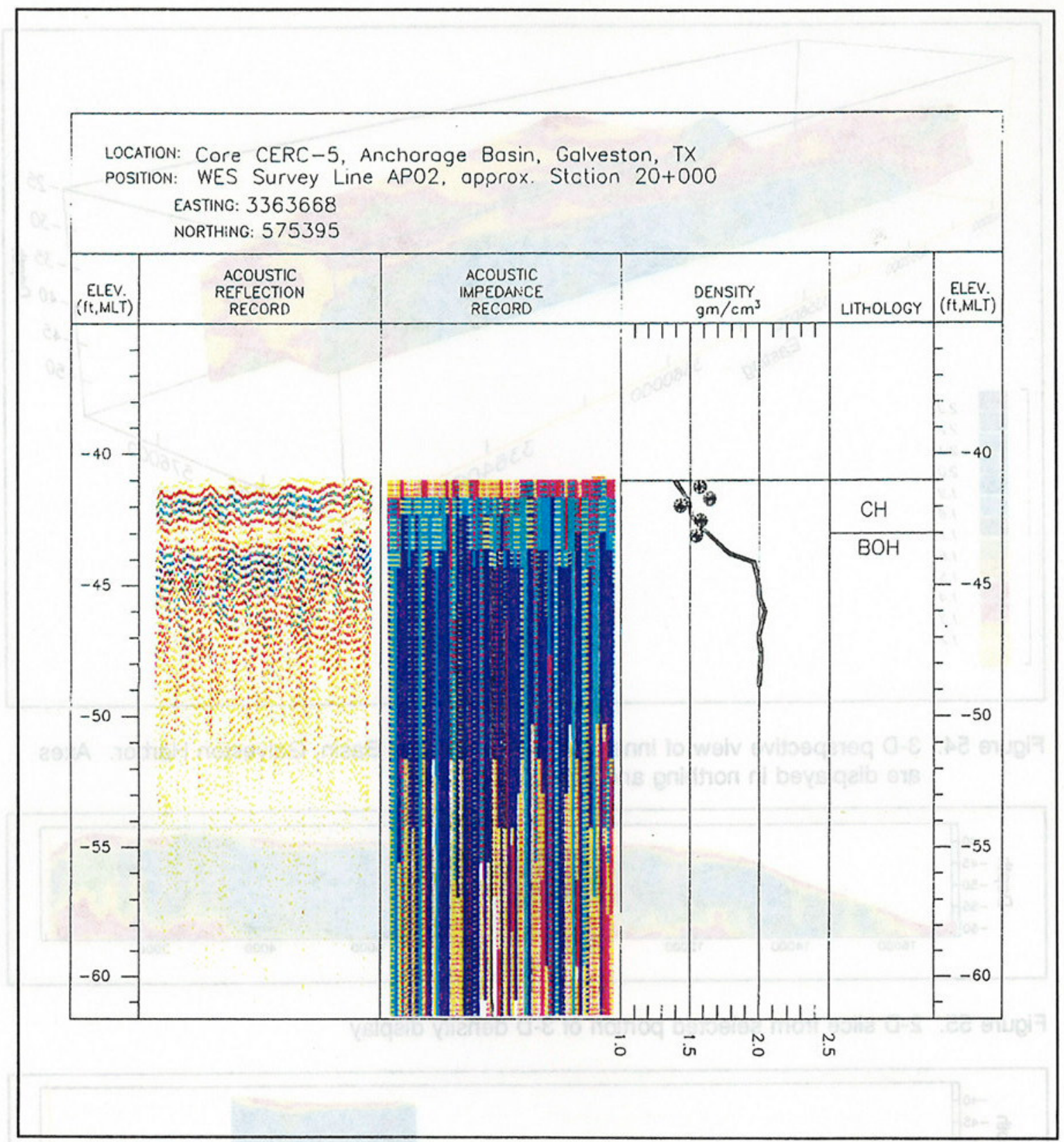

Figure 53. Check calibration at Core CERC-5, Anchorage Basin 


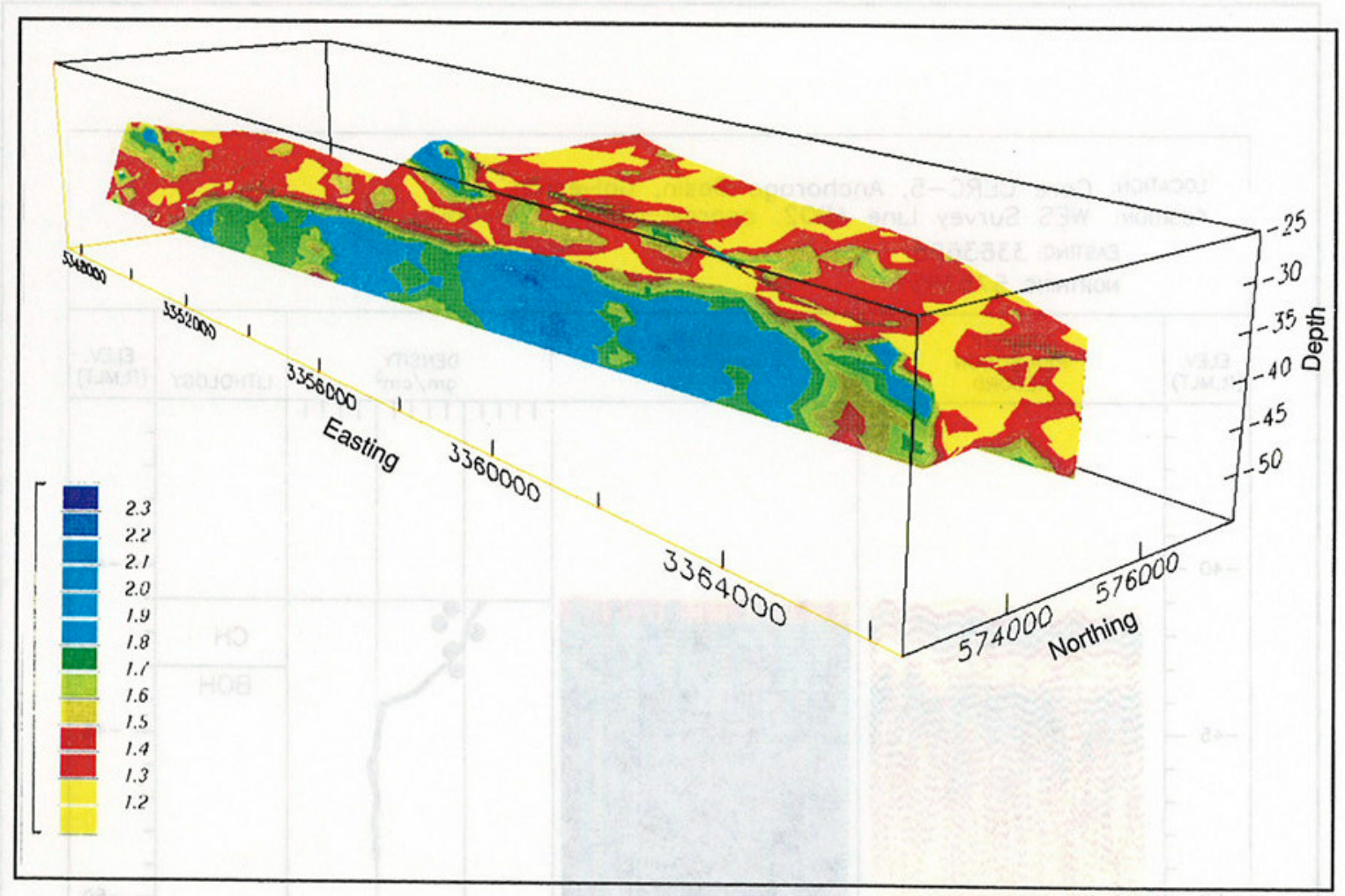

Figure 54. 3-D perspective view of inner bar and Anchorage Basin, Galveston Harbor. Axes are displayed in northing and easting coordinates

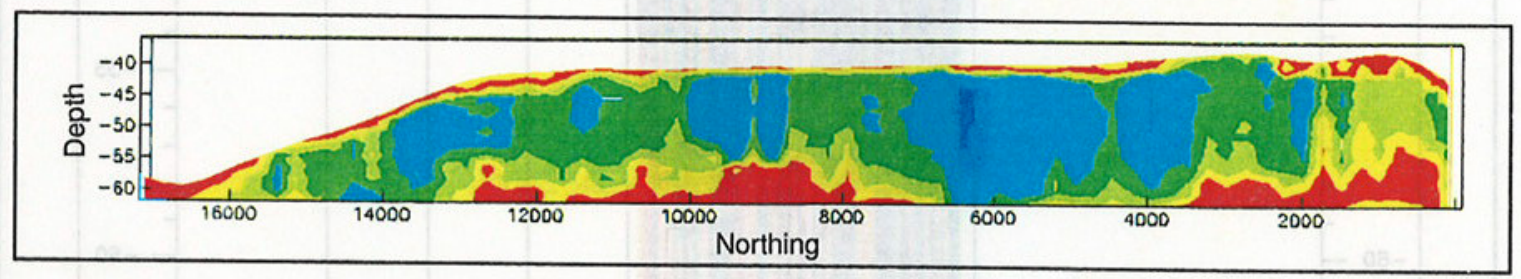

Figure 55. 2-D slice from selected portion of 3-D density display

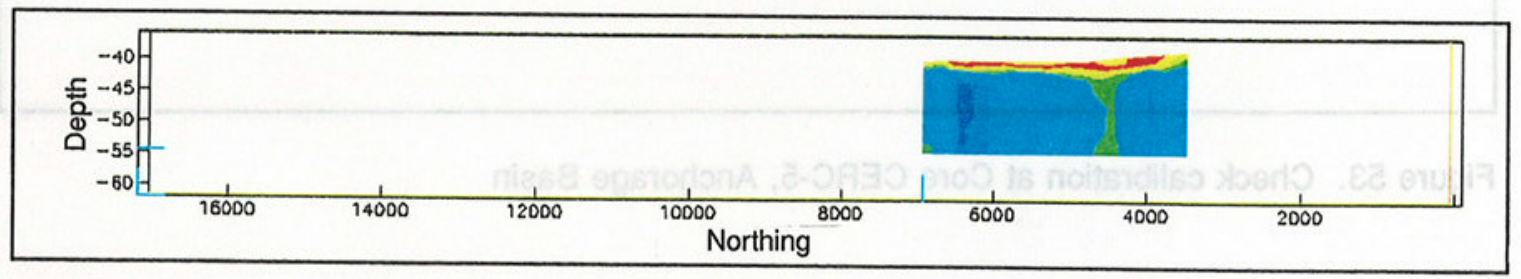

Figure 56. 2-D profile showing area of interest within depth and location boundaries

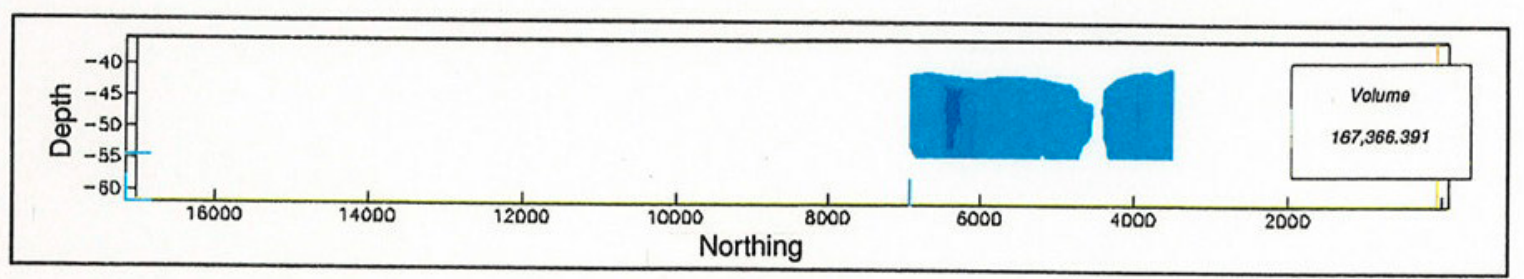

Figure 57. 2-D profile model showing only material $>1.7 \mathrm{~g} / \mathrm{cm}^{3}$ density within area of interest 


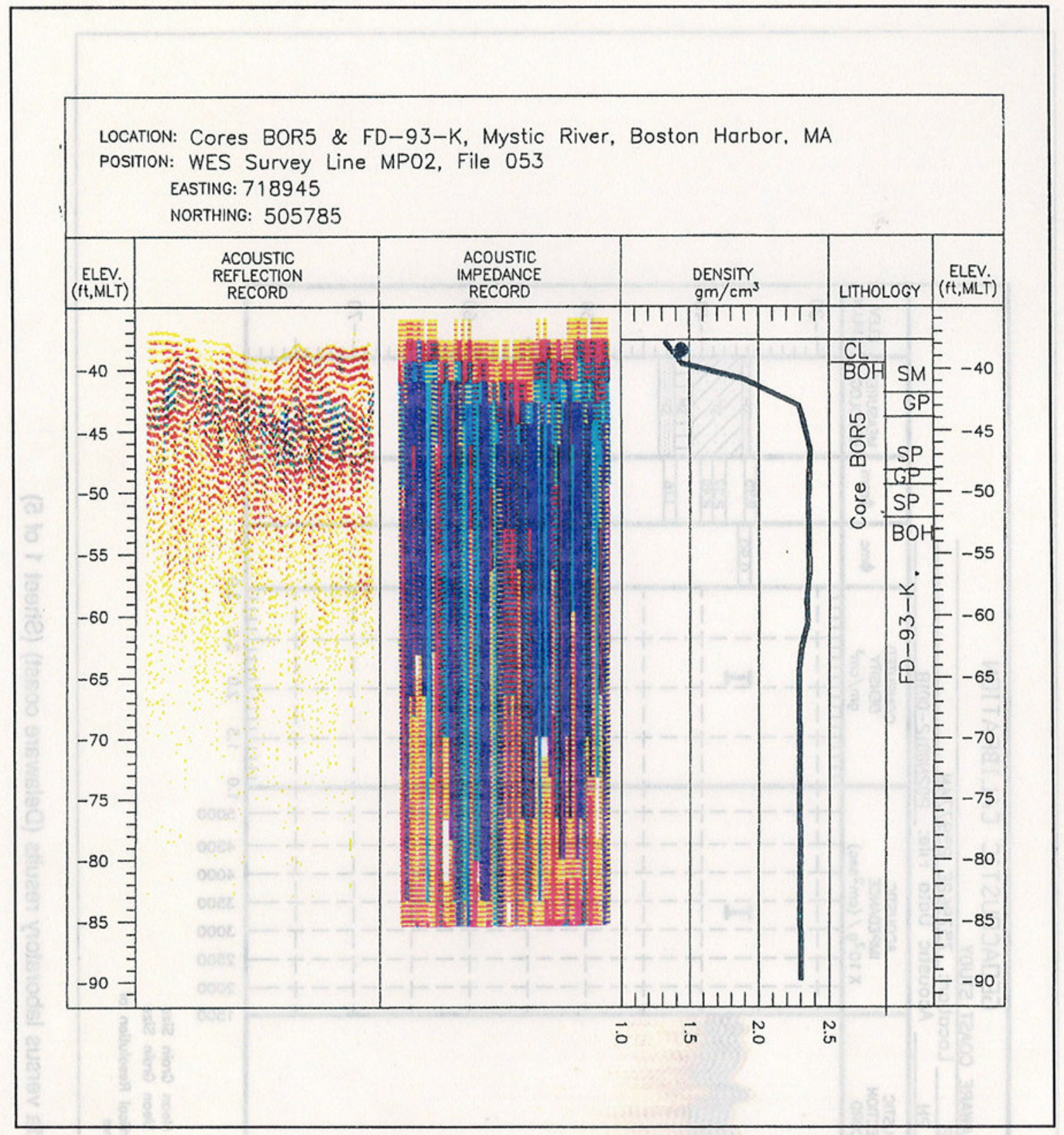

Figure 58. Typical calibration comparison display of acoustic data versus laboratory density and lithographics (Boston Harbor) 


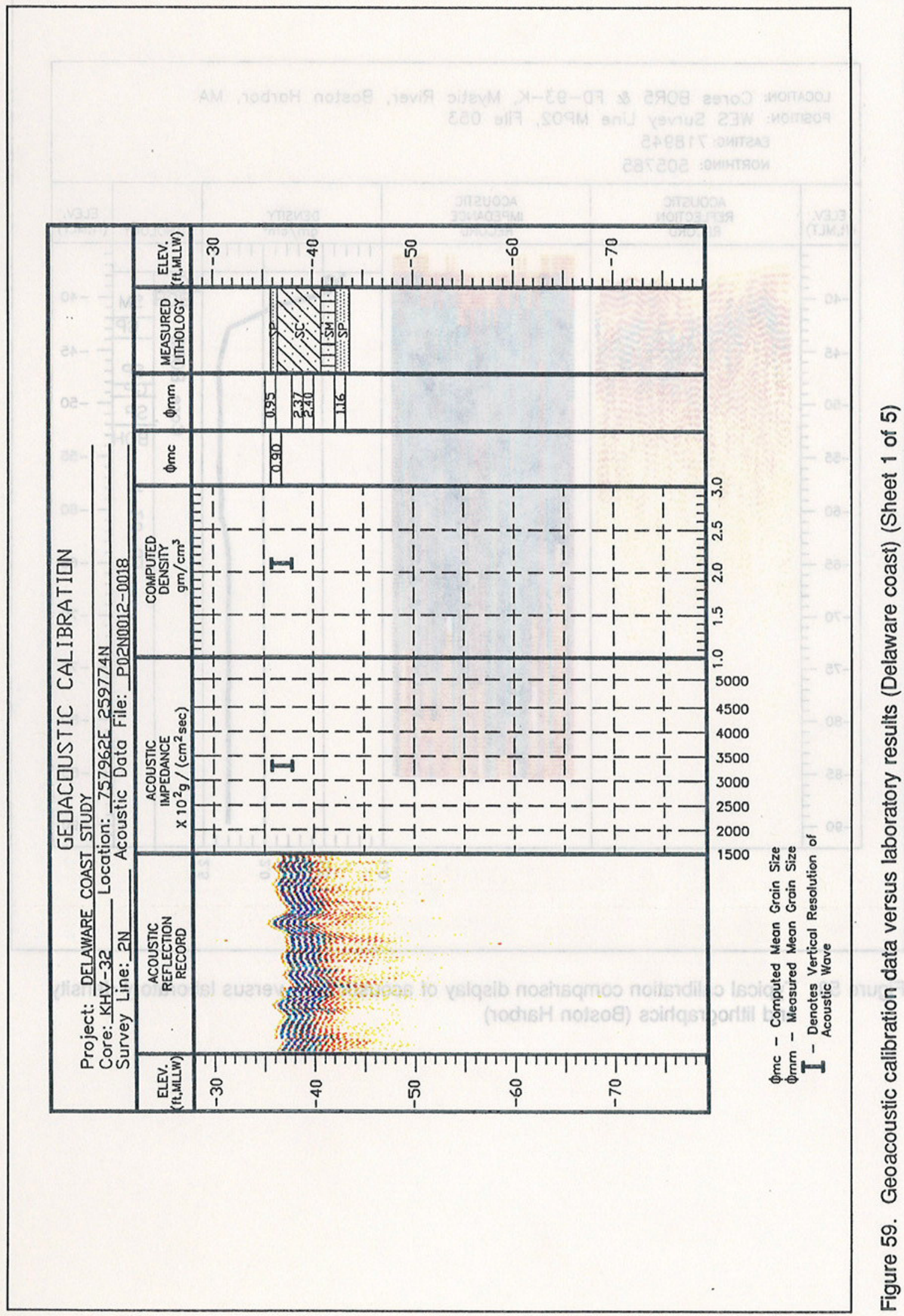




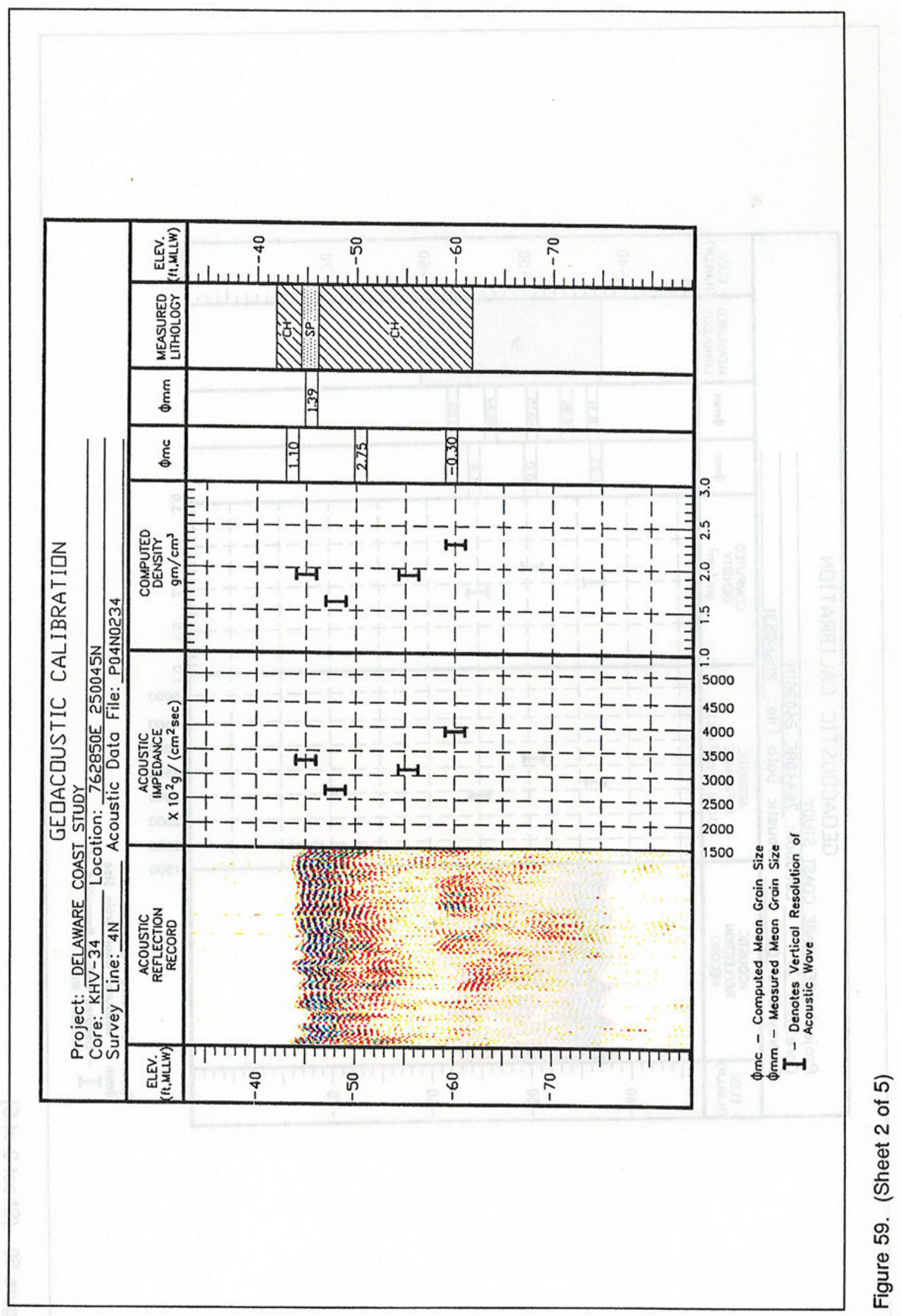




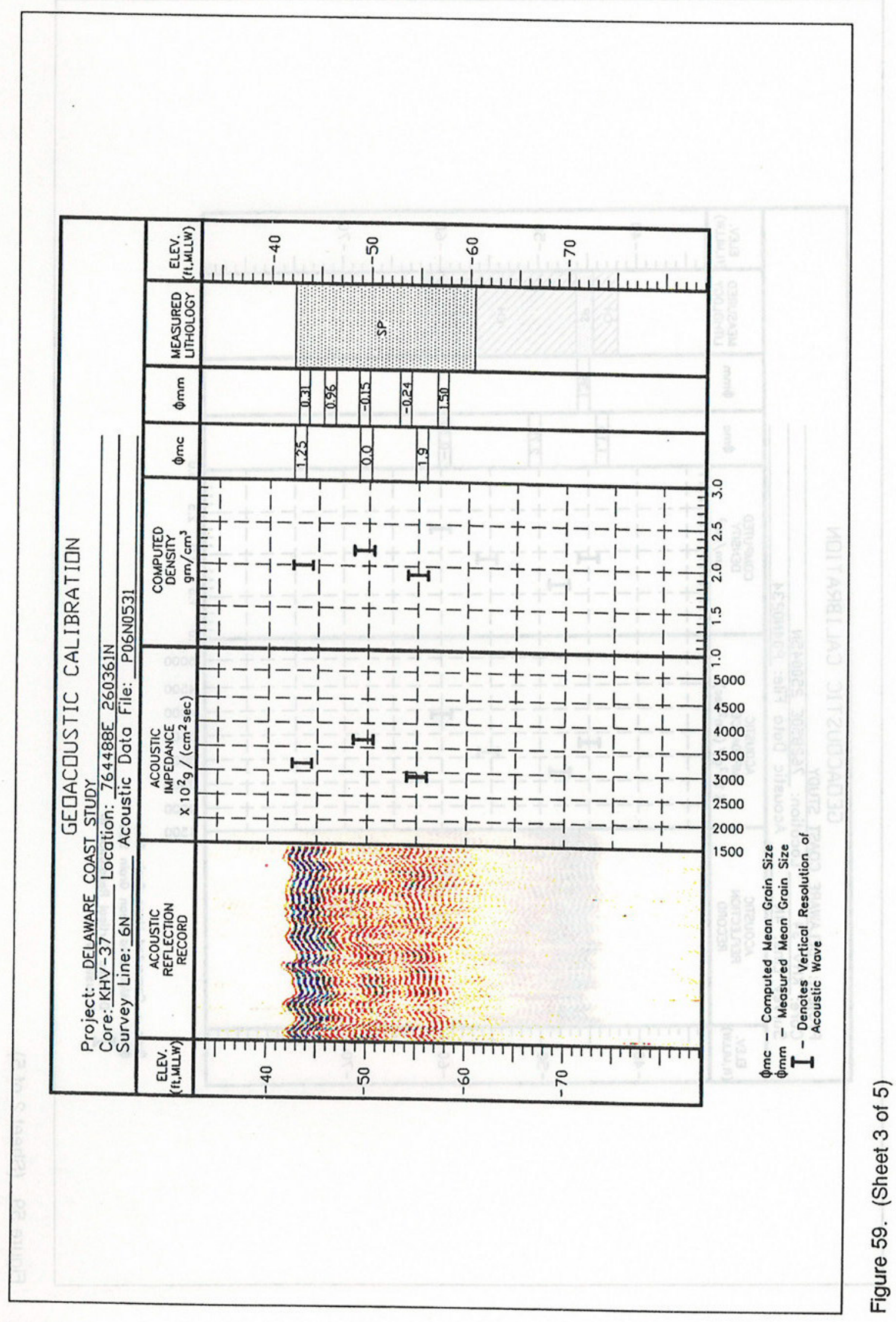




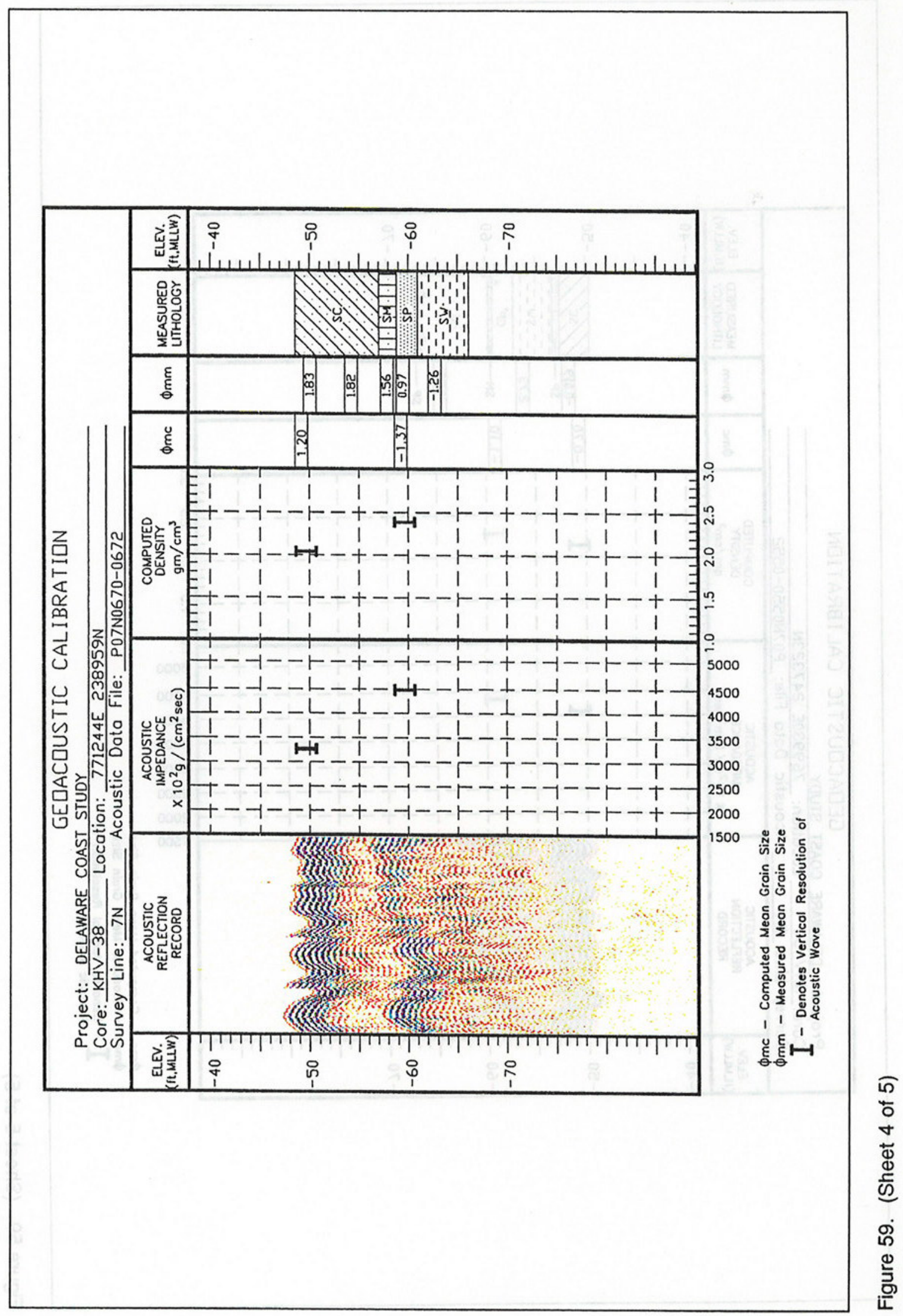




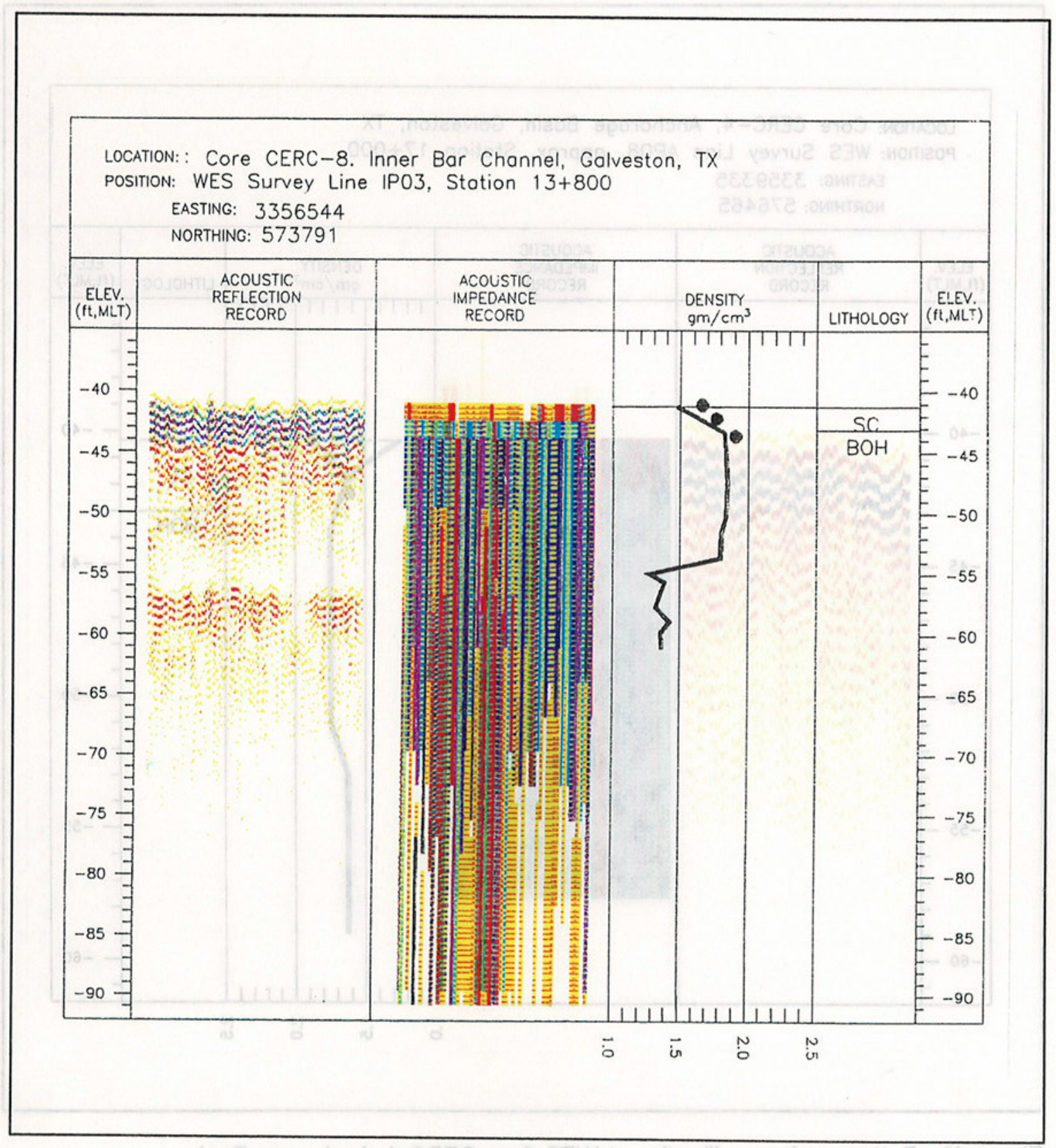

Figure 50. Bottom surface calibration at WES Core CERC-8, Inner Bar Channel 


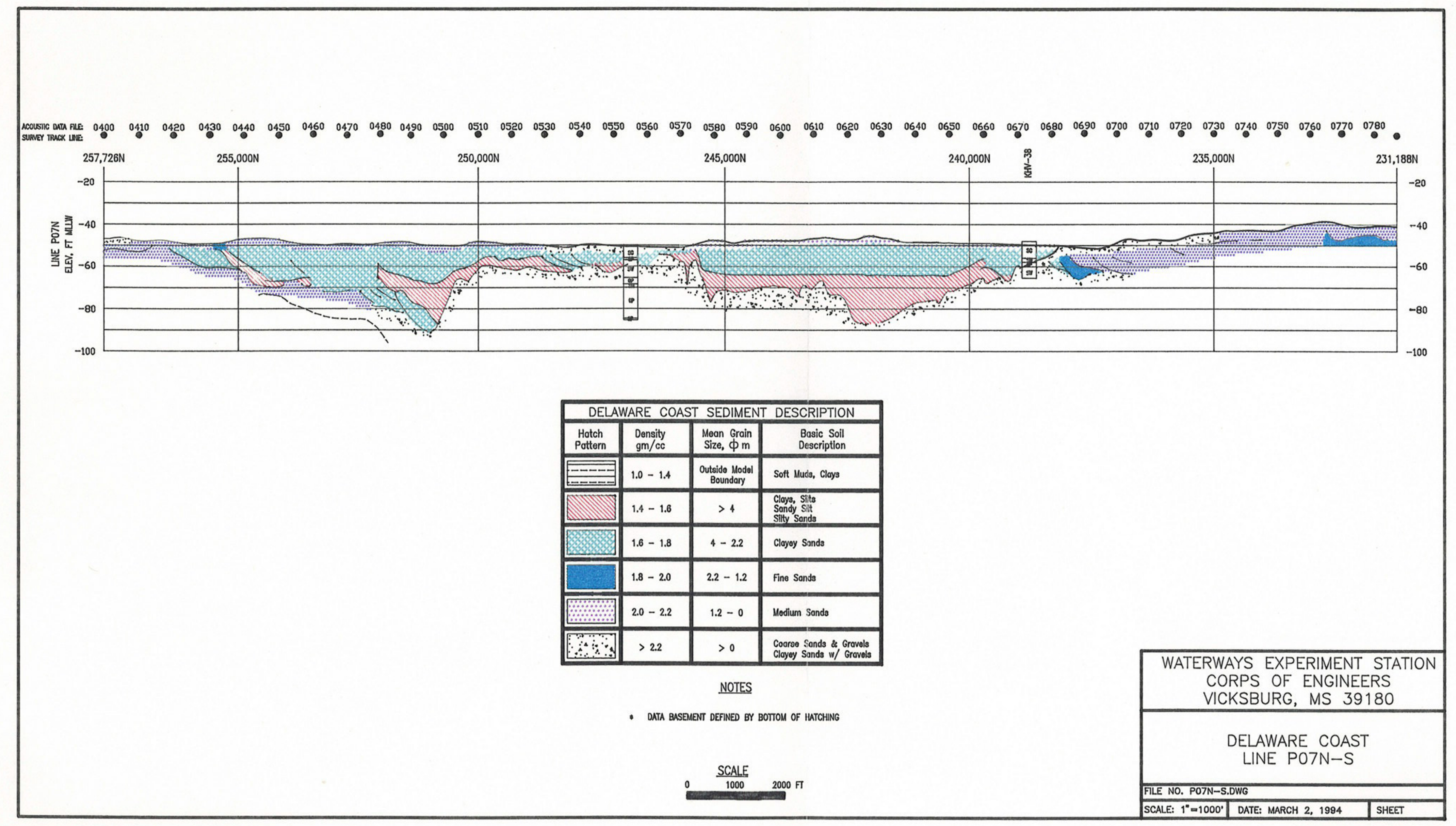

Figure 60. 2-D profile of sediment material (Delaware coast) 
3 


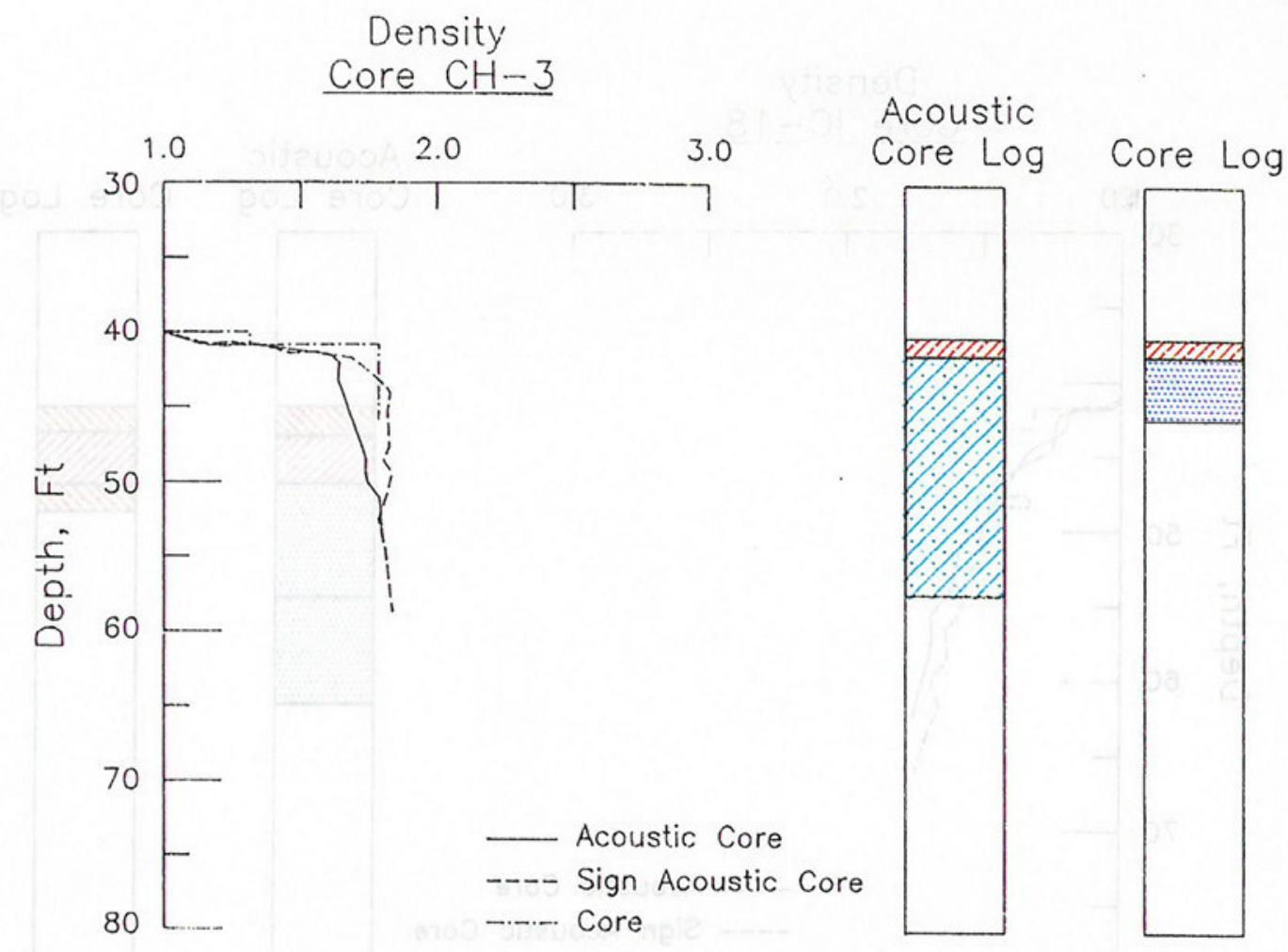

\begin{tabular}{|c|c|c|}
\hline \multicolumn{2}{|c|}{ OAKLAND HARBOR } & SEDIMENT DESC \\
\hline $\begin{array}{c}\text { Hatch } \\
\text { Pattern } \\
\end{array}$ & $\begin{array}{l}\text { Density } \\
\mathrm{gm} / \mathrm{cc}\end{array}$ & $\begin{array}{l}\text { Basic Soil } \\
\text { Description }\end{array}$ \\
\hline ('il'i), & $1.0-1.4$ & Soft Muds, Clays \\
\hline & $1.4-1.6$ & $\begin{array}{l}\text { Clays, Silts } \\
\text { Sandy Silt }\end{array}$ \\
\hline$\% \%$ & $1.6-1.8$ & Silty Sands \\
\hline & $>1.8$ & Sand \\
\hline
\end{tabular}

Figure 61. Oakland Harbor geoacoustic calibration (CORE $\mathrm{CH}-3$ ) 


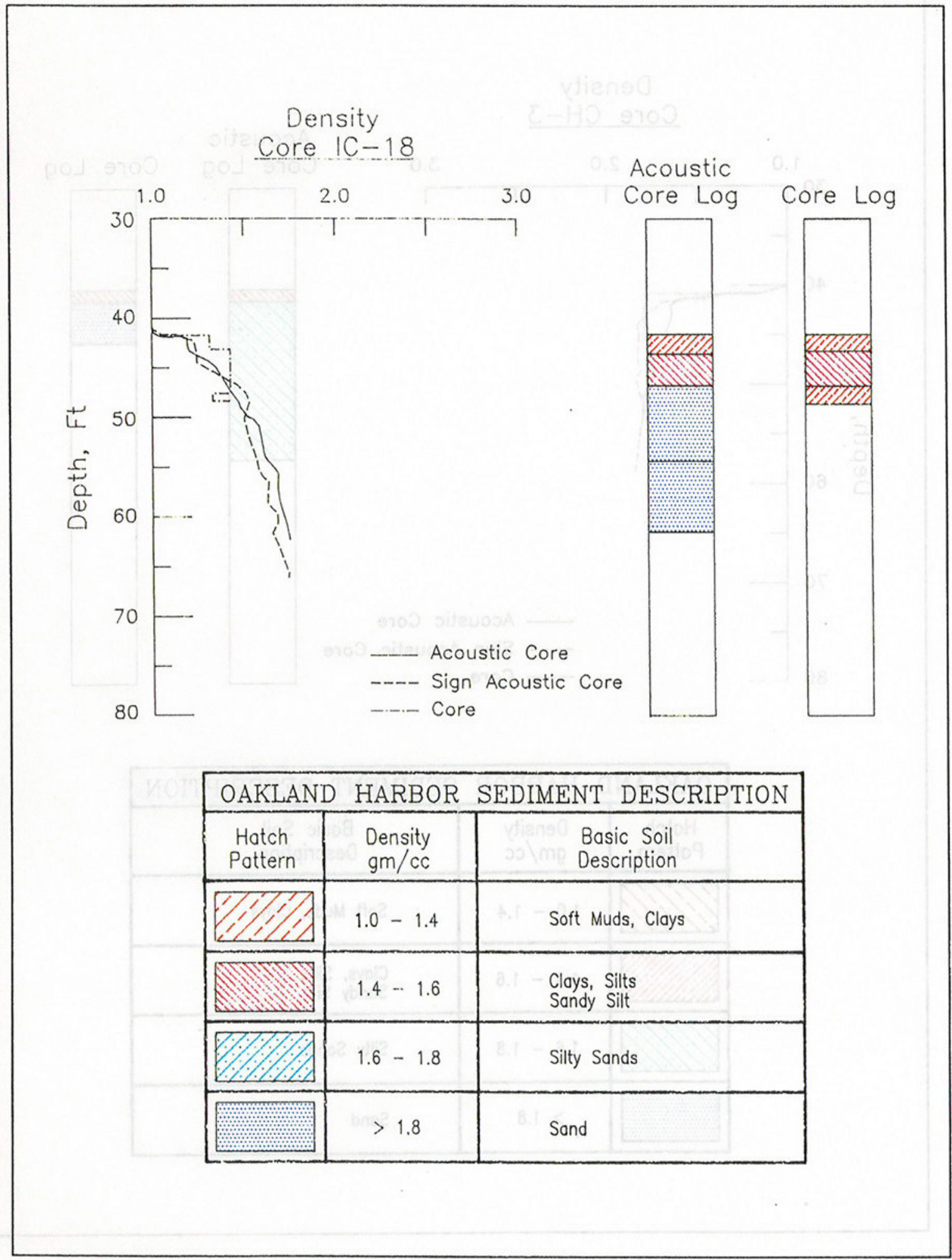

Figure 62. Oakland Harbor geoacoustic calibration (CORE IC-18) 


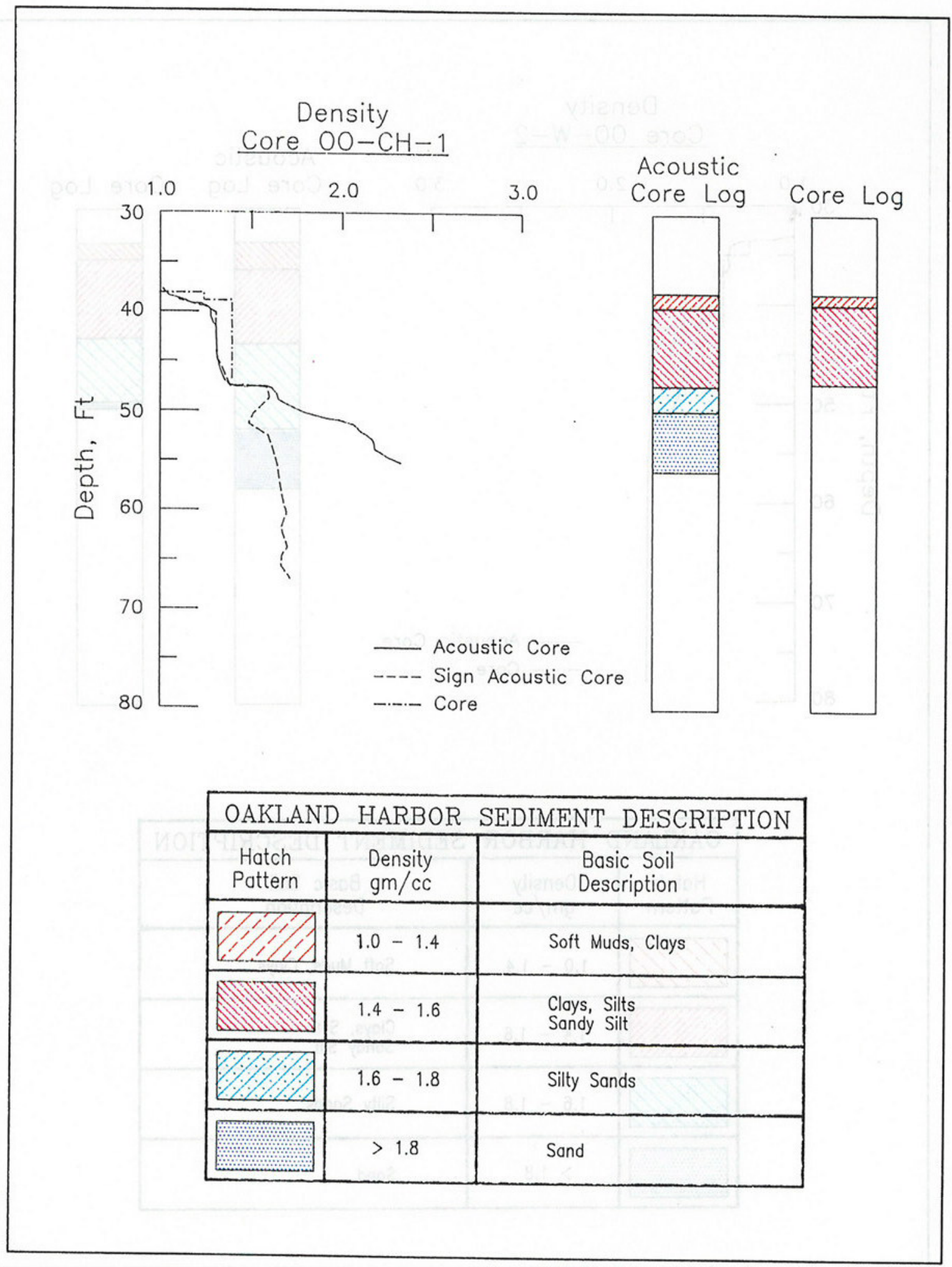

Figure 63. Oakland Harbor geoacoustic calibration (CORE 00-CH-1) 


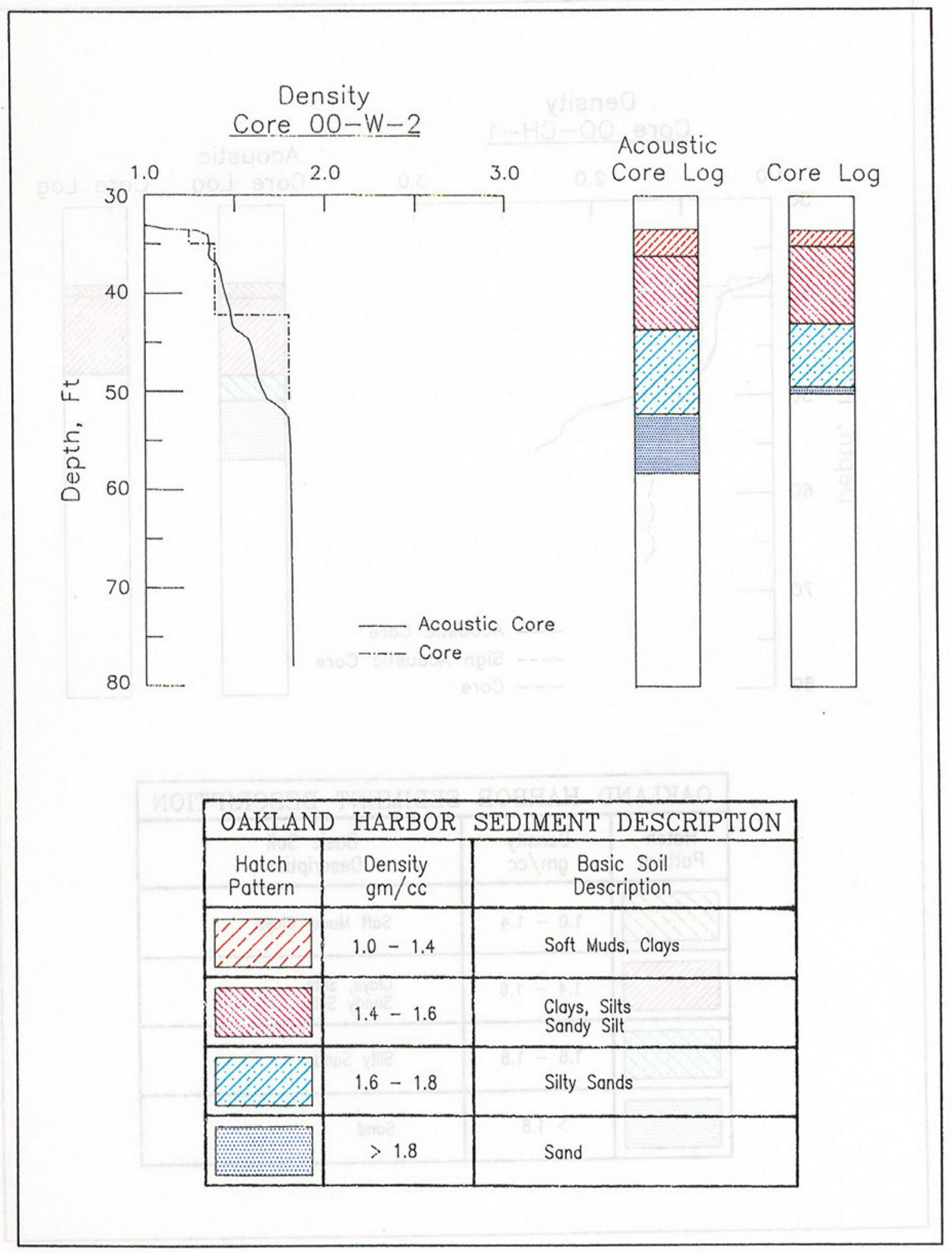

Figure 64. Oakland Harbor geoacoustic calibration (CORE 00-W-2) 


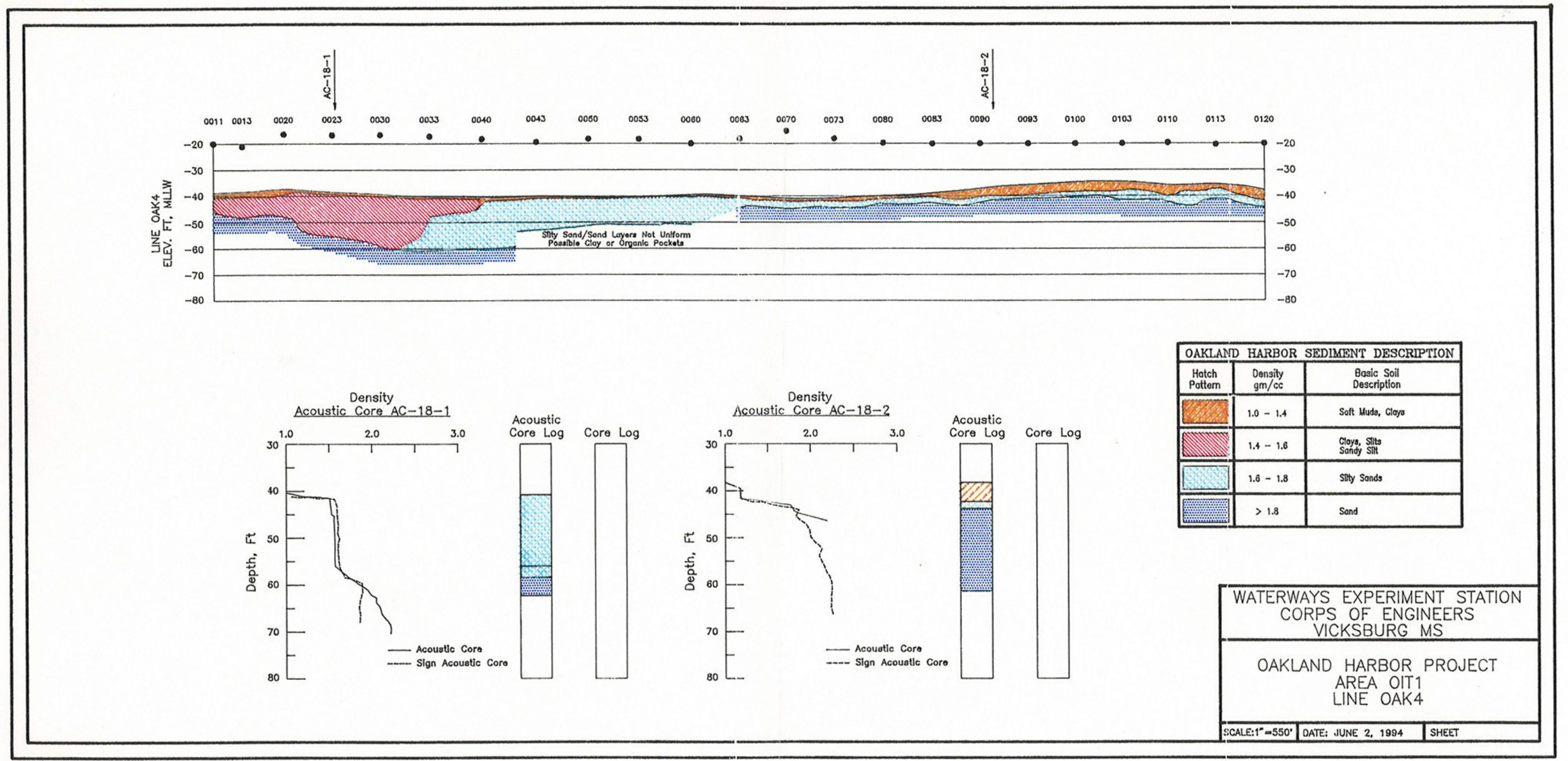

Figure 65. Typical sediment profile from Oakland Harbor 


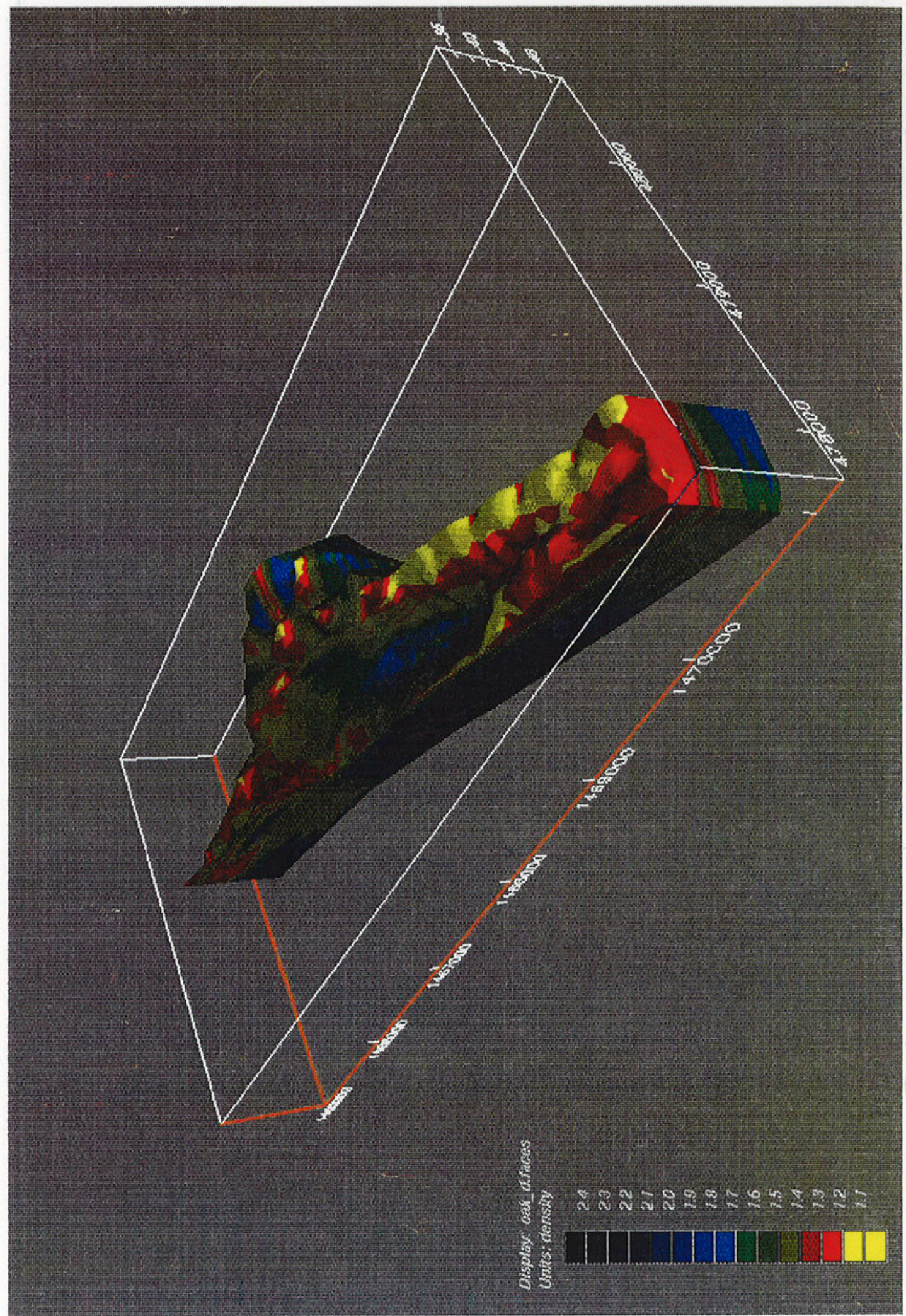

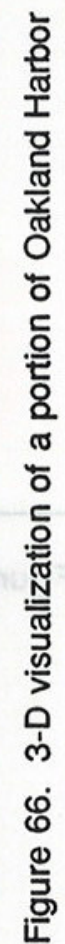




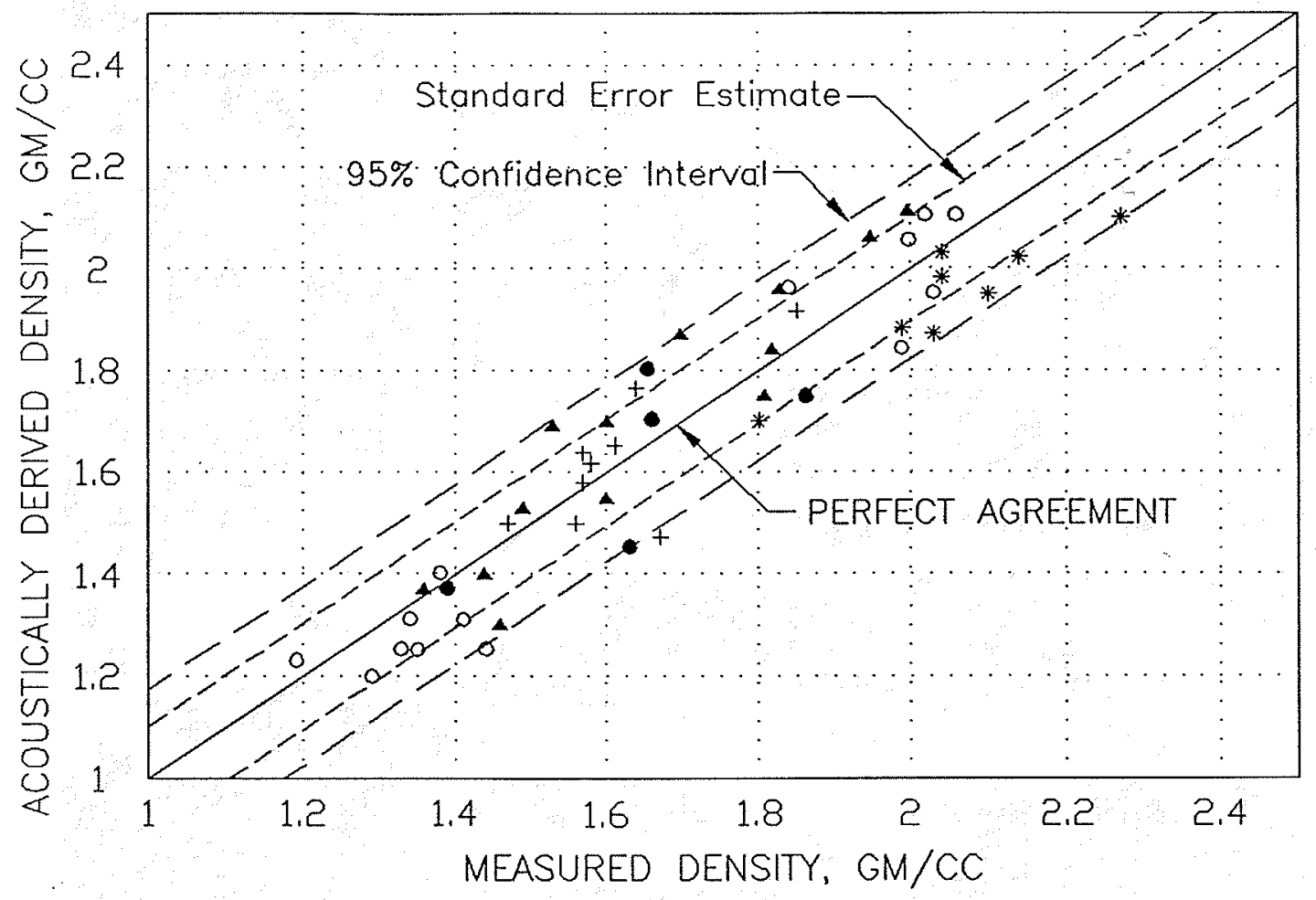

+ Galveston Inner Bar Channel and Anchorage Basin, TX

* Delaware Atlantic Coast

- Gulfport Ship Channel, MS

- Savannah Harbor, GA

- Panama City Harbor, FL

Figure 67. Statistical analysis of measured density versus acoustically derived density

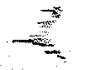




\section{Boundary Conditions and Limitations}

The method described herein represents an engineering solution to the problem of remotely assessing the physical characteristics of marine sediments. The system is not a "black box" device capable of assessing every conceivable geoacoustic situation occurring in the real world; therefore, it is important that boundary conditions and limitations of the technique be emphasized.

\section{Boundary Conditions}

A number of important assumptions and limiting conditions have been required to expedite a solution. These boundary conditions and assumptions employed in the Acoustic Impedance method, noted throughout this report, are summarized as follows:

a. Sound wave front propagated as a plane wave acting at normal incidence to a horizontally layered system. Virtually all commercially available underwater profiling systems produce spherical wave fronts with either highly directional or omnidirectional beam patterns. Certain beam pattern and bottom type combinations can significantly influence the quality of a reflected signal. For Corps projects such as ship channels, disposal mounds, or high-energy sediment zones, the bottom topography may not be horizontal. A rapidly changing bottom topography will alter the integrity of returned echoes by either redirecting the echo away from the receiver or focusing too much energy towards the receiver. Also, side echoes reflected off vertical objects or barriers can produce anomalous subsurface reflectors.

b. Increasing impedance environment. The initial approach assumed a geologic environment of increasing impedance layers. In other words, sediments become more competent with depth. Whereas this assumption holds true for many geologic situations, there exist numerous situations where soft sediments are overlaid by more competent materials. The AC50 program presently does not incorporate a correction for this condition; however, as discussed in detail in the "Layer Identification 
Methods" section of Chapter 2, techniques are provided to extemally compensate for this condition. Do not rely solely on the AC50 program for sediment characterization. A trial version of the AC50 program that performs the analysis necessary to determine the direction of the impedance change is now being fully tested. Initial results show significant improvement in the method's prediction capabilities.

c. Natural marine sediments. The initial impedance function used for this technique is based on empirical data collected in naturally occurring marine sediments from primarily deeper offshore environments. Therefore, this algorithm, without confirmatory core information, may produce anomalous estimates in the dynamic nearshore, harbor, and riverine environments-- the primary reason for the regional calibration approach.

Whereas these assumptions provide a practical engineered approach, they may also limit the technique's ability to correctly assess a specific situation. There is no one single sound source or analysis methodology that addresses all engineering and geological requirements.

\section{Limitations}

As with any remote sensing technique, limitations exist. These limitations must be understood in order to appropriately use this method. Probably the most common fault encountered in geophysical studies is improper application of a given technique for a given study objective. The following limitations exist for the present Acoustic Impedance technique.

Signal-to-noise ratio. The ability to accurately assess any environment is strictly a function of the quality of data obtained. Low S/N data will produce poor quality results or possibly no results at all. The AI method limits its processing to data with an $\mathrm{S} / \mathrm{N}$ ratio greater than $5 \mathrm{db}$. One must always be suspicious of impedance predictions in areas of poor $\mathrm{S} / \mathrm{N}$. Fortunately, most noise problems can be corrected through effective vessel mobilization and acoustic calibrations.

Layer identification. Unique sediment units can be identified only when an impedance change exists. Gradual changes in soil type may not result in an impedance differential large enough to produce a reflection.

Resolution. Vertical resolution and ultimate depth of penetfation are dependent primarily on the frequency of the sound wave. Higher operating frequencies permit greater resolution of marine sediments but shallower depths of energy penetration, depending on the characteristics of subbottom materials. Also, in high-attenuation sediments, higher frequencies are attenuated at a higher rate than low frequencies, resulting in degradation of resolution and errors in absorption estimates for very deep layers. As previously 
discussed, a number of field techniques and processing methodologies available now concurrently improve resolution and depth of penetration. However, it cannot be overemphasized that these techniques require data with high $\mathrm{S} / \mathrm{N}$ ratios.

Multiple reflections. Multiples are one of the primary causes of data quality degradation in shallow marine seismic measurements. Unlike noise, which can be distinguished from data by its lack of lateral continuity, multiples can easily be mistaken for real data, create false structures, and change reflectivity estimates. Presently, no multiple-suppression techniques have been developed and adapted to the AI system of software products. Therefore, for quantitative analysis, the maximum depth of investigation is bounded by the first multiple reflection which is approximately equal to the water depth. This can become a very limiting factor in shallow-water surveys.

Beam pattern or directivity. Experience has shown that beam pattern and transducer directivity contribute significantly to signal degradation. Sloping bottoms and rapidly dipping reflection horizons cause inconsistent reflection data through focusing and defocusing of the incident energy. Rough, irregular bottoms with numerous scatterers will specularly disperse energy away from the receiving array. For quantitative analysis, minimization of the beam angle, either through beam steering or receiver focusing, will improve results significantly and will likely be incorporated in the WES AI system. 


\section{Conclusions and Recommendations}

\section{Conclusions}

In its present state of development, acoustic impedance processing of seismic reflection data provides a reasonably accurate, continuous description of bottom and subbottom marine sediment characteristics in a rapid, cost-effective manner. From a statistical standpoint, density can be acoustically derived to within \pm 10 percent of in situ conditions. Properly calibrated surveys provided Corps Districts and dredging contractors with the following results:

a. Density estimates of marine sediments.

b. Continuous subbottom information for planning and designing dredging and sampling programs.

c. Estimates of the volume and type of material to be removed through dredging.

d. A detailed and continuous geologic database for aiding long-term planning of future work.

Acoustic impedance information, if properly implemented in the project planning stages, provides valuable data on the distribution and extent of differing marine sediments, aids in locating optimal placements of sampling cores, and supplements previously obtained soil borings by providing continuous profile coverage of sediment characteristics between sample locations.

Further, the acoustic impedance method is not limited to sediment characterization but can also provide such essential information as:

a. Location of marine sand deposits for beach replenishment.

b. Long-term monitoring of dredged material disposal areas.

c. Delineation of submarine geologic formations. 
d. Detection of submarine features such as pipelines or other dredging
hazards.

e. Identification of fluid mud in navigable waterways.

\section{Recommendations}

It is recommended that development continue beyond the DRP in expanding the capabilities of the waterborne geophysical exploration system. Emphasis should be placed on expansion of capabilities to include a wide range of geophysical techniques. Specifics include the following:

\section{Hardware}

a. Multichannel seismic acquisition and processing system. The benefits of multichannel processing include $\mathrm{S} / \mathrm{N}$ improvement, multiple and diffraction suppression, increased knowledge of the subbottom velocity profile, and the potential use of 2-D algorithms.

b. Automated gain recording. The acquisition system should be upgraded to digitally record any amplifier gain changes occurring during data acquisition. This relatively simple upgrade will eliminate potential errors in recording field data and, more importantly, will allow for maximum flexibility in acquiring highest $\mathrm{S} / \mathrm{N}$ data.

c. Minimize beam angle. For quantitative analysis, minimization of the beam angle will improve results significantly. This can be accomplished either at the source or receiver. Source beam angle is a function of transducer design. Narrow-beam transducers for the low operating frequencies ( $<10 \mathrm{deg}$ ) are generally very large arrays, in most cases impractical for small-boat, shallow-water applications. Specially designed receiving hydrophone arrays can be constructed and used in conjunction with "beam-forming" software to more practically accomplish the task. Such systems are commercially available and could be readily integrated with the existing system.

d. Core analysis standardization. Minimum core analysis requirements should be implemented to specifically address geoacoustic analysis. Minimum requirements should be as follows:

(1) Independent direct measurement of acoustic attenuation of the sediment material retrieved from the seafloor.

(2) Direct measurement of compressional (p-wave) velocity of core sediment.

(3) Determination of specific gravity, density, and porosity. 
(4) Grain size analysis of all sediment types, from fine- to coarsegrained sediments.

\section{Software}

e. Dependable algorithm for determining sign of reflection coefficient. The upgrade is highly recommended for the purpose of assessing decreasing impedances in successive layers. This algorithm should be applied directly in the AC50 program. An initial AC60 program is now undergoing beta testing.

f. Multiple suppression algorithm. This algorithm is needed to suppress false reflectors and provide better clarification of real reflectors, leading to better estimates of reflectivity, impedance, and other geotechnical parameters. It would also increase the effective depth of penetration in shallow-water studies as well as improve the reliability of deeper reflectors.

g. Improved forward modeling algorithms. More comprehensive methods for generating synthetic seismograms of geologic data are needed to better model absorption and intemal reflections.

\section{Research needs}

h. Geoacoustic relationships. An extensive database of acoustic and geotechnical data has been acquired during the development of this method. Detailed study into the geoacoustic relationships of nearshore sediments is needed, specifically:

(1) Grain size analysis (sorting, skewness, kurtosis, etc.) for the purpose of better describing sediments for applications such as beach nourishment projects.

(2) Analysis of contaminated sediments.

(3) Analysis of highly fluidized sediments such as fluff/fluid mud.

$i$. Soil properties. The database should be utilized to study the relationships between different soil properties such as density/porosity versus mean grain size. This will aid in developing better sediment characterizations using geoacoustic methods. 


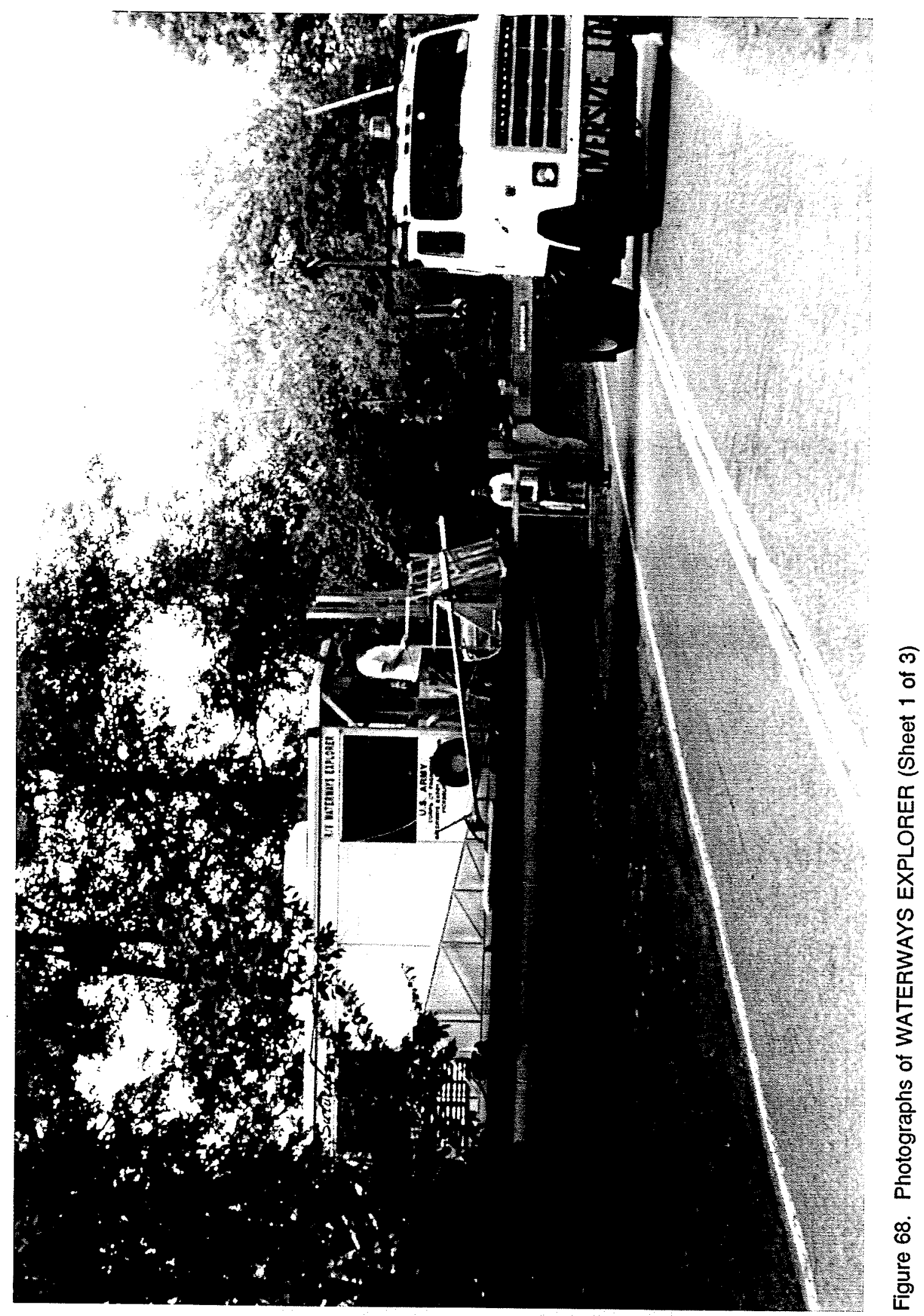




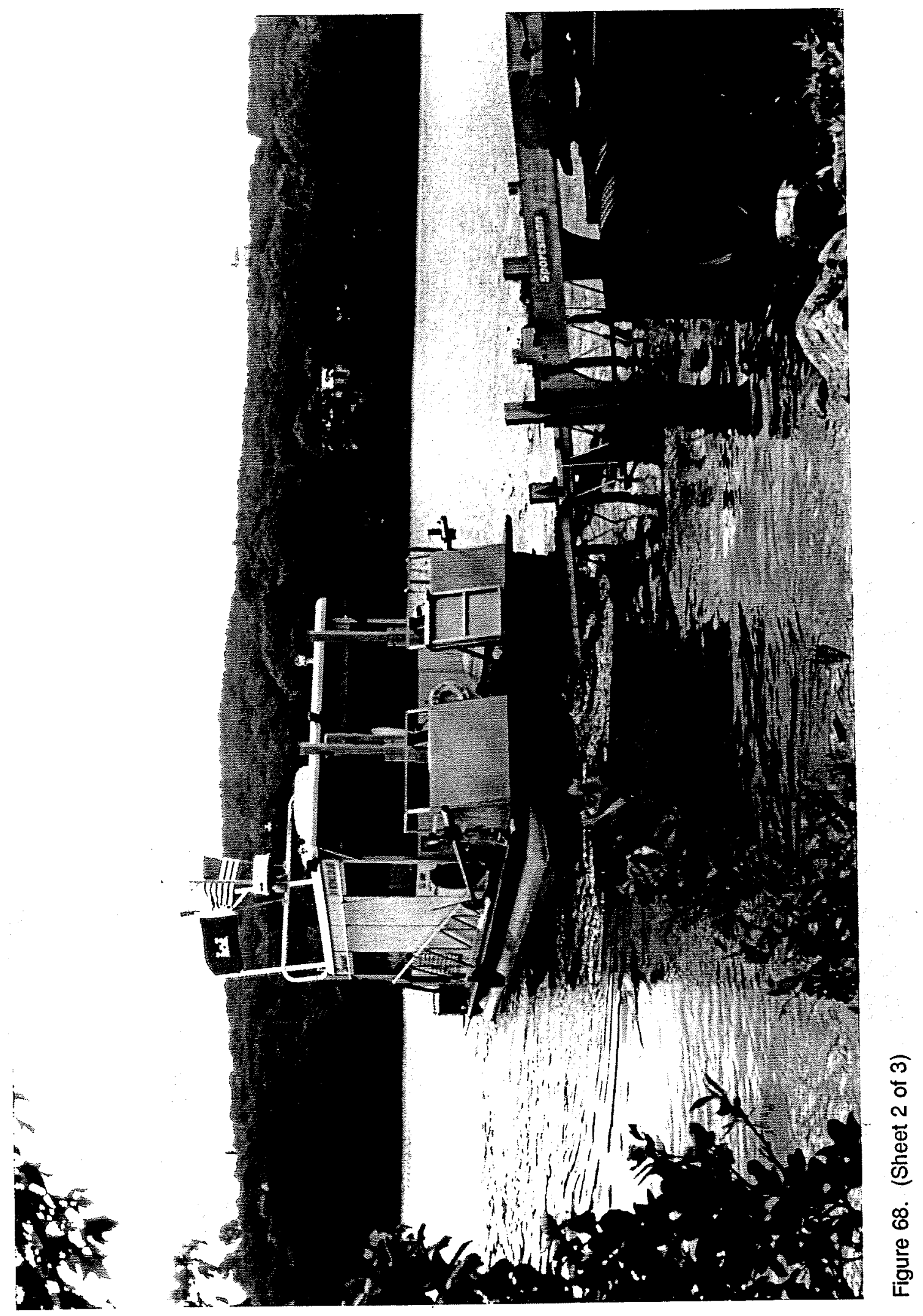




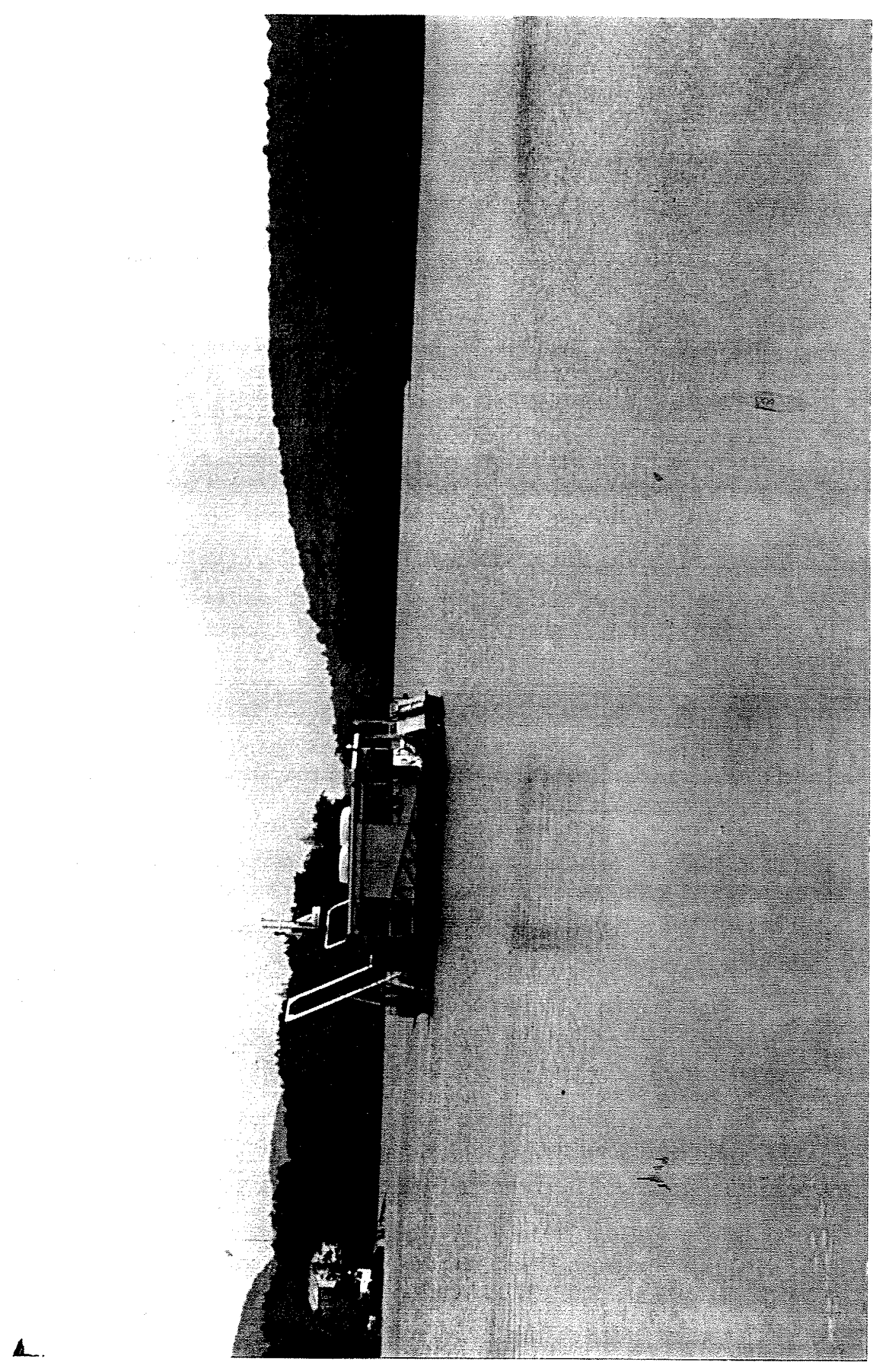

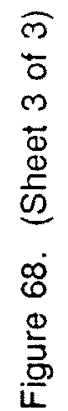

Chapter 6 Conclusions and Recommendations 


\section{References}

Ballard, R. F., Jr., and Grau, T. H. (1992). "Subbottom site characterization by acoustic impedance," WES Innovative Technology Brochure, U.S. Army Engineer Waterways Experiment Station, Vicksburg, MS.

Ballard, R. F., Jr., and McGee, R. G. (1991). "Subbottom site characterization by acoustic impedance." Proceedings of the U.S. Army Corps of Engineers Surveying Conference, Louisville, KY.

Ballard, R. F., McGee, R. G., and Harmon, T. S. (1991). "Hydrographic surveys applicable to dredging operations," Information Exchange Bulletin DRP-2-03, U.S. Army Engineer Waterways Experiment Station, Vicksburg, MS.

Ballard, R. F., Jr., McGee, R. G., and Whalin, R. W. (1992). A high-resolution subbottom imaging system." Proceedings of the Eighteenth U.S./Japan Marine Facilities Panel of US/Japan Marine Facilities Panel (UJNR). Washington, DC.

Ballard, R. F., Sjostrom, K. J., McGee, R. G., and Leist, R. L. (1992). "A rapid technique for subbottom imaging." Proceedings of the International Symposium on Spectral Sensing Research. Maui, HI, 591-602.

Ballard, R. F., Jr., Sjostrom, K. J., McGee, R. G., and Leist, R. L. (1993). "A rapid technique for subbottom imaging," Dredging Research Technical Note DRP-2-07, U.S. Army Engineer Waterways Experiment Station, Vicksburg, MS.

Biot, M. A. (1956a). "Theory of propagation of elastic waves in a fluidsaturated porous solid; I, Low frequency range," Journal of the Acoustical Society of America 28, 168-178.

. (1956b). "Theory of propagation of elastic waves in a fluid-saturated porous solid; II, Higher-frequency range," Journal of the Acoustical Society of America (28), 179-191. 
Caulfield, D. D. (1990). "Calibration manual and final report for the implementation of the acoustic core density estimating system," Caulfield Engineering, Oyama, BC, Canada.

- (1991a). "DF25, Digital Field Shallow Seismic Acquisition System" (computer program and manual), IBM-PC Caulfield Engineering, Oyama, BC, Canada.

(1991b). "DSA10, Digital Spectral Analysis System, Version 10.00" (computer program and manual), IBM-PC, Caulfield Engineering, Oyama, BC, Canada.

- (1991c). "DPC10, Digital Shallow Seismic Processing and Correlation System" (computer program and manual), IBM-PC, Caulfield Engineering, Oyama, BC, Canada.

- (1992a). "AC50-4, Acoustic Core System" (computer program and manual), IBM-PC, Caulfield Engineering, Oyama, BC, Canada.

(1992b). "Final report--Improvement in seismic resolution using correlation techniques," Caulfield Engineering Group, Oyama, British Columbia, Canada.

- (1993). "RTC10, Real Time Correlation Seismic Acquisition System, Version 10.00," (computer program and manual), IBM-PC, Caulfield Engineering, Oyama, BC, Canada.

Caulfield, D. C., Caulfield, D. D., and Yim, Y. C. (1985). "Shallow subbottom impedance structures using an iterative algorithm and empirical constraints," Journal of the Canadian Society of Exploration Geophysicists 21(1), 7-14.

Caulfield, D. D., and Yim, Y. C. (1983). "Prediction of shallow subbottom sediment acoustic impedance while estimating absorption and other losses," Journal of the Canadian Society of Exploration Geophysicists 19 (1), 44-50.

Caulfield, D. D., Yim, Yung-Chang, and McGee, T. (1982). "Application of the autocorrelation factors for layer identification in shallow seismics," 1983 CSEG Conference, Calgary.

Griffis, F. H., Jettmar, C. E., Pagdadis, S., and Tillman, R. "Dredging Research Program Benefits Analysis," in preparation, U.S. Army Engineer Waterways Experiment Station, Vicksburg, MS.

Hamilton, E. L. (1970a). "Sound velocity and related properties of marine sediments, North Pacific," Journal of Geophysical Research 75(23), 4423-4446. 
Hamilton, E. L. (1970b). "Reflection coefficients and bottom losses at normal incidence computed from Pacific sediment properties," Geophysics 35, 995-1004.

- (1971). "Prediction of in situ acoustic and elastic properties of marine sediments," Geophysics 36, 226-284.

. (1972a). "Compressional-wave attenuation in marine" sediments," Geophysics 37 (4), 620-646.

- (1972b). "Elastic properties of marine sediments," Journal of Geophysics Research 76, 579-604.

- (1980). "Geoacoustic Modeling of the Sea Floor," Journal of the Acoustical Society of America 68(5), 1313-1340.

Hamilton, E. L., and Bachman, R. T. (1982). Sound velocity and related properties of marine sediments, Journal of Acoustics Society of America 72(6), 1891-1904.

Hampton, L. (ed.) (1974). Physics of Sound in Marine Sediments. Plenum Press, New York.

Keller, J. D. (1989). "Acoustic wave propagation in composite fluid-saturated media," Geophysics 54, 1554-1563.

McGee, R. G. (1991). "Subbottom hydro-acoustic survey of Gulfport Ship Channel," Memorandum for Record, U.S. Army Engineer Waterways Experiment Station, Vicksburg, MS.

- (in publication). "Geoacoustic model study of Delaware Atlantic Coast from Cape Henlopen to Fenwick Island," U.S. Army Engineer Waterways Experiment Station, Vicksburg, MS.

McGee, R. G., and Ballard, R. F. (1992). "An acoustic impedance method for subbottom material characterization." Proceedings of American Society of Civil Engineers NHEC Water Forum '92. Baltimore, MD.

McGee, R. G., and Caulfield, D. D. (1991). "Practical implementation of the acoustic core density estimating system," Canadian Society of Exploration Geophysicists 1991 National Convention, Calgary, Alberta, Canada.

McGee, T. M. (1991). "Modelling 1D Wave Propagation in a System of Absorbing Layers," Geophysical Prospecting 39, 29-49.

Officer, C. B. (1958). Introduction to the Theory of Sound Transmission. McGraw-Hill, New York. 
Robinson, E. A., and Treitel, S. (1980). Geophysical Signal Analysis. Prentice-Hall, New Jersey.

Sheriff, R. E. (1975). "Factors Affecting Seismic Amplitudes," Geophysical Prospecting 23, 125-138.

Sjostrom, K. J., and Leist, R. L. (1994). "A waterborne seismic reflection survey of three tributaries in Boston Harbor, Massachusetts," Technical Report GL-94-28, U.S. Army Engineer Waterways Experiment Station, Vicksburg, MS.

Sjostrom, K. J., Ballard, R. F., and McGee, R. G. (1991). "Subbottom site characterization using acoustic impedance technology," WES Video File No. 92001, U.S. Army Engineer Waterways Experiment Station, Vicksburg, MS.

(1992). "A waterbome geophysical technique for assisting proposed dredging projects," Proceedings of Symposium on the Applications of Geophysics to Engineering and Environmental Problems (SAGEEP), Oakbrook, IL.

Sjostrom, K. J., McGee, R. G., and Ballard, R. F. (1992). "A waterbome geophysical technique for improved planning and monitoring of dredging projects," Proceedings of Western Dredging Association (WEDA), Mobile, AL.

Stoll, R. D. (1974). "Acoustic waves in saturated sediments." Physics of sound in marine sediments. L. Hampton, ed., Office of Naval Research Symposium, Plenum Press, New York, 19-39.

Urick, R. J. (1983). Principles of underwater sound. 3rd ed., McGraw-Hill, New York. 
$-$ 


\section{Appendix A Equipment}

\section{Hardware}

The study of the AI method did not attempt to develop and introduce new acoustic sound sources or receivers. Rather, it was decided to utilize the extensive array of commercially available systems, making the AI method both flexible and robust enough to meet the challenge of assessing a wide variety of marine environments for commercial and government surveyors.

A wide range of shallow seismic data acquisition systems, beginning with analog and transitioning to digital, were utilized during the development of the AI method. It is important to emphasize the fact that a variety of off-the-shelf commercially available equipment can be adapted to AI technology. A detailed description of every system is not appropriate within this text. A block diagram showing equipment used in the WES integrated geophysical system is shown in Figure A1. This system is currently used to perform AI surveys and other types of marine geophysical investigations. Specific systems utilized for the AI application are as follows:

a. 3.5- 7.0-kHz pinger system. This system is by far the most popular utilized in the shallow marine seismic industry. It allows transmission of variable-length pulses $(0.2-3 \mathrm{msec})$ of $3.5-$ and $7.0-\mathrm{kHz}$ frequencies. Power levels can be varied from 1 to $10 \mathrm{~kW}$. Figure A2 shows an over-the-side deployment of a pinger system. However, depth of penetration can be limited in areas of highly competent (dense) sediments. Considerable efforts were expended in developing alternative deployment configurations to improve $S / \mathrm{N}$ characteristics of pinger data in the shallow marine environment. These systems were originally designed to operate in water depths greater than about $50 \mathrm{ft}$, resulting in configurations employing integrated transmit/receive (T/R) networks in order to utilize the same transducers as transmitters and receivers. The resulting transducer ringing and coupling creates coherent noise keyed to the transmitter timing. In shallow water (less than $30 \mathrm{ft}$ ), significant $\mathrm{S} / \mathrm{N}$ problems arise due to coherent noise from the transmitter interfering with the first return. Figure A3 illustrates this problem. 
To improve the $S / N$, a separate receiving array is now deployed independent of the transmitter. By decoupling the receiving array from the transmitter and physically separating the transducers, all of the near-field transmitter ringing is eliminated from the bottom reflection, regardless of water depth. Figure A4 presents reflection data collected with this configuration. This has become the standard pinger and chirper deployment configuration for the AI method.

b. Boomer system. This system is a high-energy, medium-bandwidth unit providing up to $1,000 \mathrm{~J}$ of energy in the $400-$ to $5,000-\mathrm{Hz}$ frequency band. The system is designed to provide reasonable vertical resolution combined with greater penetration depths in more competent sediments. Because of the high power involved and because the coherent noise radiates to the receiver as well as to the bottom, a separate towed receiving array is used. This array is normally towed at right angles or directly aft of the source. The exact tow point is determined by the water depth and by minimizing the coherent noise to the receiver. In practice, the source-to-receiver separation can be fine-tuned by an experienced data observer to produce the best record quality obtainable at a specific site. Figure A5 shows a typical boomer deployment.

c. Chirp system. Commercially available chirp systems (analogous to land surface vibrators used in the petroleum industry) are designed to improve the $\mathrm{S} / \mathrm{N}$ and vertical resolution by the application of correlation processing (matched filtering) to a wide-band swept-frequency longpulse signal. The improvement is a function of the bandwidth-time product. Standard chirp systems normally operate from $1 \mathrm{kHz}$ to $10 \mathrm{kHz}$ with pulse lengths of 3 to $20 \mathrm{msec}$. At this point, it must be stated that only the chirper transducer, not a complete "off-the-shelf" chirper data acquisition system, was used in development of the AI method. Correlation processing of chirp data will be discussed in detail later in the software section of this chapter. Since the midfrequency energy range of most chirp systems is around $4 \mathrm{kHz}$, the depth of penetration achieved is about the same as pinger systems. As with the pinger system, the receiving array is deployed independently of the transmitting array. This procedure greatly improves the $S / N$ by eliminating the coherent noise resulting from transmitter ringing. The complete chirp data acquisition system developed by WES allows for unprecedented flexibility in generating source wave forms. In many cases, the need arises for tailoring the seismic source to produce maximum energy within a predetermined frequency/wavelength band for resolution of a site-specific target. Chirper transducer control software was developed by WES to allow the design of virtually any wave form type (within the design limits of transducer response) as a function of frequency, amplitude, and pulse length. This wave form is delivered directly to the power amplifier of the chirp transceiver through a digital-to-analog signal converter, linear amplifier, and analog filter. 
d. Bubble pulse system. The bubble pulser generates a low- to mid-range frequency wavelet, with a frequency content between 400 and $2,000 \mathrm{~Hz}$, with most of the energy concentrated between 600 and $900 \mathrm{~Hz}$. Because of the source's low-frequency content, penetration depth in competent materials such as sands is significantly greater than with the $3.5-\mathrm{kHz}$ system. However, increased depth of penetration comes at the cost of resolution. Because the bubble pulser exhibits bandwidth rather than single-frequency energy, the same correlation techniques to improve resolution in chirp technology can be applied, improving the $S / \mathrm{N}$ and resolution by a factor of two.

Based upon the results of numerous surveys, it is recommended that multiple systems, preferably with different frequencies and energy levels, be utilized for all AI surveys. For most Corps dredging applications, high-resolution delineation of surface sediment layers is important, requiring higher frequency devices and/or chirp technology. In order to accurately assess the absorption characteristics of subbottom sediments (required to characterize the subbottom sediments discussed in Chapter 2, "Technical Development") multiple frequencies encompassing the greatest bandwidth are required.

\section{Software}

Reflected acoustic signals detected by the receiving array are first amplified and filtered as needed to ensure maximum $S / N$. The amplifiers must be linear and must exhibit no DC bias. The AI method requires precise knowledge of the total energy due to signal amplification. Real-time filtering is provided at the front end of amplifiers to reduce undesirable noise as much as possible prior to digital sampling of data. After this preprocessing, data are recorded digitally using a specially designed Digital Field Shallow Seismic Acquisition System (DFAS). A complete description and detailed discussion of the DFAS operation is provided by Caulfield (1991a).

The DFAS is designed to provide an economical means of recording shallow marine seismic data on commonly available computing systems. The DFAS is an IBM-compatible hardware/software package that operates under DOS 3.3 or greater. The system has a minimum dynamic range of $72 \mathrm{db}$ and provides real-time visual color display, disk writing procedures, and a data processing and playback system.

Real-time data acquisition is based on the data input being wide band and having sufficient $\mathrm{S} / \mathrm{N}$ levels to meet standard communications quality control conditions. Acquisition quality control is provided to verify that the amplifier gains are set for optimum $S / N$, appropriate sample rates and trace lengths are chosen, and appropriate timing offsets are employed to maximize the reflection window. The system is designed to handle most standard shallow subbottom geophysical tools, such as $3.5-\mathrm{kHz}$ pingers, boomers, etc. The analog/digital converter has a 12-bit, $20-\mathrm{msec}$ sampling rate with precision sample and hold 
amplifiers on the front end. The actual operational sample rate is dependent on the host computer and is software controlled.

The system has been designed to operate with any user-supplied navigation system that has an RS-232 output. Navigation information is read directly into data file headers for direct correlation with subbottom data.

Limited postprocessing options are provided. These include horizontal spatial stacking, noise reduction, and linear gain manipulation. Also, data may be played back utilizing the spherical spreading correction to compensate for transmission loss. Typical data records for pinger, boomer, and bubble pulser systems are presented in Figures A6, A7, and A8, respectively.

Chirp data are recorded using Real-Time Correlation Acquisition (RTC10) System shallow seismic software. This system provides real-time matched filter correlation processing of echo time series with a true replica of the outgoing source wavelet. The match filter correlation process utilized here is described in Chapter 2 ("Technical Development"), and a detailed description of the RTC10 program is provided by Caulfield (1993).

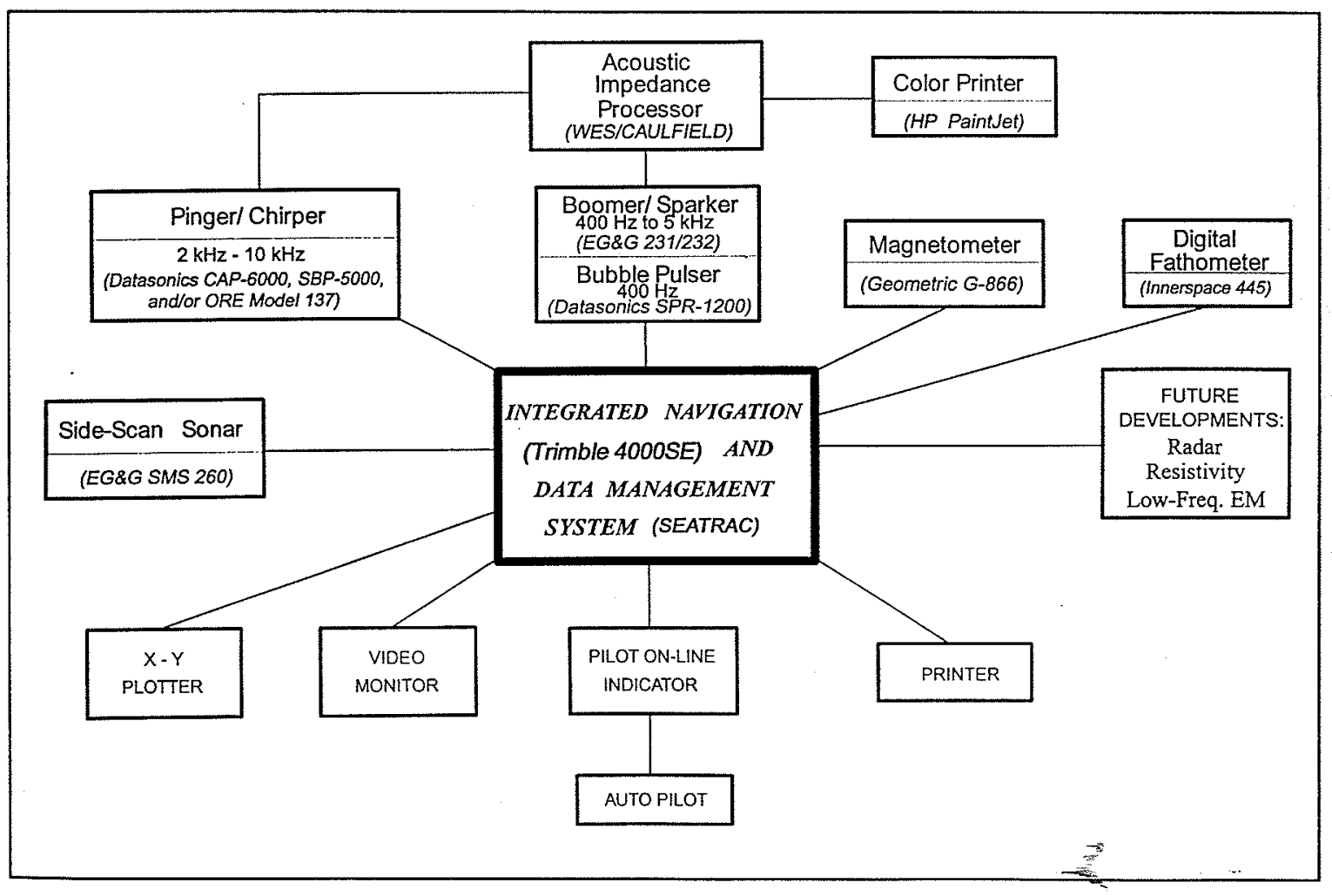

Figure A1. Block diagram of WES integrated geophysical system 


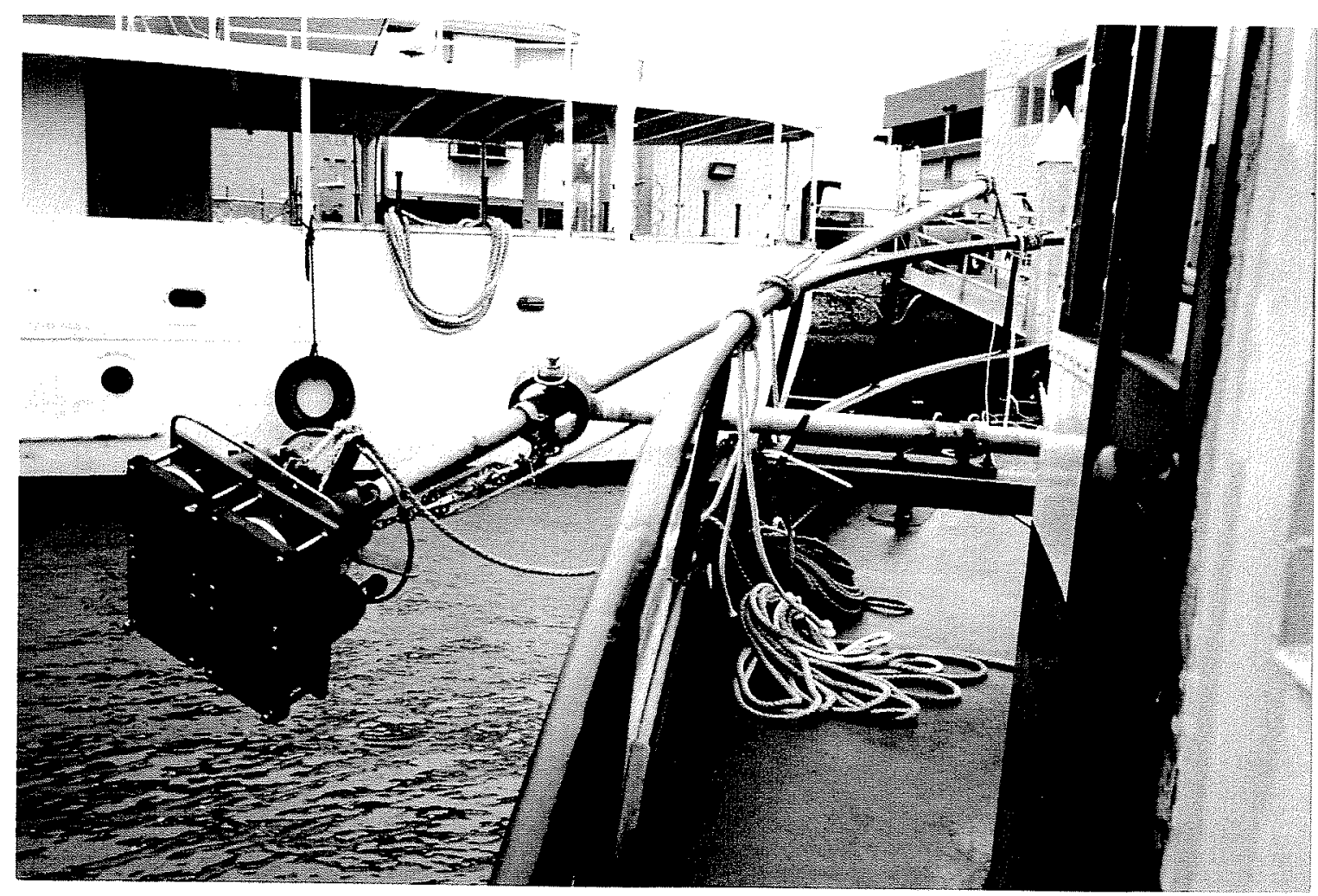

Figure A2. Over-the side deployment of pinger transducers 


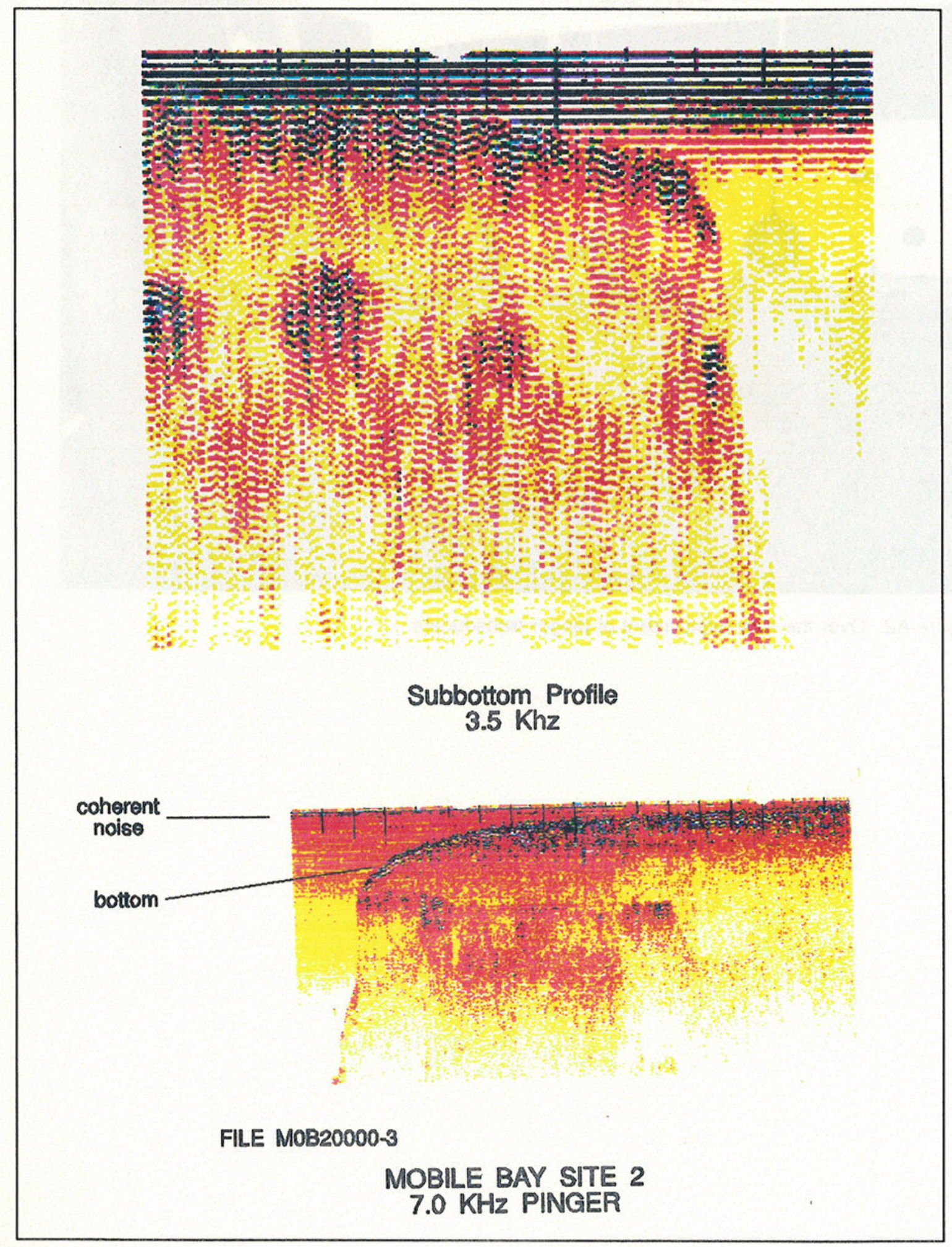

Figure A3. Coherent noise due to coupling of transmitter and receiver 


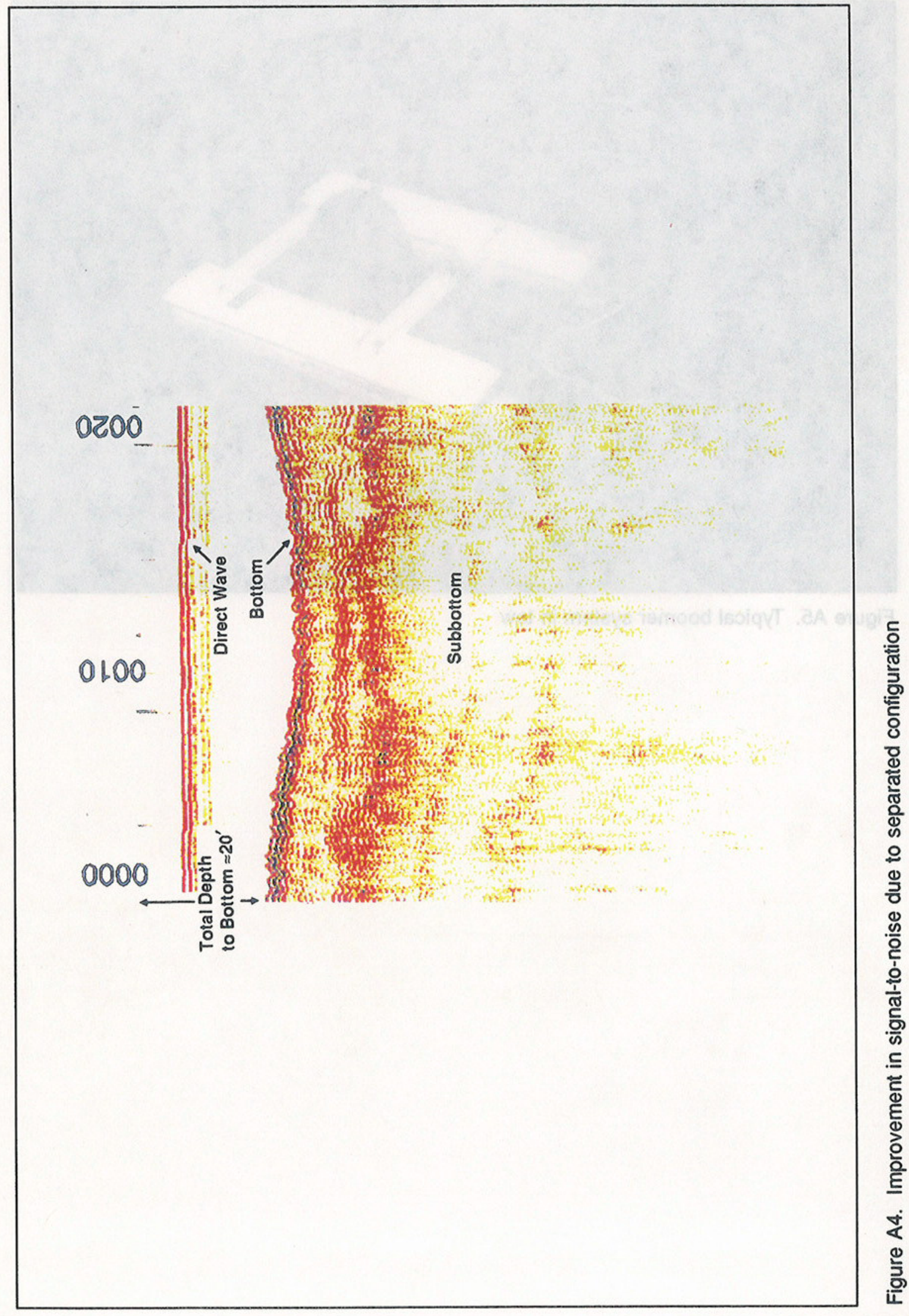




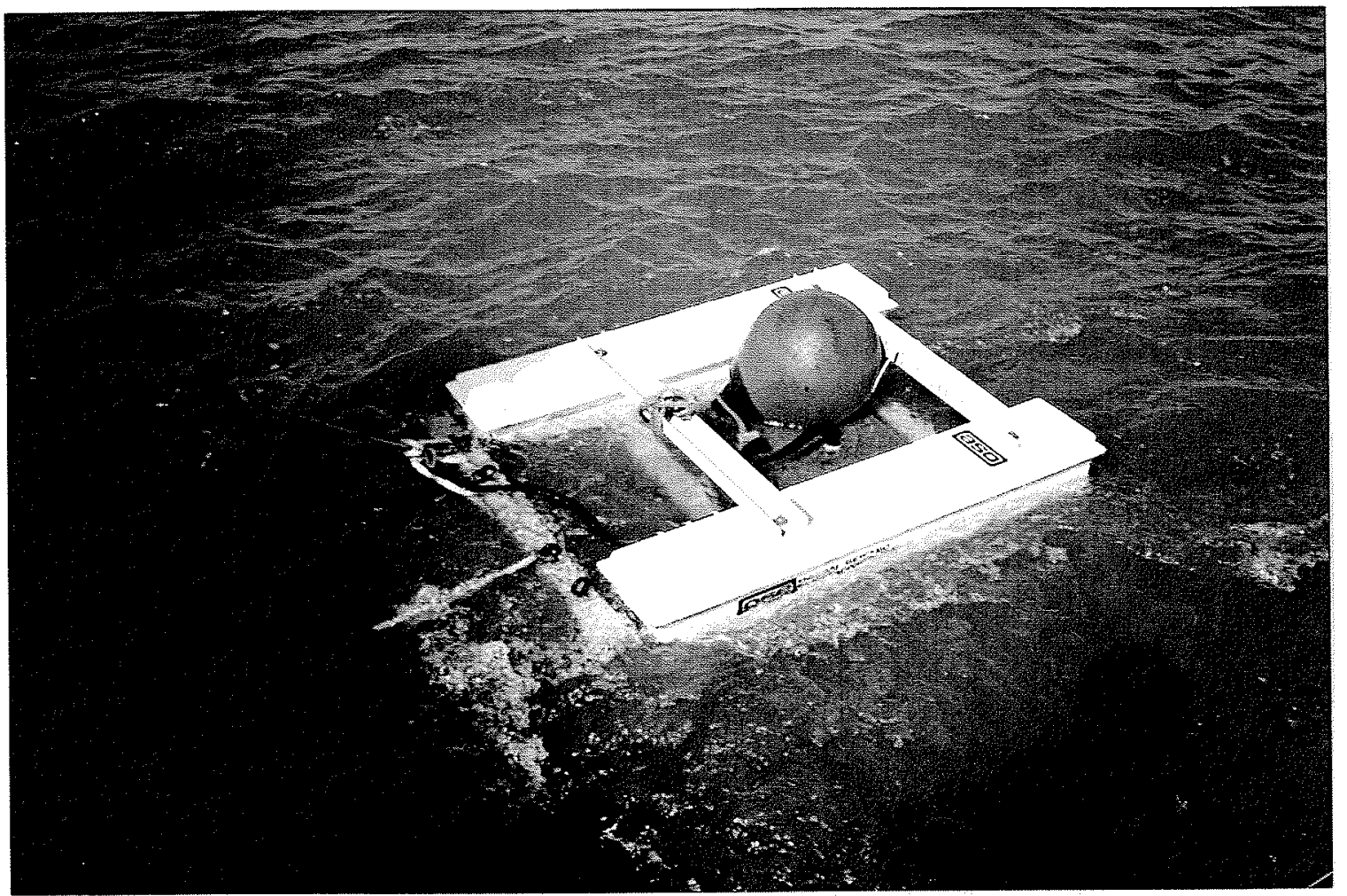

Figure A5. Typical boomer system in tow 


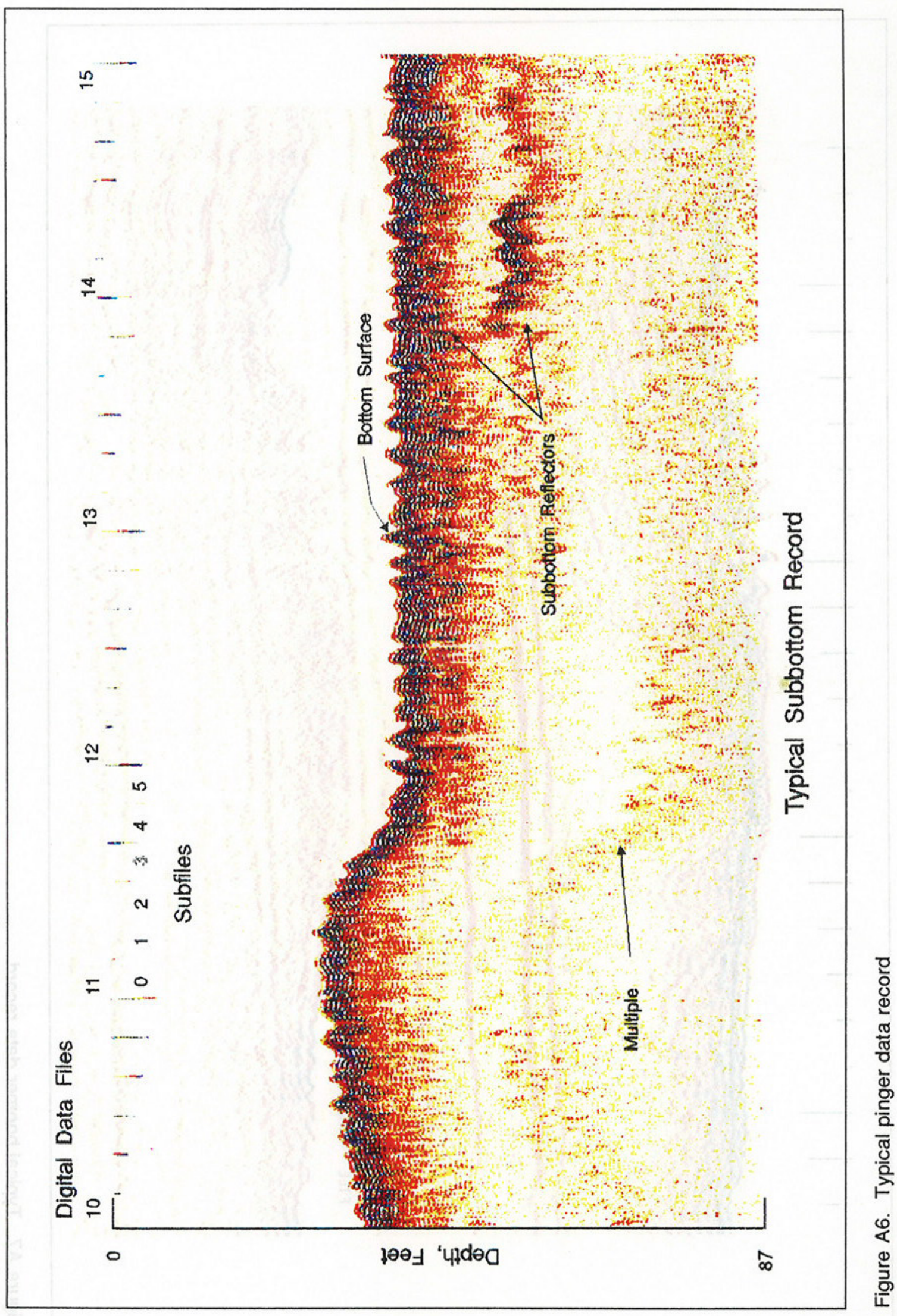




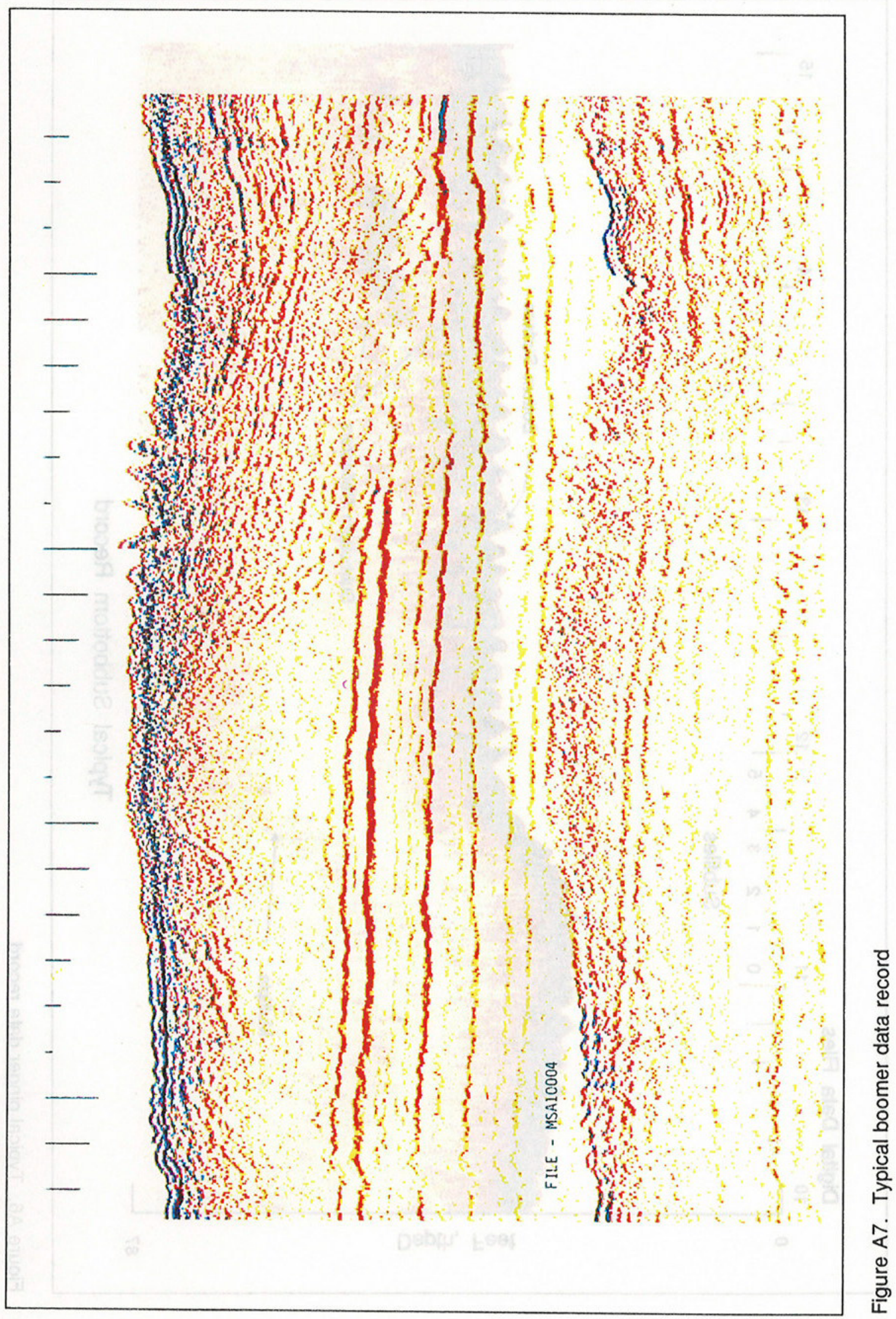




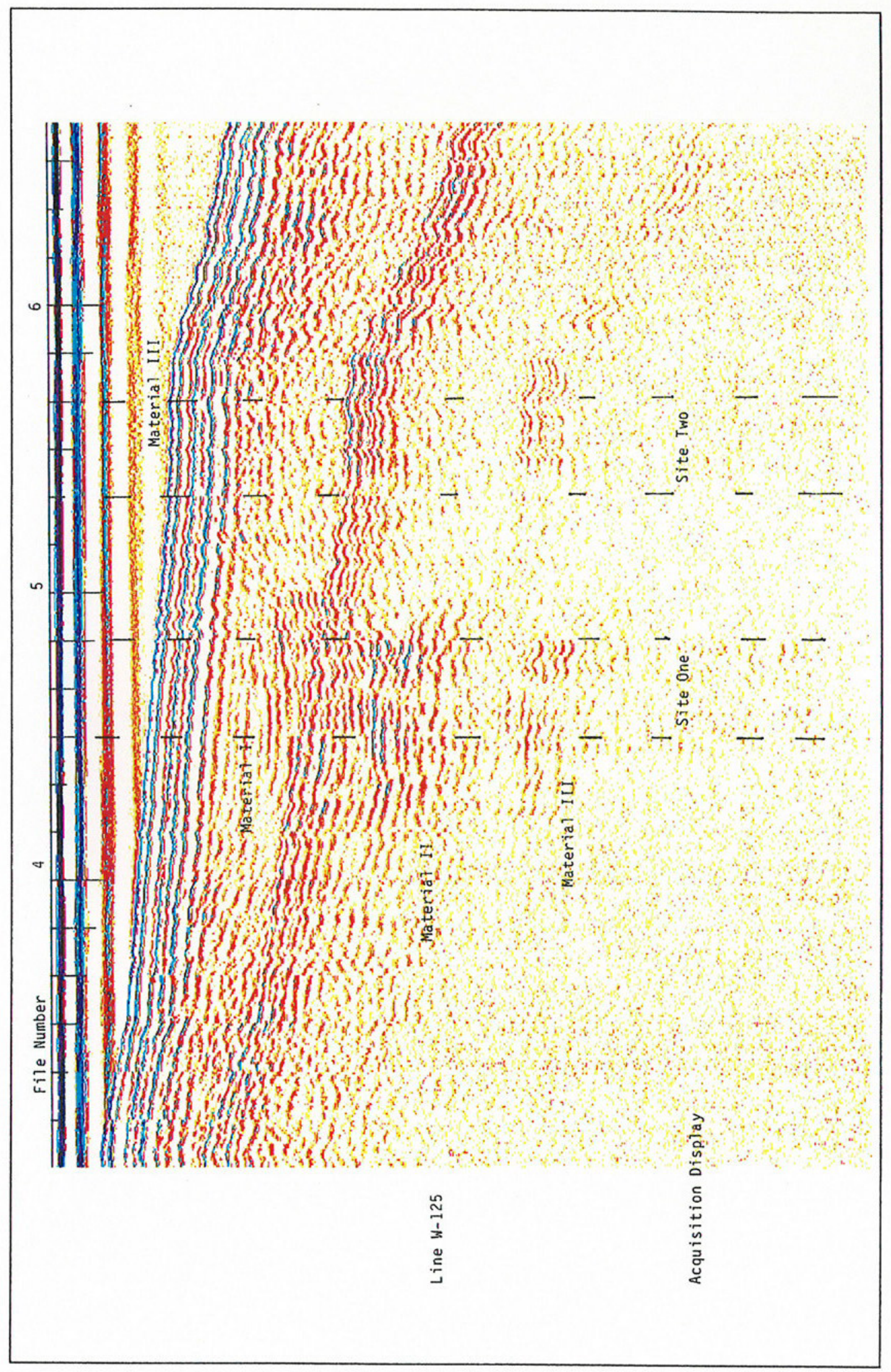

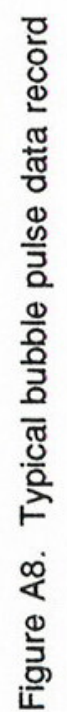


3 


\section{Appendix B Survey Planning}




\section{Boston Harbor, MA Navigation Improvement Project Information Sheet 1July 1992}

\section{US Army Corps of Engineers \\ New England Division}

Feasibility Report - Final Feasibility Report and Environmental Assessment completed in May 1988 in response to Senate resolutions, Committee on Public Works, 1 March 1968 and 11 September 1969. Report of Board of Engineers for Rivers and Harbors (BERH) was completed on 21 September 1988. The Chief of Engineers Final Report is dated 11 May 1989. The project was authorized in the Water Resources Development Act of 1990, signed on November 28, 1990.

While Boston's principal entrance and main access channels are 40 feet deep, the 3 major tributaries, along which the majority of port terminals are located, are 35 feet deep. The resulting tidal delays and limits on vessel size and loading place significant restrictions on shippers. The objective of the study was to substantially reduce the cost of transporting bulk commodities through the Port of Boston by eliminating or reducing tidal delays for larger vessels.

Alternative plans investigated included deepening of each of the three tributaries, the lower Mystic River (currently authorized as a separate project), Chelsea River and Reserved Channel were examined at incremental depths up to 42 feet. Also a nonstructural improvement entailing designation of specific Federal channel limits through the middle reaches of the harbor would result in an enlarged deepwater anchorage, at no cost.

Project Description (See Attached Figure):

- Reserved Channel - Narrow the 35-foot channel from 430 to 400 feet wide, widen the channel at its confluence with the Main Ship Channel, relocate Harbor lines at the confluence and deepen the channel to 40 feet, except for its upper 1,340 feet which would remain at 35 feet. Local dredging of widened berthing areas along the southern limit to 40 feet or greater.

- Chelsea River Channel - Deepening the existing 35-foot channel to 38 feet. Local dredging of berthing areas at the major petroleum terminals to 38 feet or greater and local relocation and alteration of utility crossings beneath the channel.

Figure B1. Boston Harbor, MA, Navigation Improvement Project information sheet (Sheet 1 of 6) 
- Mystic River Project - Deepen the existing 35-foot channel to 40 feet, except for an area at the upstream limit along the southern shoreline where the waterfront has been converted to non-navigation dependent uses and where existing users do not require depths greater than 35 feet. Local dredging of major terminal berthing areas to 40 feet or greater.

- Inner Confluence Area - Widen the 35-foot confluence of the Mystic and Chelsea Rivers and deepen to 40 feet to enable deepening of the two river channels.

- President Roads Ship Channel - Nonstructural designation and remarking of specific Federal channel limits along the southern reach of the Roads connecting the outer confluence of the three entrance channels which the Inner Harbor Main Ship Channel, resulting in a $20 \%$ enlargement of the deepwater anchorage to about 420 acres.

\section{Pertinent Data on Project Features:}

- Channel Dredging $-2,038,000 \mathrm{cy}+94,000$ cy rock $=2,132,000 \mathrm{cy}$

- Berthing Area Dredging by non-Federal interests (to - 40 feet) - 228,700 cy

- Utility Relocations - Chelsea River Channel only - bwer Boston Edison and MBTA electric cables, and remove abandoned MWRA water tunnel. Provide increased protection to Boston Gas gas siphon.

- Channel Limit Designation/Realignment - President Roads Ship Channel - Designate specific Federal channel limits through the Roads to jurisdictionally connect entrance channels with the Main Ship Channel and enlarge the anchorage area by 70 acres in deepwater.

Views of Others: The Massachusetts Port Authority (Massport), the sponsor, has indicated its willingness and capability to act as project sponsor stated in a 14 March 1989 letter. Harbor users, local chambers of commerce, etc., are supportive of the project.

The Secretary of Environmental Affairs provided a letter of strong support for this project dated 14 December 1989. State agencies condition their support for continued study on the suitability of dredging and ocean disposal of the material.

Federal agencies condition their approval of the project on the design of an acceptable dredge disposal plan.

The U.S. Coast Guard expressed concern for navigational safety in the Chelsea River Channel in the vicinity of the Chelsea Street Bridge. The City of Boston plans to replace the dilapidated fender system. 
Cost of the Recommended Project:

Estimated Implementation Costs: Fully Funded Estimate (includes inflation)

Eederal (Commercial Navigation)

Corps - $65 \%$ of General Nav. Features (GNF) Cost

U.S. Coast Guard - Rebcation Nav. Aids

$\$ 21,200,000$

TOTAL

$\$ 21,215,000$

Nen-Federal

$25 \%$ of GNF Cost - Up Front

$10 \%$ of GNF Cost - Payback (minus reloc. credit)

$100 \%$ Berthing Area Deepening

Utility Relocation - Chelsea River Only

TOTAL

IOTALPROJECT COST

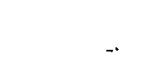

$\$ 7,790,000$

$2,160,000$

$2,400,000$

250.000

$\$ 13,300,000$

$\$ 34,515,000$

Project Economic Feasibility (March 1992):

Project Economic Life - 50 years, Base Year 1995

Benefit - Cost Ratio: 1.68 (Discount Rate FY92 8-1/2)

\section{Project Effects:}

Environmental Quality: Construction of the project will be scheduled in such a way as to avoid adverse impacts on aquatic life. Analysis of environmental testing of dredge material has found that material from the Reserved channel is suitable for open ocean disposal and that sediments from the Mystic and Chelsea channels are unsuitable for unconfined ocean disposal. Capping, using suitable project material, is included in the cost estimate and schedule.

Other Effects: As the New England Region's largest and most active port, shipping over 20 million tons of cargo annually, improvements to Boston Harbor will enhance the regional economy through lowering transportation costs for bulk and containerized cargo. The deepening of existing channels using a waterborne plant will not result in adverse social impacts.

Figure B1. (Sheet 3 of 6 ) 


\section{Direct Project Beneficiaries:}

The Reserved Channel:

Coastal Oil New England Inc.(Petroleum), Boston Edison (Petroleum for Power

Generation), and shipping lines using Massport's Conley Container Terminal.

The Mystic River Channel:

Exxon USA, Inc.(Petroleum), Distrigas of New England (LNG)

Prolerized (Scrap Metal Export), Boston Edison (Petroleum for Power Generation)

All beneficiaries on the Chelsea River Channel are petroleum:

Mobil Oil, Global , Northeast Petroleum, Gurf Oil Co., and Coastal Oil New

England Inc..

Harbor users along the project channels have contacted to reevaluate project benefits. Users, not currently listed above as direct beneficiaries will be added if it can be shown that the project will improve their operations. The results of this analysis should be available in July 1992

\section{Project Implementation Schedule:}

Initiate Design

Design Memorandum Apprv'd

Sign Local Cooperation Agreement

Complete Plans and Specifications

Award Construction Contract

Project Completion
September 1990

May 1993

November 1994

February 1994

February 1995

May 1996

Figure B1. (Sheet 4 of 6 ) 


\section{Other Information:}

Sponsor Supporting Activity - Massport is actively working with terminal owners for joining forces to perform environmental testing for dredge material to be removed from berthing areas.

Massport will obtain the required permits from Federal and state agencies. They began this process on 8 May 1991 by filing an Environmental Notification Form (ENF) with the-MEPA Office. The Secretary of Environmental Affairs Certificate was signed 7 June 1991. An Environmental Impact Report (EIR) is under preparation by Massport through a contract with Normandeau Associates. The final permits must be obtained prior to the signing of the Local Cooperation Agreement scheduled for November 1994.

EIS - The Corps decided, in April 1992, to prepare an EIS for the project. This decision was based on the substantial change in the volume of material to be dredged $(561,000 \mathrm{cy}$ of material from berths that are not project beneficiaries), and the significant public and agency controversy regarding the capping alternative for disposal. The EIS process will parallel that of the Massport EIR and will result in a combined EIS/EIR document. There is no direct impact on the environmental impact phase of the project design, however, the process will delay the request for a new construction start from June 1992 to June 1993. The impact of this decision are included in the costs and schedule shown herein.

Project Management Plan - The Project Management Plan (PMP) has been approved by NED and Massport. Modifications, to include changes made since August 1991 and summarized herein, are being prepared.

Chelsea River Issues - Massport sponsored two workshops for Chelsea Creek interests to-discuss issues related to petroleum terminals. These "tank farms" supply one quarter of the regional heating oil and over two thirds of the gasoline as well as other products. The narrow opening through the Chelsea Street Bridge severely limits the size of tankers using upstream terminals. The collapse of a bulkhead wall and blockage of the channel in January 1990 add to the vulnerability of the region to Chelsea River shipping, storage and distribution. NED has participated in these workshops. The recommended project will improve present conditions but can not resolve all issues facing this area. There has also been renewed interest in the replacement of the Chelsea Street Bridge by the City of Boston and the Coast Guard. The Coast Guard is proceeding with the required efforts to obtain funds for a new bridge through the Truman-Hobbs Act. 
Ship Simulation Model Studies - A hydrodynamic model, to determine changes in currents caused by the project, has been developed at NED. Results from this model has been used in a ship simulation model which is required to assure that the project is both safe and efficient. A deeper channel, which changes currents, and heavier ships will effect the response and handling of the pilots. Ship Simulation is underway at work on 14 October 1991 and is scheduled for completion in October 1992. Verification runs of existing channel conditions were completed in February 1992. Tests for project conditions were completed in April 1992. Analysis of the results which could lead to design changes, if any, will be completed in July 1992.

Disposal of Dredged Material - Sediments dredged from the Mystic and Chelsea channels contain some contamination which makes it unsuitable for unrestricted ocean disposal. The project cost and schedule includes capping the contaminated sediments with clay which underlies the contaminated material. There is sufficient volume for the clay in each channel to provide an adequate cap for it's sediments. Because the MBDS is located in deep water ( 80 to 100 meters), there is concern from both Federal and state agencies that capping may not be effective in protecting the water from contamination. The Corps has done extensive research and pilot studies to develop techniques for capping. A workshop held on 15 October 1991 brought together all concerned agencies to discuss disposal issues. Their concerns will be addressed in a dredge material disposal plan which will include design, construction and monitoring .

Disposal at MBDS may also be subject to more extensive controls depending on the final plan for the proposed Stellwagen Bank Sanctuary.

Economic Re-evaluation - During July 1992 results of an economic survey of project beneficiaries will be completed. The objective of this survey, and the analysis which will follow, is to update the economic justification of the project last done in 1988. Beneficiaries may be added to the project if their operations become more efficient from the deeper channels.

Other Major Projects and Issues - There are two major projects underway in Boston Harbor which will continue during the same timeframe as the Navigation Improvement Project: MWRA projects for the cleanup of the harbor and the Central Artery / Third Harbor Crossing. Close coordination with these projects will be essential.

There is major concern for the extent and toxicity of the industrial waste site adjacent to the MBDS. The EPA is investigating this issue and may recommend solutions. Close coordination with EPA's work will continue.

Figure B1. (Sheet 6 of 6 ) 
MEMO FOR: Thomas R. Patin (EP-D)

FROM: ROBERT F. BALLARD, JR.

SUBJECT: DOTS-Sponsored Trip to New England Division (NED)

1. As a result of a letter request from NED dated 6 February 1992, Subject: Dredging operations Technical support, a technologY transfer visit was made to NED on 7 April 1992. Messers. Richard G. MCGee (HS-H), Keith J. Sjostrom (GG-F), Thomas S. Harmon (GG-F), and Robert F. Ballard, Jr. (GG) were the WES personnel in attendance at the meeting. The purpose of the meeting was for WES personnel to present a seminar on the application of Acoustic Impedance Technology to the upcoming Boston Harbor Dredging Improvement Project.

2. Mr. Peter Jackson, Project Manager of the Boston Harbor Project was point of contact. Mr. Jackson's request for the seminar came about as the result of his having seen the wES Dredging Research Program video "Acoustic Impedance Technology" produced by DRP work unit \#32470 "Rapid Measurement of Properties of Consolidated sediments".

3. Prior to the meeting at NED, Mr. Jackson sent me sufficient background information on the overali project to enable us to plan a presentation tailored specifically to his application. It was felt that four wES people should participate in this meeting because each is a specialist and could perform as an expert during a formal tutoral presentation and answer questions posed in open forum at the end of the seminar. Approximately 20 people were in attendance during the meeting. Representatives in addition to NED personnel, were from the Massachusetts Port Authority, USGS, and the EPA.

4. The format and content of the seminar can be gleaned from the attached hard copies of my Vu-Graphs. Our reception was both hospitable and communicative. Audience participation was exceptional. We were told that an intelligent decision could now be made by NED regarding the possible use of Acoustic Impedance during the planning phase of the Boston Harbor Project. We will be contacted by $\mathrm{Mr}$. Jackson when our degree of participation is decided upon.

5. Closing comment: I am under the impression that this undertaking is a prime example of excellent cooperation between the complementary missions of DOTS and the DRP.

cC: Dr. Don Banks (GS)

Mr. Clark McNair (CP-D)

Mr. Russ Tillman (CP-D)

Figure B2. WES Memorandum for Record (Sheet 1 of 5) 

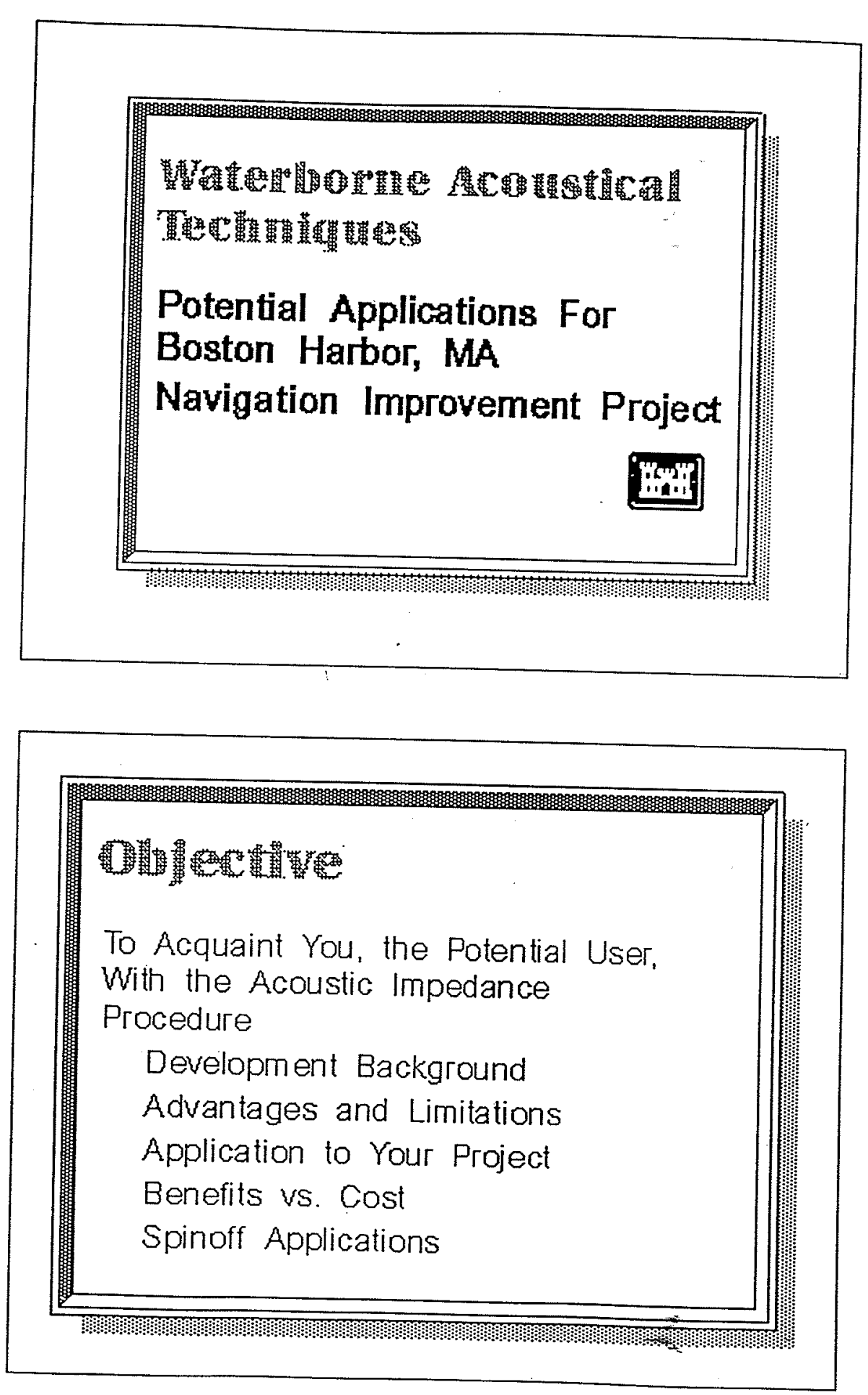

Figure B2. (Sheet 2 of 5 ) 

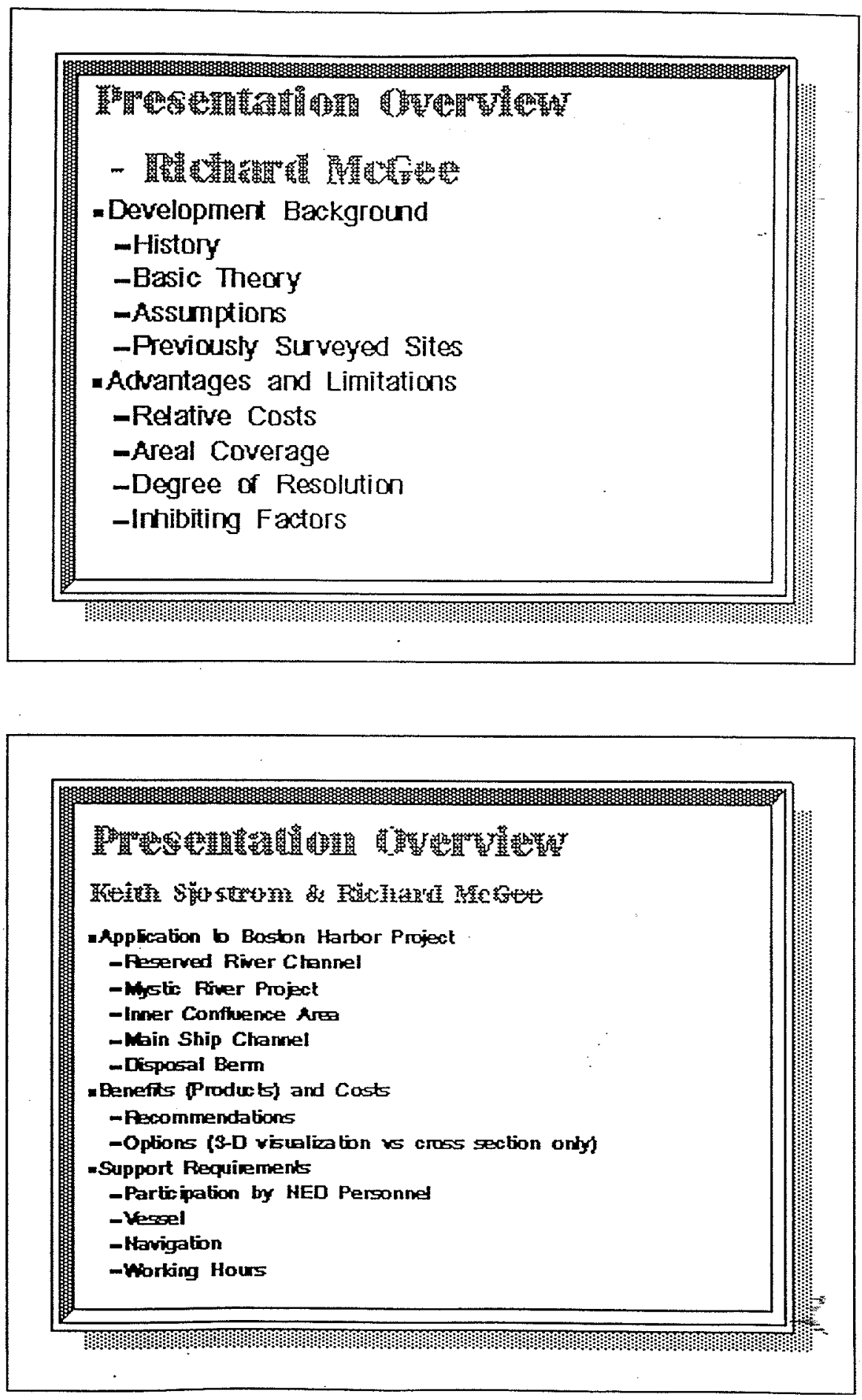

Figure B2. (Sheet 3 of 5) 

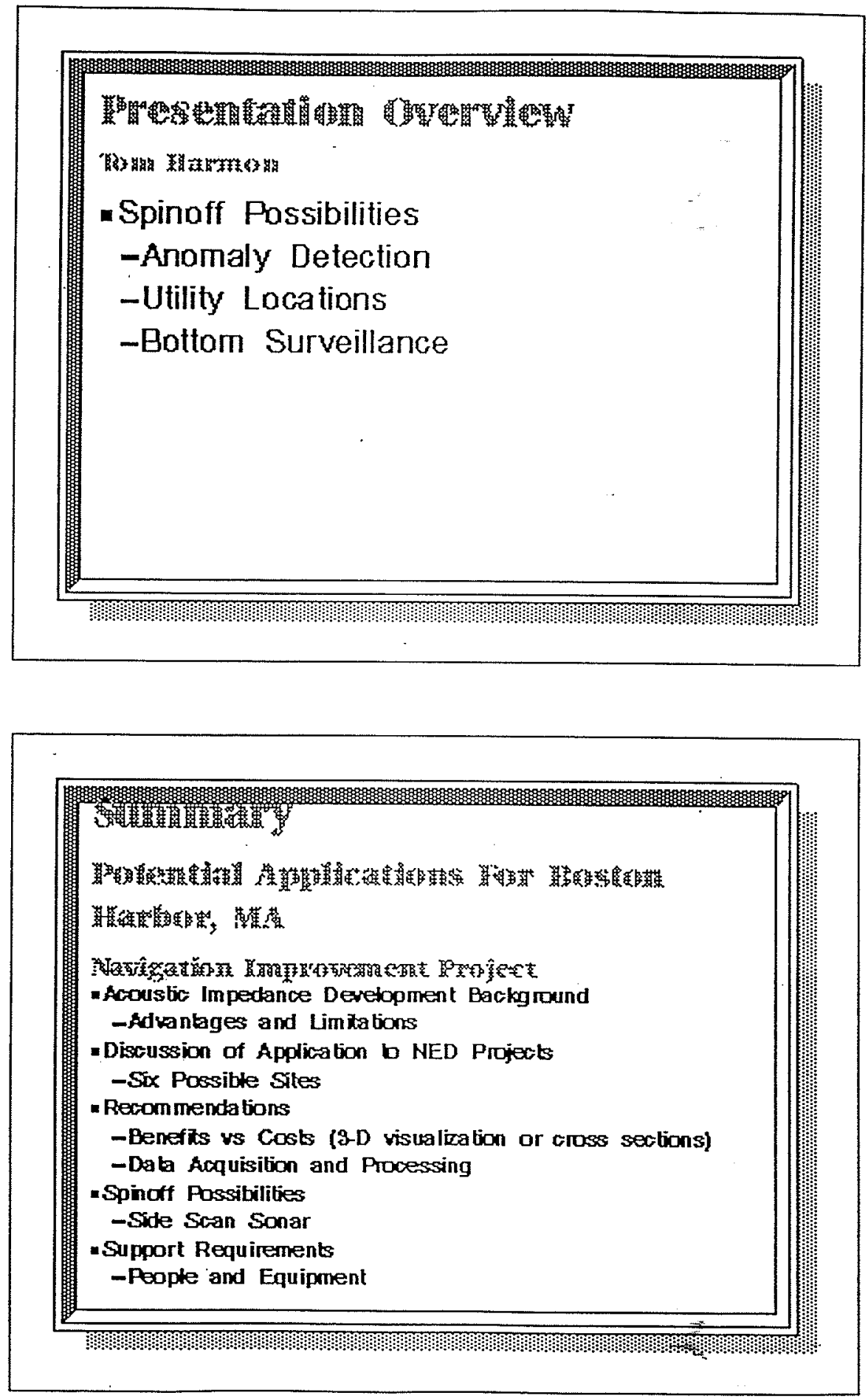

Figure B2. (Sheet 4 of 5) 


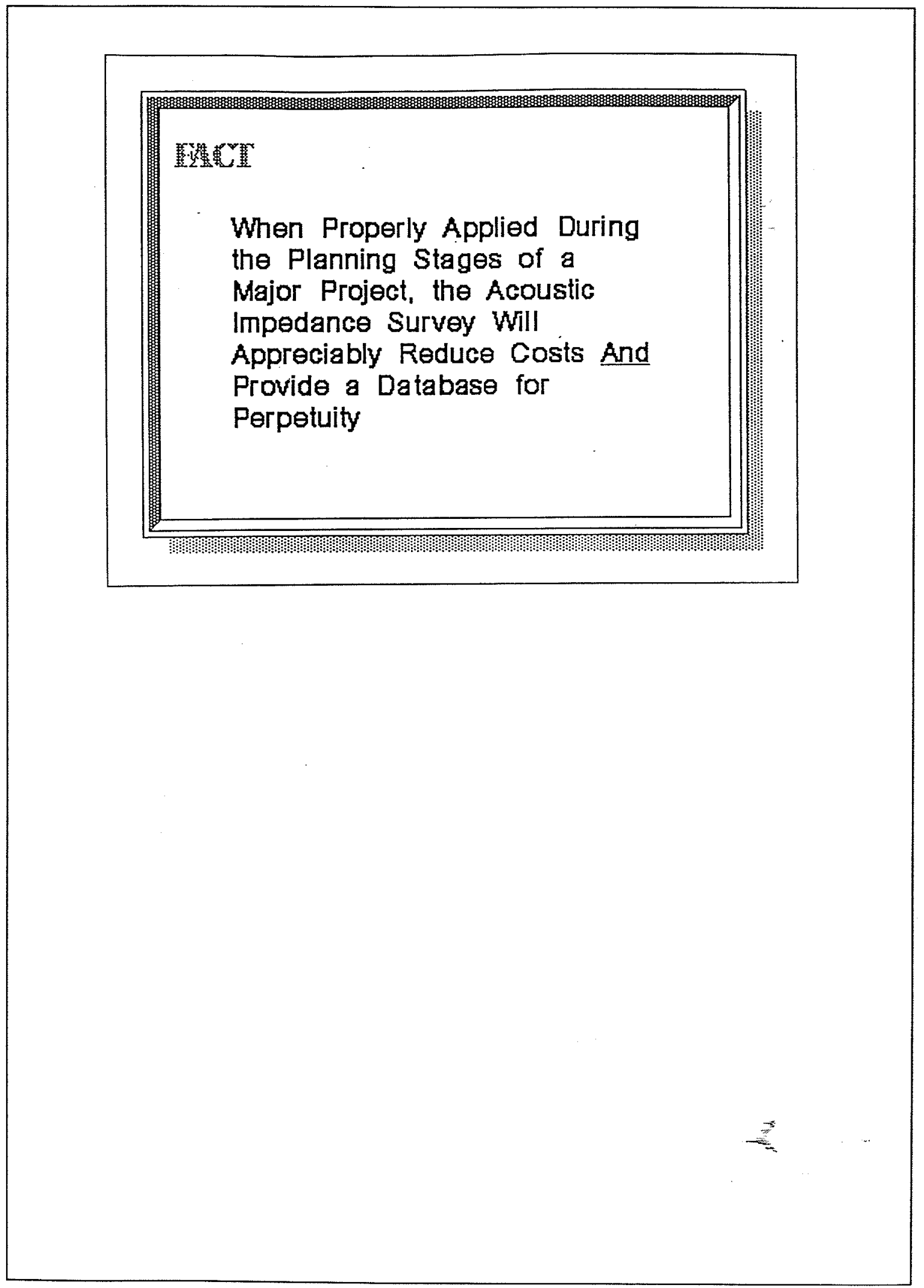

Figure B2. (Sheet 5 of 5 )

B12 


\author{
SUBBOTTOM HYDRO-ACOUSTIC SURVEY OF THE \\ BOSTON HARBOR TRIBUTARIES: RESERVED CHANNEL; \\ MYSTIC RIVER; CHEISEA RIVER; AND, INNER CONFLUENCE
}

\title{
Background
}

1. A design memorandum for improvement dredging of the three tributaries to Boston Harbor are soon to be prepared by the New England Division. A description of the materials to be dredged in terms of density and soil classification are necessary for planning and monitoring of the dredging program and disposal. The USAE Waterways Experiment station (WES) is involved, through the Dredging Research Program (DRP), in developing a rapid geophysical technique to determine material characteristics of bottom and subbottom sediments. Acoustic impedance values determined from the seismic reflection data are directly related to the density and material type of the subbottom sediments which in turn are factors related to the degree of difficulty in removing this material through dredging. Results to date indicate good correlation between the values determined with this technique and insitu information collected at several sites.

\section{objective}

2. The project objective is to quantify with depth the bottom and subbottom sediments in terms of material density and soil classifications to a minimum depth of -42 feet Mean Low water (MLW) in the Mystic River, Inner Confluence, and Reserved Channel and to a minimum depth of -40 feet MLW in the chelsea River (see Figure 1). The results will supplement soil borings previously taken by providing continuous profile line coverage of the entire length of the project area. The soil classification analysis will enable accurate estimates of volumes of clay and gravel versus silt to be made. In addition, the extent of rock zones and the volume or quantity of rock to be removed is desired. This will facilitate the accurate positioning of any additional borings as may be required, particularly in areas of suspected rock outcroppings. This information will be used to compute project costs and in the alternative disposal analysis to be included in the project Environmental Impact statement.

\section{Scope of Work}

3. An array of geophysical instruments will be utilized to meet the objectives of the investigation. The basic suite of systems include:

a) a 3.5 to $7.0 \mathrm{kHz}$ high resolution "pinger" system,

1

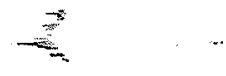

Figure B3. Final proposal submitted to NED (Sheet 1 of 17) 
b) an integrated, high definition $400 \mathrm{~Hz}$ to $5.0 \mathrm{kHz}$ "boomer" system,

c) A new 2.0 to $10.0 \mathrm{kHz}$ chirper to be used in conjunction with the above if it appears advantageous to the project, and

d) a dual frequency side scan sonar system.

This equipment will be used to produce the necessary seismic energy to obtain reflection signatures from the bottom and subbottom marine sediments. primary channels of acoustic data will be acquired with a digital data acquisition system. Data. collected during the survey allows continual data quality control and initial analysis. Further data analysis, processing, and visualization will be performed post-survey at WES. Acquisition and interpretation of traditional "shades-of-gray" analog reflection records will be performed concurrently with the digital acoustic impedance techniques.

4. A dual frequency side scan sonar is typically towed during a survey to provide increased bottom coverage and detect any possible dredging or navigation hazards. Although entirely qualitative, the side scan sonar can be interpreted to differentiate bottom sediments in terms of material types, such as sands versus clays, in a rapid continuous manner. In addition, bulkhead foundation assessment and depths along the tributaries can be determined.

5. Continuous subbottom profiles of the acoustic reflection amplitudes obtained from the seismic systems, an example of which is presented in Figure 2, will be provided within three weeks after the field survey. The analog reflection records will also be provided upon request. These records will be annotated with horizontal control, existing core locations, and preliminary interpretations of the site characteristics. Upon receipt of ground truth information from existing core locations, acoustic impedance calculations, and density estimates will be determined (see Figure 3) to develop a set of seismic parameters to process the complete data set. During processing, tabular listings of density and material type versus depth (see Figure 4) as well as plots of density versus depth (see Figure 5) will be provided at sufficient intervals along the profile lines. The processed data will be adjusted to MLW and correlated to the positioning data.

6. The virtually continuous data coverage of the subbottom material are incorporated into a terrain modeling software package to provide a three-dimensional (3-D) view of the project area. An example of 3-D view of the distribution of sediment densities in a portion of the Gulfport Ship channel, MS is shown in Figure 6,. Displays of this type provide improved data interpretation and visualization assistance as compared to

Figure B3. (Sheet 2 of 17)

B14 
traditional two-dimensional illustrations. views, color-coded according to density or material type, can be created by picturing the region from any perspective. Three-dimensional visualization also permits volumetric calculation of the differing sediment units and/or the amount of material to be removed through dredging. Furthermore, a detailed data base is established for project monitoring and long-term planning of future work.

7. Proposed Survey: Maps of the project area with the proposed survey lines illustrated are presented in Figures 7-10. The survey is divided into four parts, and is outlined as follows:

a. Survey of Reserved Channel: Improvement dredging is likely within the existing Federal channel as well as two additional areas near the mouth of the tributary. Although current proposed plans call for improvement to the channel for a distance of only 4,000', survey lines will extend approximately 4,500'. Four profile lines will be surveyed. Two lines will be 100' either side of the centerline and the remaining two will be $250^{\prime}$ to either side of the centerline. Four additional lines with spacing of $150^{\prime}$ and length of 1,600' will be run at the mouth paraliel to the the centerline starting $400^{\prime}$ to the north. Finally, seven profile lines parallel to the centerline of the 35' main ship channel with $150^{\prime}$ spacing will be taken starting at 200' downstream of buoy \#10 and proceeding upstream for 3,000'. Side scan sonar will be used particularly along channel edges where bulkheads exist. Specific effort will be made to identify, locate, and estabiish the approximate depth of a power line in the channel. Additional survey lines will be performed depending on actual subbottom conditions or as requested by New England Division personnel.

b. Survey of Mystic River: Improvement dredging is likely only within portions of the existing Federal channel. However, the entire channel between the Mystic River (Tobin) Bridge and the Alford Street Bridge will be surveyed. Seven profile lines, six 5,500' in length, and the northern most $4,500^{\prime}$ in length will be oriented about the centerline with spacing of 200 ' except for the outermost lines which will have spacing of $150^{\prime}$. Additionally, in areas where rock is expected off the Exxon Pier two additional profile lines of 1,000' in length will be made. side scan sonar will be used particularly along channel edges where bulkheads exist. Additional survey lines will be performed depending on actual subbottom conditions or as requested by New England Division personnel.

c. Survey of Inner Confluence: Improvement dredging is likely within the existing Federal channel as well as along the northeast corner of the area. Because of suspected rock, eight profile Iines, parallel with the centerline into the chelsea River, will be spaced 100' apart. Five lines will be 2,200' and

Figure B3. (Sheet 3 of 17) 
the other three will be 1,500' in length. Five lines, each $2,000^{\prime}$ in length, with a spacing of $150^{\prime}$ will be parallel with the centerline of the Mystic River approach. Finally two additional profile lines will provide information along the northern and eastern edges of the area. The northern edge profile will be $1,500^{\prime}$ in length and the eastern profile will be 3,000'. Side scan sonar will be used particularly along channel edges where bulkheads exist. Specific effort will be made- to identify, locate, and establish the approximate depth of a telephone cable crossing the Inner confluence. Additional survey lines will performed depending on actual subbottom conditions or as requested by New England Division personnel.

d. Survey of the Chelsea River: Improvement dredging is likely within the existing Federal channel. Because of the narrowness of the channel below the chelsea street Bridge only two profiles will be taken -- one on either side of the channel. In the upper reaches a total of thirteen profiles will be obtained. Directly upstream of the Chelsea street Bridge five profiles each 3,000' in length will be parallel to the eastern bank and spaced $350^{\prime}$ apart. Further upstream three profiles $2,500^{\prime}$ in length parallel to the Gulf oil dock shall be spaced 200' apart. Finally, parallel to those profiles there will be four more profiles covering the turning basin each being $1,500^{\prime}$ in length and spaced $200^{\prime}$ apart. The last profile will be along the front of the Global-Gibbs and Northeast oil docks. Side scan sonar will be used particularly along channel edges where bulkheads exist. Specific effort will be made to identify, locate, and establish the approximate depth of utility crossings in the channel. Additional survey lines will be performed depending on actual subbottom conditions or as requested by New England Division personnel.

8. WES will provide all necessary geophysical equipment and recording devices to complete the project. WEs personnel will set up and operate all geophysical equipment during subbottom surveying exercises and coordinate survey operational procedures. WES also has the authority to decide on a daily basis, with input from the captain of the survey vessel, if conditions (weather, sea state, white-capping, etc.) are acceptable for subbottom profiling tests. New England Division project personnel are encouraged to actively participate in the data acquisition and processing exercises to both assist in and gain an understanding of the survey and analysis procedures.

9. One eight-hour day for dock-side mobilization to load, set up, calibrate, and, if necessary, troubleshoot the geophysical equipment will be allowed. In addition, one day of project site reconnaissance will be allowed to acquire subbottom signatures in all three areas where physical cores have been obtained. This will provide ground truth information to calibrate the acoustic predictions.

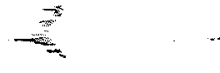

Figure B3. (Sheet 4 of 17) 
10. WES personnel will post-process all geophysical field data and prepare a letter and final report of the test results. The continuous subbottom cross-sections of the acoustic reflection amplitudes will be provided within three weeks after the field survey: These records will be annotated with horizontal control, existing core locations, and preliminary interpretations of the site characteristics. A letter report of the results will be presented to the New England Division personnel in a one-on-one visit before mid-January 1993. All aspects of the survey and the results determined will be carefully explained so that maximum benefits will be derived from the investigation. The final report will detail the methods used to acquire, calibrate, and process the data and present the findings and conclusions in a clear, concise manner that will directly address the purpose of the geophysical survey. The final report will be completed by April 1993 and will document, in addition to soil classification densities and volumes, items such as utility crossings, bulkhead foundation information, and suggestions for additional borings.

\section{Support Requirements}

11. The New England Division is expected to provide the following support for the successful completion of this task. The cost of these items is not reflected in the project cost estimate.

a. A survey vessel and crew able to conduct the required survey. The vessel must be at least $45^{\prime}$ in length with at least 60 square feet of back deck areas and an enclosed area to house the graphic recorders and computers and protect them from the elements.

b. Navigational and positioning support (horizontal control) to include pre- and post-plots of the survey area with reference marks every 200'. If possible, the digital data acquisition system will be interfaced directly with the vessel's positioning system. An on-board $x-y$ plotter is recommended if the capability exists.

c. Continuous fathometer soundings and water depths corrected for MLW. This is required to correlate depth measurements with the geophysical equipment and to allow adjustments for tidal fluctuations.

d. The equipment and means necessary to take 5 to 10 gravity cores at locations within the survey site. These locations will be selected by wes personnel during the data acquisition phase of the investigation. The insitu information (bulk density, mean grain size, water content, etc.) will be used to construct acoustic impedance and density estimates for

5

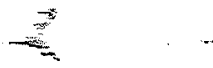

Figure B3. (Sheet 5 of 17) 
the local sediment regime. The cores will be analyzed by the WES Soils Testing Facility or at the New England Division Environmental/Materials Laboratory.

e. If necessary, assistance in loading and unloading the geophysical equipment on and off the survey vessel.

12. It is recognized that during data acquisition, wES personnel typically work 12 hour days to minimize the number of days on the water and to expedite data collection. The exact days and times will be finalized two weeks prior to the start of the survey. As with all field operations, considerable flexibility should be allowed in the schedule.

\section{Reporting Results}

13. The goal is to have the results available to New England Division personnel as soon as possible after the field work is completed since the results will likely be used in preparation of an Environmental Impact statement requiring this input by 15 January 1993. The annotated amplitude cross-sections and preliminary data analysis will be made available within two weeks of completion of the field survey. The results and interpretations will be drafted into a letter report and presented to New England Division personnel during January 1993. A complete and comprehensive final report of the data acquisition and processing procedures, final results, interpretations, and conclusions will be completed by April 1993. 


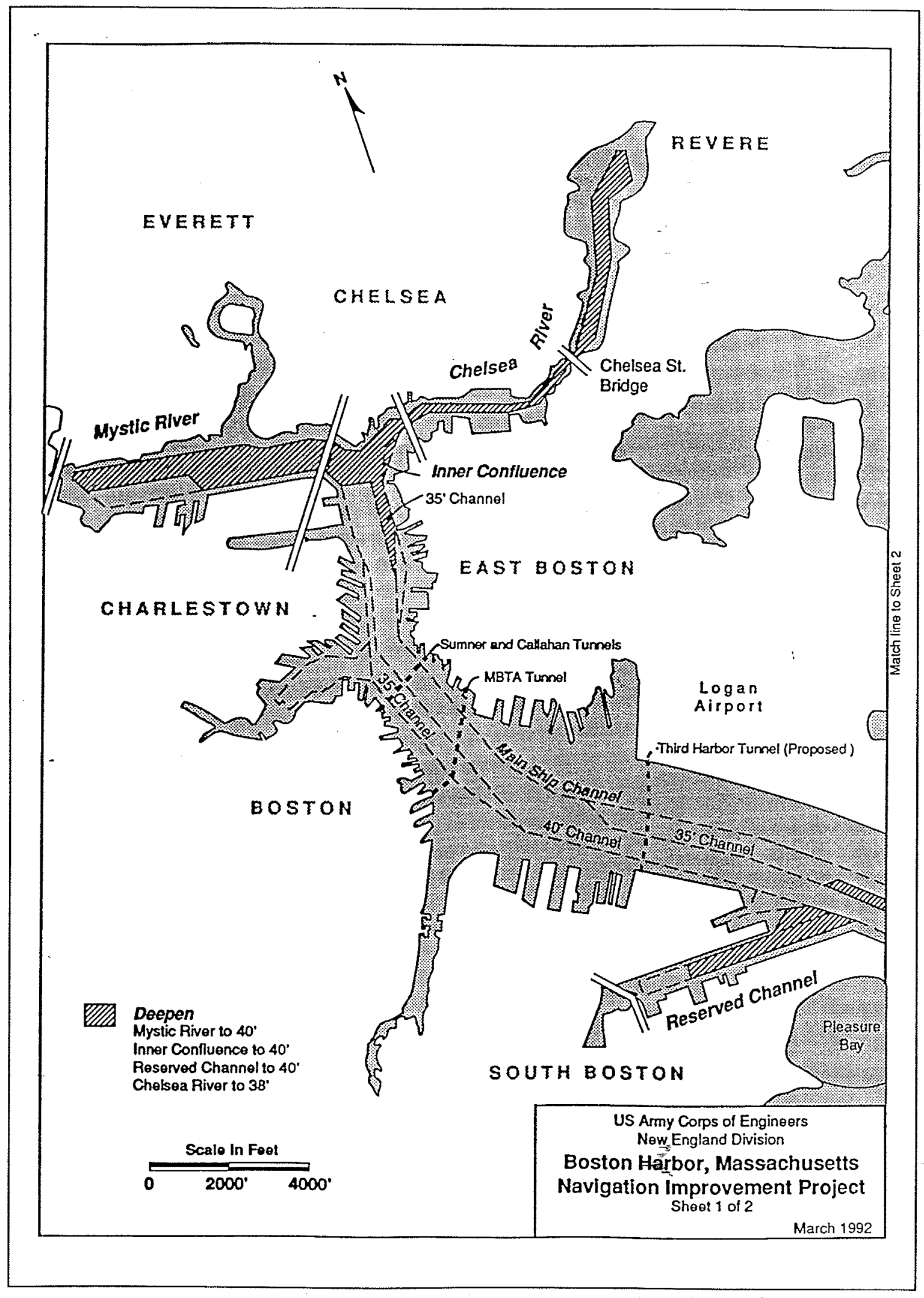

Figure B3. (Sheet 7 of 17) 


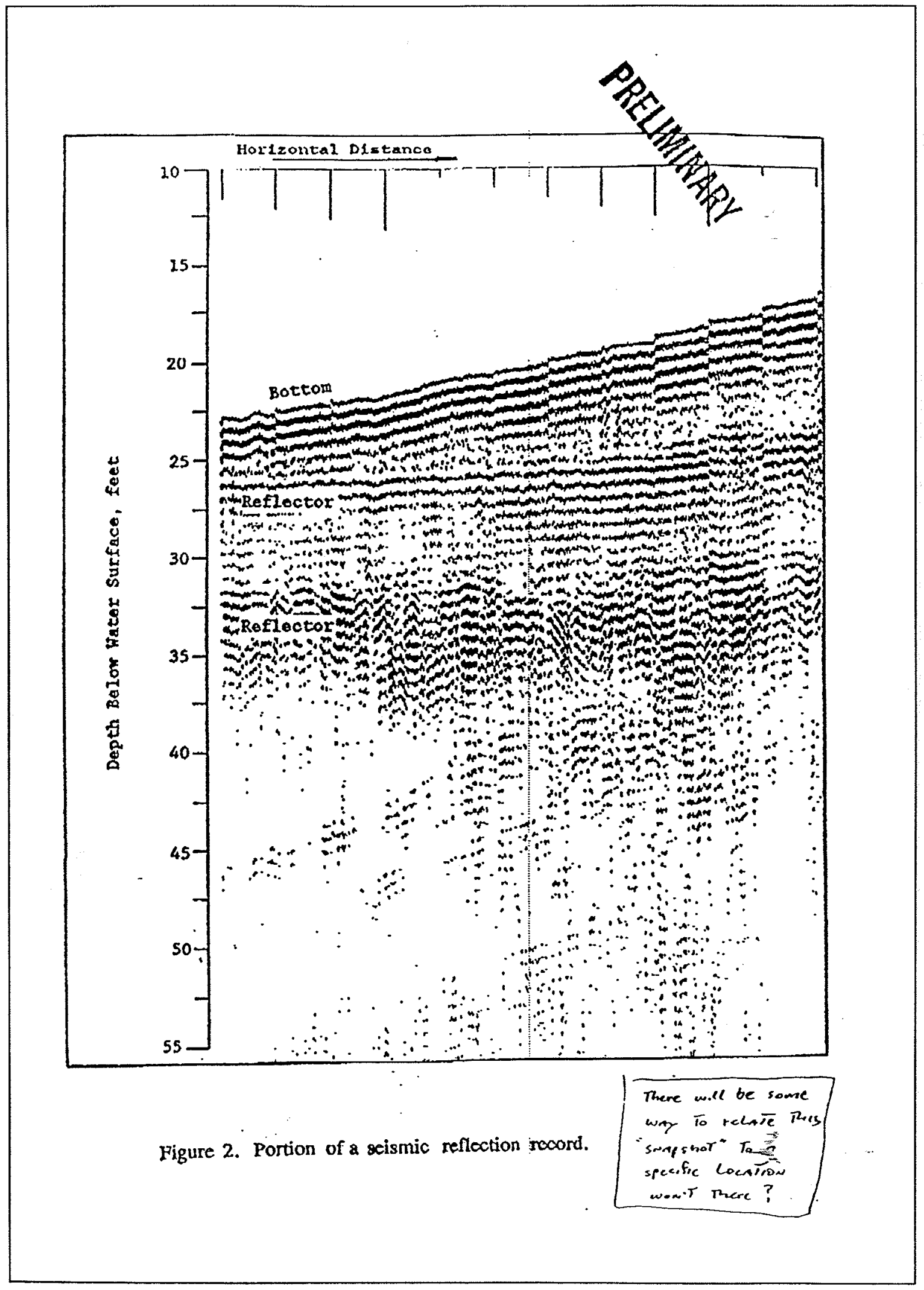

Figure B3. (Sheet 8 of 17) 


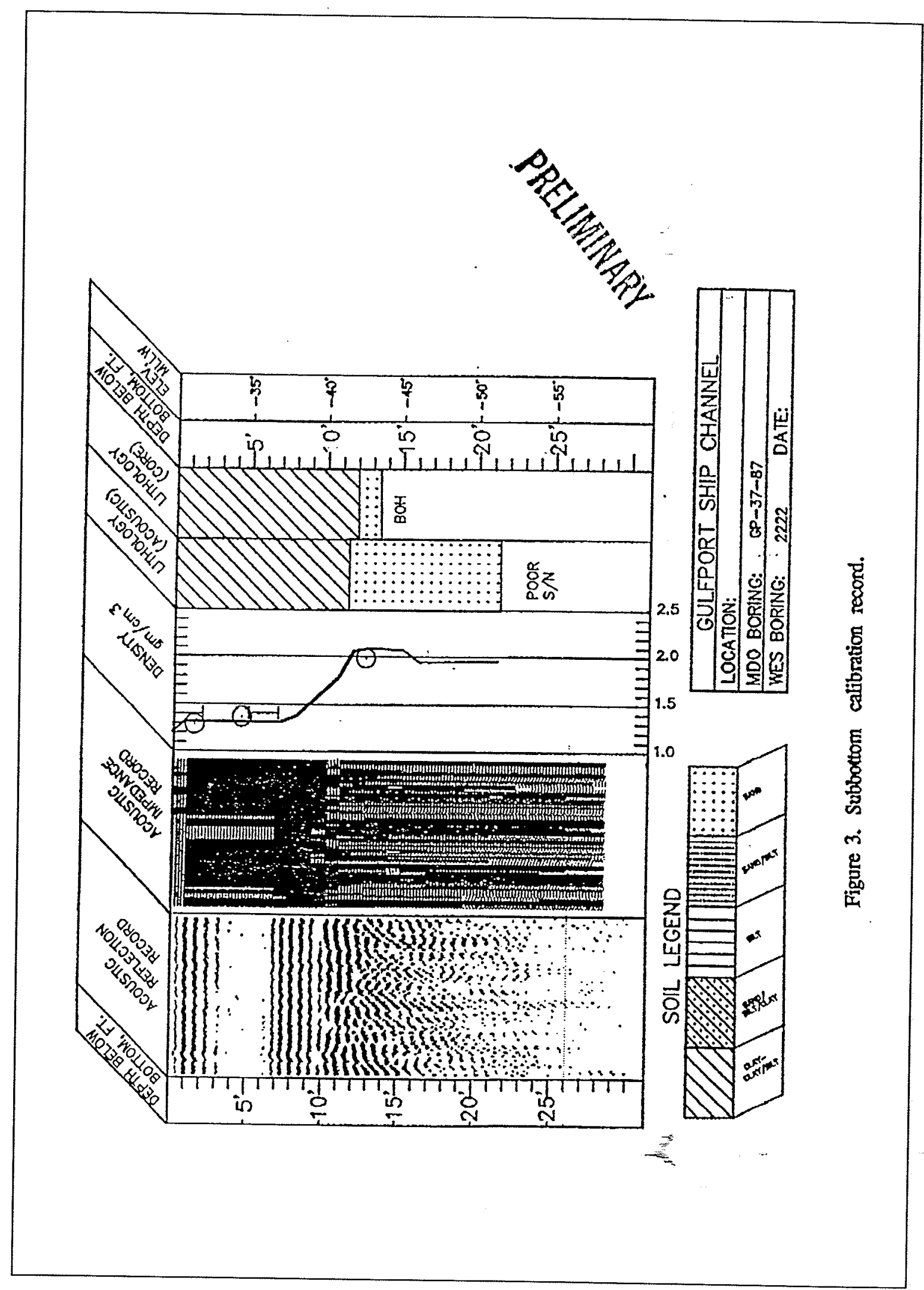

Figure B3. (Sheet 9 of 17) 


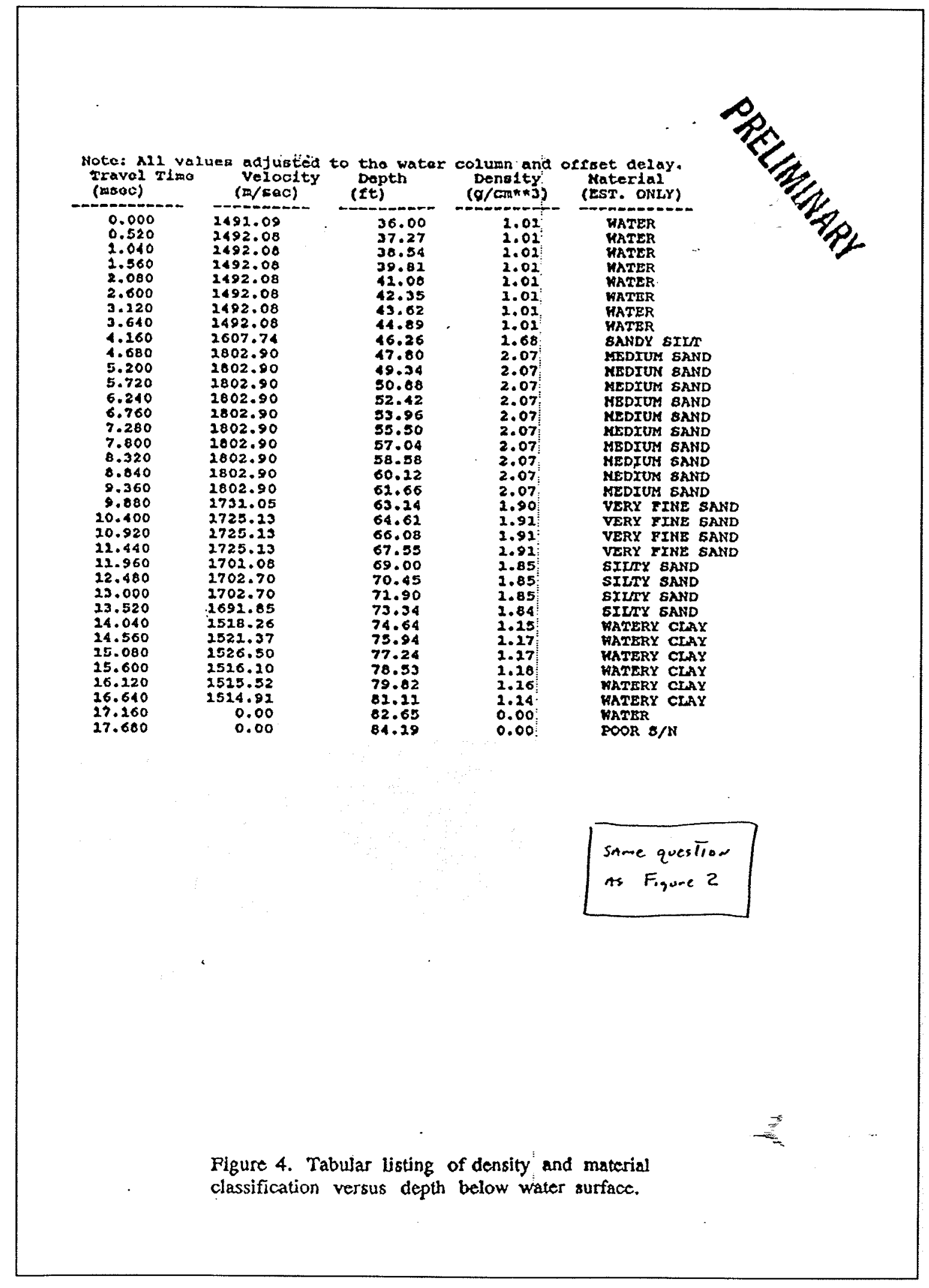

Figure B3. (Sheet 10 of 17) 


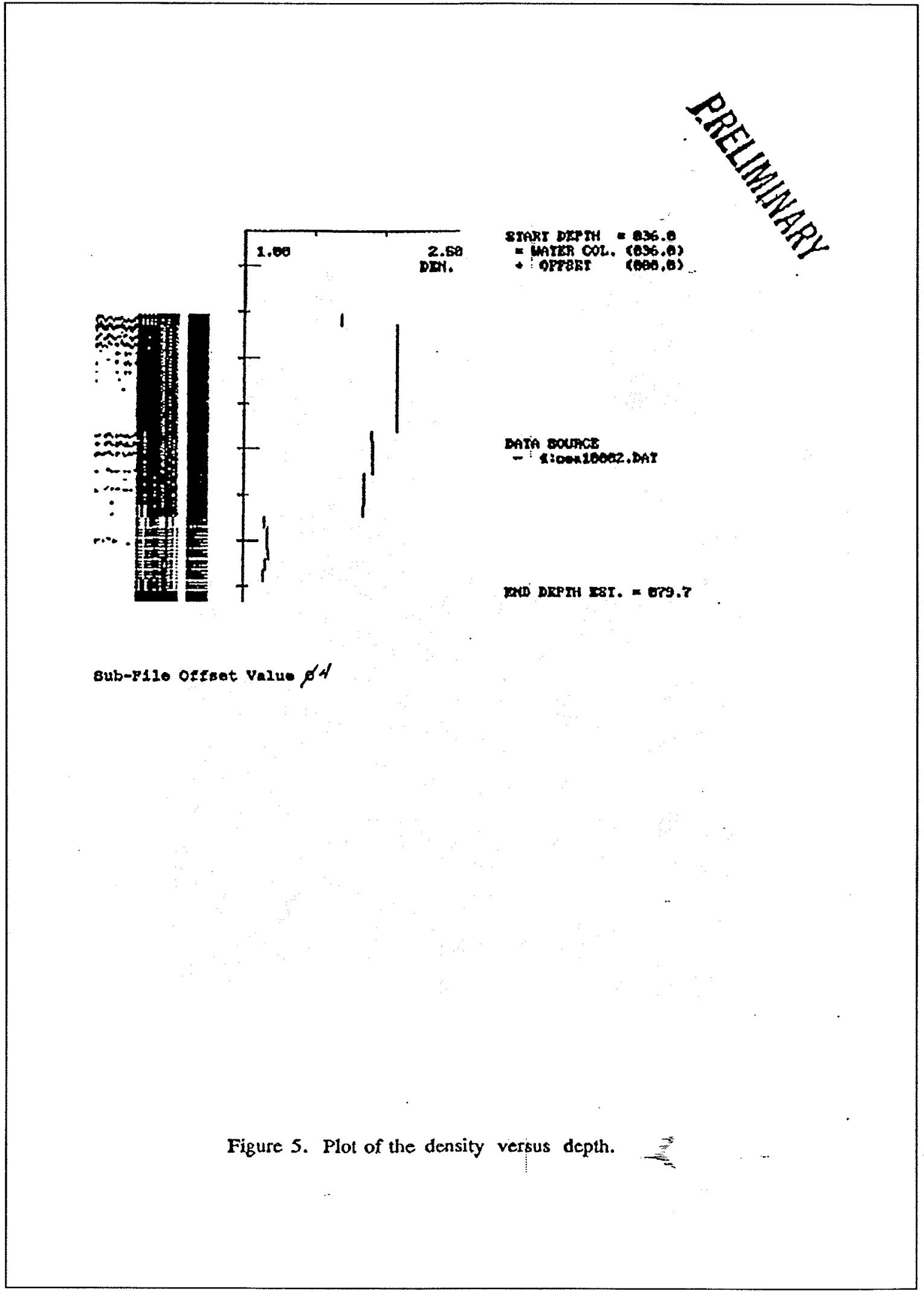

Figure B3. (Sheet 11 of 17) 


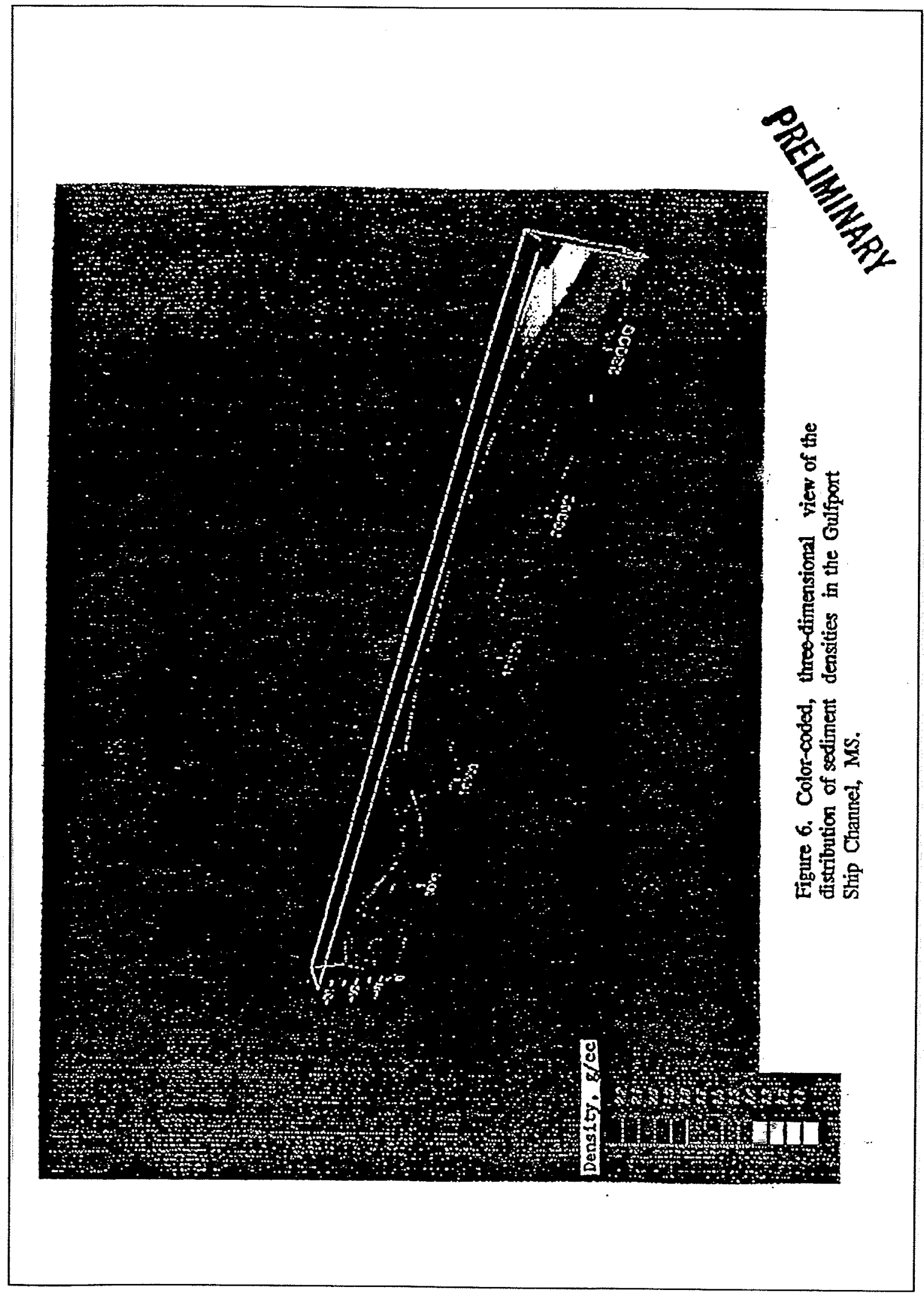

Figure B3. (Sheet 12 of 17) 


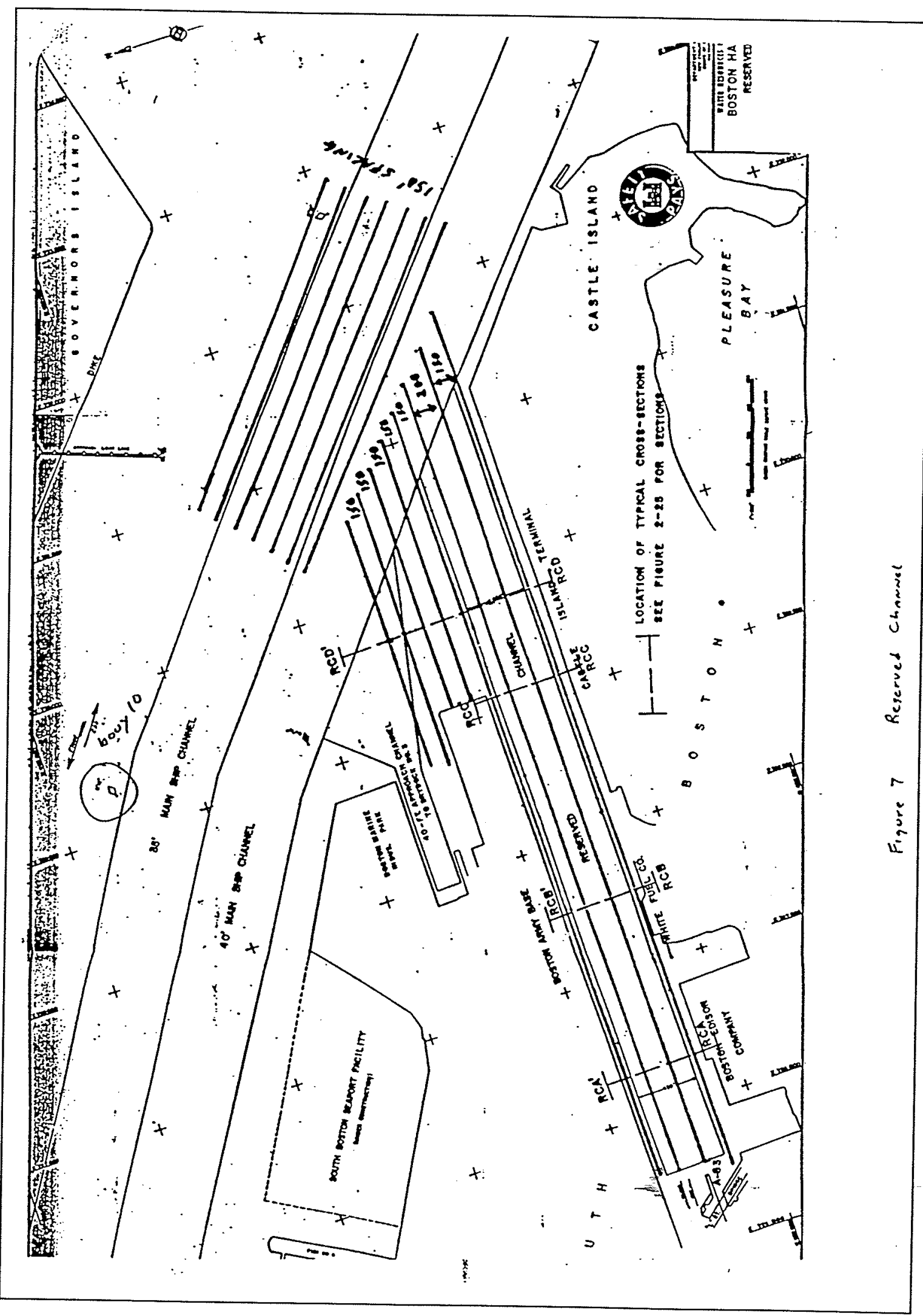

Figure B3. (Sheet 13 of 17) 


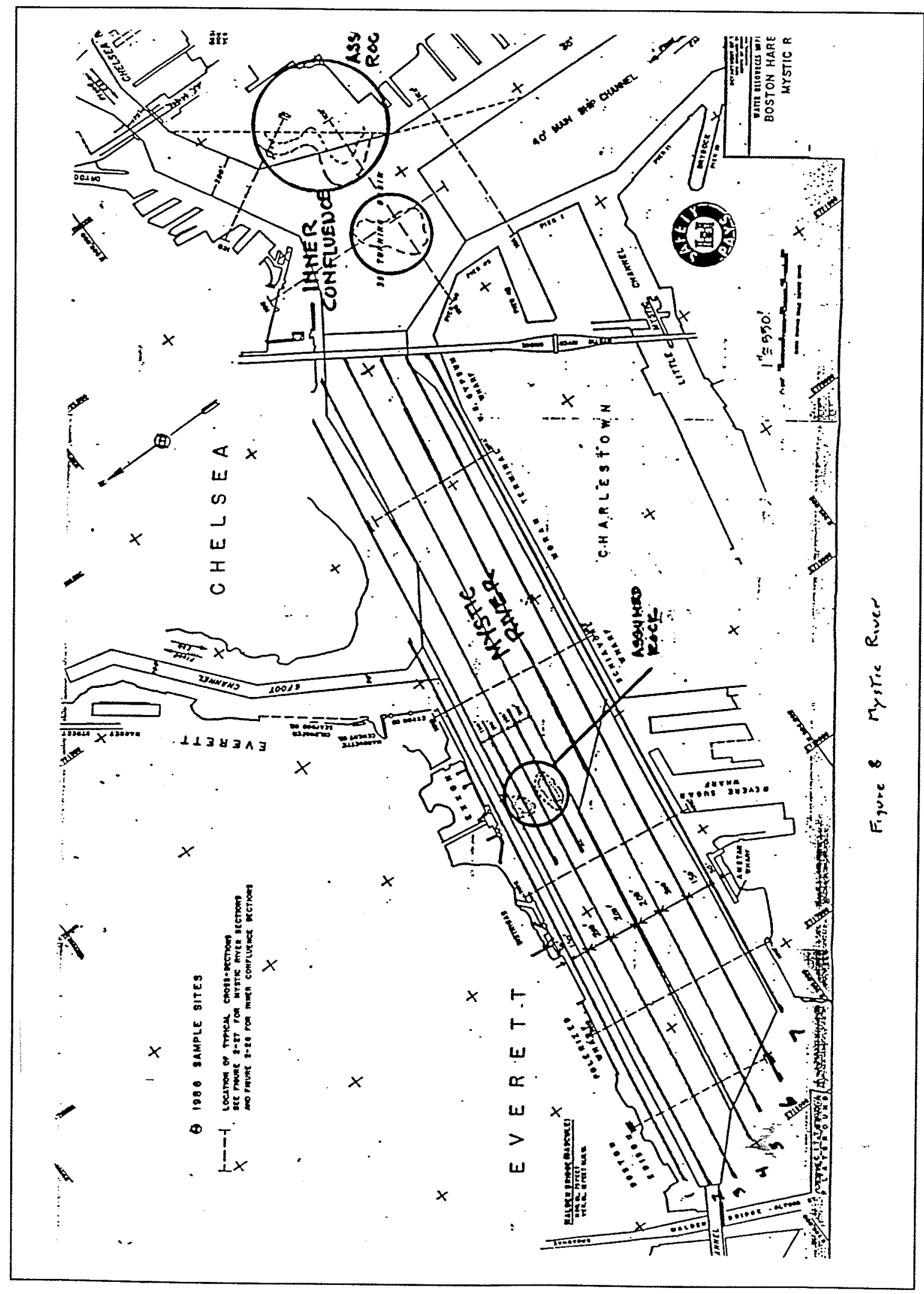

Figure B3. (Sheet 14 of 17) 


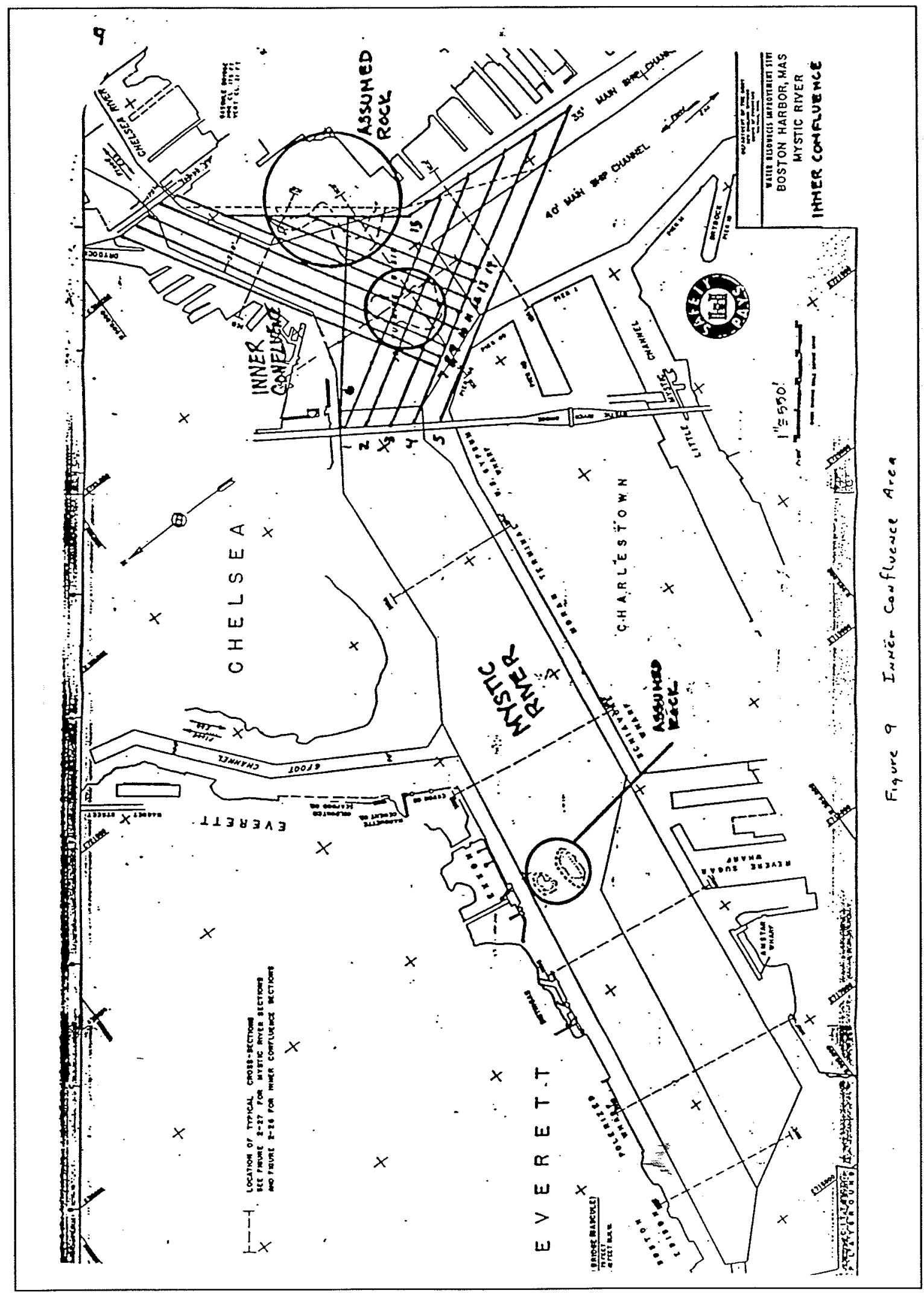

Figure B3. (Sheet 15 of 17) 


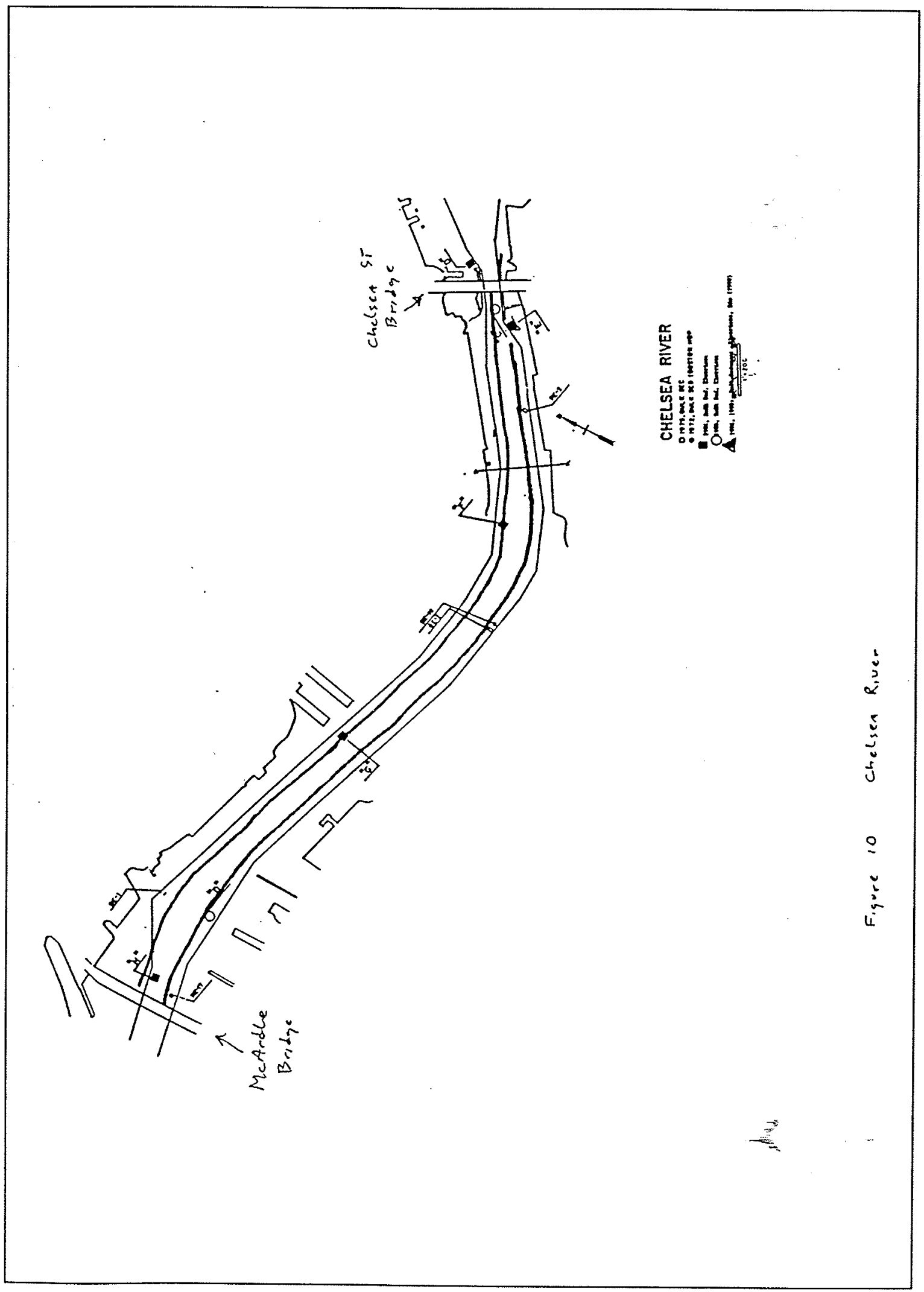

Figure B3. (Sheet 16 of 17)

B28 


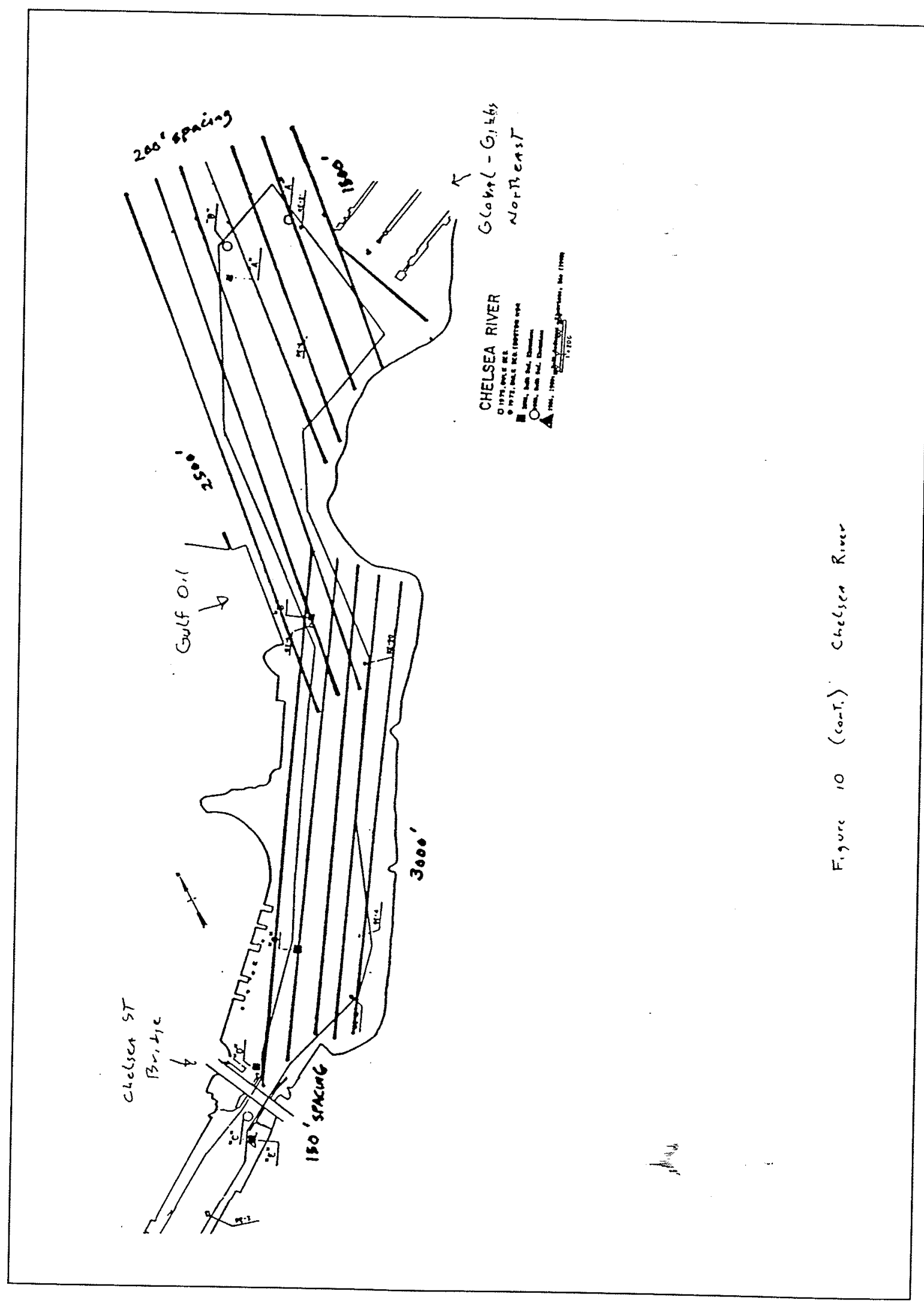

Figure B3. (Sheet 17 of 17) 


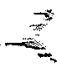




\section{Appendix C Epilogue}

During preparation of this report, fabrication of the waterborne integrated geophysical system (IGS) was completed. That system, funded from sources other than the DRP, now includes a support vessel (shown in Figures 76, 77, and 78) housing an integrated GPS navigation and data management computer with appurtenances necessary for acquiring and processing a wide variety of geophysical data. The vessel, christened WATERWAYS EXPLORER, was designed to be highway transportable and capable of stable operation in coastal regions, harbors, and inland waterways. Needless to say, the IGS concept greatly benefited through research performed under the DRP. (Refer to Appendix A, Figure A1 for the block diagram depicting equipment currently on board and including future plans for increased capability.) When the vessel was designed, immediate emphasis was placed upon the incorporation of equipment (including drop tube sampling for immediate ground truth verification) capable of acquiring high-resolution reflection seismic information compatible with acoustic impedance processing algorithms. That capability is supplemented with side-scan sonar (with target enhancement), multi-frequency Fathometers, and magnetometers.

The WATERWAYS EXPLORER has surveyed four sites to date with others scheduled. Sites already surveyed include shorelines, harbors, and inland lakes. Its tri-pontoon, shallow-draft platform has provided the necessary stability for extremely high-quality data acquisition. With continued use, however, improvements in design will be incorporated. 


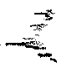




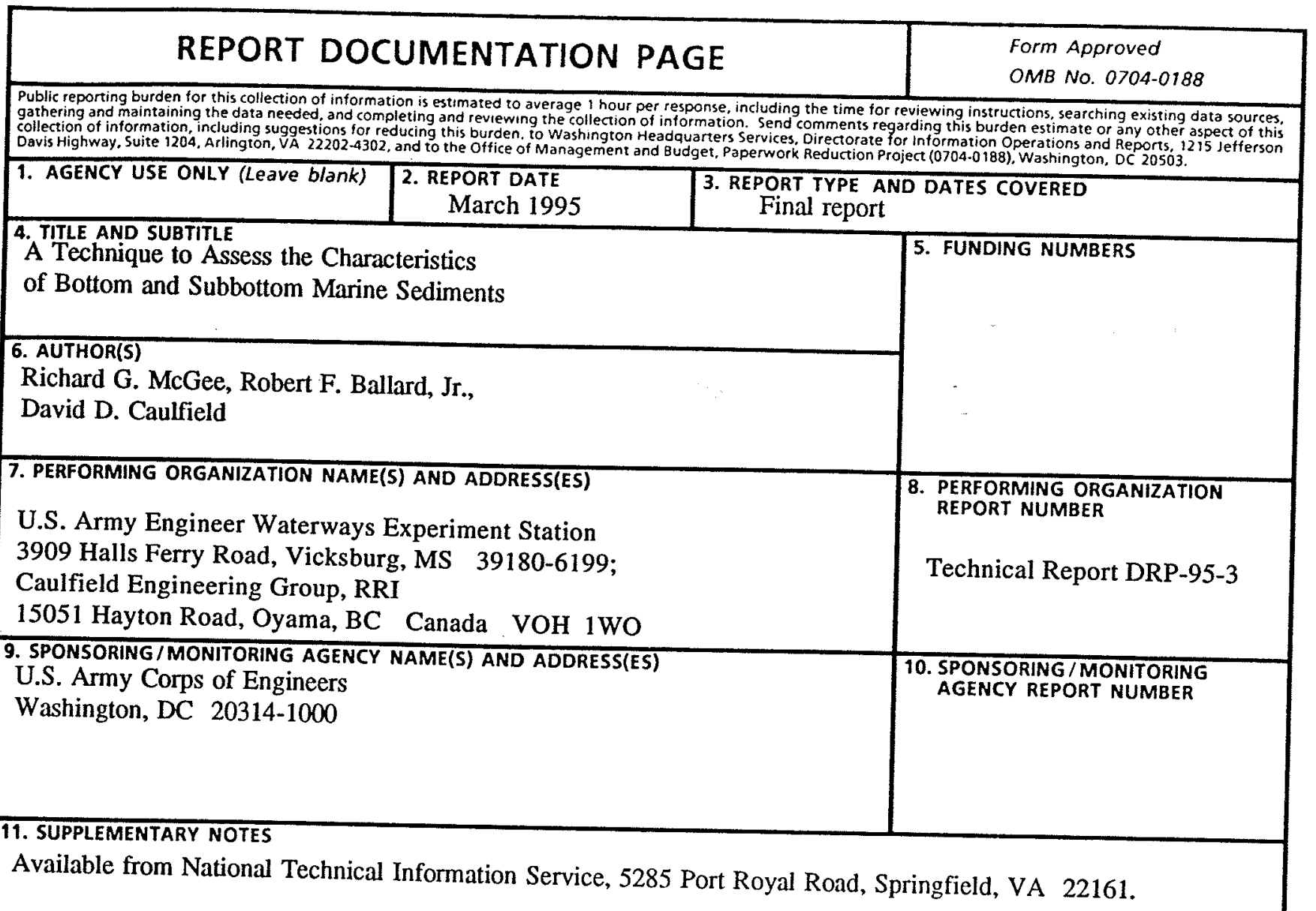

\begin{tabular}{|l|l|}
\hline 12a. DISTRIBUTION/AVAILABILITY STATEMENT & 12b. DISTRIBUTION CODE \\
Approved for public release; \\
distribution is unlimited.
\end{tabular}

This report presents the theoretical concept, assembly, and field testing of a waterborne seismic acoustic impedance technique which has been developed to characterize bottom and subbottom sediments as they relate to removal by dredging. This method, developed under the Dredging Research Program (DRP), provides estimates of in situ density and soil type in a rapid, cost-effective manner using digital acoustic subbottom profiling methodology.

In situ densities obtained by the acoustic impedance technique to date, when compared to those obtained by conventional means at several different sites under a wide variety of marine conditions, have statistically been with \pm 10 percent. However, only marine sediments considered to be fully saturated, inorganic, and uncontaminated have been investigated and "ground truthed." After comparisons with ground truth information and laboratory testing, a critical analysis of the acoustic impedance technique reveals it to be a valid and useful approach to bottom and subbottom material and density prediction. While some development is still needed to fully establish advantages and limitations, its potential usefulness warrants technology transfer now, provided proper cautions are observed. This suppositioin is corroborated by the fact that numerous

\begin{tabular}{|c|c|c|c|}
\hline \multirow{2}{*}{\multicolumn{3}{|c|}{ 14. SUBJECT TERMS }} & (Continued) \\
\hline \multirow{2}{*}{\multicolumn{2}{|c|}{$\begin{array}{l}\text { Acoustic impedance } \\
\text { Acoustic subbottom profiling }\end{array}$}} & & $\begin{array}{r}\text { 15. NUMBER OF PAGES } \\
174 \\
\end{array}$ \\
\hline & & $\begin{array}{l}\text { Bottom sediments } \\
\text { Subbottom sediments }\end{array}$ & 16. PRICE CODE \\
\hline $\begin{array}{l}\text { 17. SECURITY CLASSIFICATION } \\
\text { OF REPORT } \\
\text { UNCLASSIFIED } \\
\end{array}$ & $\begin{array}{l}\text { 18. SECURITY CLASSIFICATION } \\
\text { OF THIS PAGE } \\
\text { UNCLASSIFIED }\end{array}$ & $\begin{array}{l}\text { 19. SECURITY CLASSIFICATION } \\
\text { OF ABSTRACT }\end{array}$ & 20. LIMITATION OF ABSTRACT \\
\hline
\end{tabular}


13. (Concluded).

reimbursable surveys have been successfully conducted while products were still in the development stage. Each site surveyed provided valuable input to the research and development evolutionary processes and enabled researchers to fine-tune procedures while still providing a useful and timely service to sponsoring Districts and Divisions. 